\title{
TOUGHREACT User's Guide: A Simulation Program for Non-isothermal Multiphase Reactive Geochemical Transport in Variably Saturated Geologic Media, V1.2.1
}

\author{
Tianfu Xu, Eric Sonnenthal, Nicolas Spycher, and Karsten Pruess \\ Earth Sciences Division, Lawrence Berkeley National Laboratory, \\ University of California, Berkeley, CA 94720.
}

August 2008

(V1.2.1)

This work was supported by the Laboratory Directed Research and Development Program of the Ernest Orlando Lawrence Berkeley National Laboratory; by the Assistant Secretary for Energy Efficiency and Renewable Energy, Office of Geothermal Technologies; and by the Director, Office of Science, Office of Basic Energy Sciences; and by the Zero Emission Research and Technology Project (ZERT) of the U.S. Department of Energy, Contract No. DE-AC02-05CH11231. 


\section{TABLE OF CONTENTS}

1. INTRODUCTION

1

2. REQUIREMENTS _......................................................................................... 3

2.1 Computer requirements and code installation ............................................ 3

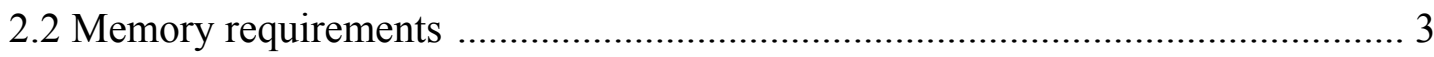

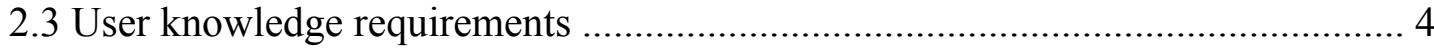

3. MODEL DESCRIPTION .................................................................................. 5

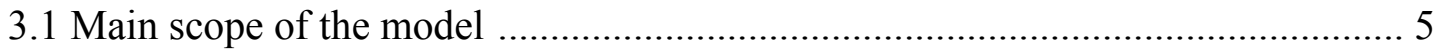

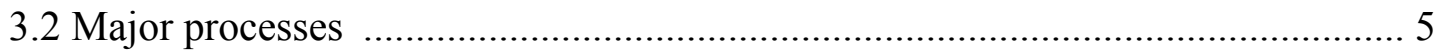

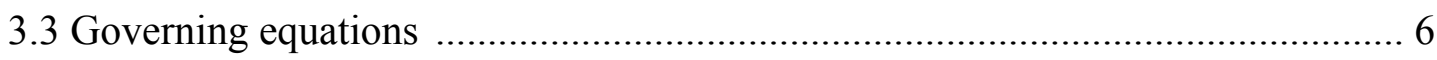

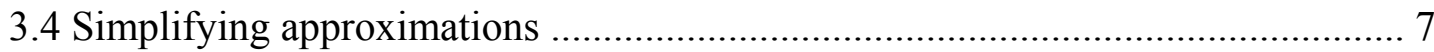

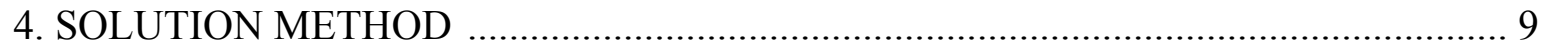

5. GENERAL DESCRIPTION OF INPUT AND OUTPUT FILES ............................. 13

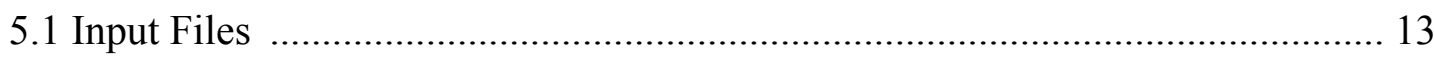

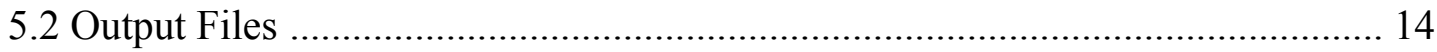

5.2.1 Fixed-name output files ............................................................ 14

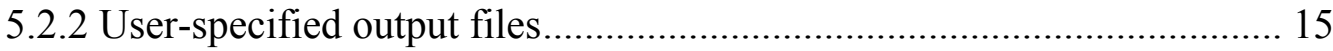

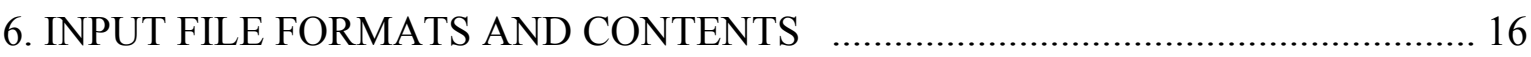

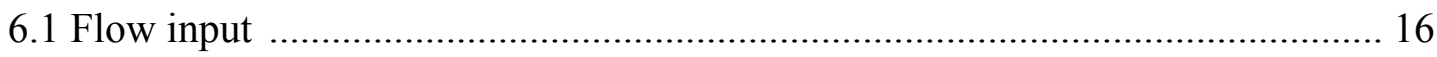

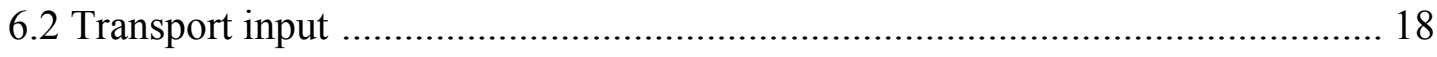

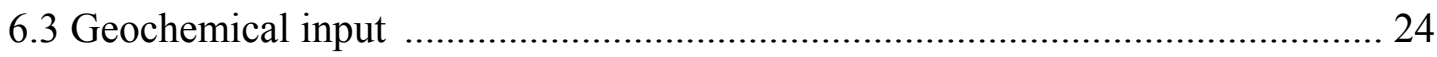

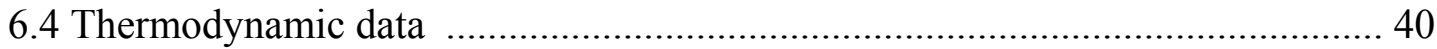


8. SAMPLE PROBLEMS ................................................................................ 48

8.1 Aqueous transport with adsorption (Linear Kd) and decay (EOS9) .................. 48

8.2 Water quality in the Aquia aquifer, Maryland (EOS9) ................................. 54

8.3 Infiltration and calcite deposition at Yucca Mountain, Nevada (EOS3) ............ 61

8.4 Heater test problem (EOS4 or EOS3) ........................................................ 73

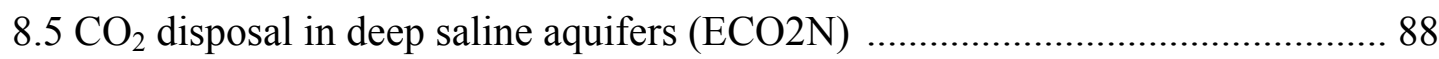

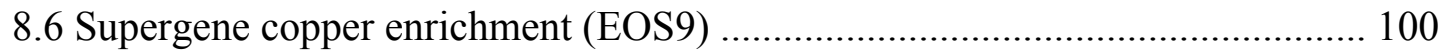

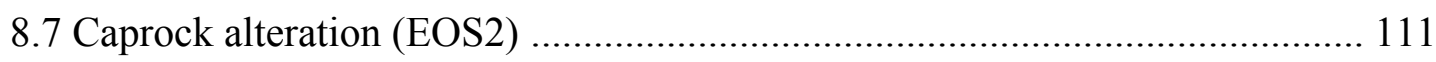

8.8 Injection well scaling and acidizing at Tiwi field, Philippines (EOS1) .......... 119

9. CONCLUDING REMARKS ........................................................................ 132

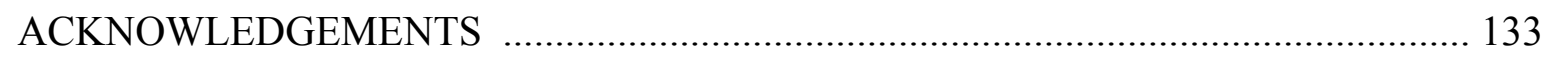

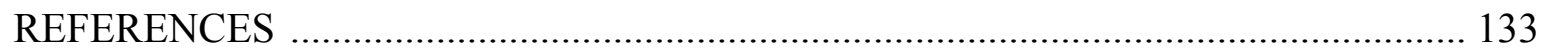

APPENDIX A. Mathematical equations for flow and transport .................................. 146

APPENDIX B. Mathematical formulation of chemical reactions ............................... 148

APPENDIX C. Solution method for solute transport equations ................................. 158

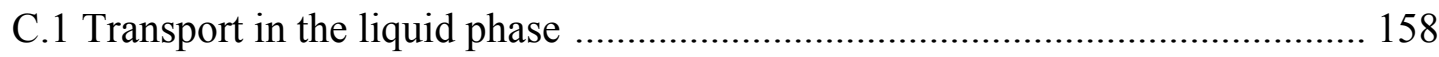

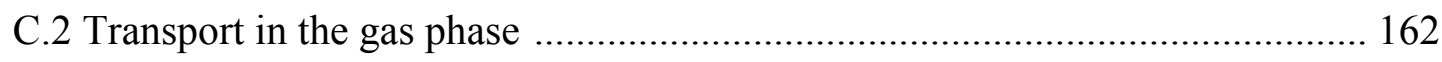

APPENDIX D. Solution method for mixed equilibrium-kinetics chemical system ........ 164

APPENDIX E. Evaluation of the Jacobian matrix for chemical equations ..................... 168

APPENDIX F. Effects of mineral precipitation/dissolution on hydrologic properties ... 170

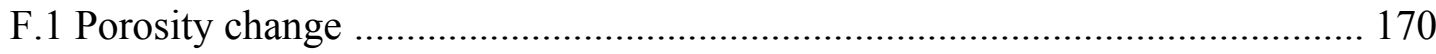

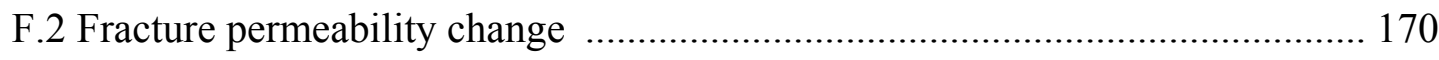




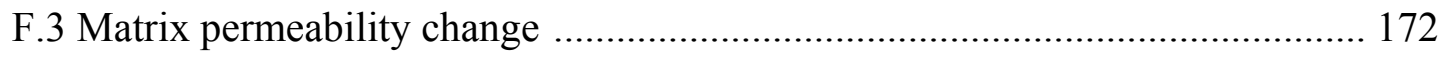

F.4 Effects of permeability and porosity changes on capillary pressures ............... 173

APPENDIX G. Mineral reactive surface areas .......................................................... 174

APPENDIX H: Calculation of activity coefficients of aqueous species …………….... 177

APPENDIX I: Treatment for mineral solid solutions …………………..................... 185

APPENDIX J: Additions to the flow input file for Yucca Mountain Project ...............188

APPENDIX K: Utility programs for chemical database ................................................ 191

K.1. Converting EQ3/6 to TOUGHREACT database ......................................... 191

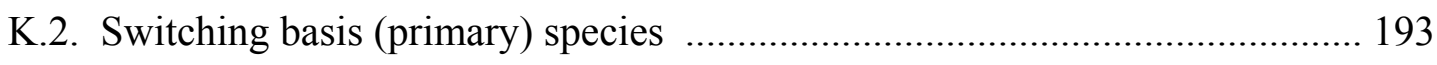

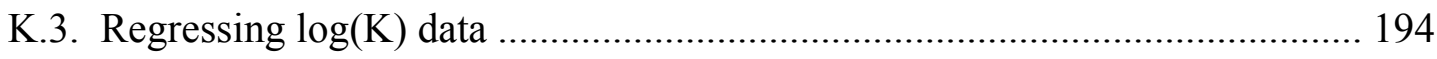

K.4. Checking mass and charge balances ............................................................. 195

Subject index 


\section{Introduction}

Coupled modeling of subsurface multiphase fluid and heat flow, solute transport, and chemical reactions can be applied to many geologic systems and environmental problems, including geothermal systems, diagenetic and weathering processes, subsurface waste disposal, acid mine drainage remediation, contaminant transport, and groundwater quality. TOUGHREACT has been developed as a comprehensive non-isothermal multi-component reactive fluid flow and geochemical transport simulator to investigate these and other problems. A number of subsurface thermo-physical-chemical processes are considered under various thermohydrological and geochemical conditions of pressure, temperature, water saturation, and ionic strength. TOUGHREACT can be applied to one-, two- or three-dimensional porous and fractured media with physical and chemical heterogeneity. The code can accommodate any number of chemical species present in liquid, gas and solid phases. A variety of equilibrium chemical reactions are considered, such as aqueous complexation, gas dissolution/exsolution, and cation exchange. Mineral dissolution/precipitation can take place subject to either local equilibrium or kinetic controls, with coupling to changes in porosity and permeability and capillary pressure in unsaturated systems. Chemical components can also be treated by linear adsorption and radioactive decay.

The first version of the non-isothermal reactive geochemical transport code TOUGHREACT was developed (Xu and Pruess, 1998) by introducing reactive geochemistry into the framework of the existing multi-phase fluid and heat flow code TOUGH2 (Pruess, 1991). TOUGHREACT was further enhanced with the addition of (1) treatment of mineral-water-gas reactive-transport under boiling conditions, (2) an improved HKF activity model for aqueous species, (3) gas species diffusion coefficients calculated as a function of pressure, temperature, and molecular properties, (4) mineral reactive surface area formulations for fractured and porous media, and (5) porosity, permeability, and capillary pressure changes owing to mineral precipitation/dissolution (Sonnenthal et al., 1998, 2000, 2001; Spycher et al., 2003a). Subsequently, TOUGH2 V2 was released with additional EOS modules and features (Pruess et al., 1999). The present version of TOUGHREACT includes all of the previous extensions to the original version, along with the replacement of the original TOUGH2 (Pruess, 1991) by TOUGH2 V2 (Pruess et al., 1999). 
TOUGHREACT has been applied to a wide variety of problems, some of which are included as examples, such as:

(1) Supergene copper enrichment (Xu et al., 2001).

(2) Mineral alteration in hydrothermal systems (Xu and Pruess, 2001a; Xu et al., 2004b; Dobson et al., 2004).

(3) Mineral trapping for $\mathrm{CO}_{2}$ disposal in deep saline aquifers (Xu et al., 2003b and 2004a).

(4) Coupled thermal, hydrological, and chemical processes in boiling unsaturated tuff for the proposed nuclear waste emplacement site at Yucca Mountain, Nevada (Sonnenthal et al., 1998, 2001; Sonnenthal and Spycher, 2000; Spycher et al., 2003a, b; Xu et al., 2001).

(5) Modeling of mineral precipitation/dissolution in plug-flow and fracture-flow experiments under boiling conditions (Dobson et al., 2003).

(6) Calcite precipitation in the vadose zone as a function of net infiltration (Xu et al., 2003).

(7) Stable isotope fractionation in unsaturated zone pore water and vapor (Singleton et al., 2004).

The TOUGHREACT program makes use of "self-documenting" features. It is distributed with a number of input data files for sample problems. Besides providing benchmarks for proper code installation, these can serve as a self-teaching tutorial in the use of TOUGHREACT, and they provide templates to help jump-start new applications. The fluid and heat flow part of TOUGHREACT is derived from TOUGH2 V2, so in addition to the current manual, users must have the manual of the TOUGH2 V2 (Pruess et al., 1999).

The present version of TOUGHREACT provides the following TOUGH2 fluid property or "EOS" (equation-of-state) modules: (1) EOS1 for water, or two waters with typical applications to hydrothermal problems, (2) EOS2 for multiphase mixtures of water and $\mathrm{CO}_{2}$ also with typical applications to hydrothermal problems, (3) EOS3 for multiphase mixtures of water and air with typical applications to vadose zone and nuclear waste disposal problems, (4) EOS4 that has the same capabilities as EOS3 but with vapor pressure lowering effects due to capillary pressure, (5) EOS9 for single phase water (Richards' equation) with typical applications to ambient temperature and pressure reactive geochemical transport problems, and (6) ECO2N for 
multiphase mixtures of water, $\mathrm{CO}_{2}$ and $\mathrm{NaCl}$ with typical applications to $\mathrm{CO}_{2}$ disposal in deep brine aquifers.

\section{Requirements}

\subsection{Computer Requirements and Code Installation}

Like TOUGH2, TOUGHREACT is written in FORTRAN 77. It has been tested on various computer platforms, including Microsoft Windows- and Linux-based PCs, SUN Ultrasparc systems, Compaq Alpha-based workstations, Apple Macintosh G4 and G5 computers, and IBM RISC System/6000 workstations. An effort was made to have the TOUGHREACT source code comply with the ANSIX3.9-1978 (FORTRAN 77) standard, and on most machines the code should compile and run without modification. TOUGHREACT (like TOUGH2 V2) requires 64-bit arithmetic ( 8 byte word length for floating point numbers) for successful execution. The TOUGHREACT (V1.2.1) source program on the distribution compact diskette (CD), contains IMPLICIT DOUBLE PRECISION (A-H, O-Z) and IMPLICIT INTEGER*8 (I-N) statements that will automatically generate 64-bit arithmetic on 32 bit processors. The distribution CD includes a README file, the documentation (this manual), source files, some executable files generated from COMPAQ Visual Fortran compiler 6.6 on a PC, and sample problems. Several MAKEFILEs for different computer platforms such as SUN SPARC Workstation, Compaq ALPHA Workstation, Intel Fortran Compiler on Linux, g77 on Apple Macintosh G4 and G5 computers, and IBM RISC System/6000 workstation are provided in a subdirectory of the CD. Details on compilation, linking, and program installation and execution are given in the README file.

\subsection{Memory Requirements}

The computer memory required by TOUGHREACT depends on the problem size. Parameter statements are used in three INCLUDE files: T2 (for fluid and heat flow dimension parameters), PERM23.INC for extra permeability-porosity coupling parameters, and CHEMPAR23.INC file (for reactive chemistry dimension parameters). All major arrays in the problem are automatically adjusted according to these dimension parameters. Different size problems can be modeled by changing the dimensions in the parameter statements, compiling all source files, and linking them to create an executable file. In the distribution $\mathrm{CD}$, some major 
dimensioning variables are specified in the two INCLUDE files as follows: MNEL $=8000$ (maximum number of grid blocks), $\mathrm{MNCON}=20000$ (maximum number of connections), MPRI $=20$ (maximum number of primary species), $\mathrm{MAQX}=70$ (maximum number of secondary species), MMIN = 32 (maximum number of minerals), MGAS = 5 (maximum number of gaseous species), and $\mathrm{MEXC}=5$ (maximum number of cation-exchangeable species). At the beginning of a simulation, the program automatically checks the array dimensions related to reactive geochemistry. If the dimensions are insufficient for the specific problem, it provides the user a message to change the parameter statements.

As an example, a 2-D problem of the Drift Scale Test at Yucca Mountain (Nevada) with 4,900 grid blocks, 30 minerals, 14 primary aqueous species, 46 secondary aqueous species, and 1 gaseous species (in addition to air and water vapor) were handled with TOUGHREACT on a Compaq ALPHA Workstation (similar to Sample Problem 4 presented in this manual).

\subsection{User Knowledge Requirements}

The correct implementation, setup, problem formulation, and interpretation of the results of TOUGHREACT requires knowledge of the basic equations of multiphase non-isothermal fluid flow and transport in geologic media and a basic understanding of the numerical solution of the equations that are used to describe these processes. In addition, the formulation of the geochemical problem requires familiarity with geochemical modeling and an in-depth understanding of the system that is being modeled and of the data used for input to the model. The model boundary conditions, time step length, convergence criteria, and grid properties are crucial elements for a realistic and accurate solution to a problem. The input files for flow parameters are based on TOUGH2 V2, with some extensions. However, TOUGH2 V2 input files can be used without modification. A comprehensive reference of TOUGH2 input formats along with illustrative sample problems are provided in the TOUGH2 user's guide, Version 2.0 (Pruess et al., 1999). This information is essential for successful application of TOUGHREACT; it is not duplicated in the current manual. 


\section{Model Description}

\subsection{Main Scope of the Model}

TOUGHREACT is applicable to one-, two-, or three-dimensional geologic domains with physical and chemical heterogeneity and can be applied to a wide range of subsurface conditions. The temperature $(\mathrm{T})$ and pressure $(\mathrm{P})$ range is controlled by the applicable range of the chemical thermodynamic database, and the range of the EOS module employed. For example, typical applications for the Yucca Mountain project use thermodynamic data derived for temperatures between 0 and $300^{\circ} \mathrm{C}$, at 1 bar below $100^{\circ} \mathrm{C}$, and water saturation pressure above $100^{\circ} \mathrm{C}$. Note that because the equilibrium constants are generally not as sensitive to pressure as to temperature, the temperature dependence of equilibrium constants is taken into account by TOUGHREACT but the pressure dependence is not. The temperature and pressure range of thermodynamic data can be extended by changing the thermodynamic database without code modifications. It is the user's responsability to ensure that the thermodynamic data used with this software is appropriate for the temperature and pressure range of the simulated systems. Water saturation can vary from completely dry to fully water-saturated. The model can deal with ionic strengths from dilute to moderately saline water (up to ionic strengths in the 2-4 molal range, for an NaCl-dominant solution, depending on the system being modeled; see Appendix $\mathrm{H}$ for details).

TOUGHREACT is applicable to a variety of reactive fluid and geochemical transport problems, including (a) contaminant transport with linear $\mathrm{Kd}$ adsorption and radioactive decay (Sample problem 1), (b) natural groundwater chemistry evolution under ambient conditions (Sample 2), (c) assessment of nuclear waste disposal sites (Samples 3-4), (d) sedimentary diagenesis, and $\mathrm{CO}_{2}$ disposal in deep formations (Sample 5), (e) mineral deposition such as supergene copper enrichment (Sample 6), and (f) mineral alteration and silica scaling in hydrothermal systems under natural and production conditions (Samples 7-8).

\subsection{Major Processes}

The major processes for fluid and heat flow are: (1) fluid flow in both liquid and gas

phases occurs under pressure, viscous, and gravity forces; (2) interactions between flowing phases are represented by characteristic curves (relative permeability and capillary pressure); (3) heat flow by conduction and convection, and (4) diffusion of water vapor and air. Thermophysical 
and geochemical properties are calculated as a function of temperature, such as fluid (gas and liquid) density and viscosity, and thermodynamic and kinetic data for mineral-water-gas reactions. Transport of aqueous and gaseous species by advection and molecular diffusion are considered in both liquid and gas phases. Depending on the computer memory and CPU performance, any number of chemical species in the liquid, gas and solid phases can be accommodated. Aqueous complexation, acid-base, redox, gas dissolution/exsolution, and cation exchange are considered under the local equilibrium assumption. Mineral dissolution and precipitation can proceed either subject to local equilibrium or kinetic conditions. Linear adsorption and decay can be included.

\subsection{Governing Equations}

The primary governing equations for multiphase fluid and heat flow, and chemical transport have the same structure, derived from the principle of mass (or energy) conservation. These equations are presented in Appendix A. Expressions for non-isothermal multiphase flow are given in Pruess (1987) and Pruess et al. (1999). The transport equations are written in terms of total dissolved concentrations of chemical components, which are concentrations of the basis species plus their associated aqueous secondary species (Yeh and Tripathi, 1991; Steefel and Lasaga, 1994; Walter and others, 1994; Lichtner, 1996; and Xu and Pruess, 2001b). If kineticallycontrolled reactions occur between aqueous species, then additional ordinary differential equations need to be solved to link the total concentrations of the primary species with the evolving concentrations of the secondary species (Steefel and MacQuarrie, 1996). Kineticallycontrolled reactions between aqueous species are not considered in the present version. Slow aqueous phase reactions are common in the case of redox reactions and will be addressed in future development. Advection and diffusion processes are considered for both the aqueous and gaseous species. Aqueous species diffusion coefficients are assumed to be the same. Gaseous

species, having a neutral valence, can have differing diffusion coefficients calculated as a function of T, P, molecular weight, and molecular diameter.. The local chemical interactions in the transport equations are represented by reaction source/sink terms.

The primary governing equations must be complemented with constitutive local relationships that express all parameters as functions of fundamental thermophysical and chemical variables. The equations for chemical reactions are presented in Appendix B. Mass 
conservation in the closed chemical system is written in terms of basis (component) species. The species distribution must be governed by the total concentrations of the components. The oxygen is used for formulating redox reactions by attributing the oxidizing potential to the dissolved oxygen (Nordstrom and Muñoz, 1986; Wolery, 1992). In contrast to the free electron in the hypothetical electron approach (Yeh and Tripathi, 1991), oxygen can be present and can be transported in natural subsurface flow systems. The formulation for cation exchange is similar to that of Appelo and Postma (1993). For kinetically-controlled mineral dissolution and precipitation, a general form of rate law (Lasaga, 1984; Steefel and Lasaga, 1994; Palandri and Kharaka, 2004) is used (Appendix B). Thermodynamic and kinetic data are functions of temperature.

Temporal changes in porosity, permeability, and unsaturated hydrologic properties owing to mineral dissolution and precipitation can modify fluid flow. This feedback between transport and chemistry can be important (e.g., Raffensperger, 1996), and can be treated by TOUGHREACT. Changes in porosity during the simulation are calculated from changes in mineral volume fractions. The porosity-permeability correlation in geologic media can be complex, depending on several factors, such as pore size distribution, pore shapes, connectivity (Verma and Pruess, 1988), and crystal morphology. Several porosity-permeability and fracture aperture-permeability relationships are included in the model (Appendix F). The code can also be set to monitor changes in porosity and permeability during the simulation without considering their effects on fluid flow. In unsaturated systems, capillary pressure can be modified via permeability and porosity changes using Leverett scaling, (based on Slider, 1976).

\subsection{Simplifying Approximations}

Hydrodynamic dispersion is an important solute transport phenomenon that arises from aninterplay between non-uniform advection and molecular diffusion. In geologic media, velocities of fluid parcels are spatially variable due to heterogeneities on multiple scales, all the way from the pore scale to the basin scale. The process is often represented by a Fickian diffusion analog (convection-dispersion equation). This approach, however, has fundamental flaws and limitations, as has been demonstrated in numerous studies in the hydrogeology literature over the last twenty years. Although field tracer tests can generally be matched with the convectiondispersion equation, such matching and associated parameters have little predictive power. There 
is much evidence that when a Fickian dispersion model is calibrated to field tracer data, such success does not indicate that a realistic description of in-situ solute distribution has been attained. Dispersivities are generally found to increase with space and time scale of observation (Gelhar et al., 1992). Observed dispersivities are only partly due to mixing and dilution in-situ; they also reflect the mixing that occurs when subsurface flow systems are observed (perturbed) and sampled, as when fluids are extracted from wells (Chesnut, 1994). It has been established that Fickian dispersion implies an unrealistically large level of mixing and dilution (Kapoor et al., 1997). Fickian plumes represent a probability distribution, not a distribution of solute; they strongly overestimate dilution in any particular representation of a heterogeneous medium. This can produce erroneous predictions for transport, and even more unrealistic consequences for reactions that depend on concentrations in a non-linear manner. Fickian dispersion also gives rise to spurious upstream dispersion opposing the direction of advective flow. For these reasons, we are not using a Fickian model for dispersion. Instead, hydrodynamic dispersion is modeled through appropriate spatial resolution on multiple scales, using multiple continua (or multiregion) models (Pruess and Narasimhan, 1985; Gwo et al., 1996) to describe interactions between fluid regions with different velocities.

We currently neglect deformation of the porous skeleton., and fluid pressure effects owing to porosity changes. Heat effects from chemical reactions are neglected, as are changes in thermophysical properties of fluid phases (such as viscosity, surface tension, and density) owing to changes in chemical composition. 


\section{Solution Method}

Figure 4.1 shows the flow chart for solving coupled non-isothermal multiphase fluid flow, solute transport, and reactive geochemistry in TOUGHREACT.

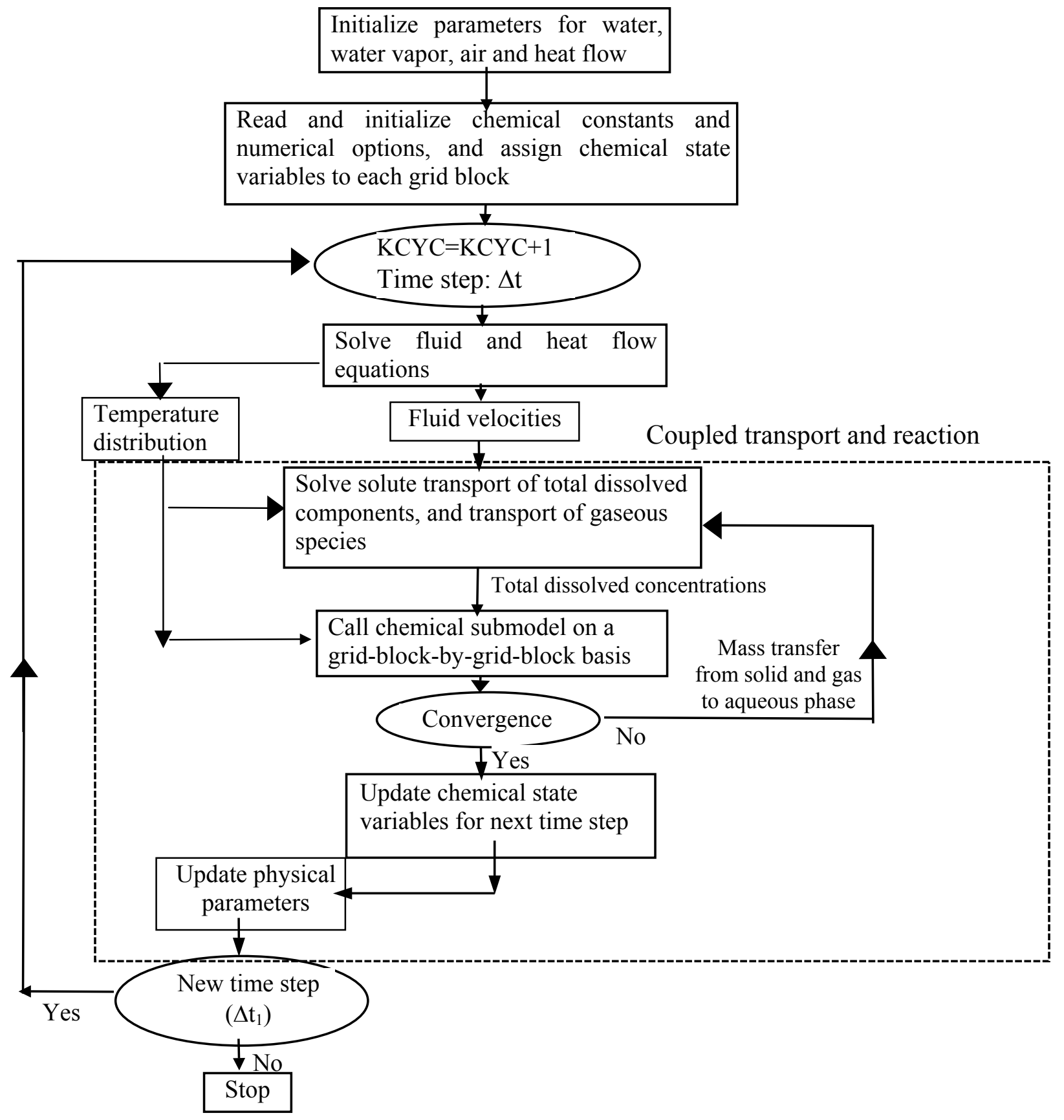

Figure 4.1. Flow chart of the TOUGHREACT program. 
The numerical solution of multi-phase flows proceeds as in TOUGH2. Space discretization is employed by means of integral finite differences (IFD; Narasimhan and Witherspoon, 1976). Because chemical transport equations (derived from mass conservation) have the same structure as fluid and heat flow equations, the transport equations can be solved by the same numerical method. The discretization approach used in the IFD method and the definition of the geometric parameters are illustrated in Figure 4.2. The basic mass- (for water, air, and chemical components) and energy- (for heat) balance equations are written in integral form for an arbitrary domain $\mathrm{V}_{\mathrm{n}}$

$$
\mathrm{V}_{\mathrm{n}} \frac{\Delta \mathrm{M}_{\mathrm{n}}}{\Delta \mathrm{t}}=\sum_{\mathrm{m}} \mathrm{A}_{\mathrm{nm}} \mathrm{F}_{\mathrm{nm}}+\mathrm{V}_{\mathrm{n}} \mathrm{q}_{\mathrm{n}}
$$

where subscript $\mathrm{n}$ labels a grid block, subscript $\mathrm{m}$ labels grid blocks connected to grid block $\mathrm{n}, \Delta \mathrm{t}$ is time step size, and $M_{n}$ is the average mass or energy density in grid block $n$. Surface integrals are approximated as a discrete sum of averages over surface segments $A_{n m}, F_{n m}$ is the average flux (of mass or energy) over the surface segment $A_{n m}$ between volume elements $n$ and $m$, and $q_{n}$ is the average source/sink rate in grid block n per unit volume. Time is discretized fully implicitly as a first-order finite difference to achieve unconditional stability. More detail on the numerical discretization is given in Pruess et al. (1999). The IFD method gives a flexible discretization for geologic media that allows the use of irregular unstructured grids, which is well suited for simulation of flow, transport, and fluid-rock interaction in multi-region heterogeneous and fractured rock systems. For systems with regular grids, IFD is equivalent to conventional finite differences. 

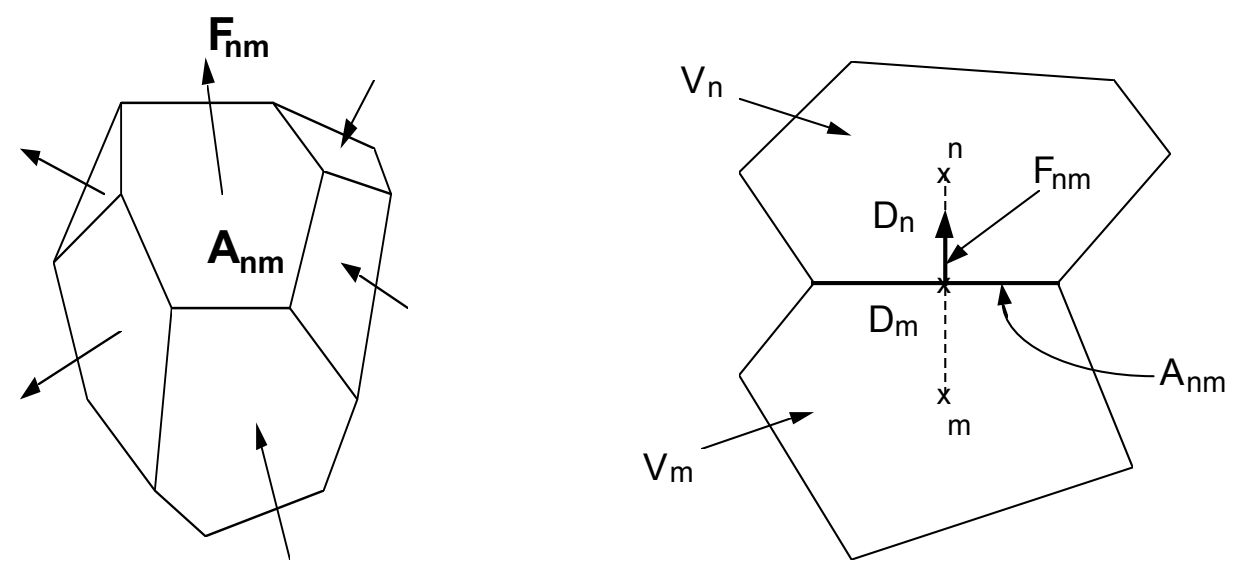

Figure 4.2. Space discretization and geometric data for the integral finite difference method.

The time discretization of fluid and heat flow equations results in a set of coupled nonlinear algebraic equations for the unknown thermodynamic state variables in all grid blocks. These equations are solved by Newton-Raphson iteration as implemented in the original TOUGH2 simulator (Pruess, 1991). The set of coupled linear equations arising at each iteration step is solved iteratively by means of preconditioned conjugate gradient methods (Moridis and Pruess, 1998).

TOUGHREACT uses a sequential iteration approach (SIA) similar to Yeh and Tripathi (1991), Engesgaard and Kipp (1992), Simunek and Suares (1994), and Walter et al. (1994). After solution of the flow equations, the fluid velocities and phase saturations are used for chemical transport simulation. The chemical transport is solved on a component-by-component basis (details on the solution method are given in Appendix C). The resulting concentrations obtained from solving transport equations are substituted into the chemical reaction model. The system of mixed equilibrium-kinetic chemical reaction equations is solved on a grid block by grid block basis by Newton-Raphson iteration (details are given in Appendix D). Optionally, the chemical transport and reactions are solved iteratively until convergence. An automatic time stepping scheme is implemented in TOUGHREACT, which includes an option to recognize "quasistationary states" (QSS; Lichtner, 1988) and perform a "large" time step towards the end of a QSS.

As an alternative to the sequential iterative approach, a sequential non-iterative approach (SNIA) may be used, in which the sequence of transport and reaction equations is solved only 
once (Walter et al., 1994; Steefel and MacQuarrie, 1996; and Xu et al., 1999a). Xu et al. (1999a) analyzed the accuracy of SIA and SNIA using several test cases. They concluded that the accuracy of SNIA depends mainly on the Courant number, which is defined as $C=v \Delta t / \Delta x$, where $\mathrm{v}$ is fluid velocity and $\Delta \mathrm{x}$ is grid spacing. For small Courant numbers, satisfying the stability condition $\mathrm{C} \leq 1$, the differences between SNIA and SIA are generally small. The accuracy of SNIA also depends on the type of chemical process. Therefore, the applicability of the decoupling of chemical reactions from transport will depend on time and space discretization parameters, the nature of the chemical reactions and the desired accuracy. When SNIA is used, the Courant number condition $\mathrm{C} \leq 1$ can be automatically enforced during the simulation.

When analyzing water flow through partially saturated porous media, the gas phase may often be considered a passive by stander and not be represented explicitly (Richards, 1931). This means that for the purpose of solving for water flow, the entire gas phase is at the same pressure (usually the atmospheric pressure). TOUGHREACT allows a choice of considering saturatedunsaturated liquid phase flow in which case only molecular diffusion is considered for gaseous species transport. Alternatively, the full non-isothermal multiphase flow equations (liquid, gas, and heat) may be solved. To test the passive gas phase approach under ambient conditions, $\mathrm{Xu}$ et al. (2000) performed numerical simulation experiments on pyrite oxidation in a variably saturated porous medium. They found that under ambient conditions the effects of partial pressure reduction due to oxygen consumption on the fluid flow is not significant, and oxygen diffusion is the dominant gas phase transport process. However, when fluid flow and chemical reactions are strongly coupled, as e.g. in boiling hydrothermal reservoirs, gas phase advection could be essential (White, 1995). 


\section{General Description of Input and Output Files}

\subsection{Input Files}

Three user-specified input files are required. The input file names have been fixed in the program (i.e., names cannot be specified by the user). Descriptions of these input files are given below. Details on input formats and contents are given in Chapter 6 .

flow.inp - Flow input. This file mainly includes rock properties, time-stepping information, geometric grid information, initial and boundary conditions, and data related to a multi-phase fluid and heat flow simulation. The flow input is the same as the original TOUGH2 V2 (see the manual; Pruess et al., 1999), with an additional data block REACT (see Section 6.1), and a few other extensions.

solute.inp - Transport and other run parameters. This file contains various flags and input parameters for calculations of reactive transport, such as diffusion coefficients, tolerance limits for convergence of transport and chemical iterations, printout flags for mineral and aqueous species, and the configuration of model zones with different chemical composition (the composition of each zone, however, is defined in file chemical.inp described below).

chemical.inp - Geochemical parameters and properties. This file is used to define the geochemical system (i.e. the type and number of aqueous component species, minerals, gases, and sorbed species considered in the simulation). It also includes the initial compositions of water, minerals, and gases in zones that are assigned to grid blocks in file solute.inp, and kinetic data for minerals (rate constants, surface areas, etc.).

In addition to the above-mentioned three input files, the program requires a thermodynamic database file with a file name specified in the solute.inp file. This file contains reaction stoichiometries, dissociation constants $(\log (\mathrm{K}))$, and regression coefficients of $\log (\mathrm{K})$ as a function of temperature (see Section 6.4 for details).

\subsection{Output Files}

Two types of output files are generated from TOUGHREACT: (1) fixed file names, and (2) user-specified file names. 


\subsubsection{Fixed-name output files}

flow.out - Flow output. This file is identical to the original TOUGH2 output file, including data on temperature, pressure, liquid saturation, mass flux, and phase velocities for all grid blocks of the model.

solute.out - Echo of input file solute.inp. This file lists data that was read from input file solute.inp, including all transport parameters, chemical zone configuration, and other run-specific parameters.

chemical.out - Echo of input file chemical.inp. This file lists data that was read from input files chemical.inp and the thermodynamic database, including initial water, rock, and gas compositions, equilibrium constants and stoichiometries of chemical reactions, kinetic data, and linear adsorption $\mathrm{Kd}$ values and decay constants for certain species.

runlog.out - Log of the simulation progress. This file is updated throughout the simulation. It lists some run input parameters and all run-related messages, including error messages (Chapter 7).

chdump.out - chemical speciation data. This file contains results of geochemical speciation calculations for each initial water composition input into the model, including a printout of chemical mass balances (total mass balance and aqueous species mass balance). It also lists these data for grid blocks where chemical convergence fails (not reaching the specified convergence criteria). For debugging purposes, or for small grids, the flag ICHDUMP in the solute.inp input file (if set equal to 1), allows geochemical speciation results to be output in the chdump.out file for every grid block at every time step. As a precaution to avoid filling up disk space, results of speciation calculations are output only for the first thousand grid blocks and/or time steps, after which the program will abort.

savechem - save of geochemical data for restart. This file can be used to restart a TOUGHREACT run from the end of a previous run. Geochemical conditions obtained in one run are written to disk file savechem, and can be used as initial conditions in a subsequent run. The restart run for reactive geochemical transport simulation must be used together with a restart of the flow simulation (see p. 61 of the TOUGH2 V2 manual; Pruess et al., 1999). For a restart run, file savechem must be changed to inchem, and file SAVE to INCON (same as in the original TOUGH2).

In addition, TOUGHREACT creates the following optional fixed-name output files: 
mbalance.out - chemical mass balance information

min_SI.dat - mineral saturation indices

rct_area.out - mineral reactive surface areas

rctn_rate.out - mineral reaction rates

Printing of these files is controlled by parameter $\operatorname{MOPR}(8)$ in the flow.inp file, which is described in Section 6.1.

\subsubsection{User-specified output files}

The names of these files must be specified in the input file solute.inp, and cannot be left blank. The output files are described below:

Iteration data. This file lists the number of flow, transport, and chemical iterations used to reach convergence at each time step.

Aqueous species data. This file contains times, grid block coordinates (m), gas and liquid saturations, temperature $\left({ }^{\circ} \mathrm{C}\right), \mathrm{pH}$, and aqueous species concentrations at all grid blocks for times specified in the flow.inp file. The number and types of species output are specified by flags in the input file solute.inp. This file has a TECPLOT-compatible format.

Solid phase data. This file contains time, grid point coordinates $(\mathrm{m})$, temperature $\left({ }^{\circ} \mathrm{C}\right)$, mineral abundance, and exchanged species concentrations at all grid blocks for time printout intervals specified in the flow.inp file. This file has a TECPLOT-compatible format.

Gas phase data. This file contains time, grid point coordinates $(\mathrm{m})$, temperature $\left({ }^{\circ} \mathrm{C}\right)$, and gas partial pressures for all grid blocks at times specified in the flow.inp file. This file has a TECPLOT-compatible format.

Plot data at specified grid blocks (time evolution). This file contains the grid block identifier, time, gas and liquid saturations, temperature, $\mathrm{pH}$, aqueous species concentrations, mineral abundances, gas pressures, and exchanged species concentrations for specific grid blocks and time intervals, as specified in the input file solute.inp. 


\section{Input File Formats and Contents}

\subsection{Flow Input (flow.inp)}

Input formats for multiphase flow are very similar to TOUGH2 Version 2.0 (Pruess et al. 1999, Appendix E), with the addition of keyword block 'REACT' having one record that must be included (see below) for a reactive geochemical transport simulation. This record specifies option parameters related to reactive transport. Without this data block, the program only runs a multiphase flow simulation. In addition, keyword blocks 'PARAM' and 'INCON' in the original TOUGH2 were extended. Inputs for these options are discussed below. Also note that the TOUGH2 capability of defining an "inactive" grid block with a zero or negative volume in the input block 'ELEME' (used for a constant boundary condition), is not operational in TOUGHREACT. Instead, constant boundary conditions are set in TOUGHREACT by inputting a large (infinite) volume $\left(\geq 10^{20} \mathrm{~m}^{3}\right)$ for boundary grid blocks. In this case, the chemical concentrations in this infinite volume block remain essentially unchanged, as well as pressure and temperature.

TOUGHREACT also incorporates options of other TOUGH2 versions that are specific to the Yucca Mountain project. Yucca Mountain in southern Nevada (USA) is being investigated as a possible site for an underground nuclear waste repository. A sample problem related to this project is presented in Section 8.4. The addition to the flow input file for this project is given in Appendix J.

REACT Parameter choices for reactive transport simulation Variable: $\operatorname{MOPR}(20)$

Format: 20I1

$\operatorname{MOPR}(1)=0$ perform reactive transport

$=1$ no reactive transport, but input files with chemical data are read

$=2$ no reactive transport, no chemical data files are read

$\operatorname{MOPR}(2)>0$ writes the transport coefficient matrix, Darcy velocities, porosities, and other transport data in the runlog.out file during calculations of aqueous species and gas transport. For debugging uses only.

MOPR(3) $>0$ writes source terms, old and new aqueous concentrations, and various other parameters in the runlog.out file during transport calculations. Also outputs the permeability, porosity, and capillary pressure correction factor at each grid block in the runlog.out file. For debugging uses only. 

$\operatorname{MOPR}(4) \quad \neq 1$ Force at least one fluid flow step to be calculated $(\operatorname{MOPR}(4)=2$ is normally suggested)
$=1$ does not force at least one fluid flow step to be calculated. This option can be useful to compute chemical reactions in single-grid block problems. When the chemical quasi-stationary states (QSS) option is considered, MOPR(4) must be set equal to one.
MOPR(5) $\quad=0$ Subroutines MULTI, RELP (relative permeability), and PCAP (capillary pressure) provided in the original TOUGH2 V2 are used.
$=1$ Subroutines MULTI, RELP_YMP and PCAP_YMP are used.
$=2$ Subroutines MULTI_YMP, RELP_YMP and PCAP_YMP are used (YMP: Yucca Moutain project, see sample problem 4 of Section 8.4).
$\operatorname{MOPR}(6) \quad=0$ No Leverett scaling for capillary pressure when porosity and permeability change owing to mineral dissolution and precipitation.
$=1$ Leverett scaling (Eq. F.9 in Appendix F) is performed for capillary pressure modification when porosity and permeability change owing to mineral dissolution and precipitation.
MOPR(7) $\geq 0$ This option allows the specification of the \# number of digits past the decimal to be printed in chemical output files (up to 8 digits). Zero or blank gives the default of 4 digits.
$\operatorname{MOPR}(8) \quad=0$ No printout of extra output files.
$=1$ Creates two output files for (1) mass balance information and (2) mineral saturation index vs. grid block at specified times. The two file names are fixed as mbalance.out and min_SI.dat.
$\geq 2$ Creates an additional output file with mineral reaction rates at all grid blocks. The file name is fixed as rctn_rate.out.
$\geq 3$ Creates an additional output file with mineral reactive surface areas. The file name is fixed as rct_area.out.
MOPR(9)-MOPR(20): Not currenty used. Must be left blank.

PARAM The meaning of variable MCYC (maximum number of time steps to be calculated) in Record PARAM.1 was extended slightly from the original TOUGH2. In TOUGHREACT, if $\mathrm{MCYC}=9999$, the number of time steps is not controlled by MCYC, and therefore the maximum simulation time is only controlled by TIMAX in Record PARAM.2. IF MCYC $\leq$ 9998, it is the same as in TOUGH2 V2.

INCON Three variables for three components of permeability were added to Record INCON.1 after porosity PORX (..., PORX, PERM1, PERM2, PERM3 with format ..., E15.9, 3E15.9). Like porosity, if zero or blank, three values of permeability will be taken as specified in block 'ROCKS' if option START is used. For use of EOS9 flow module, in Record INCON.2 the second primary variable $\mathrm{X} 2$ is used for specifying grid block dependent temperature (in ${ }^{\circ} \mathrm{C}$ ). If zero or blank, temperature will be taken as default value specified in block 'ROCKS' 


\subsection{Transport Input (solute.inp)}

The first record of this input file is used to write a title and comments. It is followed by 12 data records. Some records can be omitted in certain conditions. Prior to each record there is always a heading (comment) line (see inputs of the sample problems, such as in Figure 8.1.3). Some variables in data records are not required under certain conditions. In such cases one should leave them blank or input an arbitrary value. Next, we describe the content of each record, indicating the description of each variable and its corresponding FORTRAN format for appropriate reading.

\section{Record_1. Title \\ Variable: TITLE \\ Format: $\quad$ A82}

TITLE: title and comments.

\section{Record_2. Options for reactive geochemical transport (1)}

$\begin{array}{llllllll}\text { Variable: ISPIA } & \text { INIBOUND } & \text { ISOLVC } & \text { RCOUR } & \text { NGAS1 } & \text { ICHDUMP } & \text { KCPL } \\ \text { ICO2H2O NUMDR } & & & & & \\ \text { Format: } & \text { I5 } & \text { I5 } & \text { I5 } & \text { F5.2 } & \text { I5 } & \text { I5 } & \text { I5 } \\ & \text { I5 } & \text { I5 } & & & & & \end{array}$

ISPIA : flag for iteration scheme between transport and reaction. ISPIA $=2$ is normally used.

0 - sequential iteration between transport and chemistry

2 - sequential no iteration (fully explicit reaction source terms)

INIBOUND : indicator of identifying boundary water solution (including pumping/injection at the internal grid blocks).

0 - not identifying

1 - identifying (normally used)

ISOLVC : flag for the linear equation solver for transport. It is the same as the original TOUGH2 V2 (see p. 73 of the manual, Pruess et al., 1999). ISOLVC $=5$ is normally used.

2 - DSLUBC, a bi-conjugate gradient solver

3 - DSLUCS, a Lanczos-type bi-conjugate gradient solver

4 - DSLUGM, a general minimum residual solver

5 - DLUSTB, a stabilized bi-conjugate gradient solver

RCOUR : both a variable and a flag to limit the time step size. RCOUR $\neq 0.0$ limits the maximum time step size to $\mid$ RCOUR $\mid \times$ Courant Number. Positive RCOUR values limit the time step by the velocity of the gas or 
liquid phase, whichever is highest. Negative RCOUR values limit the time step by the velocity of the liquid phase only. This option is disabled if RCOUR $=0.0$.

NGAS1 : inclusion of gaseous chemical species transport

0 - not included

1 - included

If gas partial pressure remains constant with time, set NGAS $1=0$.

ICHDUMP : flag to enable printout of chemical speciation results

0 - disabled

1 - printout of chemical speciation at each grid block and each time step

2 - printout of chemical speciation at times specified by NWTI in the following Record_7 and grid blocks specified in Record_8.

If this option is enabled, the program will abort after the output of speciation results for the first 1000 grid blocks and/or time steps, to avoid accidentally filling up disk space.

KCPL : flag to consider feedback effects of changes of porosity, permeability, and capillary pressure due to mineral dissolution and precipitation on fluid flow.

0 - disabled

1 - enabled

2 - only monitor the changes (printout), but without feedback on fluid flow.

ICO2H2O : flag to consider effects of $\mathrm{CO}_{2}$ and $\mathrm{H}_{2} \mathrm{O}$ reaction source/sink terms on fluid flow calculations. ICO2H2O is only used for the EOS2 and $\mathrm{ECO} 2 \mathrm{~N}$ flow modules. For other flow modules, set $\mathrm{ICO} 2 \mathrm{H} 2 \mathrm{O}=0$. 0 - effects ignored

1 - only effects of $\mathrm{CO}_{2}$ reaction source/sink terms

2 - effects of both $\mathrm{CO}_{2}$ and $\mathrm{H}_{2} \mathrm{O}$ reaction source/sink terms

NUMDR : flag for calculation of derivatives of mineral kinetic rates with respect to concentrations of primary species.

0 - Analytical method (normally used)

1 - Numerical method

\section{Record_3. Options for reactive geochemical transport (2) Variable: SL1MIN, D1MIN, STIMAX, CNFACT \\ Format: 4E10.4}

The first three parameters are used to skip geochemical speciation calculations at grid blocks where conditions of saturation, inter-grid block distance, or ionic strength are outside of the valid ranges of the model. The geochemical calculations are skipped at grid blocks where: the liquid saturation is less than SL1MIN; the minimum distance to the center of any adjacent block is less than D1MIN; or the stoichiometric ionic strength is more than STIMAX. For typical boiling simulations, use SL1MIN less than or equal to $10^{-3}$. Set D1MIN $=0.0$ (disabled) unless absolutely necessary. With this program version, STIMAX can be up to $6 \mathrm{~mol} / \mathrm{kg}$ 
$\mathrm{H}_{2} \mathrm{O}$ for $\mathrm{NaCl}$-dominant solutions. For other solutions, STIMAX can be up to a value between 2.0 and 4.0 regarding the calculation of activity coefficients at elevated ionic strengths (see Appendix $\mathrm{H}$ for details).

CNFACT is a weighting factor for mineral and gas reaction source terms in the transport equations $(1.0=$ fully implicit source terms, $0.0=$ fully explicit source terms). This parameter has an effect only if sequential iterations are enabled (ISPIA $=0$ ). In this program version, CNFACT always defaults to 1.0 if a non-zero value is input (implicit only). Simulations with CNFACT $=0.0$ using sequential iterations will produce the same results as simulations without sequential iterations (explicit source terms) but requires increased computing time and therefore should be avoided.

\section{Record_4.1 through 4.6. Output file names}

Variable: THERMO_in, OUTiter, OUTplot, OUTsolid, OUTgas, OUTtime

Format: $\quad$ A20, each file name occupies one line.

THERMO_in : name of thermodynamic data file

OUTiter : iteration information

OUTplot : aqueous concentrations for all grid blocks at specified printout times defined in FLOW.INP

OUTsolid : solid concentrations (mineral abundances and exchanged species concentrations) for all grid blocks at specified printout times defined in FLOW.INP

OUTgas : gas pressures for all grid blocks at specified times defined in FLOW.INP

OUTtime : aqueous and solid concentrations vs. time at specified grid blocks defined in SOLUTE.INP

\section{Record_5. Weighting parameters and diffusion coefficients}

Variable: WTIME, WUPC, DIFUN, DIFUNG

Format: $\quad 2 \mathrm{~F} 10.0,2 \mathrm{E} 10.3$

WTIME : time weighting factor, ranging from 0.0 to 1.0 . WTIME $=1.0$

(implicit) is suggested.

WUPC : upstream weighting factor, ranging from 0.0 to 1.0 . WUPC $=1.0$ (fully upstream) is suggested.

DIFUN : diffusion coefficient $\left(\mathrm{m}^{2} / \mathrm{s}\right)$ for aqueous species. DIFUN is multiplied by the tortuosity $(\tau)$, defined in rock property block of the flow input, and liquid saturation. Notice that if $\tau$ in flow input is zero, the program computes $\tau$ from $\tau_{\beta}=\phi^{1 / 3} S_{\beta}^{7 / 3}$ (Millington and Quirk, 1961), where $\phi$ is porosity, $S$ is phase saturation, and $\beta$ is phase index.

DIFUNG: diffusion coefficients $\left(\mathrm{m}^{2} / \mathrm{s}\right)$ of the medium for gaseous species. If DIFUNG $<0.0$, the program computes gaseous diffusion coefficients as function of temperature and pressure according to Eq. A.1 (Appendix A). 


\section{Record_6. Data related to convergence criteria Variable: MAXITPTR, TOLTR, MAXITPCH, TOLCH, MAXITPAD, TOLAD, TOLDC,TOLDR \\ Format: I5, E10.3, I5, E10.3, I5, E10.3, E10.3, E10.3,}

MAXITPTR: maximum number of sequential iterations between transport and chemistry. If MAXITPTR=1, a sequential non-iterative approach is used where transport and chemistry are sequentially solved without iteration (normally is suggested).

TOLTR: relative tolerance of aqueous concentration for sequential transport/chemistry convergence; a value between $1.0 \mathrm{E}-03$ to $1.0 \mathrm{E}$ 06 is suggested.

MAXITPCH: maximum number of iterations allowed for solving whole geochemical system.

TOLCH: relative tolerance of aqueous concentration for whole chemical system; a value between $1.0 \mathrm{E}-03$ to $1.0 \mathrm{E}-06$ is suggested.

MAXITPAD: maximum number of iterations allowed for solving sorption via surface complexation.

TOLAD: relative tolerance of aqueous concentration for sorption convergence; a value between $1.0 \mathrm{E}-03$ to $1.0 \mathrm{E}-06$ is suggested.

TOLDC: relative concentration change (between two consecutive time steps) tolerance for quasi-stationary state (QSS); a value between 1.0E-03 to 1.0E-06 is suggested; if not using QSS approximation set equal to zero. When KCPL $>0$ and $\mathrm{ICO} 2 \mathrm{H} 2 \mathrm{O}>0$ in Record_2, set equal to zero.

TOLDR: relative dissolution and/or precipitation rate change tolerance for quasistationary state (QSS); a value between $1.0 \mathrm{E}-03$ to $1.0 \mathrm{E}-06$ is suggested; if not using QSS approximation set equal to zero. When $\mathrm{KCPL}>0$ and $\mathrm{ICO} 2 \mathrm{H} 2 \mathrm{O}>0$ in Record_2, set equal to zero.

\section{Record_7. Writing control variables}

Variable: NWTI, NWNOD, NWCOM, NWMIN, IWCOMT, ICONFLAG, MINFLAG Format: $7 \mathrm{I} 5$

NWTI : printout frequency (as number of time steps) for selected grid blocks (NWNOD)

NWNOD : number of grid blocks for time evolution printout

NWCOM : number of chemical components (species) for printout

NWMIN : number of minerals for printout

IWCOMT: 0 - printout of aqueous species concentrations

1 - printout of total aqueous component concentrations

(2 - same as IWCOMT=1 except charge balance printout in the last conlumn of the time evolution output file for chemical variables)

ICONFLAG: flag for aqueous concentration unit in output files 
$0-\mathrm{mol} / \mathrm{kg} \mathrm{H}_{2} \mathrm{O}$

$1-\mathrm{mol} / \mathrm{l}$ liquid

MINFLAG: flag for units of mineral abundances in output files

0 - Change (relative to $\mathrm{t}=0$ ) of mineral abundance in $\mathrm{mol} / \mathrm{m}^{3}$ medium

1 - Change (relative to $t=0$ ) of mineral abundance in volume fraction (dimensionless)

2 - Current mineral abundance in volume fraction (dimensionless)

\section{Record_8. List of grid blocks for printout of time evolution results}

Variable: EL

Format: $15 \mathrm{~A} 5$

Five-character code name of a grid block. The name must be specified in the flow.inp input file or mesh file. If NWNOD $=0$ in Record_7, leave a blank line.

\section{Record_9. Array of component indices to be printed out} variable: (IWCOM(I), I=1,NWCOM)

Format: $15 \mathrm{I} 5$ (If $\mathrm{NWCOM}=16-30$, a second line is required; and so on)

IWCOM(I): vector component numbers

\section{Record 10. Array of mineral indices to be printed out}

Variable: (IWMIN(I), I=1, NWMIN)

Format: $20 \mathrm{I5}$ (If NWMIN =21-39, a second line is required; ans so on)

IWCOM(I): vector of the number of minerals for writing. If $\mathrm{NWMIN}=0$ in Record_7, leave a blank line.

\section{Record_11. Default values for chemical property zone related to grid blocks}

Variable: IZIWDF, IZBWDF, IZMIDF，IZGSDF，IZADDF，IZEXDF, IZPPDF, IZKDDF

Format: $8 \mathrm{I} 5$

IZIWDF，IZBWDF，IZMIDF，IZGSDF，IZADDF，IZEXDF, IZPPDF, and IZKDDF are default values of IZIW, IZBW, IZMI, IZGS, IZAD, IZEX, IZPP, and IZKD in the following record, respectively.

\section{Record_12. Chemical property zone related to grid blocks}

Variable: EL, NSEQ, NADD, IZIW, IZBW, IZMI, IZGS, IZAD, IZEX, IZPP, IZKD

Format: A5, 10I5

Remark: Repeat as many times as required, and end with a blank record.

EL: grid block name

NSEQ: number of additional grid blocks having the same chemical properties

NADD: increment between the code numbers of two successive grid blocks 
IZIW: initial water zone number

IZBW: boundary inflow (including injection at internal blocks) water zone number IZMI: mineral zone number

IZGS: gas zone number

IZAD: adsorption zone number

IZEX: ion exchange zone number

IZPP: zone number for porosity-permeability relation

IZKD: linear adsorption Kd zone number

The chemical properties for each zone are specified in the chemical.inp file.

\section{Record_13. List of grid blocks connected to constant pressure boundary of gaseous species (such as oxygen diffusion from the atmosphere)}

Variable: EL, DISG, (PFUGB(IG),IG=1,NGAS)

Format: A5, 5E10.3

Remark: Repeat as many times as required, and end with a blank record.

EL : grid block name

DISG $:=\mathrm{A} / \mathrm{D}$, where $\mathrm{A}$ is interface area and $\mathrm{D}$ is distance to the interface $(\mathrm{m})$

PFUGB: gaseous species partial pressure (bar) at the reservoir, repeat as the number of gaseous species 


\subsection{Geochemical Input (chemical.inp)}

An example of chemical.inp is given in Figure 8.2.2.

\section{Record-1. Title}

Variable: TITLE

Format: A100

TITLE: title and comments in one line

\section{Record-2. Label}

Variable: LABEL

Format: A100

LABEL: comments to appear in the output file

\subsubsection{Definition of the geochemical system}

These records contain the information on aqueous species, minerals, gases, surface complexes, species with linear adsorption $\mathrm{Kd}$ and radioactive decay, and exchangeable cations. Their names must match exactly those in the thermodynamic database file (case sensitive).

\section{Record-3. Label}

Variable: LABEL

Format: A100

LABEL: comments to appear in the output file

\section{$\underline{\text { Primary species }}$}

\section{Record-4. Label}

Variable: LABEL

Format: A100

LABEL: comments to appear in the output file

\section{Record-5. Primary aqueous species}

Variable: NAPRI

Format: A20 (write NAPRI within 'single quotes' such as ' $h+$ ')

Remark: Repeat Record-5 as many times as number of primary species

NAPRI: name of the primary species. It must match exactly that in the thermodynamic database file. If redox reactions are present in the system the species 'o2(aq)' must be included as a primary species. A record 
starting with '*' is needed to indicate the end of the list of the primary species.

\section{$\underline{\text { Aqueous complexes }}$}

The aqueous complex block (Records 6 and 7) can be omitted. In this case, all possible aqueous complexes found in the database file are automatically selected.

\section{Record-6. Label}

Variable: LABEL

Format: A76 (write LABEL within 'single quotes')

LABEL: comments to appear in the output file

\section{Record-7. Aqueous complexes}

Variable: NAAQX

Format: A20 (write NAAQX within 'single quotes')

Remark: Repeat Record-7 as many times as the number of aqueous complexes

NAAQX: name of the aqueous complex. It must match exactly that in the database file. Omit NAAQX if no aqueous complexes are required. However, a record starting with '*' is always needed to indicate the end of the list.

\section{$\underline{\text { Minerals }}$}

\section{Record-8. Label}

Variable: LABEL

Format: A76 (write LABEL within 'single quotes')

LABEL: comments to appear in the output file.

The following three records are repeated as many times as the number of minerals.

\section{Record-9-1. Mineral record 1}

Variable: NAMIN, IKIN, IDISPRE, ISS, M1

Format: A20 (write NAMIN within 'single quotes' such as 'calcite'), 4I (free)

Remark: Minerals can be entered in any order as long as the minerals at equilibrium precede those under kinetic constraints. The specified minerals consist of reactants and any possible products. Their names must match exactly the names of minerals in the database. Minerals with identical stoichiometries (i.e. quartz and cristobalite) cannot both be specified at equilibrium, but can be specified under kinetic constraints. Minerals at equilibrium are defined with one record (per mineral). Minerals under kinetic constraints require more records (per mineral). 
NAMIN: name of the mineral phase. It must be consistent with that in the database. Omit NAMIN if no minerals are required. However, a record starting with '*' is always needed to indicate the end of the list.

IKIN: a flag for the type of mineral: 0 for minerals at equilibrium, and 1 for those under kinetic constraints.

IDISPRE: a flag for the type of kinetic constraint: 1 for dissolution only, 2 for precipitation only, and 3 for both (mineral can either precipitate or dissolve). Always set IDISPRE $=0$ if IKIN $=0$ and IDISPRE $>0$ if IKIN $=1$.

ISS: an index for a solid solution mineral endmember. All endmembers for a specified phase are given the same ISS value: ISS $=1$ for each endmember of the first solid solution, ISS $=2$ for each endmember of the second solid solution, and so on (numbers cannot be skipped). Records for each member can appear in any order in the mineral records.

M1: flag to indicate that the mineral may precipitate in a dry grid block as a result of complete evaporation (when liquid saturation $<$ sll min specified in the solute.inp file), or if there is water flux into the grid block that dries out during the flow step (and therefore liquid saturation is zero). The mineral with $\mathrm{M} 1=1$ precipitates first, with $\mathrm{M} 1=2$ second, and so on. If this flag is set to zero, then the mineral will not be formed in the dry grid block.

If IKIN $=1$ and IDSPRE $=1$ or 3 , Record-9-2 is required to define dissolution rate law parameters.

\section{Record-9-2. Mineral record 2}

Variable: RKF, IDEP, CK1, CK2, EA, ACFDISS, BCFDISS, CCFDISS

Format: F, I, 6F (all are free format)

RKF: the coefficient $\mathrm{k}_{25}$ in the expression (B.6) given in Appendix B, where $\mathrm{k}_{25}$ is the rate constant (in $\mathrm{mol} / \mathrm{m}^{2} / \mathrm{sec}$ ) at $25^{\circ} \mathrm{C}$, EA is the activation energy in $\mathrm{kJ} / \mathrm{mol}$. The form of the rate law is given in Eq. (B.5).

IDEP: a flag for rate constant dependence on $\mathrm{pH}$ (see Figure B.1 in Appendix B) or multiple mechanisms (see Eq. B.12 in Appendix B). If IDEP $=0, \mathrm{pH}$ dependent rate constants and multiple mechanisms are not considered. If IDEP $=1$, Record-9-3 must include information on the rate dependence on $\mathrm{pH}$. If IDEP $=2$, Record-9-4 and Record-9-5 need to include information on the rate constants contributed from additional mechanisms.

CK1 and CK2: the exponents $\eta$ and $\theta$, respectively in in Eq. (B.5).

EA: the activation energy $(\mathrm{kJ} / \mathrm{mol})$.

ACFDISS, BCFDISS, and CCFDISS: should be set to zero, unless a different form of rate constant dependence with temperature is desired. This alternate form is: $\log (k)=a+b \cdot \mathrm{T}+c / \mathrm{T}$, where $\mathrm{T}$ is absolute temperature in $\mathrm{K}$ and $\log$ is in base 10. To enable this option, RFK must be set to 1.0, EA must be set to 0.0 , CK1 and CK2 can be set to any value, and ACFDISS, BCFDISS, and CCFDISS must be specified as the coefficients $a, b$, and $c$, respectively, in the above expression. 
If IKIN $=1$ and IDSPRE $=2$ or 3 Record-9-6 is required to define precipitation rate law parameters.

\section{Record-9-3. Mineral record 3}

Variable: PH1, SLOPE1, PH2, SLOPE2

Format: 4F (all are free format)

See Figure B.1 (in Appendix B) for the meaning of these parameters.

\section{Record-9-4. Mineral record 4}

Variable: NDIS

Format: F (free format)

NDIS is the number of additional mechanisms contributed to the rate constant (see Eq. B. 12 in Appendix B). An example of the multiple mechanisms can be found in the $\mathrm{CO}_{2}$ disposal sample problem (Section 8.5).

\section{Record-9-5. Mineral record 5}

Variable: RKDS, EADS, NSPDS, NADIS, EXPDSP

Format: $\quad 3 \mathrm{~F} \quad \mathrm{NSPDS}^{*}(2 \mathrm{~F})$

Remark: This record must be repeated as many as NDIS times (a maximum of five additional mechanisms can be considered).

RKDS is $\mathrm{k}_{\mathrm{i}}$ in Eq. (B. 12) where $\mathrm{i}$ is the additional mechanism index.

EADS: is the activation energy $(\mathrm{kJ} / \mathrm{mol})$ for each additional mechanism.

NSPDS: is the number of species involved in each mechanism (a maximum of five species can be considered).

NADIS is the name of species involved in the mechanism that must be in the list of primary or secondary species. NADIS and the following variable EXPDSP must be repeated as many as NSPDS times.

EXPDSP is the power term $n_{j}$ in Eq. (B. 12).

\section{Record-9-6. Mineral record 6}

Variable: RKPREC, IDEPREC, CK1PREC, CK2PREC, EAPREC, ACFPREC, BCFPREC, CCFPREC, RNUCL, NPLAW

Format: F, I, 7F I (all are free formats)

The first 8 input parameters are listed in the same order and have the same functions as those described above for mineral dissolution, except that the parameters apply to mineral precipitation instead of dissolution. Notice that If IDEPREC $=1$, Record-9-3 needs to include information on the rate dependence on $\mathrm{pH}$; If IDEPREC $=2$, Record-9-4 and Record-9-5 need to 
include information on the rate constants contributed from additional mechanisms.

RNUCL: the initial volume fraction $\left(\mathrm{V}_{\text {mineral }} / \mathrm{V}_{\text {solid }}\right)$ to be assumed for calculating initial effective surface area if the mineral is not present at the start of a simulation but precipitates as a new reaction product. If zero, RNUCL is assumed to be $10^{-5}$.

NPLAW: precipitation law index. NPLAW $=0$ for Eq. (B.5 and B.12) in Appendix B; NPLAW $=1$ for Eq. (B.8).

\section{Record-9-7. Mineral record 7}

This record is only required for a mineral that is allowed to precipitate.

Variable: SSQK0, SSTK1, SSTK2

Format: 3F (free format)

SSQK0: $\log (\mathrm{Q} / \mathrm{K})$ gap (supersaturation window, see Eq, B.13 in Appendix B). A zero value represents no gap.

SSTK1: temperature $\left(\right.$ in $\left.{ }^{\circ} \mathrm{C}\right)$ at which to begin reducing gap.

SSTK2: temperature (in ${ }^{\circ} \mathrm{C}$ ) endpoint at which the gap has diminished to nearly zero ( $1 \%$ of original value). The gap decreases exponentially from the first (SSTK1) to the second (SSTK2) temperature, and SSTK2 must always be greater than SSTK1.

\section{Gaseous species}

Record-10. Label

Variable: LABEL

Format: A76 (write LABEL within 'single quotes')

LABEL: comments to appear in the output file

\section{Record-11. Gases}

Variable: NAGAS

Format: A20 (write NAGAS within 'single quotes' such as 'co2(g)')

Remark: Repeat Record-11 as many times as the number of gaseous species

NAGAS: name of a gaseous species. It must match exactly that in the chemical thermodynamic database file. Omit NAGAS if no gaseous species are required. However, a record starting with ' $*$ ' is always needed to indicate the end of the list.

\section{$\underline{\text { Surface complexes }}$}

Record-12. LABEL 
Variable: LABEL

Format: A76 (write LABEL within 'single quotes')

LABEL: comments to appear in the output file

\section{Record-13. Surface complexes}

Variable: NAADS

Format: A20 (write NAADS within 'single quotes')

Remark: Repeat Record-13 as many times as the number of surface species

NAADS: name of surface complex. Omit NAADS if no surface complexes are required. However, a record starting with ' ${ }^{\prime \prime}$ ' is always needed to indicate the end of the list.

\section{$\underline{\text { Aqueous species (primary) with Kd and decay }}$}

\section{Record-14. LABEL}

Variable: LABEL

Format: A76 (write LABEL within 'single quotes')

\section{LABEL: comments to appear in the output file}

\section{Record-15. Species with Kd and decay}

Variable: NAKDD, DECAYC

Format: A20 (write NAKDD within 'single quotes'), free

Repeat Record-15 as many times as the species with $\mathrm{Kd}$ and decay

NAKDD: name of the aqueous primary species with $\mathrm{Kd}$ and/or decay. These names must appear in the above mentioned 'primary species record' of the input file.

DECAYC: radioactive decay constant (in $1 / \mathrm{s}$ ). For species with only $\mathrm{Kd}$ adsorption and without decay, set DECAYC equal to 0.0.

\section{$\underline{\text { Exchangeable cations }}$}

\section{Record-16. Label}

Variable: LABEL

Format: A76 (write LABEL within 'single quotes')

LABEL: comments to appear in the output file

\section{Record-17. Label}

Variable: LABEL

Format: A76 (write LABEL within 'single quotes') 


\section{LABEL: comments to appear in the output file}

\section{Record-18. Data related with exchangeable cations}

Variable: NAEXC IMS IEX EKX

Format: A20 I I $\quad F$ (the last three variables are free format)

Remark: Repeat Record-18 as many times as number of the exchangeable cations

NAEXC: name of exchangeable cation. Omit NAEXC if no exchangeable cations are required. However, a record starting with ' ${ }^{*}$ ' is always needed to indicate the end of the list.

IMS: If IMS $=1$, the cation is used as reference for the exchange reactions (normally $\mathrm{Na}+$ ). For the remaining cations, IMS must be 0 .

IEX: exchange convention type used in the calculations: $1=$ Gaines-Thomas; $2=$

Vanselow; $3=$ Gapon. The value of IEX must be the same for all the exchanged cations.

EKX: exchange coefficient of the cation with respect to the reference cation. If $\mathrm{IMS}=1$, then $\mathrm{EKX}=1.0$.

\subsubsection{Initial and boundary water solutions}

\section{Record-19. Label}

Variable: LABEL

Format: A76 (write LABEL within 'single quotes')

LABEL: comments to appear in the output file

\section{Record-20. Label}

Variable: LABEL

Format: A76 (write LABEL within 'single quotes')

LABEL: comments to appear in the output file

\section{Record-21. Data related with the number of aqueous solutions Variable: NIWTYPE NBWTYPE \\ Format: I I (all are free format)}

NIWTYPE: number of types of aqueous solutions initially present in the system.

NBWTYPE: number of types of boundary solutions (including pumping/injection at the internal grid blocks).

\section{Aqueous solution compositions}

This part describes the different types of aqueous solutions (initial and boundary). Repeat the following Records 22, 23, and 24 a number of times equal to (NIWTYPE + NBWTYPE), starting with initial solutions, and then boundary (including injection at the internal grid blocks) 
solutions. The flux of each chemical component at the boundary is calculated from the concentration specified in Record-24 multiplied by the water flux given under keyword block 'GENER' in the flow.inp file (or in the separate GENER file). For a negative water flux (such as pumping and discharge), the boundary solution composition is not required.

\section{Record-22. Identification of the aqueous solution}

Variable: IWTYPE TC2 ITC2

Format: $\quad$ I, F, I (all are free format)

IWTYPE: number of the initial or boundary solution. The value of IWTYPE varies from 1 to NIWTYPE; it then starts again with 1 up to NBWTYPE.

TC2: temperature of the solution $\left({ }^{\circ} \mathrm{C}\right)$.

ITC2: set zero for this version

\section{Record-23. Label}

Variable: LABEL

Format: A76 (write LABEL within 'single quotes')

LABEL: comments to appear in the output file

\section{Record-24. Composition of aqueous solution}

Variable: NAPRI ICON CGUESS CTOT NAMEQ QKSAT

Format: $\quad$ A20, I, F, F, A, F

Remark: Repeat Record-24 as many times as the number of primary species

NAPRI: name of the primary aqueous species. The name of the species must match exactly those previously listed as primary species in the definition of the system, although the order may change. Names must be included between 'single quotes' such as ' $h+$ '. A record starting with '*' indicates the end of the list.

ICON: flag indicating the type of constraint controlling the input concentration of the aqueous species:

ICON=1: input values of CTOT represent total amounts (in moles) for aqueous species, and total kilograms for liquid $\mathrm{H}_{2} \mathrm{O}$. Thus, for inputting total molalities, set CTOT $=1$ for $\mathrm{H}_{2} \mathrm{O}$.

ICON=2: the total concentration of the species will be adjusted such that the saturation index $(\log (\mathrm{Q} / \mathrm{K}))$ of mineral or gas NAMEQ equals QKSAT. Therefore, for equilibrium with a mineral, use this option with QKSAT = 0.0 , and for equilibrium with a gas at a given fugacity, use this option with QKSAT $=\log$ (fugacity). With this option, input CTOT values are irrelevant and discarded.

ICON =3: input values of CTOT represent the known activity of the specific species (i.e., not total concentration). For example, to input a known $\mathrm{pH}$ value, use this option and set CTOT $=10^{-\mathrm{pH}}$ for $\mathrm{H}^{+}$activity.

ICON=4: the total concentration of the species is adjusted to yield charge balance. Use only with a charged species. If non convergence occurs, 
choose a species with an opposite charge. With this option, input CTOT values are irrelevant and discarded.

CGUESS: initial guess for the concentration of the individual primary species (not total concentration), in moles/ $\mathrm{kg} \mathrm{H}_{2} \mathrm{O}$ (molal) for species other than $\mathrm{H}_{2} \mathrm{O}$ and in $\mathrm{kg}$ for $\mathrm{H}_{2} \mathrm{O}$. Input values of CGUESS do not affect results of speciation calculations, but could affect the number of chemical iterations required during initial speciation computations.

CTOT: if ICON=1, CTOT is total moles of aqueous species, and total amount (in $\mathrm{kg}$ ) of liquid water for $\mathrm{H}_{2} \mathrm{O}$. Molalities are then internally computed as $\mathrm{CTOT}_{\mathrm{i} \neq \mathrm{H} 2 \mathrm{O}} / \mathrm{CTOT}_{\mathrm{H} 2 \mathrm{O}}$. If ICON $>1$, refer to the discussion of ICON above for the meaning of CTOT.

NAMEQ: name of mineral or gas to use with option ICON=2. Names must be included between 'single quotes', and match exactly those previously listed as minerals or gases in the definition of the chemical system. If ICON $\neq 2$, this entry is ignored, but cannot be omitted and should be entered as one of more characters between single quotes (suggested ' ' or ' $*$ ' ).

QKSAT: desired value of mineral $\log (\mathrm{Q} / \mathrm{K})$ or gas $\log$ (fugacity) when option $\mathrm{ICON}=2$ is used. For equilibrium with mineral NAMEQ use QKSAT=0.0, and for equilibrium with gas NAMEQ at a given fugacity use QKSAT = $\log$ (fugacity). If ICON $\neq 2$, this entry is ignored, but cannot be omitted and should be entered as a real number (suggested 0.0 ).

\subsubsection{Initial mineral zones}

This section describes the mineral zones initially present in the system.

\section{Record-25. Label}

Variable: LABEL

Format: A76 (write LABEL within 'single quotes')

LABEL: comments to appear in the output file

\section{Record-26. Label}

Variable: LABEL

Format: A76 (write LABEL within 'single quotes')

LABEL: comments to appear in the output file

\section{Record-27.}

Variable: NMTYPE

Format: $\quad$ I4

NMTYPE: Number of mineral zones in the system. If minerals are not considered in the system, place NMTYPE $=1$. 
The following Records 28, 29 and 30 must be repeated NMTYPE times.

\section{Record-28.}

Variable: IMTYPE

Format: $\quad$ I4

IMTYPE: number of the mineral zone

\section{Record-29. Label}

Variable: LABEL

Format: A76 (write LABEL within 'single quotes')

LABEL: comments to appear in the output file

\section{Record-30. Data related to the composition of the mineral zone} Variable: NAMIN VOL IKIN

Format: $\quad$ A20 $\quad$ F $\quad$ I (the last two variables are free format)

NAMIN: name of the mineral present in the system. The name of the mineral must be included among those previously listed in the definition of the system, although the order may change, and it is not needed to repeat the complete list. Names must be included between 'single quotes' such as 'calcite'. A record starting with '*' indicates the end of the list of minerals.

VOL: is the initial volume fraction of the mineral, excluding liquid (mineral volume divided by total volume of solids). The sum of VOL's need not add up to 1 . The remaining solid volume fraction is considered nonreactive.

IKIN: A flag for the type of mineral: 0 for minerals at equilibrium, and 1 for those under kinetic constraints. When IKIN=1, the following record (Record-30-1) is required.

\section{Record-30-1.}

Variable: RAD, AMIN, IMFLG

Format: F, F, I (all are free format)

RAD: radius of mineral grain (in $\mathrm{m}$ ) used to calculate surface area for initial formation of secondary phase. If $\mathrm{RAD}=0.0$, the initial surface area is calculated from RNUCL in Record-9-6.

AMIN: specific reactive surface area. Its unit depends on the following flag IMFLG

IMFLG: A flag for surface area conversion

$$
\begin{aligned}
& \text { IMFLG }=0 \text { for } \mathrm{cm}^{2} / \mathrm{g} \text { mineral } \\
& \text { IMFLG }=1 \text { for } \mathrm{m}^{2} \text { rock area } / \mathrm{m}^{3} \text { medium } \\
& \text { IMFLG }=2 \text { for } \mathrm{m}^{2} / \mathrm{m}^{3} \text { mineral }
\end{aligned}
$$

\subsubsection{Initial gas zones}

This section describes the initial gas zones present in the system. 


\section{Record-31. Label}

Variable: LABEL

Format: A76 (write LABEL within 'single quotes')

LABEL: comments to appear in the output file

\section{Record-32. Label}

Variable: LABEL

Format: A76 (write LABEL within 'single quotes')

LABEL: comments to appear in the output file

\section{Record-33.}

Variable: NGTYPE

Format: $\quad$ I4

NGTYPE: number of gas zones in the system. If gaseous species are not considered in the system, enter NGTYPE $=1$

The following records 34, 35 and 36 must be repeated NGTYPE times.

\section{Record-34.}

Variable: IGTYPE

Format: $\quad$ I4

IGTYPE: number of the gas zone

\section{Record-35. Label}

Variable: LABEL

Format: A76 (write LABEL within 'single quotes')

LABEL: comments to appear in the output file

\section{Record-36. Data related to the composition of the gas zone}

Variable: NAGAS VOLG

Format: $\quad$ A20 $\quad F$ (the last one is free format)

NAGAS: name of the gaseous species present in the system. The name of the gas must be included among those previously listed in the definition of the system, although the order may change, and it is not needed to repeat the complete list. Names must be included between 'single quotes'. A record starting with '*' indicates the end of the list.

VOLG: partial pressure of the gaseous species (in bars). 


\subsubsection{Zones for permeability-porosity relationship}

\section{Record-37. Label}

Variable: LABEL

Format: A76 (write LABEL within 'single quotes')

LABEL: comments to appear in the output file

\section{Record-38. Label}

Variable: LABEL

Format: A76 (write LABEL within 'single quotes')

LABEL: comments to appear in the output file

\section{Record-39.}

Variable: NPPZON

Format: $\quad$ I4

NPPZON: Number of permeability zones. If permeability change is not considered in the simulation, place NPPZON $=1$.

The following records, 40, 41 and 42 must be repeated NPPZON times.

\section{Record-40.}

Variable: IPPZON

Format: $\quad$ I4

IPPZON: index of the permeability zone

\section{Record-41. Label}

Variable: LABEL

Format: A76 (write LABEL within 'single quotes')

\section{LABEL: comments to appear in the output file}

\section{Record-42. Data related to zone for permeability-porosity relationship}

Variable: ipptyp, apppar, bpppar

Format: I, 2F (All are free format)

Ipptyp: the index for the permeability law. Details on permeability-porosity relationships are described in Appendix F.

Ipptyp $=0$ : no change in permeability

Ipptyp $=1$ : simplified Carman-Kozeny (Eq. F.7 in Appendix F). The parameter values (apppar and bpppar) are not used and may be set to 0.0 or any real number. 
Ipptyp = 3: cubic law (Eq. (F.2)). The parameter values (apppar and bpppar) are not used and may be set to 0.0 or any real number.

Ipptyp = 4: modified Cubic Law (Eq. F.3-F.6). The parameters are: (a) fracture porosity / fracture-matrix area (analogous to fracture aperture) $\left(\mathrm{m}^{3} / \mathrm{m}^{2}\right)$ and (b) fracture spacing $(\mathrm{m})$

Ipptyp = 5: Verma-Pruess permeability-porosity relation (Eq. F.8). The parameters are: (a) the value of "critical" porosity at which permeability goes to zero and (b) a power law exponent

\subsubsection{Surface adsorption zones}

This part describes the characteristics of the zones with different surface adsorption properties present in the system. The capability of TOUGHREACT for surface complexes has not been tested in the present version. The purpose is to reserve a space for future use.

\section{Record-43. Label}

Variable: LABEL

Format: A76 (write LABEL within 'single quotes')

LABEL: comments to appear in the output file

\section{Record-44. Label}

Variable: LABEL

Format: A76 (write LABEL within 'single quotes')

LABEL: comments to appear in the output file

\section{Record-45.}

Variable: NDTYPE

Format: I4

NDTYPE: number of surface adsorption zones.

\section{Record-46. Label}

Variable: LABEL

Format: A76 (write LABEL within 'single quotes')

LABEL: comments to appear in the output file

\section{Record-47. Data related to the adsorption zone \\ Variable: IDTYPE SUPADS TSS \\ Format: I4 Free Free}

Remark: This record must be repeated NDTYPE times. If NDTYPE is zero omit this. No '*' is required to indicate the end of the list of adsorption zones. 
IDTYPE: number of the surface adsorption zone.

SUPADS: specific adsorbent surface of the solid phase per unit volume of solution $\left(\mathrm{dm}^{2} \cdot \mathrm{dm}^{-3}\right)$

TSS: Total adsorption sites per volume of solution $\left(\mathrm{mol} \cdot \mathrm{dm}^{-3}\right)$

\subsubsection{Linear Kd zones}

This section describes the linear adsorption $\mathrm{Kd}$ zones initially present in the system.

\section{Record-48. Label}

Variable: LABEL

Format: A76 (write LABEL within 'single quotes')

LABEL: comments to appear in the output file

\section{Record-49. Label}

Variable: LABEL

Format: A76 (write LABEL within 'single quotes')

LABEL: comments to appear in the output file

\section{Record-50.}

Variable: KDTYPE

Format: $\quad$ I4

KDTYPE: number of $\mathrm{Kd}$ zones in the system. If $\mathrm{Kd}$ adsorption is not considered in the simulation, place KDTYPE $=1$

The following Records 51, 52 and 53 must be repeated KDTYPE times.

\section{Record-51.}

Variable: IDTYPE

Format: $\quad$ I4

IDTYPE: number of the $\mathrm{Kd}$ zone

\section{Record-52. Label}

Variable: LABEL

Format: A76 (write LABEL within 'single quotes')

LABEL: comments to appear in the output file

\section{Record-53. Data related to the Kd zone}

Variable: 'NAME', SDEN2, VKD2

Format: A20, F, F (the last two variables are free format real numbers) 
NAME : the name of primary aqueous species with $\mathrm{Kd}$, which can be listed in any order. The species spelling must be the same as defined previously.

SDEN2: the solid density (in $\mathrm{kg} / \mathrm{dm}^{3}$ ).

VKD2 is value of $\mathrm{Kd}$ (in ( $1 / \mathrm{kg}$ which is mass $/ \mathrm{kg}$ solid divided by mass $/ 1$ solution). If SDEN2 $=0.0, \mathrm{VKD} 2$ automatically represents retardation factor $(\geq 1)$.

\subsubsection{Cation exchange zones}

This section describes the characteristics of the cation exchange capacity zones present in the system.

\section{Record-54. Label}

Variable: LABEL

Format: A76 (write LABEL within 'single quotes')

LABEL: comments to appear in the output file

\section{Record-55. Label}

Variable: LABEL

Format: A76 (write LABEL within 'single quotes')

LABEL: comments to appear in the output file

\section{Record-56.}

Variable: NXTYPE

Format: I4

NXTYPE: number of cation exchange zones.

\section{Record-57. Label}

Variable: LABEL

Format: A76 (write LABEL within 'single quotes')

LABEL: comments to appear in the output file

\section{Record-58. Data related to the cation exchange zone}

Record-58 must be repeated NXTYPE times. If NXTYPE is zero omit this card. No '*' is required to indicate the end of the list of cation exchange zones.

Variable: IXTYPE CEC

Format: $\quad \mathrm{I}, \quad \mathrm{F} \quad$ (all are free format)

IXTYPE: number of the cation exchange zone. 
CEC: cation exchange capacity (meq/100 g of solid).

\subsubsection{End of reading chemical input}

This part allows the user to be sure that the chemical data have been entirely read.

\section{Record-59. Label}

Variable: LABEL

Format: A76 (write LABEL within 'single quotes')

LABEL: comments to appear in the output file

\section{Record-60. Label to check the end of chemical data input} Variable: LABEL

Format: A76 (write LABEL within 'single quotes')

LABEL: This label must be 'end'. 


\subsection{Thermodynamic Data}

Aqueous species, minerals, and gases contained in chemical.inp must be found in the thermodynamic database file. The name of the database file is specified in solute.inp. The format of the database file is free. For most problems, the database files supplied with TOUGHREACT may be used without addition and modification. If any aqueous species, mineral, and gas are not contained in the supplied database file or one desires to use different thermodynamic data, users must add them to the database file. An example of a chemical database file is given in Figure 6.1. Because the EQ3/6 database is one of the most commonly used for geochemical modeling, the distribution $\mathrm{CD}$ provides a utility program for converting the EQ3/6 database to the TOUGHREACT database. The description of the conversion program is given in Appendix J. Appendix $\mathrm{J}$ also gives descriptions of other utility programs for switching basis species and regressing $\log (\mathrm{K})$ data.

\section{Record-1. Temperature points}

Variable: 'DUMMY', NTEMP, (TEMPC(i), i=1,NTEMP)

Format: A, I, NTEMP(F)

DUMMY: a label used to describe the data for this record.

NTEMP : the number of TEMPC values to read.

TEMPC : temperatures $\left({ }^{\circ} \mathrm{C}\right)$ at which the $\log (\mathrm{K})$ data are listed in this file. TEMPC values must be listed in order of increasing temperature. These values are used to constrain $\log (\mathrm{K})$ extrapolation within this temperature range. $\log (\mathrm{K})$ 's are not extrapolated outside this temperature range. For example, if the maximum TEMPC is $150^{\circ} \mathrm{C}$ but the computed system temperature is $250^{\circ} \mathrm{C}, \log (\mathrm{K})^{\prime} \mathrm{s}$ will be extrapolated only to $150^{\circ} \mathrm{C}$ (i.e. the geochemical speciation will be computed at $150^{\circ} \mathrm{C}$, not $250^{\circ} \mathrm{C}$ ). Therefore, users must make sure that simulation temperatures are within the range of thermodynamic data temperatures.

\section{Record-2. Basis (primary) species}

Variable: 'NAME', A0, Z, (MWT optional)

Format: $\quad \mathrm{A}, 3 \mathrm{~F}$

NAME : name or chemical formula of aqueous basis species such as ' $h+$ ', The maximum length of NAME is A20.

A0 : Ion effective or hydrated radius used to compute the Debye-Huckel a0 parameter (see Appendix $\mathrm{H}$ for details). For neutral species other than typical dissolved gases (see Section H.3 of Appendix H), if A0 > 100, the 
value of $\mathrm{A} 0$ is used to compute a salting-out coefficient $K_{i}$ equal to A0 100 (i.e., salting-out coefficients for neutral species can be entered as values of A0 equal to $100+K_{i}$; see Equation H.9 for the definition of $K_{i}$ ).

$Z$ : the ion electric charge

MWT : Optional molecular weight of the aqueous species. These values are not read or used by TOUGHREACT, and intended only for use with other codes reading the database.

This record is repeated as many times as the number of primary species. The last line must be: 'null' 0.00 .0 (where 'null' is the actual string in quotes)

\section{Record-3. Secondary (derived) species}

The data for each secondary species is given by 3 sub-records, as follows:

\section{Record-3-1.}

Variable: 'NAME', Xmwt, A0, Z, NCPS, (STQS(i), 'NAM(i)', i=1,NCPS)

Format: $\quad$ A, 3F, I, NCPS(F, A)

NAME : chemical formula of secondary species. The maximum length of NAME is A20.

Xmwt : Molecular weight of the aqueous species. These values are read but not used by TOUGHREACT, and intended only for use with other codes reading the database.

A0 : Ion effective or hydrated radius used to compute the Debye-Huckel a0 parameter (see Appendix $\mathrm{H}$ for details). For neutral species other than typical dissolved gases (see Section H.3 of Appendix H), if A0 > 100, the value of $\mathrm{A} 0$ is used to compute a salting-out coefficient $K_{i}$ equal to A0 100 (i.e., salting-out coefficients for neutral species can be entered as values of A0 equal to $100+K_{i}$; see Equation H.9 for the definition of $K_{i}$ ).

$Z$ : the ion electric charge.

NCPS : the number of basis species defining the secondary species.

STQS contains the stoichiometric coefficients of component species NAM included in the dissociation reaction of the derived species (negative and positive values for reactants and products, respectively).

\section{Record-3-2.}

Variable: 'NAME', (DUMMY(i), i=1,ntemp)

Format: $\quad \mathrm{A}, \mathrm{ntemp}(\mathrm{F})$

NAME : name or chemical formula of secondary species.

DUMMY : contains the dissociation constants $(\log (K)$ in base 10$)$ for the given reaction at each discrete temperature listed in Record-1 above. These data are skipped on input, because all $\log (\mathrm{K})$ values are computed as a function of temperature using the regression coefficients that follow (Record-3-3). 
The discrete $\log (\mathrm{K})$ values should, however, always be included in the file to provide for an easy reference of the data.

\section{Record-3-3.}

Variable: 'NAME', (AKCOES(i), $\mathrm{i}=1,5)$

Format: $\quad A, 5(E)$

NAME : name or chemical formula of secondary species.

AKCOES : contains regression coefficients a, b, c, d, and e to calculate $\log (\mathrm{K})$ as a function of temperature (within the range of temperatures listed on the first record of the file) such that $\log (\mathrm{K})=\mathrm{a}^{*} \ln (\mathrm{Tk})+\mathrm{b}+\mathrm{c}^{*} \mathrm{Tk}+\mathrm{d} / \mathrm{Tk}+\mathrm{e} / \mathrm{Tk}^{2}$, where Tk is absolute temperature (K), and $\log$ and $\ln$ stand for base-10 and natural logarithms, respectively.

Records 3-1, 3-2, and 3-3 are repeated as many times as number of secondary species. The last line must be: 'null' $0.0 \quad 0.0 \quad$ (where 'null' is the actual string in quotes).

\section{Record-4. Minerals}

The data for a mineral is given by 3 sub-records, which are as follows:

\section{Record-4-1.}

Variable: 'NAME', MOLWT, VMIN, NCPM, (STQM(i), 'NAM(i)', i=1,NCPM)

Format: $\quad \mathrm{A}, 2 \mathrm{~F}, \mathrm{I}, \operatorname{mpri}(2 \mathrm{~F}, \mathrm{~A})$

NAME : name or chemical formula of a mineral.

MOLWT : molecular weight $(\mathrm{g} / \mathrm{mol})$.

VMIN : molar volume $\left(\mathrm{cm}^{3} /\right.$ mole $)$.

NCPM : the number of component species defining the mineral.

STQM : contains the stoichiometric coefficient of basis species NAM in the dissociation (hydrolysis) reaction of the mineral (negative and positive values for reactants and products, respectively).

\section{Record-4-2.}

Variable: 'NAME', (DUMMY(i), i=1,ntemp)

Format: $\quad \mathrm{A}, \mathrm{ntemp}(\mathrm{F})$

NAME : name or chemical formula of the mineral.

DUMMY : the dissociation constants $(\log (\mathrm{K})$ in base 10$)$ for the given reaction at each discrete temperature listed in the first record of the file. These data are skipped on input, because all $\log (\mathrm{K})$ values are computed as a function of temperature using the regression coefficients that follow (below). The discrete $\log (\mathrm{K})$ values should, however, always be included in the file to provide for an easy reference of the data. 


\section{Record-4-3.}

Variable: 'NAME', (AKCOEM(i), i=1,5)

Format: $\quad \mathrm{A}, 5(\mathrm{E})$

NAME : name or chemical formula of the mineral.

AKCOEM : contains regression coefficients a, b, c, d, and e to calculate $\log (K)$ as a function of temperature (within the range of temperatures listed on the first record of the file) such that $\log (\mathrm{K})=\mathrm{a}^{*} \ln (\mathrm{Tk})+\mathrm{b}+\mathrm{c}^{*} \mathrm{Tk}+\mathrm{d} / \mathrm{Tk}+$ $\mathrm{e} / \mathrm{Tk}^{2}$.

Records 4-1, 4-2, and 4-3 are repeated as many times as number of minerals. The last line must be: 'null' 0.00 .0 (where 'null' is the actual string in quotes).

\section{Record-5. Gases}

The data for a gas species are given by 3 sub-records, as follows:

\section{Record-5-1.}

Variable: 'NAME', DMOLWT, DMDIAM, NCPG, (STQG(i), 'NAM(i)', i=1,NCPG)

Format: $\quad$ A, 2 F I, NCPG(F, A)

NAME : name or chemical formula of a gas species.

DMOLWT : molecular weight $(\mathrm{g} / \mathrm{mol})$

DMDIAM: molecular diameter (m) used to calculate gas diffusion coefficient (see Eq. (A.1) in Appendix A)

NCPG : the number of basis species defining the gas.

STQG : contains the stoichiometric coefficient of component species NAM in the dissociation reaction of the gas (negative and positive values for reactants and products, respectively).

\section{Record-5-2.}

Variable: 'NAME', (DUMMY(i), i=1,ntemp)

Format: $\quad$ A, ntemp $(\mathrm{F})$

NAME : name or chemical formula of the gas.

DUMMY : the dissociation constants $(\log (\mathrm{K})$ in base 10$)$ for the given reaction at each discrete temperature listed in the first record of the file. These data are skipped on input, because all $\log (\mathrm{K})$ values are computed as a function of temperature using the regression coefficients that follow (below). The discrete $\log (\mathrm{K})$ values should, however, always be included in the file to provide an easy reference of the data.

\section{Record-5-3.}

Variable: 'NAME', (AKCOEG(i), i=1,5)

Format: $\quad$ A, 5(E) 
NAME : name or chemical formula of the gas.

AKCOEG : contains regression coefficients a, b, c, d, and e to calculate $\log (\mathrm{K})$ as a function of temperature (within the range of temperatures listed on the first record of the file) such that $\log (\mathrm{K})=\mathrm{a} * \ln (\mathrm{Tk})+\mathrm{b}+\mathrm{c} * \mathrm{Tk}+\mathrm{d} / \mathrm{Tk}+\mathrm{e} / \mathrm{Tk}^{2}$.

Records 5-1, 5-2, and 5-3 are repeated as many times as number of gases. The last line must be: 'null' $0.0 \quad 0.0 \quad 0 \quad$ (where 'null' is the actual string in quotes).

\section{Record-6. Surface complexes}

The capability of TOUGHREACT for surface complexes has not been tested in the present version. Therefore, no data should be entered, except for the termination record: 'null' 0 . 0 (where 'null' is the actual string in quotes). The purpose is to reserve a space for a future extension to TOUGHREACT.

Figure 6.1. An example of chemical database file.

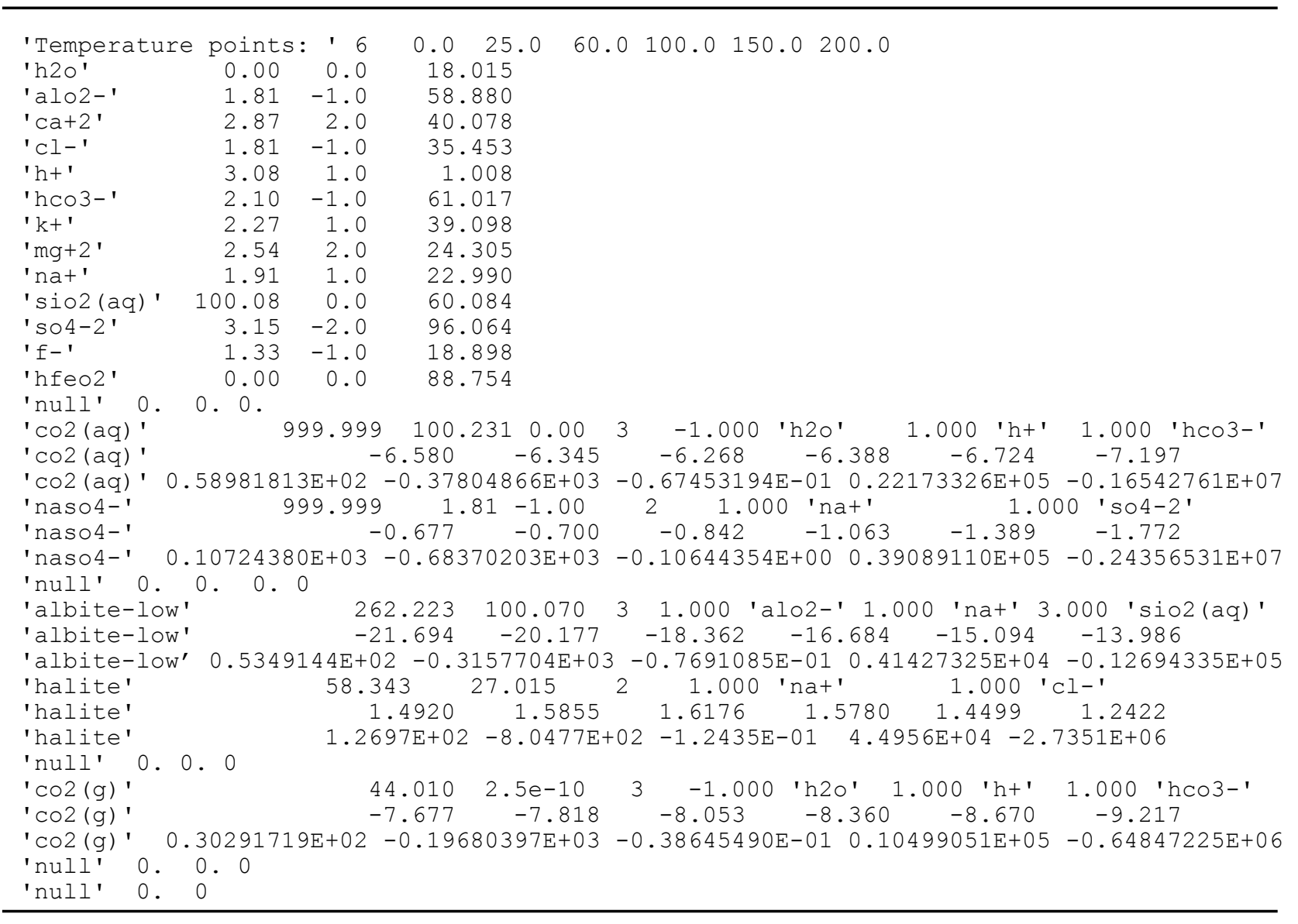




\section{Anticipated Error Messages}

All execution stops built into TOUGHREACT are accompanied by a message indicating why the execution was aborted. These messages are written to file runlog.out. Other error messages do not lead to a program interruption. Only messages related to the reactive transport part of the program are reviewed below. Error messages originating from fluid and heat flow calculations are the same as for TOUGH2 V2 (Pruess et al., 1999).

\subsection{From Routine: INIT (reads the CHEMICAL.INP file)}

Most of these messages are self-explanatory and refer to exceeded array dimensions or other errors encountered when reading the chemical.inp file. Array dimension problems can be corrected by reducing the problem size or changing array dimensions in the source file chempar23.inc and recompiling the program. Some examples are given as follows:

Error: maximum number of component species (MPRI) was exceeded. Current $\max =(M P R I)$

Execution stop: yes. Self-explanatory.

Error: maximum number of minerals (MMIN) was exceeded. Current max $=(M M I N)$

Execution stop: yes. Self-explanatory.

error reading aqueous species of the system

Execution stop: yes. Self-explanatory.

error reading minerals of the system

Execution stop: yes. Self-explanatory.

error reading gases of the system

Execution stop: yes. Self-explanatory.

error reading initial water zone $=$ (iwtype)

Execution stop: yes. Self-explanatory.

error reading initial mineral zone $=$

Execution stop: yes. Self-explanatory. (imtype)

error reading initial gas zone $=$ (imtype)

Execution stop: yes. Self-explanatory. 


\subsection{From Routine: NRINIT (initial Newton-Raphson iterations)}

ERROR (convergence problem in initialization of water composition)

Please adjust convergence criteria regarding chemical iteration

and initial guess of concentration of primary species

Execution stop: yes. Self-explanatory. This error results in calling routine chdump for troubleshooting (i.e. the last chemical speciation data are output in the chdump.out file). This error occurs during the initial geochemical speciation of waters specified in chemical.inp (no minerals, before the first time step). Check the chdump.out file for clues, and also check that water temperatures specified in chemical.inp data are not too different than the initial condition of temperature specified in the flow.inp file.

\subsection{From Routine: READTHERM (reads thermodynamic database file)}

All these messages occur while reading the thermodynamic database and are selfexplanatory. These indicate improperly formatted records in the database file. All errors result in a program execution stop. Some examples are:

Error reading temperature data: stop

Error reading primary species: stop

Error reading secondary species: stop (followed by the species name)

Error reading minerals: stop (followed by the mineral name)

Error reading gases: stop (followed by the gas name)

Error reading adsorbed species: stop (followed by the species name)

Error in opening database file: stop

\subsection{From Routine: READSOLU (reads the file solute.inp)}

There are currently no specific error messages generated while reading the file solute.inp. The unit number of this file is 31 . System error messages relating to this $\mathrm{I} / \mathrm{O}$ number originate while reading this file. Make sure the fixed formats of this file are respected.

\subsection{From Routine: CR_CP (kinetic data calculations)}

error in data option for mineral (kinetic) $=$

Execution stop: yes. This message occurs if the flag IDEP for any of the kinetic minerals is not set to either 0 or 1 . With this program version, IDEP must always be zero (this flag is specified in the mineral section of the chemical.inp file).

\subsection{From Routine: NEWTONEQ (Newton-Raphson iterations after 1st time step)}

ERROR: chemistry did not converge at node Species: _ Error $=$ Error limit $=$ (routine NEWTONEQ)

Node temperature $(C)$ : relative

Program execution was not aborted. Check results! 
Execution stop: only if this error occurs at more than fifty grid blocks at any given time step. This error also calls routine chdump for troubleshooting (i.e., the last chemistry calculation data are output in the chdump.out file). This error occurs during the blockby-block geochemical speciation computations after the first time step (complete system, with minerals and gases if any). Check the chdump.out file for clues on why convergence was not reached. You may need to increase the loop limit (MAXITCH) and/or tolerance (TOLCH) in the solute.inp file. If boiling occurs, you may try increasing ST1MIN or decreasing STIMAX (specified in solute.inp). Chemical convergence may also fail because of errors during transport, resulting in erroneous system compositions that cannot yield a solution to geochemical speciation calculations. In this case, the time step may be decreased and/or the Courant number option enabled (RCOUR in solute.inp input file). Depending on the type of problem, chemical speciation in closely spaced grid blocks can be skipped by setting D1MAX $>0$ (last resort).

Error: Negative concentration for species

Execution stop: no. Self-explanatory. A concentration may temporarily become negative during the chemical Newton-Raphson iterations, but should not remain negative. This error may indicate problems to come. It is rarely encountered.

\subsection{From Routine: LUDCMP (linear equation solver)}

This routine is called during the Newton-Raphson iterations to compute geochemical speciation.

Singular Matrix in Chemical Solver, STOP

Execution stop: yes. Self-explanatory. This indicates an ill-defined chemical system.

This error results in calling chdump to output the last geochemical speciation data in the chdump.out file. A phase-rule violation or inclusion of minerals (at equilibrium) with identical stoichiometries in the simulation will cause this error. In some cases, divergence and over/underflows during Newton-Raphson iterations (sometimes related to transport problems) may cause this error even though a true singularity has not occurred. Check the chdump.out file for clues on why the error happened. 


\section{Sample Problems}

In this section we present applications of TOUGHREACT to problems in geothermal reservoir behavior, groundwater quality, nuclear waste isolation, supergene copper enrichment, and geologic disposal of greenhouse gases. The test problems serve as checks and benchmarks to verify proper code installation. The input files can be used as templates to facilitate preparation of input data for new problems. To assist with checking on code performance, we provide printouts of portions of the output files generated for each of the sample problems. Simulations of sample problems presented here were run on Pentium-4 PC machines $(1.7 \mathrm{GHz})$. The compiled EXE files provided in the distribution $\mathrm{CD}$ were generated from the COMPAQ Visual Fortran compiler version 6.6.

\subsection{Aqueous Transport with Adsorption (Linear Kd) and Decay (EOS9)}

A 1-D homogeneous fully water-saturated porous medium is considered (Figure 8.1.1), using the following parameters: a porosity of 0.1 , a pore velocity $\mathrm{v}$ of $0.1 \mathrm{~m} /$ day, a solid density of $2600 \mathrm{~kg} / \mathrm{m}^{3}$, a distribution coefficient $(\mathrm{Kd})$ of $0.042735 \mathrm{l} / \mathrm{kg}$, which corresponds to a retardation factor R of 2 (Equation C.8 in Appendix C), and a half-life $\mathrm{t}_{1 / 2}$ of 20 days. The flow system is a cylindrical, horizontal porous medium with cross-sectional area of $1 \mathrm{~m}^{2}$ and $12 \mathrm{~m}$ length, divided into 60 grid blocks of $0.2 \mathrm{~m}$ thickness. Parameters for water flow are specified in file flow.inp (Fig. 8.1.2). Water chemical compositions are assigned through data in files solute.inp (Figure 8.1.3) and chemical.inp (Fig. 8.1.4). In chemical.inp, the record starting with “(1 1)" following the record 'INITIAL AND BOUNDARY WATER TYPES' specify that one initial water composition will be read, as well as one boundary water composition. The data entered in solute.inp under "default values of chemical zone codes for grid blocks" assign the first (and only) initial water type to all grid blocks in the problem, as well as assigning the first (only) boundary water composition to all injection grid blocks. Injection occurs only in block " $\mathrm{F} 1$ " (GENER block in file flow.inp), and with the boundary water chemical composition. 


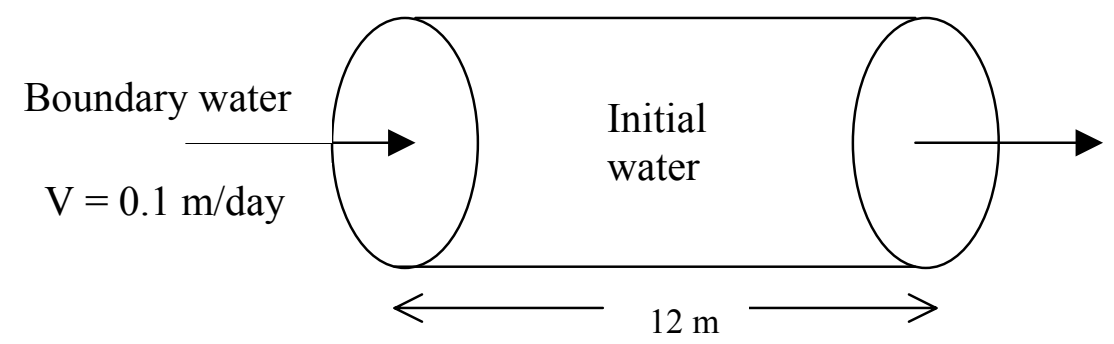

Figure 8.1.1. Simplified conceptual model for 1-D transport with linear Kd and decay.

The EOS9 flow module is used. Part of the concentration output file is given in Figure 8.1.5. The complete input and output files are given in the distribution CD (subdirectory: 〜sample-problems/P1_EOS9_kd-decay).

A total of four species are simulated in a single run. Species 1 is not subject to adsorption $(\mathrm{R}=1)$ and decay $\left(\mathrm{t}_{1 / 2}=\right.$ infinite $)$, and is denoted by ' $\mathrm{a}^{+}$' in chemical input file 'chemical.inp'. Species 2 has $\mathrm{R}=2$ and $\mathrm{t}_{1 / 2}=$ infinite, and is denoted by 'skdd1' in the chemical input file 'chemical.inp'. Species 3 has a $\mathrm{R}=1$ and a $\mathrm{t}_{1 / 2}=20$ days, and is denoted by 'skdd2' in the input file. Species 4 has $R=2$ and $t_{1 / 2}=20$ days, and is denoted by 'skdd3' in the input file. Species skdd1, skdd2, and skdd3 are artificial tracer species. The species names must appear in the primary species block of the thermodynamic database. Initial concentrations for all four species are set equal to a very small value of $10^{-10} \mathrm{~mol} / 1$ (practically zero, because TOUGHREACT uses $\log 10$ calculations for concentrations in order to avoid convergence problems). The inlet concentrations are set equal to $10^{-4} \mathrm{~mol} / 1$ for all four species. An analytical solution for this problem is given in Javandel et al. (1984). In the numerical simulation, we give a diffusion coefficient of zero. Dispersion is not considered in this code. However, the upstream weighting scheme used in the code results in a numerical dispersivity $\alpha_{\mathrm{n}}=\Delta \mathrm{x} / 2=0.1 \mathrm{~m}$ (where $\Delta \mathrm{x}$ is the grid size, $0.2 \mathrm{~m}$ is used in the simulation). In the analytical calculations, we use a dispersion coefficient $\mathrm{D}=\alpha_{\mathrm{n}} \mathrm{V}=0.01 \mathrm{~m}^{2} /$ day to account for the numerical dispersion in the simulation. The numerical results together with analytical solution are presented in Figure 8.1.6. 
Figure 8.12. Flow input file (flow.inp) for the problem with $\mathrm{Kd}$ and decay

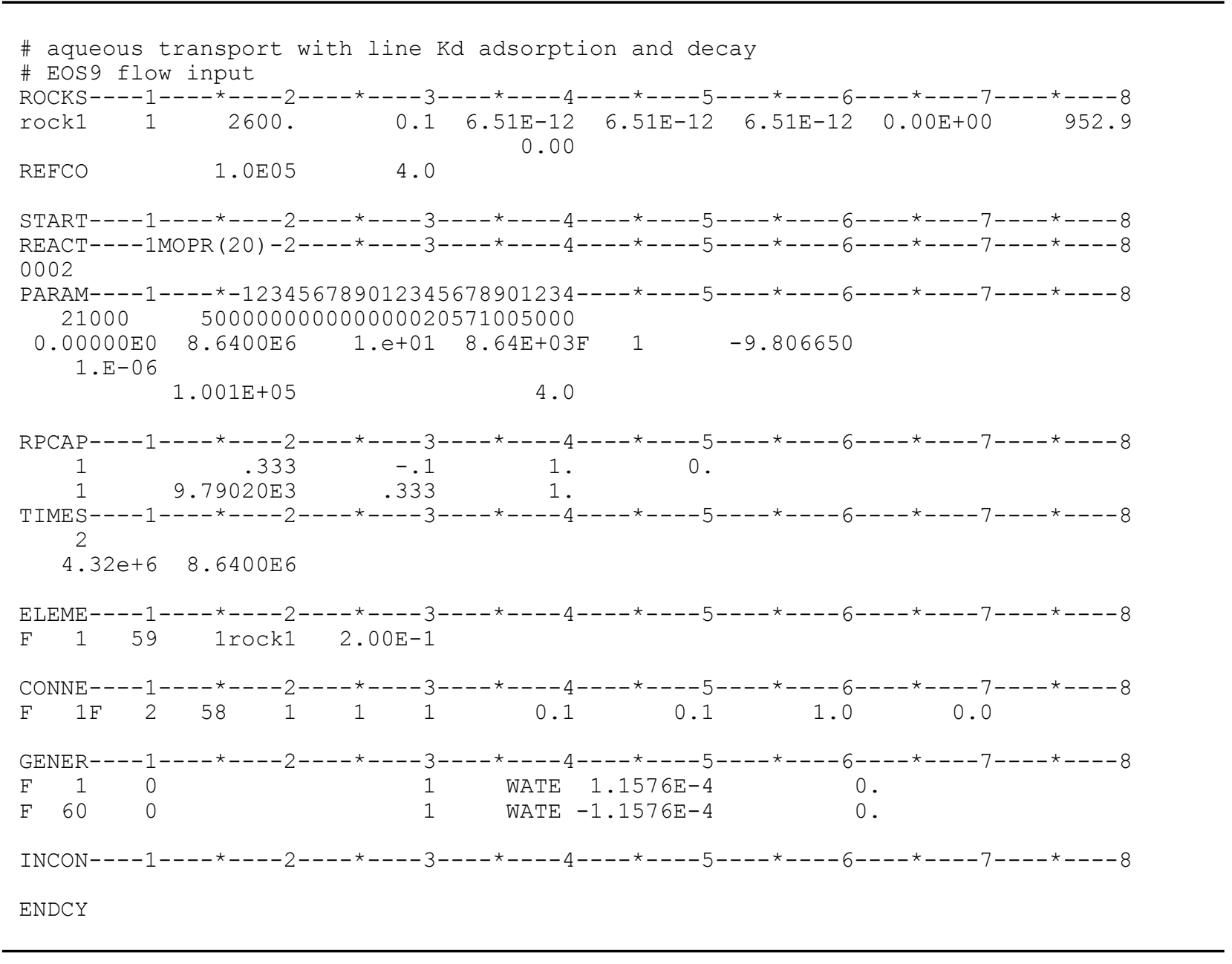


Figure 8.1.3. Solute transport input file (solute.inp) for problem of aqueous transport with $\mathrm{Kd}$ adsorption and decay.

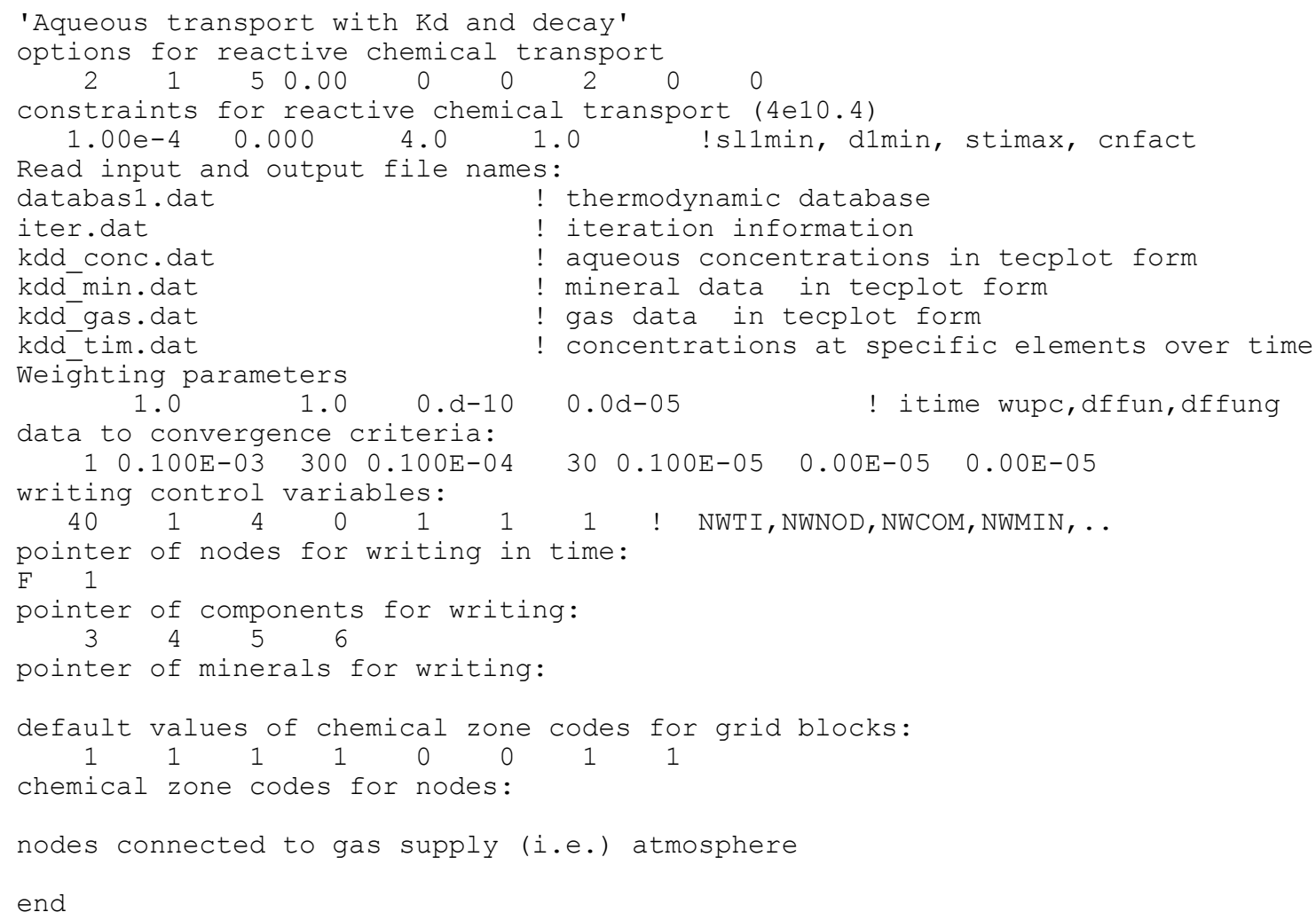

Figure 8.1.4. Chemical input file (chemical.inp) for problem of aqueous transport with $\mathrm{Kd}$ adsorption and decay.

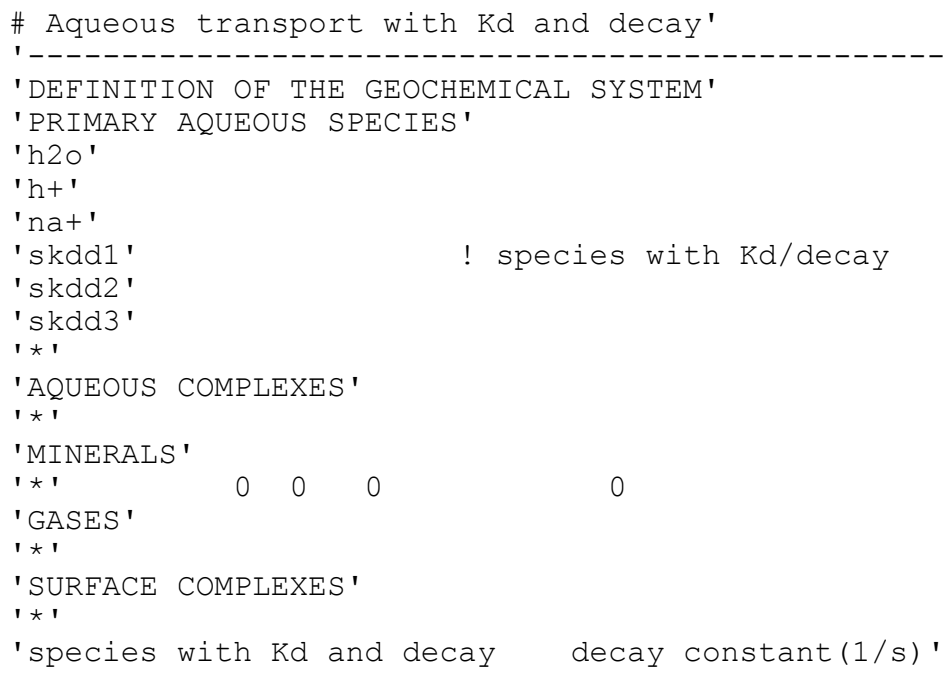




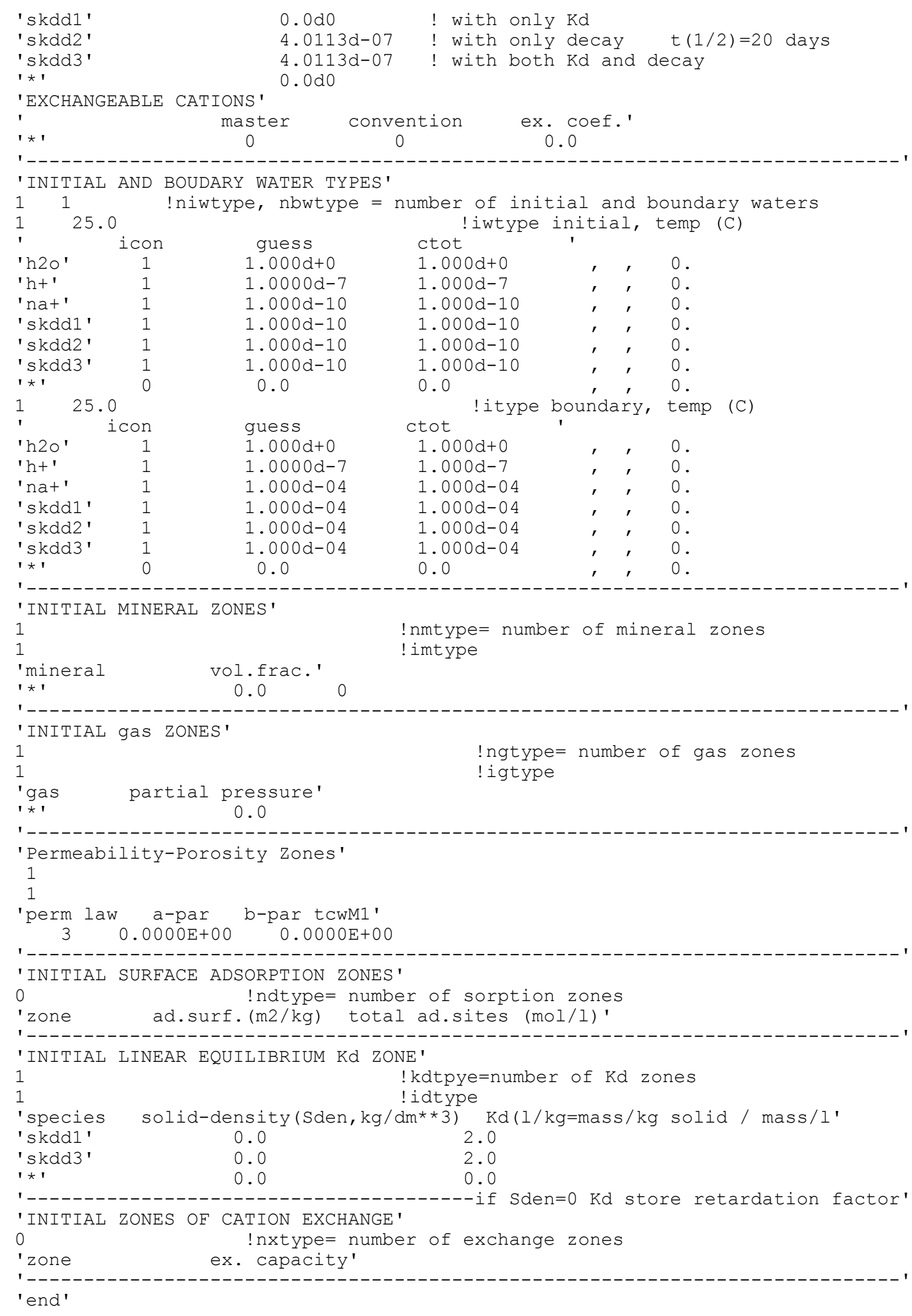


Figure 8.1.5. Part of aqueous concentrations output file (kdd_conc.dat) for problem of aqueous transport with $\mathrm{Kd}$ adsorption and decay after 50 days $(0.136893 \mathrm{yr})$.

\begin{tabular}{cccccccc}
\hline $\mathrm{X}$ & $\mathrm{SL}$ & $\mathrm{T}$ & $\mathrm{pH}$ & $\mathrm{na}+$ & $\mathrm{skdd}$ & $\mathrm{skdd2}$ & skdd3 \\
0.000 & 1.0000 & 4.000 & 7.0035 & $0.1000 \mathrm{E}-03$ & $0.1000 \mathrm{E}-03$ & $0.9352 \mathrm{E}-04$ & $0.8783 \mathrm{E}-04$ \\
0.000 & 1.0000 & 4.000 & 7.0035 & $0.1000 \mathrm{E}-03$ & $0.1000 \mathrm{E}-03$ & $0.8746 \mathrm{E}-04$ & $0.7714 \mathrm{E}-04$ \\
0.000 & 1.0000 & 4.000 & 7.0035 & $0.1000 \mathrm{E}-03$ & $0.9996 \mathrm{E}-04$ & $0.8180 \mathrm{E}-04$ & $0.6775 \mathrm{E}-04$ \\
0.000 & 1.0000 & 4.000 & 7.0035 & $0.1000 \mathrm{E}-03$ & $0.9983 \mathrm{E}-04$ & $0.7650 \mathrm{E}-04$ & $0.5948 \mathrm{E}-04$ \\
0.000 & 1.0000 & 4.000 & 7.0035 & $0.1000 \mathrm{E}-03$ & $0.9943 \mathrm{E}-04$ & $0.7154 \mathrm{E}-04$ & $0.5218 \mathrm{E}-04$ \\
0.000 & 1.0000 & 4.000 & 7.0035 & $0.1000 \mathrm{E}-03$ & $0.9844 \mathrm{E}-04$ & $0.6690 \mathrm{E}-04$ & $0.4567 \mathrm{E}-04$ \\
0.000 & 1.0000 & 4.000 & 7.0035 & $0.1000 \mathrm{E}-03$ & $0.9640 \mathrm{E}-04$ & $0.6257 \mathrm{E}-04$ & $0.3979 \mathrm{E}-04$ \\
0.000 & 1.0000 & 4.000 & 7.0035 & $0.1000 \mathrm{E}-03$ & $0.9280 \mathrm{E}-04$ & $0.5852 \mathrm{E}-04$ & $0.3437 \mathrm{E}-04$ \\
0.000 & 1.0000 & 4.000 & 7.0035 & $0.9999 \mathrm{E}-04$ & $0.8724 \mathrm{E}-04$ & $0.5472 \mathrm{E}-04$ & $0.2931 \mathrm{E}-04$ \\
0.000 & 1.0000 & 4.000 & 7.0035 & $0.9997 \mathrm{E}-04$ & $0.7957 \mathrm{E}-04$ & $0.5117 \mathrm{E}-04$ & $0.2454 \mathrm{E}-04$ \\
0.000 & 1.0000 & 4.000 & 7.0035 & $0.9993 \mathrm{E}-04$ & $0.7006 \mathrm{E}-04$ & $0.4785 \mathrm{E}-04$ & $0.2006 \mathrm{E}-04$ \\
0.000 & 1.0000 & 4.000 & 7.0035 & $0.9983 \mathrm{E}-04$ & $0.5929 \mathrm{E}-04$ & $0.4473 \mathrm{E}-04$ & $0.1593 \mathrm{E}-04$ \\
0.000 & 1.0000 & 4.000 & 7.0035 & $0.9963 \mathrm{E}-04$ & $0.4810 \mathrm{E}-04$ & $0.4180 \mathrm{E}-04$ & $0.1225 \mathrm{E}-04$ \\
0.000 & 1.0000 & 4.000 & 7.0034 & $0.9926 \mathrm{E}-04$ & $0.3735 \mathrm{E}-04$ & $0.3903 \mathrm{E}-04$ & $0.9085 \mathrm{E}-05$ \\
0.000 & 1.0000 & 4.000 & 7.0034 & $0.9860 \mathrm{E}-04$ & $0.2774 \mathrm{E}-04$ & $0.3639 \mathrm{E}-04$ & $0.6490 \mathrm{E}-05$ \\
0.000 & 1.0000 & 4.000 & 7.0034 & $0.9753 \mathrm{E}-04$ & $0.1970 \mathrm{E}-04$ & $0.3385 \mathrm{E}-04$ & $0.4458 \mathrm{E}-05$ \\
0.000 & 1.0000 & 4.000 & 7.0034 & $0.9590 \mathrm{E}-04$ & $0.1338 \mathrm{E}-04$ & $0.3137 \mathrm{E}-04$ & $0.2944 \mathrm{E}-05$ \\
& & & & & & & \\
\hline
\end{tabular}

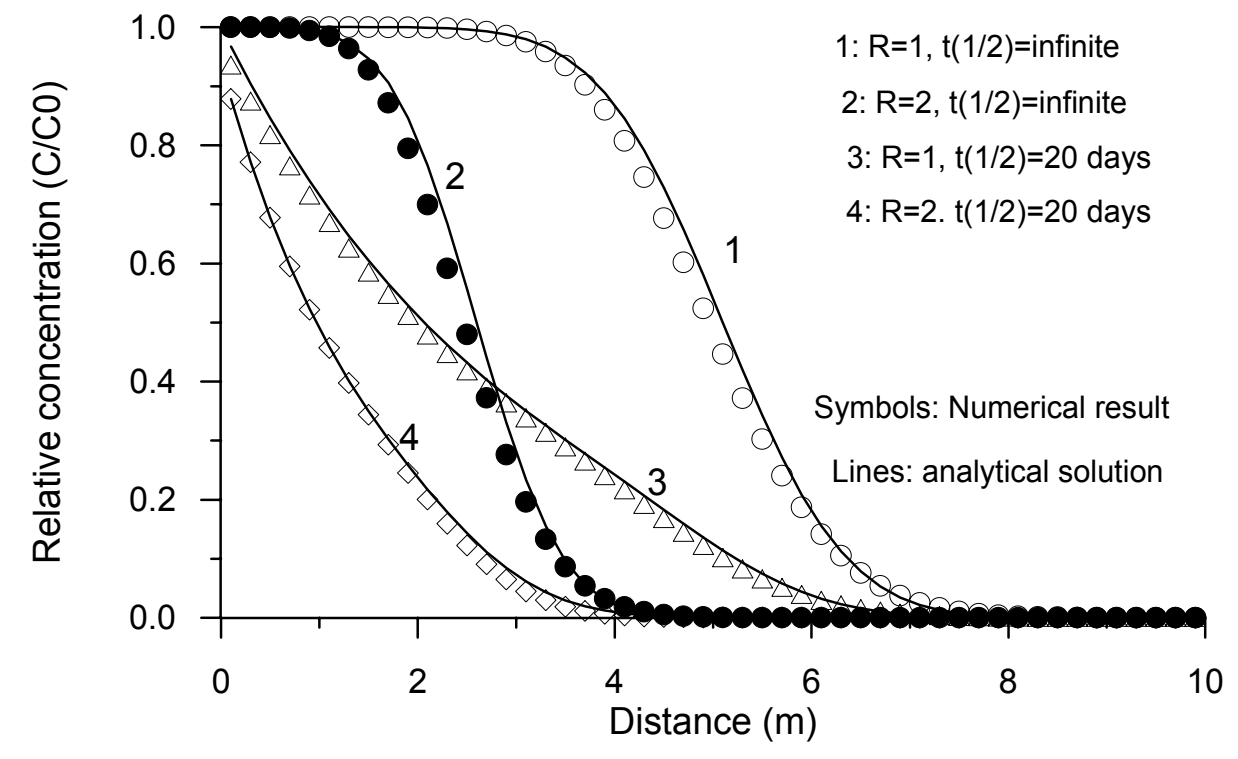

Figure 8.1.6. Relative concentrations at 50 days for 1-D aqueous solute transport with adsorption (linear $\mathrm{Kd}$ ) and decay (concentrations are normalized to the inlet concentration of $10^{-4} \mathrm{~mol} / \mathrm{l}$ ). 


\subsection{Water Quality in the Aquia Aquifer, Maryland (EOS9)}

$\mathrm{NaHCO}_{3}$ type waters in coastal plain aquifers of the eastern United States have been related to freshening of the aquifer (Chapelle and Knobel, 1983). These investigators depict major cation concentration patterns as a function of flow length in the Aquia aquifer (Maryland). The water composition in this aquifer shows zonal bands with changes in concentrations of major cations that have been attributed to cation exchange and calcite dissolution/precipitation.

The observed water compositional pattern has been simulated previously using PHREEQM (Appelo, 1994). For the TOUGHREACT simulation, hydrological conditions and all input data are the same as those used in Appelo (1994). The aim is to validate our model applicability to field-scale ambient problems. Figure 8.2.1 shows a schematic cross section along a flow path. The aquifer is bounded to the east by a change in facies. The prepumping hydraulic head distribution suggests a confined aquifer in the upstream half and gradual loss of water in the downstream part of the aquifer (Chapelle and Drummond, 1983). Leakage probably occurs via Pleistocene channels that cut through the confining beds. The hydrological conditions have been modeled assuming a one-dimensional flow tube with recharge at $\mathrm{x}=0$, and with seepage into the confining layers evenly distributed over the second half of the flow tube.

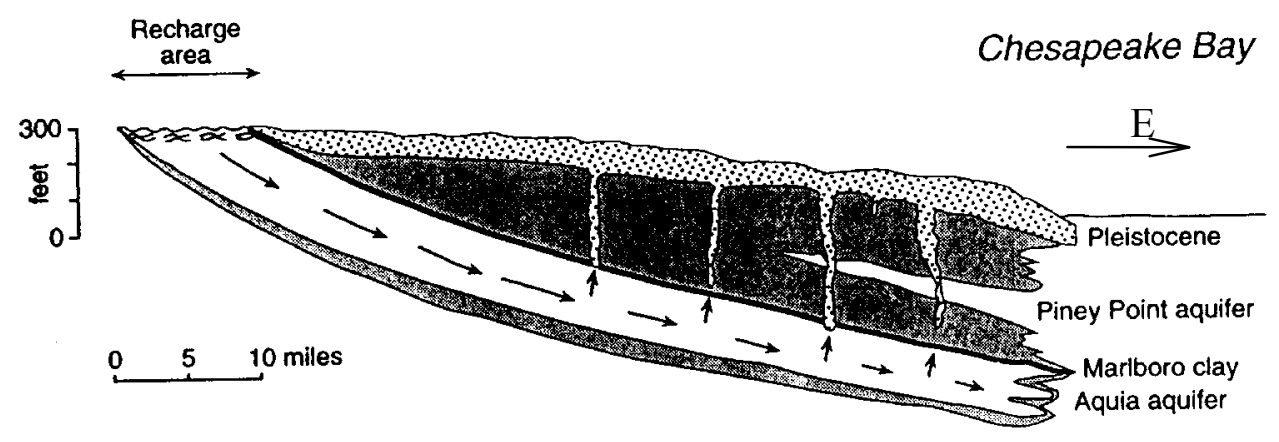

Figure 8.2.1. Schematic cross section of the Aquia aquifer (Maryland) adapted from Appelo (1994). Recharge occurs in the outcrop of the formation: discharge is assumed to take place evenly in the downstream half. ( 1 foot equals $0.3048 \mathrm{~m} ; 1$ mile equals $1.609 \mathrm{~km}$ )

It was assumed that the initial water composition was brackish as a result of mixing of seawater with fresh water during deposition of the overlying Marlboro clay, a brackish water 
clay. The recharge water composition is presumed to be unchanged from that analyzed in the upstream reaches of the aquifer. The initial and recharge water compositions are presented in Table 8.2.1. These data are inferred from observations and paleohydrochemical conditions. A detailed analysis of this problem is presented in Appelo (1994). To obtain the recharge water composition in the first 10 miles $(16 \mathrm{~km})$ of the flow path, the exchange capacity for the first 10 miles was set to zero.

Table 8.2.1. Initial and recharge water composition (concentrations are given in mmol/l) for modeling the water quality patterns in the Aquia aquifer. $\mathrm{X}^{-}$represents cation exchange sites. Data are from Appelo (1994).

\begin{tabular}{llllllllll}
\hline & $\mathrm{pH}$ & $\mathrm{Na}^{+}$ & $\mathrm{K}^{+}$ & $\mathrm{Mg}^{2+}$ & $\mathrm{Ca}^{2+}$ & $\mathrm{Cl}^{-}$ & $\mathrm{HCO}_{3}^{-}$ & $\mathrm{SO}_{4}{ }^{2-}$ & $\mathrm{X}^{-}$ \\
\hline Initial & 6.80 & 87.4 & 1.9 & 9.92 & 4.38 & 101.8 & 15.5 & 0.27 & 200 \\
Recharg & 7.57 & 0.1 & 0.05 & 0.0 & 1.40 & 0.1 & 2.8 & 0.0 & \\
$\mathrm{e}$ & & & & & & & & & \\
\hline
\end{tabular}

The EOS9 flow module is used. The flow and solute transport input files are similar to the previous example. Here we only present the chemical input file in Figure 8.2.2. The complete input and output files are given in the distribution CD (subdirectory: /sampleproblems/P2_EOS9_Aquia-aquifer). The thermodynamic data used for aqueous species and mineral (calcite) can be found in the database file databas 1.dat. Part of the output file for aqueous chemical concentrations is given in Figure 8.2.3. Parameters for water flow are specified in file flow.inp. A pore velocity of $2.42 \mathrm{mile} / \mathrm{ka}\left(1.2347 \times 10^{-10} \mathrm{~m} / \mathrm{s}\right)$ was used in the upper part of the aquifer. A porosity of 0.3 was used throughout. A dispersivity of 2.0 miles $(3.2 \mathrm{~km})$ was used by Appelo (1994). Dispersion is not treated in TOUGHREACT, and therefore it was approximated by setting the diffusion coefficient $\mathrm{D}=\alpha \mathrm{v}=3.951 \times 10^{-7} \mathrm{~m}^{2} / \mathrm{s}$ (entered in solute.inp) and setting the tortuosity to 1.0 in flow.inp.

Aqueous species chemical compositions are assigned in files solute.inp and chemical.inp. In chemical.inp, the record with "(1 1 )" following the record 'INITIAL AND BOUNDARY WATER TYPES' specifies that one initial water composition as well as one boundary water composition will be read. The data entered in solute.inp under "default values of chemical zone codes for nodes" assign the first (and only) initial water type to all grid blocks in the problem, as 
well as assigning the first (only) boundary (recharge) water composition to all injection grid blocks. Recharge takes place only in grid block " $\mathrm{F} 1$ " using the boundary water chemical composition. The cation exchange reactions and their selectivities are listed in Table 8.2.2 (from Appelo, 1993). The Gaines-Thomas convention (Appelo, 1993) was used for cation exchange. In this convention, selectivities are calculated by using the equivalent fraction of the exchanged cations for the activity of the exchanged cations. It should be pointed out that selectivity is a relative concept. $\mathrm{Na}^{+}$was chosen as the reference. Therefore, $\mathrm{Na}^{+}$selectivity is equal to one. According to this definition, a lower selectivity corresponds to a higher exchange capacity. A divalent cation, in general, is more strongly exchanged than a monovalent cation. Usually, $\mathrm{Ca}^{2+}$ has a higher affinity for the exchange complex, usually in the following exchange order: $\mathrm{Ca}^{2+}>$ $\mathrm{Mg}^{2+}>\mathrm{K}^{+}>\mathrm{Na}^{+}$(Appelo, 1993). Selectivity of $\mathrm{H}^{+}$is very sensitive in the simulation, because it affects $\mathrm{pH}$ and thus calcite dissolution and the availability of $\mathrm{Ca}^{2+}$. To obtain a better $\mathrm{pH}$ fit with the observations, the original $\mathrm{H}^{+}$selectivity $\left(1.3092 \times 10^{-6}\right.$ ) was adjusted to $3.1 \times 10^{-6}$ (Figure 8.2.4).

Table 8.2.2. List of cation exchange reactions considered for modeling the water quality patterns in the Aquia aquifer ( $\mathrm{X}$ represents cation exchange sites). The cation selectivity listed is based on Appelo (1994).

\begin{tabular}{|c|c|}
\hline Cation exchange: & Selectivity (in terms of $\mathrm{Na}^{+}$) \\
\hline $\mathrm{Na}^{+}+0.5 \mathrm{Ca}-\mathrm{X}_{2}=0.5 \mathrm{Ca}^{2+}+\mathrm{Na}-\mathrm{X}$ & 0.3981 \\
\hline $\mathrm{Na}^{+}+0.5 \mathrm{Mg}-\mathrm{X}_{2}=0.5 \mathrm{Mg}^{2+}+\mathrm{Na}-\mathrm{X}$ & 0.5012 \\
\hline $\mathrm{Na}^{+}+\mathrm{K}-\mathrm{X}=\mathrm{K}^{+}+\mathrm{Na}-\mathrm{X}$ & 0.1995 \\
\hline $\mathrm{Na}^{+}+\mathrm{H}-\mathrm{X}=\mathrm{H}^{+}+\mathrm{Na}-\mathrm{X}$ & $1.3092 \times 10^{-6}$ \\
\hline
\end{tabular}


Figure 8.2.2. Chemical input file (chemical.inp) for simulating water quality in the Aquia aquifer.

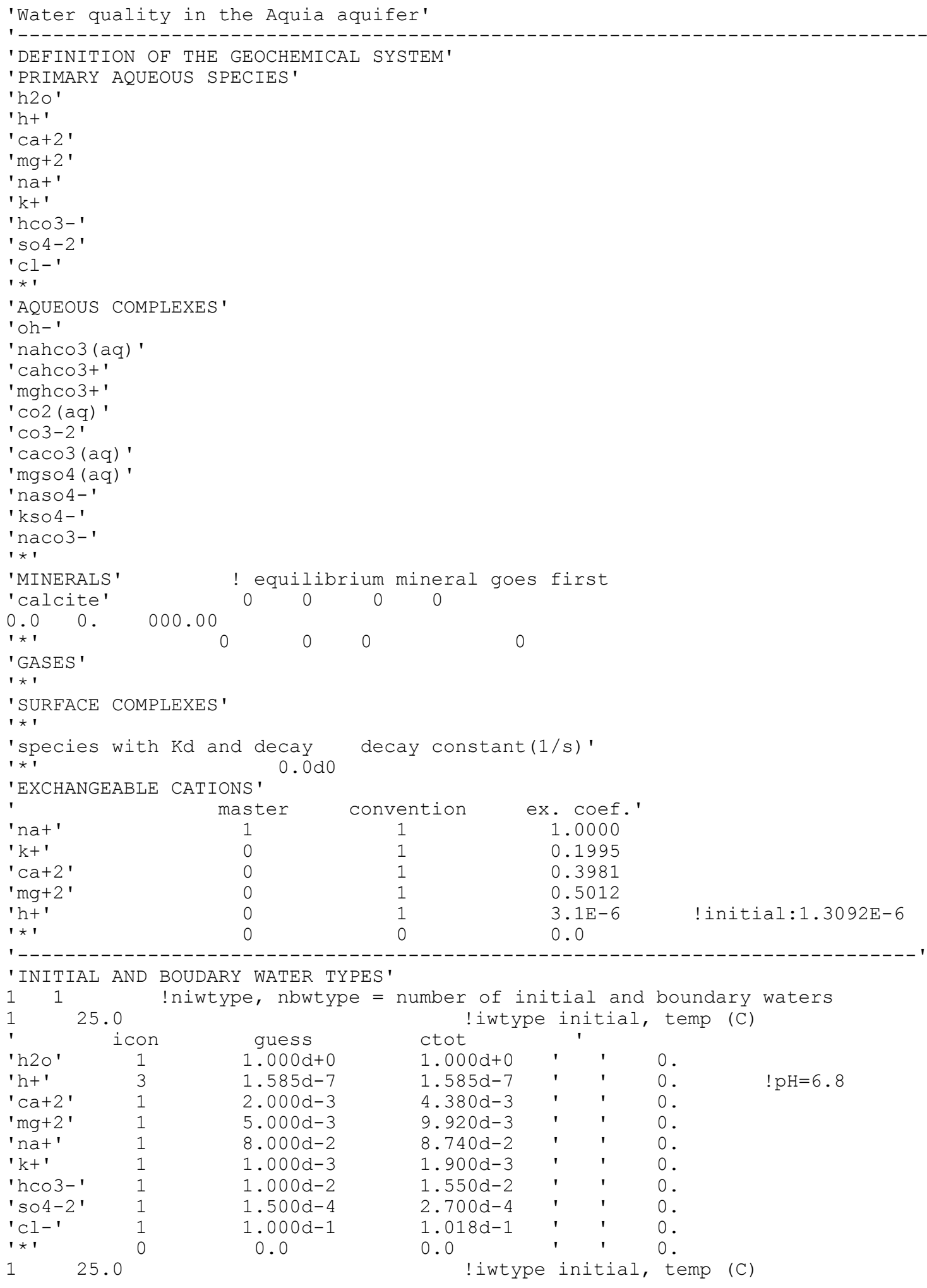




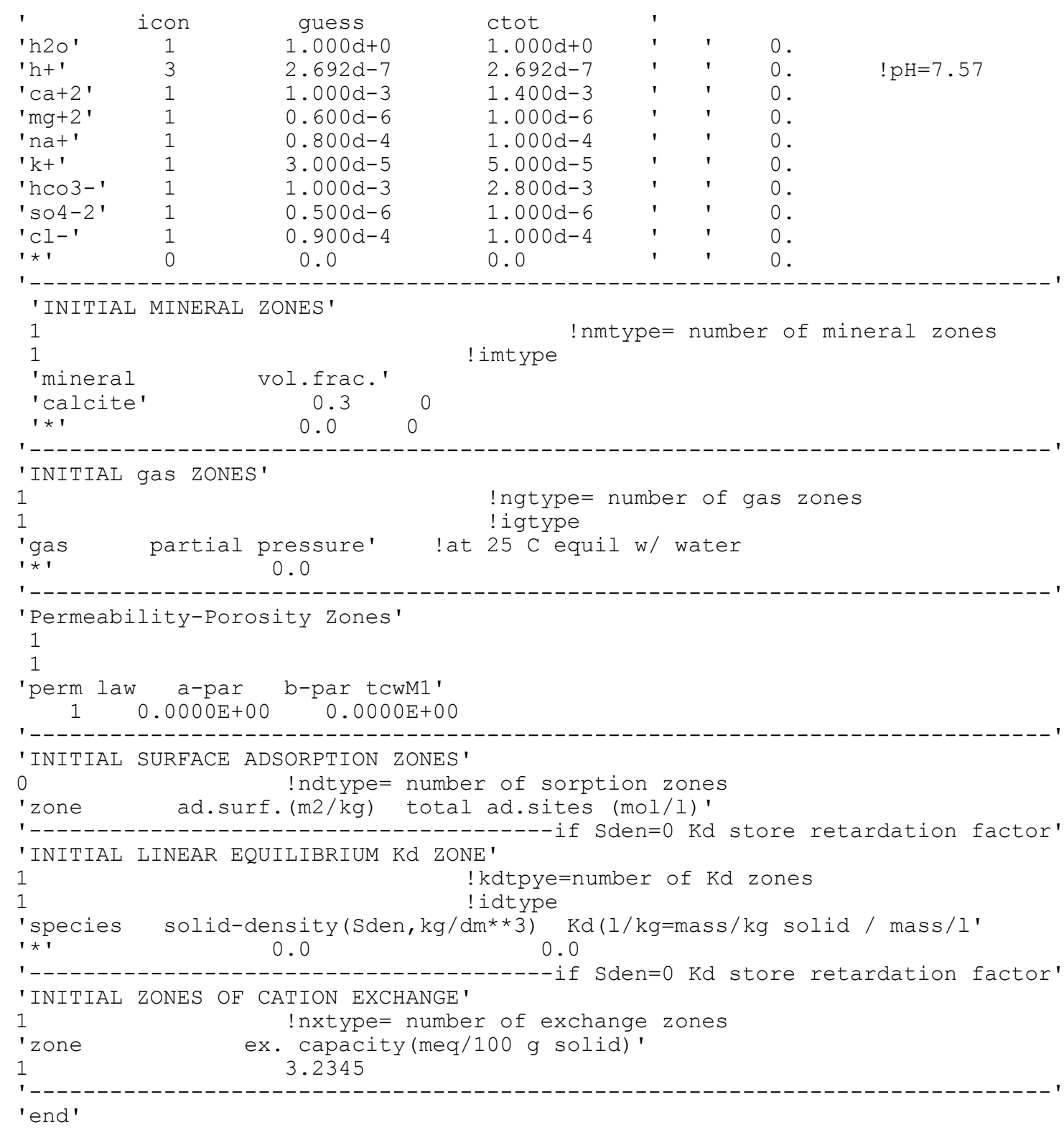


Figure 8.2.3. Part of aqueous concentrations output file (aqui_con.dat) for problem of water quality in Aquia aquifer after $144 \times 10^{6}$ years.

\begin{tabular}{rcccccc}
\hline \multicolumn{1}{c}{$\mathrm{X}$} & $\mathrm{pH}$ & $\mathrm{ca}+2$ & $\mathrm{mg}+2$ & $\mathrm{na}$ & $\mathrm{k}+$ & $\mathrm{hco3}-$ \\
& & & & & \\
6.000 & 7.5720 & $0.1901 \mathrm{E}-02$ & $0.2010 \mathrm{E}-03$ & $0.1022 \mathrm{E}-03$ & $0.6322 \mathrm{E}-04$ & $0.3483 \mathrm{E}-02$ \\
10.000 & 7.6229 & $0.1689 \mathrm{E}-02$ & $0.4059 \mathrm{E}-03$ & $0.1054 \mathrm{E}-03$ & $0.8020 \mathrm{E}-04$ & $0.3459 \mathrm{E}-02$ \\
14.000 & 7.6907 & $0.1444 \mathrm{E}-02$ & $0.6359 \mathrm{E}-03$ & $0.1122 \mathrm{E}-03$ & $0.1094 \mathrm{E}-03$ & $0.3430 \mathrm{E}-02$ \\
18.000 & 7.7605 & $0.1230 \mathrm{E}-02$ & $0.8199 \mathrm{E}-03$ & $0.1265 \mathrm{E}-03$ & $0.1547 \mathrm{E}-03$ & $0.3399 \mathrm{E}-02$ \\
22.000 & 7.8194 & $0.1077 \mathrm{E}-02$ & $0.9190 \mathrm{E}-03$ & $0.1557 \mathrm{E}-03$ & $0.2190 \mathrm{E}-03$ & $0.3362 \mathrm{E}-02$ \\
26.000 & 7.8669 & $0.9721 \mathrm{E}-03$ & $0.9364 \mathrm{E}-03$ & $0.2151 \mathrm{E}-03$ & $0.3021 \mathrm{E}-03$ & $0.3312 \mathrm{E}-02$ \\
30.000 & 7.9134 & $0.8838 \mathrm{E}-03$ & $0.8886 \mathrm{E}-03$ & $0.3346 \mathrm{E}-03$ & $0.3992 \mathrm{E}-03$ & $0.3240 \mathrm{E}-02$ \\
34.000 & 7.9755 & $0.7799 \mathrm{E}-03$ & $0.7839 \mathrm{E}-03$ & $0.5725 \mathrm{E}-03$ & $0.4954 \mathrm{E}-03$ & $0.3139 \mathrm{E}-02$ \\
38.000 & 8.0787 & $0.6296 \mathrm{E}-03$ & $0.6169 \mathrm{E}-03$ & $0.1038 \mathrm{E}-02$ & $0.5577 \mathrm{E}-03$ & $0.3006 \mathrm{E}-02$ \\
42.000 & 8.2838 & $0.4020 \mathrm{E}-03$ & $0.3745 \mathrm{E}-03$ & $0.1910 \mathrm{E}-02$ & $0.5226 \mathrm{E}-03$ & $0.2866 \mathrm{E}-02$ \\
46.000 & 8.6455 & $0.1757 \mathrm{E}-03$ & $0.1511 \mathrm{E}-03$ & $0.3041 \mathrm{E}-02$ & $0.3328 \mathrm{E}-03$ & $0.2859 \mathrm{E}-02$ \\
50.000 & 8.8680 & $0.1026 \mathrm{E}-03$ & $0.8378 \mathrm{E}-04$ & $0.3680 \mathrm{E}-02$ & $0.2006 \mathrm{E}-03$ & $0.3043 \mathrm{E}-02$ \\
54.000 & 8.8666 & $0.9478 \mathrm{E}-04$ & $0.7723 \mathrm{E}-04$ & $0.4078 \mathrm{E}-02$ & $0.1660 \mathrm{E}-03$ & $0.3369 \mathrm{E}-02$ \\
58.000 & 8.7777 & $0.1032 \mathrm{E}-03$ & $0.8510 \mathrm{E}-04$ & $0.4514 \mathrm{E}-02$ & $0.1670 \mathrm{E}-03$ & $0.3845 \mathrm{E}-02$ \\
62.000 & 8.6786 & $0.1151 \mathrm{E}-03$ & $0.9624 \mathrm{E}-04$ & $0.4995 \mathrm{E}-02$ & $0.1784 \mathrm{E}-03$ & $0.4393 \mathrm{E}-02$ \\
66.000 & 8.6146 & $0.1235 \mathrm{E}-03$ & $0.1043 \mathrm{E}-03$ & $0.5353 \mathrm{E}-02$ & $0.1881 \mathrm{E}-03$ & $0.4801 \mathrm{E}-02$
\end{tabular}

The results after a simulation time of $144 \mathrm{ka}$ are compared to observations of major cations and alkalinity (Figure 8.2.4). The agreement between numerical results and observations is reasonably satisfactory. The fit for $\mathrm{Mg}^{2+}$ can be further improved by adjusting $\mathrm{Mg}^{2+}$ selectivity. The sequential appearance of $\mathrm{Mg}^{2+}$ and $\mathrm{K}^{+}$is attributed to chromatographic separation and can be varied in the model only by varying the $\mathrm{Mg}^{2+} / \mathrm{K}^{+}$selectivity. An apparent dip in alkalinity is observed just before $\mathrm{Na}^{+}$concentrations increase, which is matched by the simulation. The upstream increase of $\mathrm{Ca}^{2+}$ concentrations in the region where $\mathrm{K}^{+}$and $\mathrm{Mg}^{2+}$ are at a peak indicates an increased concentration of $\mathrm{Ca}-\mathrm{X}_{2}$ (X represents cation exchange sites). The increase occurred during flushing of $\mathrm{Na}^{+}$and is due to dissolution of calcite. The increase of $\mathrm{Na}^{+}$and alkalinity at the downstream end agrees with earlier conclusions about the development of $\mathrm{NaHCO}_{3}$ water quality in a freshening aquifer (Chapelle and Knobel, 1983). 

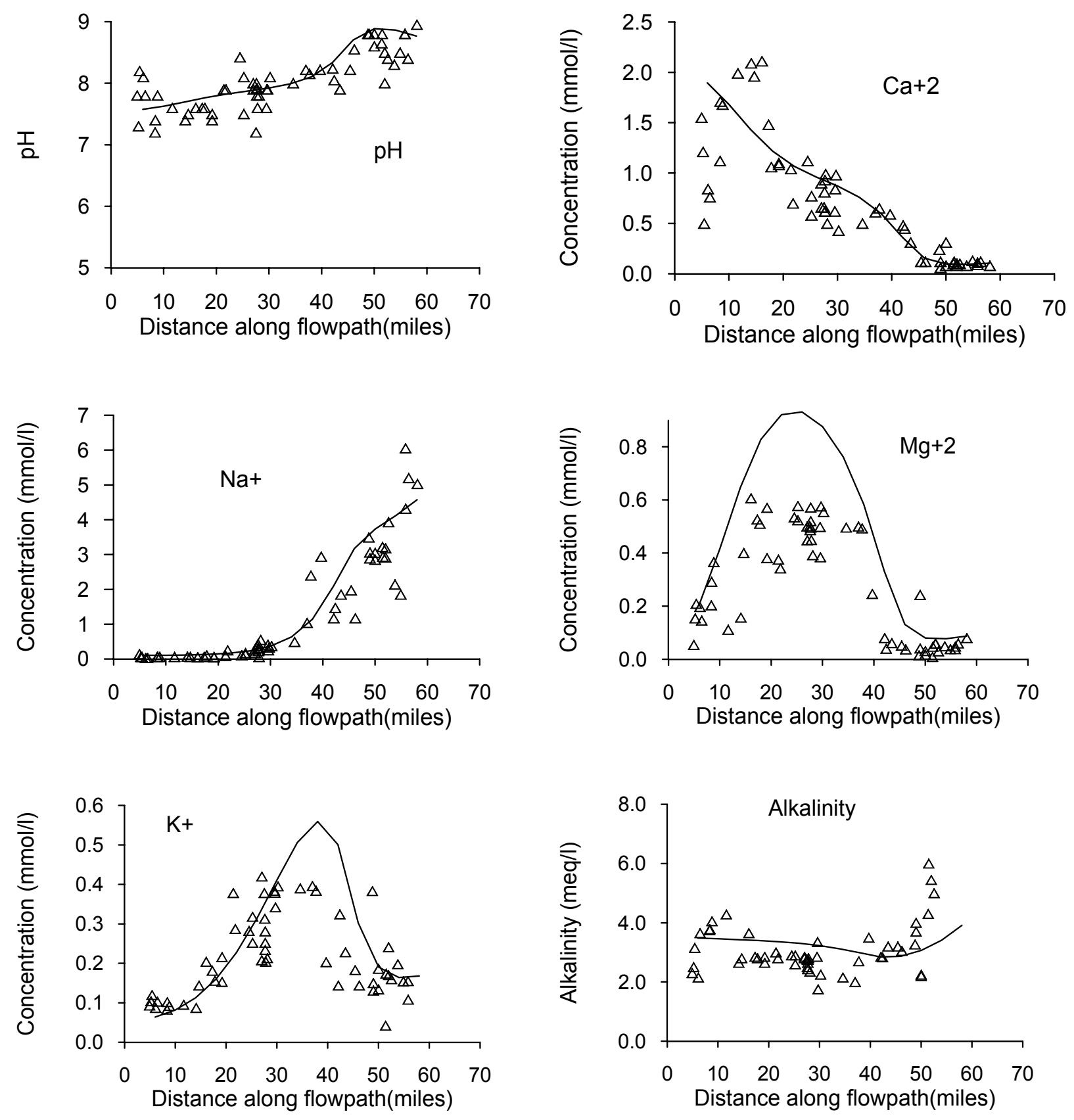

Figure 8.2.4. Concentrations of $\mathrm{Na}^{+}, \mathrm{K}^{+}, \mathrm{Mg}^{2+}, \mathrm{Ca}^{2+}$, alkalinity, and $\mathrm{pH}$ along a flow path in the Aquia aquifer (Maryland). Symbols indicate observations provided by Appelo (1994) and originally from Chapelle and Knobel (1983); solid lines represent simulated concentrations using TOUGHREACT. 


\subsection{Infiltration and Calcite Deposition at Yucca Mountain, Nevada (EOS3)}

\subsubsection{Problem statement}

Yucca Mountain in southern Nevada (USA) is being investigated as a possible site for an underground nuclear waste repository. The semiarid environment and a thick (500 to $700 \mathrm{~m}$ ) unsaturated zone (UZ) are considered to be favorable for long-term isolation of radioactive waste (Montazer and Wilson, 1984). The percolation flux in the UZ is an important parameter addressed in site characterization and hydrological modeling of Yucca Mountain, because it controls seepage into drifts that may contact waste packages. Hydrogenic calcite deposits in fractures and lithophysal cavities at Yucca Mountain were studied to estimate past percolation fluxes (Carlos, 1995; Vaniman and Chipera, 1996; Paces et al., 1998; Marshall et al., 1998; Marshall, 1999; Paces et al., 2001). These deposits provide evidence of water flow in the past and may improve an understanding of current and future UZ percolation rates, because direct measurements of infiltration fluxes over thousands of years are not possible.

An objective of these prior studies was to investigate the relationship between percolation flux and measured calcite abundances. The U.S. Geological Survey determined calcite abundances from a deep surface-based borehole (WT-24) (Paces et al., 2001) by measuring the $\mathrm{CO}_{2}$ given off by heating of the rock. Geochronology work performed by the Geological Survey (Paces et al., 1998; Neymark et al., 2001) indicates that calcite formed over approximately 10 million years. Hydrogenic mineral coatings in the UZ are non-uniformly distributed and located almost entirely on fracture footwalls and cavity floors, in contrast to saturated environments, in which vein and cavity deposits usually coat all surfaces (Paces et al., 1998).

Here, we present some results of a reaction-transport numerical model for calcite deposition under different infiltration conditions using TOUGHREACT. The model considers a complete set of hydrological and geochemical processes, including the following essential factors affecting calcite precipitation: (1) infiltration, (2) the ambient geothermal gradient, (3) gaseous $\mathrm{CO}_{2}$ diffusive transport and partitioning in liquid and gas phases, (4) fracture-matrix interaction for water flow and chemical constituents (dual permeability), and (5) water-rock interaction. In addition, any effects of water-rock interaction (e.g., pH modification) also affects the calcite solubility and hence its abundance in each rock unit. The dual permeability model allows us to 
address not only the abundances of calcite with depth, but also their relative abundances in fractures and in the rock matrix as a function of the hydrological/geochemical processes. More details on problem setup and results are given in Xu et al. (2003a).

\subsubsection{Calcite precipitation mechanisms}

Rainfall, along with wind-blown dust, carries much of the calcium to the surface (Vaniman et al., 2001). In the soil zone, strong evapotranspiration along with some water-rock interaction and root-zone biological processes leads to saturation with respect to calcite. The depth to reach calcite equilibrium depends on climate and infiltration variations over time and episodic water flow, as well as on near-surface biogeochemical conditions. During more typical smaller infiltration events, calcite may reach equilibrium close to the surface. However, large infiltration pulses of calcite-undersaturated water can dissolve near-surface calcite and reach equilibrium at a greater depth. Because we are primarily interested in calcite deposition in a deep geological unit, the Topopah Spring welded tuff (TSw), where the potential repository may be located, uncertainties in the infiltrating water composition near the surface are not significant because calcite reaches saturation well above this unit. In addition, the constant infiltration rate and steady-state water flow conditions over geological time used in our simulations are also justified by evidence that calcite growth in the UZ has remained approximately constant over at least the past 8 million years, as indicated by radiocarbon, ${ }^{230} \mathrm{Th} / \mathrm{U}$, and $\mathrm{U}-\mathrm{Pb}$ ages (Paces et al., 1998).

The primary driving force for calcite precipitation from percolating waters in the UZ is its decreasing solubility with increasing temperature. Therefore, consideration of the ambient geothermal gradient is very important for calcite precipitation. The temperature distribution is a function of the crustal heat flow and the effect of infiltration, which has been evaluated in Sonnenthal and Bodvarsson (1998). The modeled temperature distributions in borehole WT-24 are discussed later. Pore waters extracted from deep locations of the Yucca Mountain rock matrix are close to equilibrium with respect to calcite (Paces et al., 2001), and no measurements of aqueous concentrations are available from fractures because they generally have low liquid saturations. Previous models for calcite precipitation, under conditions of local equilibrium (Marshall et al., 1999), have indicated that increased infiltration-percolation fluxes result in greater abundances of calcite precipitated over time. These models have not considered, 
however, effects such as water-rock interaction, changes to the geothermal gradient, and fracturematrix interaction. They have also assumed a fixed partial pressure of $\mathrm{CO}_{2}$.

The $\mathrm{Ca}$ concentration and $\mathrm{CO}_{2}$ partial pressure in percolating water are major controlling factors for the abundance of calcite and its stability. This is a result of the decreasing solubility of $\mathrm{CO}_{2}$ gas in water with increasing temperature, which in turn causes the following degassing process: $\mathrm{HCO}_{3}{ }^{-}+\mathrm{H}^{+} \rightarrow \mathrm{CO}_{2}(\mathrm{~g})+\mathrm{H}_{2} \mathrm{O}$. Gaseous $\mathrm{CO}_{2}$ is also redistributed by gas phase diffusive transport. Degassing increases the $\mathrm{pH}$, and then contributes to calcite precipitation: $\mathrm{Ca}^{2+}+\mathrm{HCO}_{3}^{-}$ $\rightarrow \mathrm{CaCO}_{3}$ (calcite) $+\mathrm{H}^{+}$. Water and gas flow between fractures and the adjacent matrix governs the resulting calcite distribution within each medium. Calcite precipitation is also affected by other factors such as the dissolution and precipitation of aluminosilicate minerals (mainly through modifying the $\mathrm{pH}$ and the $\mathrm{CO}_{2}$ partial pressure).

\subsubsection{Hydrogeological and geochemical conditions}

\section{Hydrogeological Conditions}

The Yucca Mountain UZ consists of layers of welded and non-welded volcanic tuffs. The welded and non-welded tuffs have vastly different hydrologic properties. The welded units are characterized by relatively low porosity, low matrix permeability, and high fracture density, whereas the nonwelded tuffs have higher matrix porosity and permeability, and lower fracture density (Liu et al., 1998; Sonnenthal and Bodvarsson, 1999). Montazer and Wilson (1984) developed a conceptual model for the UZ at Yucca Mountain that identified five main hydrogeological units based on the degree of welding and on the associated relationship to fracture intensity. This conceptual model has formed the basis for modeling flow in the UZ at Yucca Mountain. A schematic East-West cross-section through Yucca Mountain illustrating the major hydrogeological units in the UZ at Yucca Mountain is shown in Figure 8.3.1. Table 8.3.1 provides a description of the units, each of which is further divided into a number of model layers with different hydrogeological and geochemical properties (Ahlers and Liu, 2000; Sonnenthal and Spycher, 2001; Spycher et al., 2003a). The Calico Hills nonwelded (CHn) unit is comprised of zeolitic and vitric nonwelded tuffs underlying the basal vitrophyre of the Topopah Spring Tuff. Below the $\mathrm{CHn}$ are the Crater Flat undifferentiated ( $\mathrm{CFu}$ ) units, consisting of the lower Bullfrog and Tram Tuffs of the Crater Flat Group. The hydrogeological units below the TSw were not considered in the geochemical transport simulations, so details regarding these units are not given 
in Table 8.3.1. This is based on: (1) the lateral flow that may occur in these units, (2) they have a more complex mineral assemblage (zeolites, glass, and clays) which has a less well-constrained effect on calcite reactions, and (3) we are primarily interested in calcite deposition within the TSw unit, where the potential repository is located (TSw4 and TSw5 model layers in Table 8.3.1). The exclusion of the underlying hydrogeological units does not affect the results in the TSw unit because flow is predominantly gravity driven, and upward chemical diffusion is subordinate to downward advective transport.

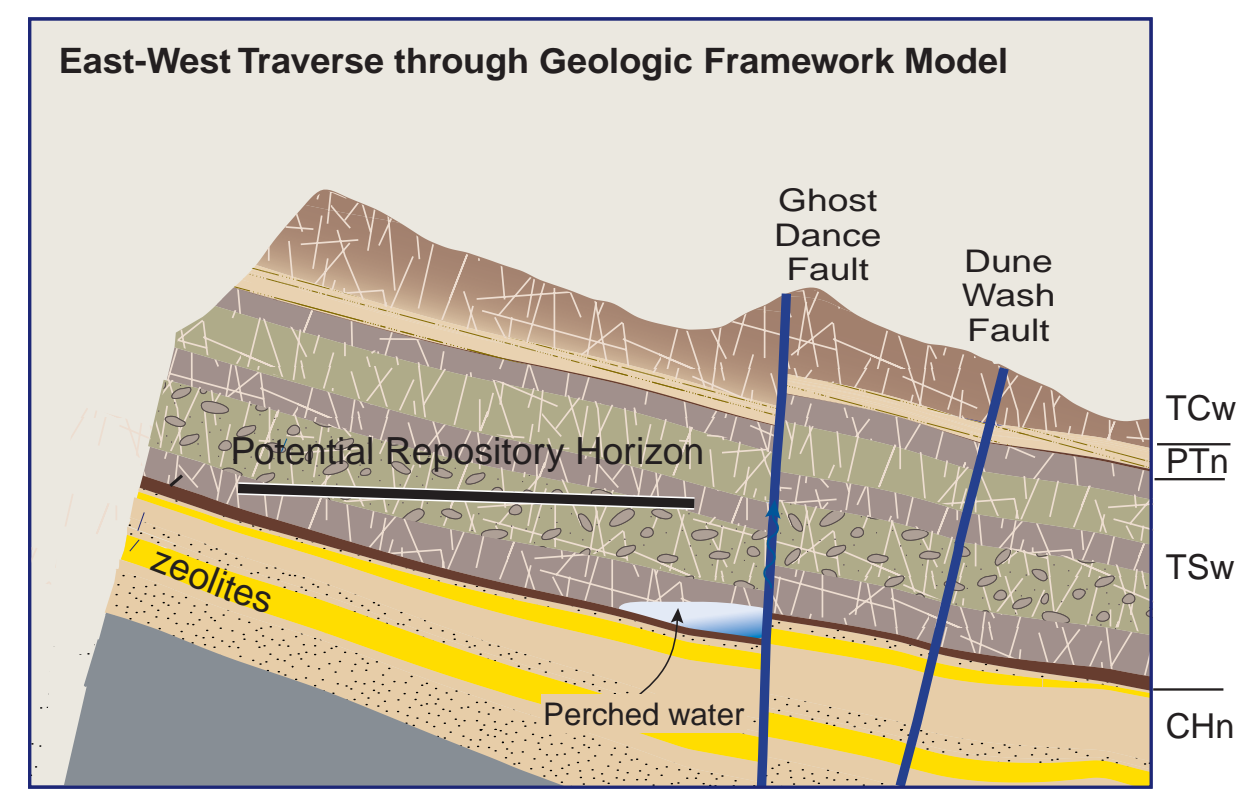

Figure 8.3.1. Schematic East-West cross-section through Yucca Mountain depicting the major hydrogeological units in the unsaturated zone and the approximate location of the potential repository horizon (Xu et al., 2003; Sonnenthal and Bodvarsson, 1999). 
Table 8.3.1. Hydrogeologic units, model layers, and hydrogeological properties for the Yucca Mountain Unsaturated Zone Flow and Transport Model as given by the property calibration model (Ahlers and Liu, 2000).

\begin{tabular}{|c|c|c|c|c|c|c|}
\hline \multirow{2}{*}{$\begin{array}{l}\text { Hydrogeologic } \\
\text { unit }\end{array}$} & \multirow[t]{2}{*}{ Description } & \multirow{2}{*}{$\begin{array}{l}\text { Model } \\
\text { layer }\end{array}$} & \multicolumn{2}{|l|}{ Fracture } & \multicolumn{2}{|l|}{ Matrix } \\
\hline & & & $\begin{array}{l}\text { Permeability } \\
\left(\mathrm{m}^{2}\right)\end{array}$ & Porosity & $\begin{array}{l}\text { Permeability } \\
\left(\mathrm{m}^{2}\right)\end{array}$ & Porosity \\
\hline \multirow{3}{*}{$\begin{array}{l}\text { TCw: Tiva } \\
\text { Canyon } \\
\text { Welded unit }\end{array}$} & \multirow{3}{*}{$\begin{array}{l}\text { Moderately to } \\
\text { densely welded } \\
\text { portions of the Tiva } \\
\text { Canyon Tuff of the } \\
\text { Paintbrush Group }\end{array}$} & TCw1 & $2.41 \times 10^{-12}$ & $3.7 \times 10^{-2}$ & $3.86 \times 10^{-15}$ & 0.253 \\
\hline & & TCw2 & $1.00 \times 10^{-10}$ & $2.6 \times 10^{-2}$ & $2.74 \times 10^{-19}$ & 0.082 \\
\hline & & TCw3 & $5.42 \times 10^{-12}$ & $1.9 \times 10^{-2}$ & $9.23 \times 10^{-17}$ & 0.203 \\
\hline \multirow{6}{*}{$\begin{array}{l}\text { PTn: } \\
\text { Paintbrush } \\
\text { Nonwelded } \\
\text { unit }\end{array}$} & \multirow{6}{*}{$\begin{array}{l}\text { Variably welded } \\
\text { Paintbrush Tuff and } \\
\text { its associated bedded } \\
\text { tuffs, including those } \\
\text { located at the bottom } \\
\text { of the Tiva Canyon } \\
\text { and top of the } \\
\text { Topopah Spring } \\
\text { Tuffs }\end{array}$} & PTn1 & $1.86 \times 10^{-12}$ & $1.4 \times 10^{-2}$ & $9.90 \times 10^{-13}$ & 0.387 \\
\hline & & PTn2 & $2.00 \times 10^{-11}$ & $1.5 \times 10^{-2}$ & $2.65 \times 10^{-12}$ & 0.439 \\
\hline & & PTn3 & $2.60 \times 10^{-13}$ & $3.2 \times 10^{-3}$ & $1.23 \times 10^{-13}$ & 0.254 \\
\hline & & PTn4 & $4.67 \times 10^{-13}$ & $1.5 \times 10^{-2}$ & $7.86 \times 10^{-14}$ & 0.411 \\
\hline & & PTn5 & $7.03 \times 10^{-13}$ & $7.9 \times 10^{-3}$ & $7.00 \times 10^{-14}$ & 0.499 \\
\hline & & PTn6 & $4.44 \times 10^{-13}$ & $4.6 \times 10^{-3}$ & $2.21 \times 10^{-13}$ & 0.492 \\
\hline \multirow{9}{*}{$\begin{array}{l}\text { TSw: Topopah } \\
\text { Spring welded } \\
\text { unit }\end{array}$} & \multirow{9}{*}{$\begin{array}{l}\text { Moderately to } \\
\text { densely welded } \\
\text { portions of the } \\
\text { Topopah Spring Tuff } \\
\text { down to and } \\
\text { including the densely } \\
\text { welded basal } \\
\text { vitrophyre }\end{array}$} & TSw1 & $3.21 \times 10^{-11}$ & $7.1 \times 10^{-3}$ & $6.32 \times 10^{-17}$ & 0.053 \\
\hline & & TSw2 & $3.56 \times 10^{-11}$ & $1.2 \times 10^{-2}$ & $5.83 \times 10^{-16}$ & 0.157 \\
\hline & & TSw3 & $3.86 \times 10^{-11}$ & $8.4 \times 10^{-3}$ & $3.08 \times 10^{-17}$ & 0.154 \\
\hline & & TSw4 & $1.70 \times 10^{-11}$ & $1.0 \times 10^{-2}$ & $4.07 \times 10^{-18}$ & 0.110 \\
\hline & & TSw5 & $4.51 \times 10^{-11}$ & $1.5 \times 10^{-2}$ & $3.04 \times 10^{-17}$ & 0.131 \\
\hline & & TSw6 & $7.01 \times 10^{-11}$ & $2.0 \times 10^{-2}$ & $5.71 \times 10^{-18}$ & 0.112 \\
\hline & & TSw7 & $7.01 \times 10^{-11}$ & $2.0 \times 10^{-2}$ & $4.49 \times 10^{-18}$ & 0.094 \\
\hline & & TSw8 & $5.92 \times 10^{-13}$ & $1.6 \times 10^{-2}$ & $4.53 \times 10^{-18}$ & 0.037 \\
\hline & & TSw9 & $4.57 \times 10^{-13}$ & $5.9 \times 10^{-3}$ & $5.46 \times 10^{-17}$ & 0.173 \\
\hline
\end{tabular}

A one-dimensional vertical column corresponding to the location of a deep borehole (WT-24) was chosen for modeling calcite deposition because measured calcite abundances (Paces et al., 2001) were available for comparison. The model grid, hydrogeological parameters and flow conditions were adopted from the hydrological property calibration work performed by Ahlers and Liu (2000).

Geochemical Model 
Initial mineral abundances, potential secondary minerals, reactive surface areas, kinetic and thermodynamic data were taken from the modeling work of coupled thermal, hydrological, and chemical (THC) processes for the potential high-level nuclear waste repository at Yucca Mountain (Sonnenthal and Spycher, 2001; Spycher et al., 2003a). Minerals considered in the simulations are calcite, gypsum, goethite, tridymite, cristobalite- $\alpha$, quartz, amorphous silica, hematite, fluorite, albite, $\mathrm{K}$-feldspar, anorthite, Ca-smectite, Mg-smectite, Na-smectite, illite, kaolinite, opal-CT, stellerite, heulandite, mordenite, clinoptilolite, and volcanic glass. This full assemblage of minerals and the corresponding aqueous species are hereafter termed the extendedcase geochemical system, because it has more complexities and uncertainties in terms of thermodynamics and kinetics of mineral solid solutions (clays, zeolites and feldspars), effects on $\mathrm{pH}$, and the partial pressure of $\mathrm{CO}_{2}$. A simpler set of minerals and aqueous species (base-case geochemical system) disregards all aluminosilicates, Fe- and Mg-bearing minerals.

Calcite and gypsum dissolution and precipitation were assumed to take place under geochemical equilibrium, whereas dissolution and precipitation of the other minerals was treated under kinetic constraints. Initial mineral abundances were derived from X-ray diffraction measurements on cores and studies of fracture surfaces (Carey et al., 1998; S. Levy, unpublished data). Potential secondary minerals (i.e., those allowed to precipitate but which may not necessarily form) were determined from field and experimental observations of water-rock interaction and from equilibrium geochemical model calculations. Reactive surface areas of minerals on fracture walls were calculated from the fracture-matrix interface area/volume ratio, the fracture porosity, and the derived mineral volume fractions. These areas were based on the fracture densities, fracture porosities, and mean fracture diameter. Mineral surface areas in the rock matrix were calculated using the geometric area of a cubic array of truncated spheres that make up the framework of the rock and reductions to those areas owing to the presence of alteration phases such as clays and zeolites. Full details are given in Sonnenthal and Spycher (2001).

Initial pore water chemical concentrations were based on analyses of ultracentrifuged water (L. DeLoach, unpublished data) and chemical speciation calculations (Sonnenthal and Spycher, 2001; Spycher et al., 2003a). Except for perched water that lies well below the potential repository horizon, water has not been observed in fractures in the UZ. Therefore, the initial composition of water in the fractures was assumed to be the same as the matrix pore water (Table 
8.3.2). The same water composition, re-equilibrated at the temperature of the top model boundary, was assumed for infiltrating water. Oxidizing conditions were considered for this water, because the fracture permeability of the rock is high and the system is unsaturated (air phase is everywhere present). The $\mathrm{CO}_{2}$ gas partial pressures used for initial and top boundary conditions of the gas transport are in equilibrium with the corresponding aqueous chemical composition. An elevated gas partial pressure (relative to an atmospheric value of $0.344 \times 10^{-3}$ bar) at the upper boundary can be attributed to soil-zone $\mathrm{CO}_{2}$ production.

Table 8.3.2. Water and gas chemistry used for initial and boundary conditions of the reactiontransport simulations (Sonnenthal and Spycher, 2001).

\begin{tabular}{|l|l|l|}
\hline Component & Concentration & Unit \\
\hline $\mathrm{Ca}^{2+}$ & 101 & $\mathrm{mg} / \mathrm{L}$ \\
\hline $\mathrm{Mg}^{2+}$ & 17 & $\mathrm{mg} / \mathrm{L}$ \\
\hline $\mathrm{Na}^{+}$ & 61.3 & $\mathrm{mg} / \mathrm{L}$ \\
\hline $\mathrm{K}^{+}$ & 8 & $\mathrm{mg} / \mathrm{L}$ \\
\hline $\mathrm{SiO}_{2}(\mathrm{aq})$ & 70.5 & $\mathrm{mg} / \mathrm{L}$ \\
\hline $\mathrm{Al}^{3+}$ & $1.67 \times 10^{-5}$ & $\mathrm{mg} / \mathrm{L}$ \\
\hline $\mathrm{HCO}_{3}{ }^{-}$ & 200 & $\mathrm{mg} / \mathrm{L}$ \\
\hline $\mathrm{Cl}^{-}$ & 117 & $\mathrm{mg} / \mathrm{L}$ \\
\hline $\mathrm{SO}_{4}{ }^{2-}$ & 116 & $\mathrm{mg} / \mathrm{L}$ \\
\hline $\mathrm{F}^{-}$ & 0.86 & $\mathrm{mg} / \mathrm{L}$ \\
\hline $\mathrm{Fe}^{3+}$ & $6.46 \times 10^{-8}$ & $\mathrm{mg} / \mathrm{L}$ \\
\hline & & \\
\hline $\mathrm{pH}^{3+}$ & $8.32\left(\right.$ at $\left.25^{\circ} \mathrm{C}\right)$ & \\
\hline $\mathrm{PCO}_{2}$ & $7.75\left(\right.$ at $\left.17^{\circ} \mathrm{C}\right)$ & \\
\hline & $2.726 \times 10^{-3}$ at $17^{\circ} \mathrm{C}$ & bar \\
\hline
\end{tabular}




\section{Simulation Setup}

Simulations were performed using three infiltration rates, a base-case rate of $5.92 \mathrm{~mm} / \mathrm{yr}$ (Ahlers and Liu, 2000), and bounding rates of $2 \mathrm{~mm} / \mathrm{yr}$ and $20 \mathrm{~mm} / \mathrm{yr}$. The corresponding steadystate water flow conditions were used for geochemical transport simulations. Steady-state temperature distributions corresponding to the same three infiltration rates were obtained using a top temperature of $15.6^{\circ} \mathrm{C}$ at the land surface and a bottom temperature of $28^{\circ} \mathrm{C}$ at the water table (Figure 8.3.5). For the three infiltration rates, the same water and gas chemistry was used for the top boundary condition. The EOS3 flow module was used for these simulations.

For the reactive transport simulations of calcite precipitation, a simulation time of 10 million years was selected, based on the following inferences: (1) calcite growth has remained approximately constant over the past 8 million years, as indicated by radiocarbon, ${ }^{230} \mathrm{Th} / \mathrm{U}$, and U-Pb ages (Paces et al., 1998) (2) the tuff is 12.7 million years old (Paces et al., 1998), and (3) all dated surfaces indicated by ages of outer mineral surfaces are young compared to the age of the tuffs. Infiltration rates and temperatures were held constant throughout the simulation, and therefore the results can only be considered to reflect the average conditions over this period of time.

In this manual, we only present results for a base-case infiltration rate of $5.92 \mathrm{~mm} / \mathrm{yr}$. More results are given in Xu et al. (2003a). The corresponding input and output files are given in the distribution CD (subdirectory: /sample-problems/P3_EOS3-YM-calcite). To shorten the run time for testing, the simulation time in the PARAM input block of flow.inp is specified as 3.15576E09 s (100 years). For a simulation of ten million years, users can reset this variable to 3.15576E13. Parts of output files for fluid flow, aqueous chemical concentrations, and changes of mineral abundances are given in Figures 8.3.2, 8.3.3 and 8.3.4. 
Figure 8.3.2. Part of file flow.out for problem no. 3 (calcite and infiltration).

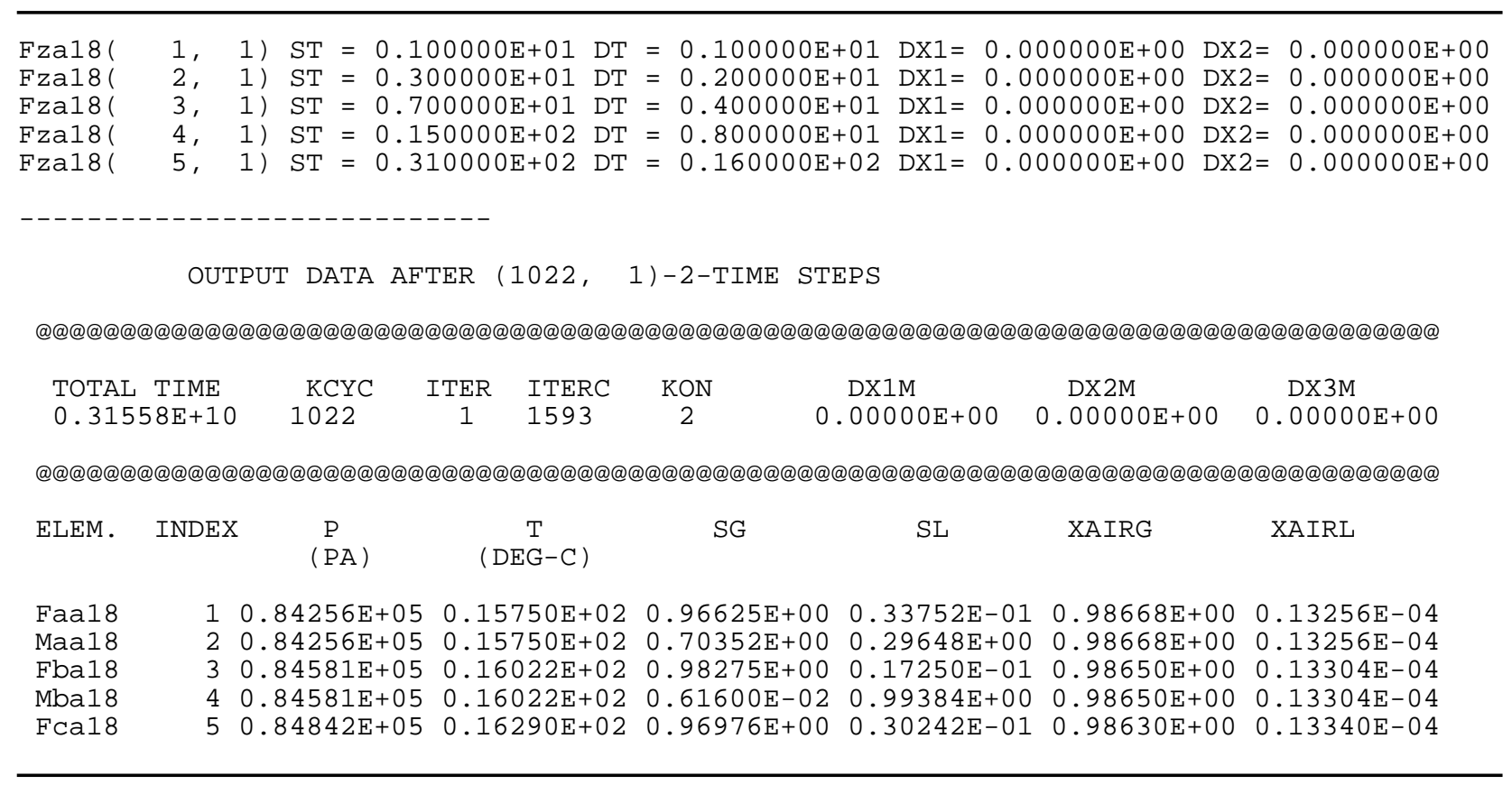

Figure 8.3.3. Part of file YMC_conc.dat for problem no. 3 after $\mathrm{t}=100 \mathrm{yr}$ (SL is water saturation, $\mathrm{T}$ is temperature in ${ }^{\circ} \mathrm{C}$, unit of concentrations is $\mathrm{mol} / \mathrm{l}$ ).

\begin{tabular}{cccccccc}
\hline & & & & & & \\
$\mathrm{Z}$ & $\mathrm{SI}$ & $\mathrm{T}(\mathrm{C})$ & $\mathrm{pH}$ & $\mathrm{ca}+2$ & $\mathrm{nat}$ & $\mathrm{cl}-$ & $\mathrm{sio2}(\mathrm{aq})$ \\
1482.000 & $0.3375 \mathrm{E}-01$ & 15.750 & 8.2011 & $0.2253 \mathrm{E}-02$ & $0.2666 \mathrm{E}-02$ & $0.3303 \mathrm{E}-02$ & $0.1232 \mathrm{E}-02$ \\
1482.000 & $0.2965 \mathrm{E}+00$ & 15.750 & 8.2021 & $0.2252 \mathrm{E}-02$ & $0.2666 \mathrm{E}-02$ & $0.3303 \mathrm{E}-02$ & $0.1236 \mathrm{E}-02$ \\
1449.000 & $0.1725 \mathrm{E}-01$ & 16.022 & 8.1439 & $0.2370 \mathrm{E}-02$ & $0.2665 \mathrm{E}-02$ & $0.3299 \mathrm{E}-02$ & $0.1402 \mathrm{E}-02$ \\
1449.000 & $0.9938 \mathrm{E}+00$ & 16.022 & 8.1437 & $0.2370 \mathrm{E}-02$ & $0.2665 \mathrm{E}-02$ & $0.3299 \mathrm{E}-02$ & $0.1402 \mathrm{E}-02$ \\
1422.000 & $0.3024 \mathrm{E}-01$ & 16.290 & 8.1102 & $0.2399 \mathrm{E}-02$ & $0.2665 \mathrm{E}-02$ & $0.3299 \mathrm{E}-02$ & $0.1293 \mathrm{E}-02$ \\
1422.000 & $0.8104 \mathrm{E}+00$ & 16.290 & 8.1102 & $0.2399 \mathrm{E}-02$ & $0.2665 \mathrm{E}-02$ & $0.3299 \mathrm{E}-02$ & $0.1292 \mathrm{E}-02$ \\
1413.000 & $0.4217 \mathrm{E}-01$ & 16.448 & 8.1064 & $0.2404 \mathrm{E}-02$ & $0.2665 \mathrm{E}-02$ & $0.3299 \mathrm{E}-02$ & $0.1201 \mathrm{E}-02$ \\
1413.000 & $0.8338 \mathrm{E}+00$ & 16.448 & 8.1065 & $0.2404 \mathrm{E}-02$ & $0.2665 \mathrm{E}-02$ & $0.3299 \mathrm{E}-02$ & $0.1194 \mathrm{E}-02$ \\
1404.000 & $0.2536 \mathrm{E}-01$ & 16.680 & 8.1024 & $0.2393 \mathrm{E}-02$ & $0.2666 \mathrm{E}-02$ & $0.3299 \mathrm{E}-02$ & $0.1182 \mathrm{E}-02$ \\
1404.000 & $0.3328 \mathrm{E}+00$ & 16.680 & 8.1023 & $0.2393 \mathrm{E}-02$ & $0.2666 \mathrm{E}-02$ & $0.3299 \mathrm{E}-02$ & $0.1181 \mathrm{E}-02$ \\
1396.000 & $0.3065 \mathrm{E}-01$ & 16.940 & 8.1020 & $0.2396 \mathrm{E}-02$ & $0.2665 \mathrm{E}-02$ & $0.3299 \mathrm{E}-02$ & $0.1185 \mathrm{E}-02$ \\
1396.000 & $0.6580 \mathrm{E}+00$ & 16.940 & 8.1020 & $0.2396 \mathrm{E}-02$ & $0.2665 \mathrm{E}-02$ & $0.3299 \mathrm{E}-02$ & $0.1185 \mathrm{E}-02$ \\
1370.000 & $0.2464 \mathrm{E}-01$ & 17.425 & 8.0978 & $0.2399 \mathrm{E}-02$ & $0.2665 \mathrm{E}-02$ & $0.3298 \mathrm{E}-02$ & $0.1180 \mathrm{E}-02$ \\
1370.000 & $0.6159 \mathrm{E}+00$ & 17.425 & 8.0978 & $0.2399 \mathrm{E}-02$ & $0.2665 \mathrm{E}-02$ & $0.3298 \mathrm{E}-02$ & $0.1180 \mathrm{E}-02$ \\
1344.000 & $0.2052 \mathrm{E}-01$ & 17.995 & 8.0945 & $0.2391 \mathrm{E}-02$ & $0.2665 \mathrm{E}-02$ & $0.3298 \mathrm{E}-02$ & $0.1179 \mathrm{E}-02$ \\
1344.000 & $0.4469 \mathrm{E}+00$ & 17.995 & 8.0945 & $0.2391 \mathrm{E}-02$ & $0.2665 \mathrm{E}-02$ & $0.3298 \mathrm{E}-02$ & $0.1179 \mathrm{E}-02$ \\
& & & & & & & \\
\hline
\end{tabular}


Figure 8.3.4. Part of file YMC_min.dat for problem no. 3 after $t=100 \mathrm{yr}$, giving changes in mineral abundances (in volume fraction, positive values indicate precipitation and negative dissolution).

\begin{tabular}{|c|c|c|c|c|c|c|c|}
\hline Z & $\mathrm{T}(\mathrm{C})$ & Porosity & calcite & cristoba-a & quartz & sio2 (amor.) & glass \\
\hline 1482.000 & 15.750 & 0.99000 & $0.5503 E-05$ & $0.0000 \mathrm{E}+00$ & $0.0000 \mathrm{E}+00$ & $0.0000 E+00$ & $-0.2534 E-11$ \\
\hline 1449.000 & 16.022 & 0.99000 & $0.2643 E-05$ & $0.0000 \mathrm{E}+00$ & $0.0000 \mathrm{E}+00$ & $0.0000 \mathrm{E}+00$ & $-0.9460 \mathrm{E}-12$ \\
\hline 1449.000 & 16.022 & 0.08200 & $0.3276 \mathrm{E}-06$ & $0.0000 \mathrm{E}+00$ & $0.0000 E+00$ & $0.0000 \mathrm{E}+00$ & $-0.5837 \mathrm{E}-06$ \\
\hline 1422.000 & 16.290 & 0.99000 & $0.2567 \mathrm{E}-06$ & $0.0000 \mathrm{E}+00$ & $0.0000 \mathrm{E}+00$ & $0.0000 \mathrm{E}+00$ & $-0.2290 \mathrm{E}-11$ \\
\hline 1422.000 & 16.290 & 0.20300 & $0.6889 \mathrm{E}-06$ & $0.0000 \mathrm{E}+00$ & $0.0000 E+00$ & $0.0000 \mathrm{E}+00$ & $-0.4821 \mathrm{E}-06$ \\
\hline 1413.000 & 16.448 & 0.99000 & $0.3485 \mathrm{E}-06$ & $0.0000 \mathrm{E}+00$ & $0.0000 \mathrm{E}+00$ & $0.0000 \mathrm{E}+00$ & $-0.4364 \mathrm{E}-11$ \\
\hline 1413.000 & 16.448 & 0.38700 & $0.1348 \mathrm{E}-05$ & $0.0000 \mathrm{E}+00$ & $0.0000 E+00$ & $0.0000 \mathrm{E}+00$ & $-0.5207 \mathrm{E}-07$ \\
\hline 1404.000 & 16.680 & 0.99000 & $0.2255 \mathrm{E}-06$ & $0.0000 \mathrm{E}+00$ & $0.0000 E+00$ & $0.0000 \mathrm{E}+00$ & $-0.3221 \mathrm{E}-11$ \\
\hline 1404.000 & 16.680 & 0.43900 & $0.7173 \mathrm{E}-06$ & $0.0000 \mathrm{E}+00$ & $0.0000 \mathrm{E}+00$ & $0.0000 \mathrm{E}+00$ & $-0.2130 \mathrm{E}-07$ \\
\hline 1396.000 & 16.940 & 0.99000 & $0.2982 \mathrm{E}-06$ & $0.0000 \mathrm{E}+00$ & $0.0000 E+00$ & $0.0000 \mathrm{E}+00$ & $-0.3077 \mathrm{E}-10$ \\
\hline 1396.000 & 16.940 & 0.25400 & $0.7333 \mathrm{E}-06$ & $0.0000 \mathrm{E}+00$ & $0.0000 E+00$ & $0.0000 \mathrm{E}+00$ & $-0.6026 \mathrm{E}-07$ \\
\hline 1370.000 & 17.425 & 0.99000 & $0.2325 \mathrm{E}-06$ & $0.0000 \mathrm{E}+00$ & $0.0000 \mathrm{E}+00$ & $0.0000 \mathrm{E}+00$ & $-0.8920 \mathrm{E}-12$ \\
\hline 1370.000 & 17.425 & 0.41100 & $0.1117 \mathrm{E}-05$ & $0.0000 \mathrm{E}+00$ & $0.0000 E+00$ & $0.0000 \mathrm{E}+00$ & $-0.5303 E-07$ \\
\hline 1344.000 & 17.995 & 0.49900 & $0.1059 \mathrm{E}-05$ & $0.0000 \mathrm{E}+00$ & $0.0000 E+00$ & $0.0000 \mathrm{E}+00$ & $-0.4488 E-07$ \\
\hline
\end{tabular}

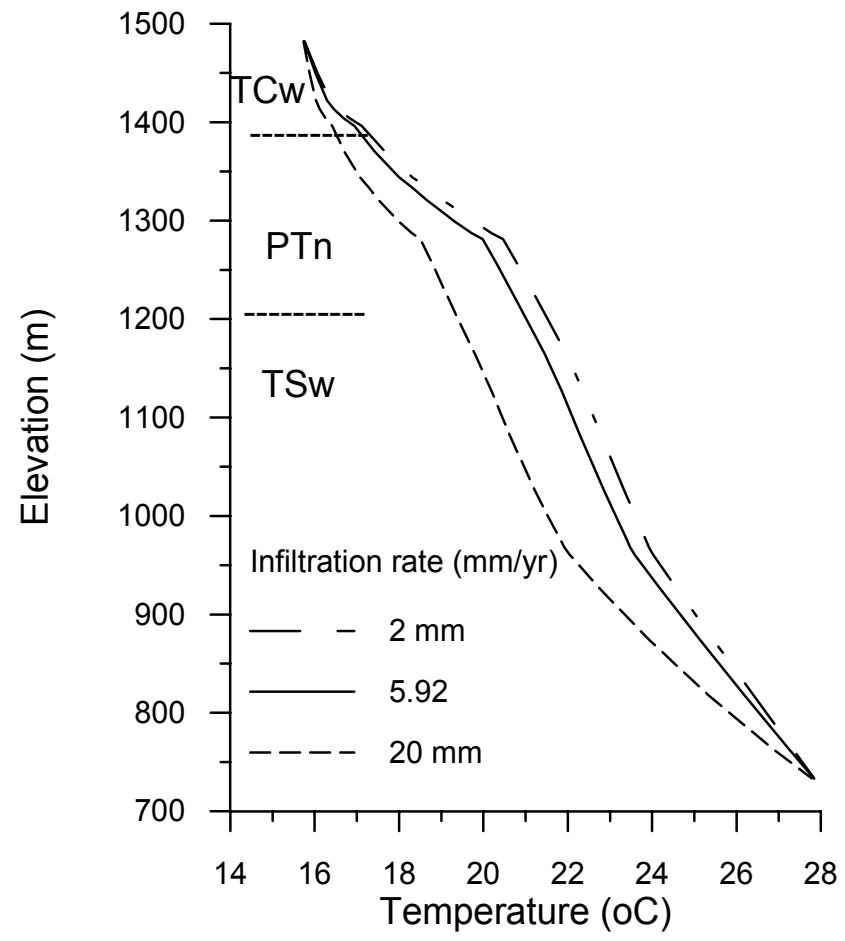

Figure 8.3.5. Modeled temperature profiles in borehole WT-24 as a function of depth for three infiltration rates. 


\subsubsection{Results and discussion}

The simulated total (fracture plus matrix) calcite abundances in the WT-24 column for three infiltration rates, together with USGS measured data, are presented in Figure 8.3.6. In general, the results obtained using the base-case infiltration rate $(5.92 \mathrm{~mm} / \mathrm{yr})$ agree more closely with the measured WT-24 calcite abundances than those obtained using the other infiltration rates, especially for the PTn unit.

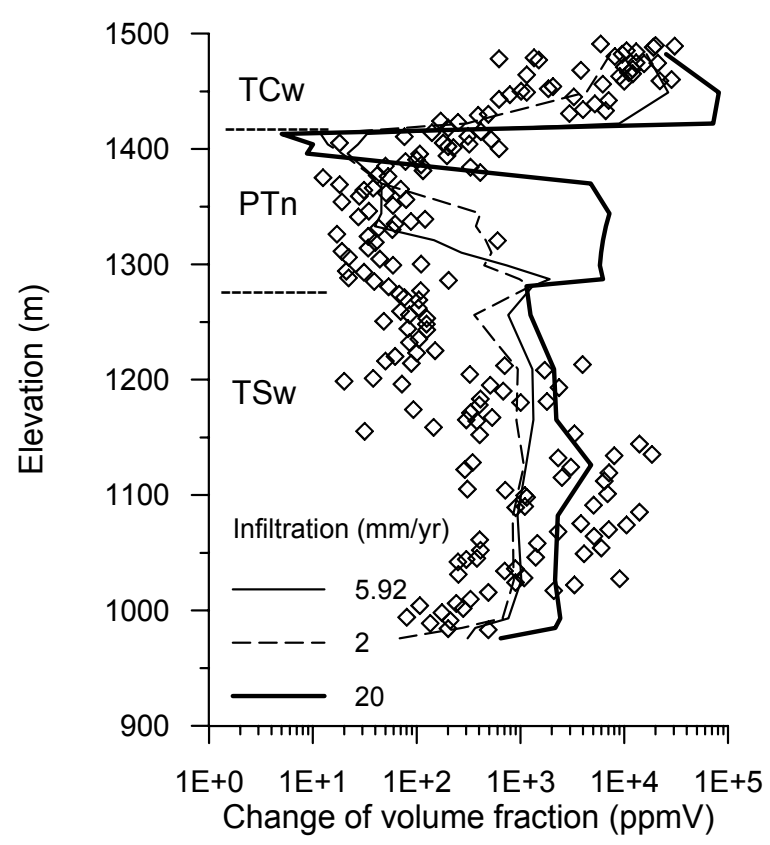

Figure 8.3.6. Simulated total (fracture plus matrix) calcite abundances (volume fraction) in the WT-24 column for different infiltration rates after 10 million years (Extended geochemical system). Diamonds represent bulk rock calcite abundances measured by the U.S. Geological Survey (Paces et al., 2001).

The simulated calcite abundances in the basal PTn layer for the three infiltration simulations are higher than those measured in WT-24. This is a result of an increase in the temperature gradient (Figure 8.3.5) resulting in a concomitant decrease in calcite solubility. Relatively greater calcite abundances in the bottom layer of the PTn have been observed at other locations such as in another deep borehole USW G-2 (Carey et al., 1998). The lower measured 
calcite abundances may also be a result of lateral flow that is not captured in the one-dimensional simulations.

Results for the welded TSw unit (a potential repository host rock unit) generally fall in the wide range of measured calcite data. Calcite abundances obtained using the highest infiltration rate $(20 \mathrm{~mm} / \mathrm{yr})$ are closer to the high bound of measured values. Those values from the base-case $(5.92 \mathrm{~mm} / \mathrm{yr})$ fall in the middle of the TSw measured data range. This may imply that $20 \mathrm{~mm} / \mathrm{yr}$ is the high bound for the infiltration rate at the WT-24 location; whereas the base-case infiltration (5.92 $\mathrm{mm} / \mathrm{yr}$ ) from the flow property calibration (used for the flow model) may be close to the long-term mean infiltration rate for this location. More results are presented in Xu et al. (2003a) 


\subsection{Heater Test Problem (EOS4 or EOS3)}

This test problem of a large-scale in-situ thermal test at Yucca Mountain (Nevada) provides a complex 2-D example of coupled thermal, hydrological, and chemical (THC) processes in unsaturated fractured rock. The model setup incorporates many aspects of the capabilities of both TOUGH2 and TOUGHREACT, including time-dependent heat generation, dual-permeability, vapor pressure lowering (EOS4), numerous aqueous, gaseous, and mineral species, $\mathrm{CO}_{2}$ diffusion (P- and $\mathrm{T}$-dependent), and coupling of permeability and capillary pressure to porosity changes.

\subsubsection{Background}

The Drift Scale Test (DST) is the second underground thermal test carried out in the Exploratory Studies Facility (ESF) at Yucca Mountain, Nevada. The purpose of the test was to evaluate the coupled thermal, hydrological, chemical, and mechanical processes that take place in unsaturated fractured tuff over a range of temperatures (approximately $25^{\circ} \mathrm{C}$ to $200^{\circ} \mathrm{C}$ ). Briefly, the DST consists of an approximately $50 \mathrm{~m}$ long drift that is $5 \mathrm{~m}$ in diameter. Nine electrical floor canister heaters were placed in this drift (the Heated Drift) to simulate nuclear-waste-bearing containers. Electrical heaters were also placed in a series of horizontal boreholes (wing heaters) drilled perpendicular outward from the central axis of the Heated Drift. These heaters were emplaced to simulate the effect of adjacent emplacement drifts. The DST heaters were activated on December 3, 1997, with a planned period of 4 years of heating, followed by 4 years of cooling. After just over 4 years, the heaters were switched off on January 14, 2002, and since that time the test area has been slowly cooling.

The first predictive model for THC processes in the DST was begun just prior to the initiation of heating in late 1997 with the final predictive report completed several months after the test had begun (Sonnenthal et al. 1998; Xu et al., 2001). The 2-D numerical grid, and thermal and hydrological properties for the THC model were based on the original TH model developed for the DST (Birkholzer and Tsang, 1997; 1998). Model development, results, and data shown in this test problem are based on Spycher et al. (2003b), and Sonnenthal et al. (in prep. for a special issue of the International Journal of Rock Mechanics and Mining Sciences). 


\subsubsection{Conceptual model for THC processes}

The evolution of the chemical regime in the unsaturated zone surrounding a heat source is closely related to the spatial distribution of temperature and the transport of water and vapor. An important aspect of the unsaturated fractured tuff at Yucca Mountain is that the highly permeable fractures are nearly dry, whereas the low permeability and porosity rock matrix has a water saturation of about 90 percent. Heating of the rock results in boiling of the matrix pore water, transport of water vapor into fractures, and condensation along fracture walls. The numerical model for reaction-transport processes in the fractured welded tuffs must account for the different rates of transport in fractures, compared to a much less permeable rock matrix. Transport rates greater than the rate of equilibration via diffusion leads to disequilibrium between waters in fractures and matrix. Because the system is unsaturated, and undergoes boiling, the transport of gaseous species, especially $\mathrm{CO}_{2}$, is an important consideration. The model must also capture the differences in initial mineralogy in fractures and matrix and their evolution.

In order to handle separate yet interacting processes in fractures and matrix, the dual permeability method has been adopted, such that each grid block is divided into matrix and fracture continua, characterized by their own pressure, temperature, liquid saturation, water and gas chemistry, and mineralogy. In the dual-permeability model, the fracture continuum is considered as co-located but interacting with the matrix continuum, in terms of the flow of heat, water, and vapor through advection, diffusion, and conduction (for heat). The aqueous and gaseous species are transported via advection and molecular diffusion between the fractures and matrix. Each continuum has its own well-defined initial physical and chemical properties.

\subsubsection{Drift Scale Test 2-D numerical grid}

The two-dimensional dual-permeability numerical grid for the DST represents a vertical cross section through the Heated Drift at a distance approximately $30 \mathrm{~m}$ from the bulkhead, separating the Heated Drift from the Access Drift (Figure 8.4.1a). The mesh consists of 4,490 grid blocks, including fracture and matrix (Figure 8.4.1a and b). The top boundary is approximately 99 $\mathrm{m}$ above the drift center, with the bottom boundary at approximately $157 \mathrm{~m}$ below the center. The DST includes a plane of linear wing heaters on each side of the drift that are given small grid blocks in the model. Small grid blocks are also employed adjacent to the wing heaters and drift 
wall to capture the strong gradients in temperature and liquid saturation in these regions (Figure 8.4.1b). Radial mesh blocks in the drift interior were removed from the original mesh and replaced near the drift base by Cartesian grid blocks to represent the concrete invert (Figure 8.4.1b). The Heated Drift grid block is connected directly to the Heater Test Alcove grid block. The connection area and distance were adjusted so that heat loss from the drift resulted in roughly similar crown temperatures to the maximum observed values. In the approximate location of the observation drift, the grid block volumes were increased to a large value to represent connection to the atmosphere. The distances from the drift center grid block and the connecting elements were modified to represent the true distance, so that heat could be applied to the drift center to approximate the effect of the electrical canister heaters.

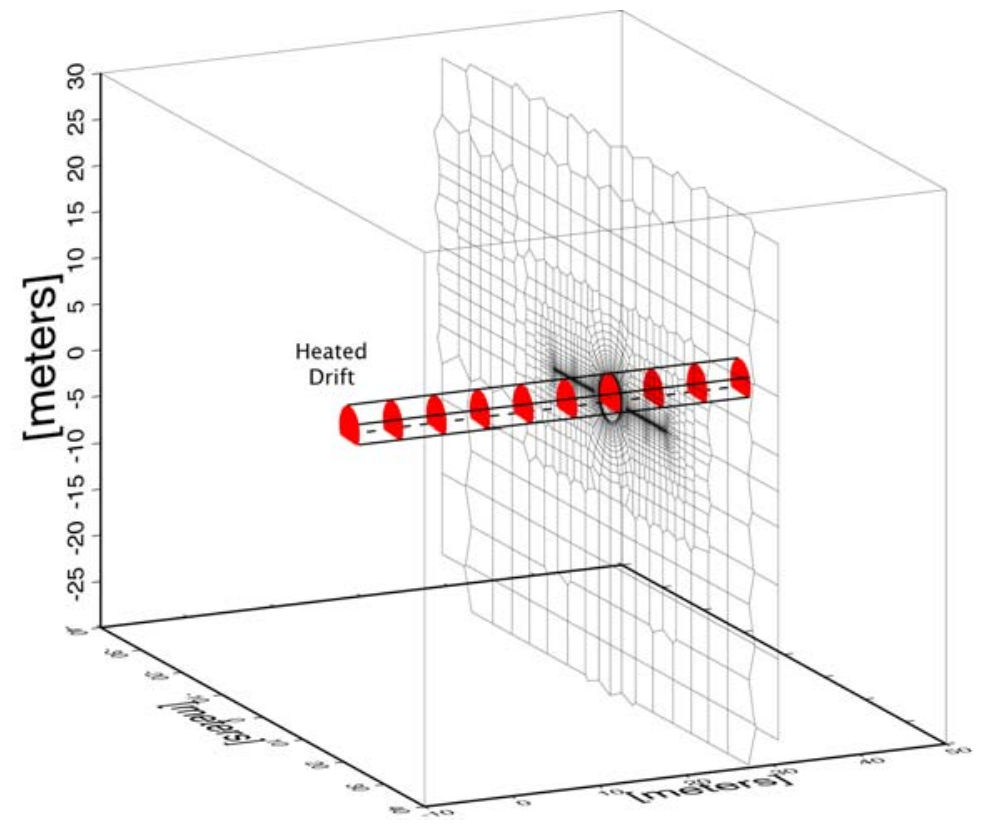

Figure 8.4.1a. Three-dimensional schematic diagram of the DST showing perspective view of 2D numerical mesh for DST THC model simulations (mesh extends in all directions from area shown). 


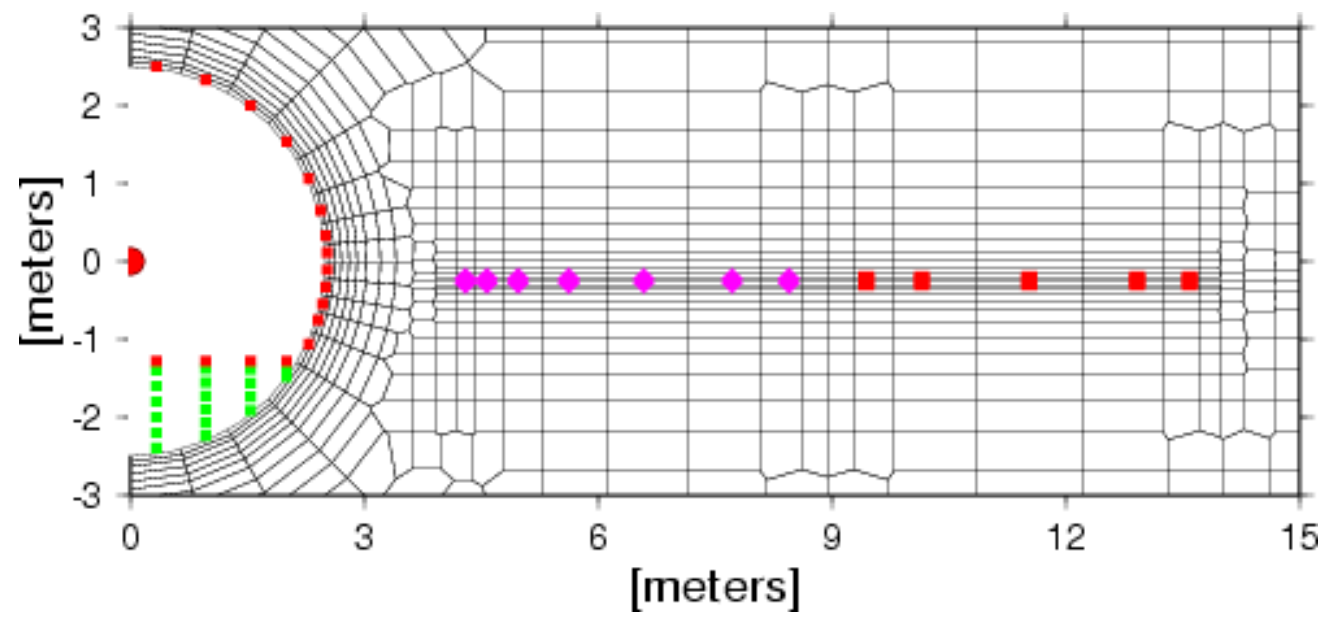

NOTE: Inner (violet diamonds closer to drift) and outer wing heater (red squares) indicate grid block coordinates. Heat was applied to the drift center. Green squares indicate grid block locations for the concrete invert.

Figure 8.4.1b. Enlarged view of the numerical mesh showing the locations of grid blocks representing the heated drift, wing heaters, and concrete invert.

In the Heated Drift, heat was applied solely to the drift-center grid block, which is connected to all surrounding grid blocks. The wing heaters are split into inner and outer zones, with more power applied to the outer zone to approximate the presence of an adjacent parallel drift. The positions of grid blocks representing heaters are shown in Figure 8.4.1b. The heating schedule was based on step-wise averages of the 10-day incremented power data. A 9-month initial period is set to the ambient temperature, corresponding approximately to the time that was required to set up the test. Intentional power reductions were directly accounted from the power data. Estimates were made of the duration of the longer (approximately greater than $1 / 2$ day) temporary power outages. Table 8.4.1 gives the step-wise averaged power data implemented in the model simulations in the GENER file. Each time in Table 8.4.1 represents the initiation of a specific period of heating or power loss that continues until the succeeding time. The simulation can be run for the full period of heating plus a 4-year period of cooling (shown by the hypothetical end time at the base of Table 8.4.1). Depending on the speed of floating point calculations on a particular computer, the full simulation could take up to a few days or longer. The complexity of this heating schedule provides a good example of stepwise heat generation in TOUGH2/TOUGHREACT. 
Table 8.4.1. Step-Wise Averaged Power Data

\begin{tabular}{|c|c|c|c|c|c|c|}
\hline Date & Time (s) & $\begin{array}{l}\text { Time } \\
\text { (days) }\end{array}$ & $\begin{array}{l}\text { Canister } \\
\text { Power (watts) }\end{array}$ & $\begin{array}{l}\text { WH (inner) } \\
\text { Power (watts) }\end{array}$ & $\begin{array}{l}\text { WH (outer) } \\
\text { Power (watts) }\end{array}$ & Comments \\
\hline $3 / 5 / 97$ & $0.00000 \mathrm{E}+00$ & 0.00 & 0.0000 & 0.0000 & 0.0000 & pre-test \\
\hline $12 / 3 / 97$ & $2.35872 \mathrm{E}+07$ & 273.00 & 1091.3740 & 1232.4007 & 1626.7690 & heaters turned on \\
\hline $3 / 15 / 98$ & $3.24000 \mathrm{E}+07$ & 375.00 & 1091.3740 & 0.0000 & 0.0000 & outage - right rib \\
\hline $3 / 16 / 98$ & $3.25080 \mathrm{E}+07$ & 376.25 & 1091.3740 & 1232.4007 & 1626.7690 & \\
\hline $4 / 12 / 98$ & $3.48192 \mathrm{E}+07$ & 403.00 & 1077.9972 & 1198.5773 & 1582.1220 & \\
\hline $8 / 10 / 98$ & $4.51872 \mathrm{E}+07$ & 523.00 & 1119.6842 & 1201.8035 & 1586.3807 & \\
\hline $1 / 27 / 99$ & $5.98752 \mathrm{E}+07$ & 693.00 & 0.0000 & 0.0000 & 0.0000 & power outage \\
\hline $1 / 27 / 99$ & $5.99400 \mathrm{E}+07$ & 693.75 & 1123.5789 & 1204.4465 & 1589.8693 & \\
\hline $2 / 16 / 99$ & $6.16032 \mathrm{E}+07$ & 713.00 & 1102.5965 & 1189.0805 & 1569.5862 & \\
\hline $5 / 27 / 99$ & $7.02432 \mathrm{E}+07$ & 813.00 & 0.0000 & 0.0000 & 0.0000 & power outage \\
\hline $5 / 27 / 99$ & $7.03080 \mathrm{E}+07$ & 813.75 & 1102.5965 & 1189.0805 & 1569.5862 & \\
\hline $5 / 29 / 99$ & $7.04160 \mathrm{E}+07$ & 815.00 & 0.0000 & 0.0000 & 0.0000 & power outage \\
\hline $5 / 30 / 99$ & $7.04808 \mathrm{E}+07$ & 815.75 & 1087.8653 & 1155.5245 & 1525.2923 & \\
\hline $6 / 18 / 99$ & $7.21440 \mathrm{E}+07$ & 835.00 & 0.0000 & 0.0000 & 0.0000 & power outage \\
\hline $6 / 19 / 99$ & $7.22088 \mathrm{E}+07$ & 835.75 & 1087.8653 & 1155.5245 & 1525.2923 & \\
\hline 7/9/99 & $7.39584 \mathrm{E}+07$ & 856.00 & 0.0000 & 0.0000 & 0.0000 & power outage \\
\hline $7 / 15 / 99$ & $7.44768 \mathrm{E}+07$ & 862.00 & 1087.8653 & 1155.5245 & 1525.2923 & \\
\hline $8 / 27 / 99$ & $7.81920 \mathrm{E}+07$ & 905.00 & 0.0000 & 0.0000 & 0.0000 & power outage \\
\hline $8 / 29 / 99$ & $7.83216 \mathrm{E}+07$ & 906.50 & 1087.8653 & 1155.5245 & 1525.2923 & \\
\hline $11 / 22 / 99$ & $8.57088 \mathrm{E}+07$ & 992.00 & 1087.8653 & 0.0000 & 0.0000 & outage - right rib \\
\hline $11 / 24 / 99$ & $8.58816 \mathrm{E}+07$ & 994.00 & 1087.8653 & 1155.5245 & 1525.2923 & \\
\hline $2 / 11 / 00$ & $9.27072 \mathrm{E}+07$ & 1073.00 & 0.0000 & 0.0000 & 0.0000 & power outage \\
\hline $2 / 11 / 00$ & $9.27720 \mathrm{E}+07$ & 1073.75 & 1078.7421 & 1184.6642 & 1563.7568 & \\
\hline $3 / 2 / 00$ & $9.44352 \mathrm{E}+07$ & 1093.00 & 1029.1930 & 1115.3660 & 1472.2831 & power reduction \\
\hline $3 / 12 / 00$ & $9.52992 \mathrm{E}+07$ & 1103.00 & 0.0000 & 0.0000 & 0.0000 & power loss \\
\hline $3 / 13 / 00$ & $9.54072 \mathrm{E}+07$ & 1104.25 & 1029.1930 & 1115.3660 & 1472.2831 & \\
\hline $5 / 2 / 00$ & $9.97056 \mathrm{E}+07$ & 1154.00 & 964.5263 & 1040.2813 & 1373.1713 & power reduction \\
\hline $8 / 15 / 00$ & $1.08778 \mathrm{E}+08$ & 1259.00 & 917.3463 & 978.6397 & 1291.9364 & power reduction \\
\hline $1 / 20 / 01$ & $1.22429 \mathrm{E}+08$ & 1417.00 & 0.0000 & 0.0000 & 0.0000 & power outage \\
\hline $1 / 21 / 01$ & $1.22515 \mathrm{E}+08$ & 1418.00 & 917.3463 & 978.6397 & 1291.9364 & \\
\hline $5 / 1 / 01$ & $1.31155 \mathrm{E}+08$ & 1518.00 & 875.5711 & 925.4672 & 1221.6168 & power reduction \\
\hline $7 / 1 / 01$ & $1.36426 \mathrm{E}+08$ & 1579.00 & 0.0000 & 0.0000 & 0.0000 & power outage \\
\hline $7 / 1 / 01$ & $1.36490 \mathrm{E}+08$ & 1579.75 & 875.5711 & 925.4672 & 1221.6168 & \\
\hline $8 / 22 / 01$ & $1.40918 \mathrm{E}+08$ & 1631.00 & 826.8171 & 875.8317 & 1156.0979 & power reduction \\
\hline $1 / 14 / 02$ & $1.53446 \mathrm{E}+08$ & 1776.00 & 0.0000 & 0.0000 & 0.0000 & heaters turned off \\
\hline $1 / 14 / 06$ & $2.79677 \mathrm{E}+08$ & 3237.00 & 0.0000 & 0.0000 & 0.0000 & cooling period end \\
\hline
\end{tabular}

\subsubsection{Hydrological and thermal parameters}

Values of hydrological and thermal input data are listed in Table 8.4.2. The fracture tortuosity (0.7) is based on models of in situ testing data. This value was further modified for 
fracture-fracture connections by multiplication of the tortuosity by the fracture porosity of the bulk rock. This operation yields a better approximation for the fracture-to-fracture interconnection area (only for calculation of diffusive fluxes; the entire grid block connection area is used for calculating advective fluxes, because the bulk fracture permeability is used for flow calculations). The capillary pressure in both fractures and matrix must reach some maximum, finite value upon complete dryout (zero liquid saturation). For fractures and matrix in the Tptpmn and Tptpll lithostratigraphic units (model units tsw34 and tsw35, respectively), the limit is set by the calculated slope of the $\mathrm{P}_{\text {cap }}$ versus liquid saturation curve at a liquid saturation value equal to $\mathrm{S}_{\mathrm{r}}+\varepsilon$. For these units, $\varepsilon$ values for the matrix yield maximum $\mathrm{P}_{\text {cap }}$ values of $10^{8} \mathrm{~Pa}$ (Table 8.4.2); for fractures, $\varepsilon$ is set to 0.01 (maximum $\mathrm{P}_{\text {cap }}$ values around $10^{3}-10^{4} \mathrm{~Pa}$ ). These specific implementations of the van Genuchten equations are invoked by setting the MOPR(5) parameter to "2", in addition to the specific values given in the ROCKS block.

Table 8.4.2. Hydrological and thermal properties

\begin{tabular}{|c|c|c|c|c|}
\hline \multicolumn{2}{|c|}{$\begin{array}{r}\text { Model Layer }> \\
\text { Lithostratigraphic Unit }>\end{array}$} & $\begin{array}{l}\text { tsw33 } \\
\text { Tptpul }\end{array}$ & $\begin{array}{l}\text { tsw34 } \\
\text { Tptpmn }\end{array}$ & $\begin{array}{l}\text { tsw35 } \\
\text { Tptpll }\end{array}$ \\
\hline \multicolumn{5}{|l|}{ MATRIX DATA } \\
\hline permeability & $\mathrm{k}_{\mathrm{m}}\left(\mathrm{m}^{2}\right)$ & $6.57 \mathrm{E}-18$ & $1.77 \mathrm{E}-19$ & $4.48 \mathrm{E}-18$ \\
\hline porosity & $\phi_{\mathrm{m}}$ & 0.1425 & 0.1287 & 0.1486 \\
\hline van Genuchten & ${ }_{m}(1 / \mathrm{Pa})$ & $6.17 \mathrm{E}-6$ & $8.45 \mathrm{E}-6$ & $1.08 \mathrm{E}-5$ \\
\hline van Genuchten m (or ) & $\mathrm{m}_{\mathrm{m}}$ & 0.283 & 0.317 & 0.216 \\
\hline residual saturation & $\mathrm{S}_{\mathrm{Irm}}$ & 0.12 & 0.19 & 0.12 \\
\hline satiated saturation & $\mathrm{S}_{\mathrm{lsm}}$ & 1.00 & 1.00 & 1.00 \\
\hline epsilon (for max $\mathrm{P}_{\text {cap }}$ ) & $\varepsilon$ & 0.138 & 0.091 & 0.216 \\
\hline rock grain density & ${ }_{\mathrm{g}}\left(\mathrm{kg} / \mathrm{m}^{3}\right)$ & 2358 & 2466 & 2325 \\
\hline rock grain specific heat & $\mathrm{Cp}(\mathrm{J} / \mathrm{kg}-\mathrm{K})$ & 985 & 985 & 985 \\
\hline dry conductivity & $\lambda_{\text {dry }}(\mathrm{W} / \mathrm{m}-\mathrm{K})$ & $1.164 *$ & $1.419^{*}$ & $1.278^{*}$ \\
\hline wet conductivity & $\lambda_{\text {wet }}(\mathrm{W} / \mathrm{m}-\mathrm{K})$ & $1.675^{*}$ & $2.074 *$ & $1.890^{*}$ \\
\hline tortuosity & $\tau$ & 0.2 & 0.2 & 0.2 \\
\hline \multicolumn{5}{|l|}{ FRACTURE DATA $^{1}$} \\
\hline permeability & $\mathrm{k}_{\mathrm{f}}\left(\mathrm{m}^{2}\right)$ & $7.80 \mathrm{E}-13$ & $3.30 \mathrm{E}-13$ & $9.10 \mathrm{E}-13$ \\
\hline porosity & $\phi_{\mathrm{f}}$ & $5.8 \mathrm{E}-3$ & $8.5 \mathrm{E}-3$ & $9.6 \mathrm{E}-3$ \\
\hline van Genuchten & $\mathrm{f}(1 / \mathrm{Pa})$ & $1.59 \mathrm{E}-3$ & $1.04 \mathrm{E}-4$ & $1.02 \mathrm{E}-4$ \\
\hline
\end{tabular}


Table 8.4.2. Summary of hydrological and thermal properties of repository units (continued)

\begin{tabular}{|l|l|l|l|l|}
\hline \multicolumn{2}{|l|}{$\begin{array}{l}\text { Model Layer }> \\
\text { Lithostratigraphic Unit }>\end{array}$} & $\begin{array}{c}\text { tsw33 } \\
\text { Tptpul }\end{array}$ & $\begin{array}{c}\text { tsw34 } \\
\text { Tptpmn }\end{array}$ & $\begin{array}{c}\text { tsw35 } \\
\text { Tptpll }\end{array}$ \\
\hline van Genuchten $\mathrm{m}(\mathrm{or} \lambda)$ & $\mathrm{m}_{\mathrm{f}}$ & 0.633 & 0.633 & 0.633 \\
\hline residual saturation & $\mathrm{S}_{\text {Iff }}$ & 0.01 & 0.01 & 0.01 \\
\hline satiated saturation & $\mathrm{S}_{\text {Isf }}$ & 1.00 & 1.00 & 1.00 \\
\hline active fracture parameter & $\mathrm{gamma}$ & 0.60 & 0.57 & 0.57 \\
\hline Frequency & $\mathrm{f}(1 / \mathrm{m})$ & 0.81 & 4.32 & 3.16 \\
\hline fracture to matrix area & $\mathrm{A}\left(\mathrm{m}^{2} / \mathrm{m}^{3}\right)$ & 4.44 & 13.54 & 9.68 \\
\hline Tortuosity & $\mathrm{t}$ & 0.7 & 0.7 & 0.7 \\
\hline epsilon (for max $\left.\mathrm{P}_{\text {cap }}\right)$ & $\varepsilon$ & 0.01 & 0.01 & 0.01 \\
\hline
\end{tabular}

NOTE: ${ }^{1}$ Fracture thermal properties are derived using matrix properties.

* Bulk conductivities converted from grain conductivity values and lithophysal porosities, using $\mathrm{K}_{\text {bulk }}=$ $\mathrm{K}_{\text {grain }}\left(1-\phi_{\text {lith }}\right)+\phi_{\text {lith }} \mathrm{K}_{\text {air }}$, with $\mathrm{K}_{\text {air }}=0.028(\mathrm{~W} / \mathrm{m}-\mathrm{K})$ (see Spycher et al., 2003b).

The thermal conductivities of fracture and matrix grid blocks are calculated assuming a linear interpolation between dry and wet conductivities as a function of liquid saturation. These are the thermal conductivities for the solid + fluid system. For fractures, thermal conductivities are multiplied by the fracture porosity to account for the correct fracture-to-fracture connection area in calculations of heat conduction (i.e., this is needed because full grid block areas are input into the model). Fracture thermal conductivities are also reduced by a factor of 10 to account for the limited spatial continuity and connectivity between fracture grid blocks. The volume of the fracture continuum is, however, only a small fraction of the matrix continuum. Therefore heat conduction occurs primarily through the matrix continuum and, as a result, the model is not sensitive to the amount of heat conduction in fractures.

\subsubsection{Geochemical input data}

Thermodynamic data and kinetic data are provided in the thermok1.01.dat and the chemical.inp files, respectively. Equilibrium and kinetic mineral-water reactions are treated in this test problem. Different representations for reactive surface areas of minerals in fractures and in the porous rock matrix are provided in the chemical.inp file. In most cases, the chemical and physical properties of minerals that form solid solutions are approximated by their individual endmember compositions and properties. An ideal solid-solution model was implemented for smectite ( $\mathrm{Na}, \mathrm{Ca}$, and $\mathrm{Mg}$ endmembers), with each endmember's activity equaling its mole 
fraction. Treating the smectite as a solid solution, results in individual smectite endmembers either all dissolving or all precipitating, providing a better physical representation of dissolution/precipitation processes. Feldspar solid solutions are not considered because albite (Na-feldspar) and anorthite (Ca-feldspar) are generally strongly undersaturated in the simulations, and thus their dissolution rates are governed primarily by the kinetic rate constant rather than the saturation index. Coupling of permeability to mineral precipitation for fractures is given as a function of the hydraulic aperture and fracture porosity for each rock type (see Appendix F). For the rock matrix it is given as a relation to porosity, using a simplified form of the Kozeny-Carman equation. Coupling of capillary pressure to porosity and permeability is performed using Leverett scaling and "turned on" by setting the MOPR(6) parameter in the flow.inp file to "1".

\subsubsection{Initial and boundary conditions: Hydrological and thermal}

The top and bottom boundaries were set to constant temperature, pressure, and liquid saturation, based on steady-state values obtained from simulations of a 1-D column extending from the land surface to the water table. The top boundary of the 2-D model extends $150 \mathrm{~m}$ above and below the drift center, but does not reach either the land surface or the water table. Under these conditions, the percolation flux at the top boundary is approximately $0.5 \mathrm{~mm} / \mathrm{yr}$. The bottom boundary condition is open to gas and to liquid flow. The side boundaries of the domain are located $81.5 \mathrm{~m}$ away from the drift center on each side (outside of the test influence area) and are no-flux for mass and heat. The air pressure and temperature in the observation drift are set to constant values. The Heated Drift wall is open to advection and conduction of heat and mass (e.g., air, water vapor, and $\mathrm{CO}_{2}$ ). The INCON file provides the steady-state thermohydrological conditions in EOS3 format. Vapor-pressure lowering (EOS4) is implemented by setting MOP(19) $=2$, and the simulation can be run using either EOS module.

\subsubsection{Initial and boundary conditions: Geochemical}

Aqueous and gaseous species concentrations in the rock were initially set to uniform values, based on the measured pore water composition and calculated equilibrium values for $\mathrm{CO}_{2}$ and some aqueous species. The Heater Alcove and Observation Drift $\mathrm{CO}_{2}$ concentrations were fixed to approximately that of the atmosphere. The Heated Drift $\mathrm{CO}_{2}$ concentration was initially set to the same value as that in the Observation Drift, but was allowed to exchange $\mathrm{CO}_{2}$ with the 
Heater Test Alcove and with the surrounding rock. All initial geochemical conditions are provided in the chemical.inp and solute.inp files. Both the top and bottom boundary conditions are open to gas and aqueous species transport. The top and bottom boundaries were also set so that no mineral reactions take place (and therefore no changes in aqueous species concentrations occur as a result of mineral-water reactions). Their volumes were set to extremely large values, so that they act essentially as constant concentration boundaries. The side boundaries are no-flux for gas and aqueous-species transport.

\subsubsection{Simulation parameters}

The maximum simulation time for this test problem is set in the flow.inp file to 2.75 years (0.75 preheating period plus 2 years of heating), although the GENER file includes the full 8.65 year periods of preheating, heating, and cooling. The maximum time step is set to one day, so that errors due to the non-sequential iteration method, in particular related to gas phase $\mathrm{CO}_{2}$ diffusion and rapid reaction rates, are reduced.

The corresponding input and some output files are given in the distribution CD (subdirectory: /sample-problems/P4_EOS4_heat-test). To shorten the simulation time for installation, the simulation time step variable, MCYC, in the PARAM input block of flow.inp is specified as 99. For the full simulation, users can reset MCYC to 9999. In TOUGHREACT, if MCYC $=9999$, the simulation time is not controlled by MCYC, and is only controlled by TIMAX in Record PARAM.2 (see section 6.1). Parts of output files for fluid flow, aqueous chemical concentrations, and changes of mineral abundances are given in Figures 8.4.2, 8.4.3 and 8.4.4. 
Figure 8.4.4. Part of file tec_min.dat for problem no. 4, giving changes in mineral abundances (in volume fraction, positive values indicate precipitation and negative dissolution) after $\mathrm{t}=0.237909$ yr.

\begin{tabular}{|c|c|c|c|c|c|c|}
\hline $\mathrm{X}$ & Z & hematite & calcite & microcline & albite-low & anorthite \\
\hline 1.999 & -1.534 & $-0.3450 E-16$ & $0.2265 E-05$ & $-0.3190 \mathrm{E}-08$ & $-0.1235 E-07$ & $-0.3164 \mathrm{E}-11$ \\
\hline 1.999 & -1.534 & $-0.6980 \mathrm{E}-16$ & $0.1734 \mathrm{E}-06$ & $0.2155 \mathrm{E}-05$ & $-0.2688 E-05$ & $-0.4152 \mathrm{E}-08$ \\
\hline 2.039 & -1.565 & $-0.4763 E-16$ & $0.1999 \mathrm{E}-05$ & $-0.3319 E-08$ & $-0.1234 E-07$ & $-0.3165 E-11$ \\
\hline 2.039 & -1.565 & $-0.5399 E-16$ & $0.1710 \mathrm{E}-06$ & $0.1842 \mathrm{E}-05$ & $-0.2411 \mathrm{E}-05$ & $-0.4154 \mathrm{E}-08$ \\
\hline 2.102 & -1.613 & $-0.4830 E-16$ & $0.1748 E-05$ & $-0.3341 E-08$ & $-0.1227 E-07$ & $-0.3148 E-11$ \\
\hline 2.102 & -1.613 & $-0.5556 E-16$ & $0.1669 \mathrm{E}-06$ & $0.1808 E-05$ & $-0.2382 E-05$ & $-0.4157 E-08$ \\
\hline 2.182 & -1.674 & $-0.4385 E-16$ & $0.1501 E-05$ & $-0.3315 E-08$ & $-0.1213 E-07$ & $-0.3110 E-11$ \\
\hline 2.182 & -1.674 & $-0.5756 E-16$ & $0.1627 \mathrm{E}-06$ & $0.1806 \mathrm{E}-05$ & $-0.2381 E-05$ & $-0.4160 \mathrm{E}-08$ \\
\hline 2.261 & -1.735 & $-0.3882 E-16$ & $0.1293 E-05$ & $-0.3275 E-08$ & $-0.1195 E-07$ & $-0.3062 E-11$ \\
\hline 2.261 & -1.735 & $-0.5950 E-16$ & $0.1592 \mathrm{E}-06$ & $0.1805 \mathrm{E}-05$ & $-0.2382 E-05$ & $-0.4163 E-08$ \\
\hline 2.340 & -1.796 & $-0.3402 E-16$ & $0.1117 \mathrm{E}-05$ & $-0.3229 E-08$ & $-0.1175 \mathrm{E}-07$ & $-0.3011 E-11$ \\
\hline 2.340 & -1.796 & $-0.6123 E-16$ & $0.1563 E-06$ & $0.1805 E-05$ & $-0.2383 E-05$ & $-0.4167 E-08$ \\
\hline 2.459 & -1.887 & $-0.2884 E-16$ & $0.9019 E-06$ & $-0.3157 E-08$ & $-0.1145 E-07$ & $-0.2933 E-11$ \\
\hline 2.459 & -1.887 & $-0.6407 E-16$ & $0.1530 E-06$ & $0.1804 E-05$ & $-0.2384 E-05$ & $-0.4171 E-08$ \\
\hline 2.618 & -2.009 & $-0.2427 E-16$ & $0.6859 E-06$ & $-0.3068 E-08$ & $-0.1108 \mathrm{E}-07$ & $-0.2838 E-11$ \\
\hline 2.618 & -2.009 & $-0.6748 E-16$ & $0.1499 \mathrm{E}-06$ & $0.1803 E-05$ & $-0.2386 E-05$ & $-0.4176 \mathrm{E}-08$ \\
\hline 2.777 & -2.131 & $-0.2044 \mathrm{E}-16$ & $0.5270 E-06$ & $-0.2985 E-08$ & $-0.1074 \mathrm{E}-07$ & $-0.2752 E-11$ \\
\hline 2.777 & -2.131 & $-0.7074 E-16$ & $0.1477 E-06$ & $0.1802 \mathrm{E}-05$ & $-0.2387 E-05$ & $-0.4181 E-08$ \\
\hline 2.975 & -2.283 & $-0.1722 E-16$ & $0.3847 E-06$ & $-0.2896 E-08$ & $-0.1038 E-07$ & $-0.2660 \mathrm{E}-11$ \\
\hline 2.975 & -2.283 & $-0.7436 E-16$ & $0.1461 E-06$ & $0.1801 E-05$ & $-0.2388 E-05$ & $-0.4187 \mathrm{E}-08$ \\
\hline 3.213 & -2.465 & $-0.1472 E-16$ & $0.2656 \mathrm{E}-06$ & $-0.2798 E-08$ & $-0.1001 E-07$ & $-0.2563 E-11$ \\
\hline 3.213 & -2.465 & $-0.7846 \mathrm{E}-16$ & $0.1450 \mathrm{E}-06$ & $0.1801 \mathrm{E}-05$ & $-0.2389 E-05$ & $-0.4192 E-08$ \\
\hline 3.768 & -2.892 & $-0.1278 E-16$ & $0.1218 E-06$ & $-0.2611 E-08$ & $-0.9329 E-08$ & $-0.2389 E-11$ \\
\hline 3.768 & -2.892 & $-0.8602 E-16$ & $0.1448 \mathrm{E}-06$ & $0.1799 \mathrm{E}-05$ & $-0.2391 E-05$ & $-0.4202 E-08$ \\
\hline
\end{tabular}

\subsubsection{Model results and comparisons to measured data}

\section{Gas-Phase $\mathrm{CO}_{2}$ Evolution}

The concentration of $\mathrm{CO}_{2}$ in the gas phase is a function of temperature, pressure, aqueousphase chemistry, mineral-water reactions, and advective and diffusive transport. Simulation results are compared to concentrations measured in gas samples taken from boreholes during the heating phase of the DST. The modeled evolution of $\mathrm{CO}_{2}$ has been validated by comparison to over 4 years of measurements from the Drift Scale Test. Simulated $\mathrm{CO}_{2}$ concentrations in the fracture gas phase are shown after 3 years of heating in Figure 8.4.5. The results show the general outward migration of elevated $\mathrm{CO}_{2}$ concentrations as the boiling front moves outward. The peak in $\mathrm{CO}_{2}$ concentrations is centered at approximately the $60^{\circ} \mathrm{C}$ isotherm, and at higher temperatures the concentrations generally decline as a result of degassing and transport with water vapor to cooler regions. 


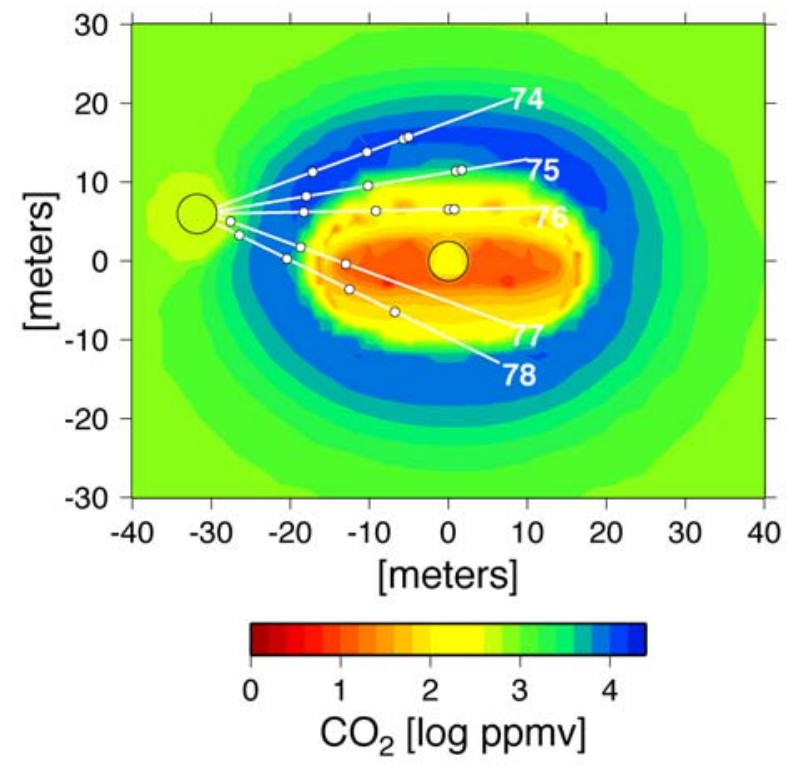

Figure 8.4.5. Modeled gas phase $\mathrm{CO}_{2}$ concentrations in fractures after 3 years of heating. Note locations of numbered boreholes collared in the Observation Drift (circular region at left).

Comparisons of modeled $\mathrm{CO}_{2}$ concentrations to measurements performed on gas samples from boreholes (shown in Figure 8.4.5) are presented in Figure 8.4.6. Samples were collected from zones a few meters (borehole interval 76-3) to about 15 meters away from the Heated Drift (borehole interval 74-3). Measured concentrations were corrected for water vapor condensation that took place as part of the procedure for gas sampling. Zones closest to the heaters (interval 763) exhibit narrower and earlier peaks in concentration compared to zones further out in the rock (interval 74-3). Simulated and measured concentrations are close in magnitude and in their trends. There is little difference between fracture and matrix concentrations, because of rapid equilibration by advection and diffusion of gas species and their local equilibration with pore water. 

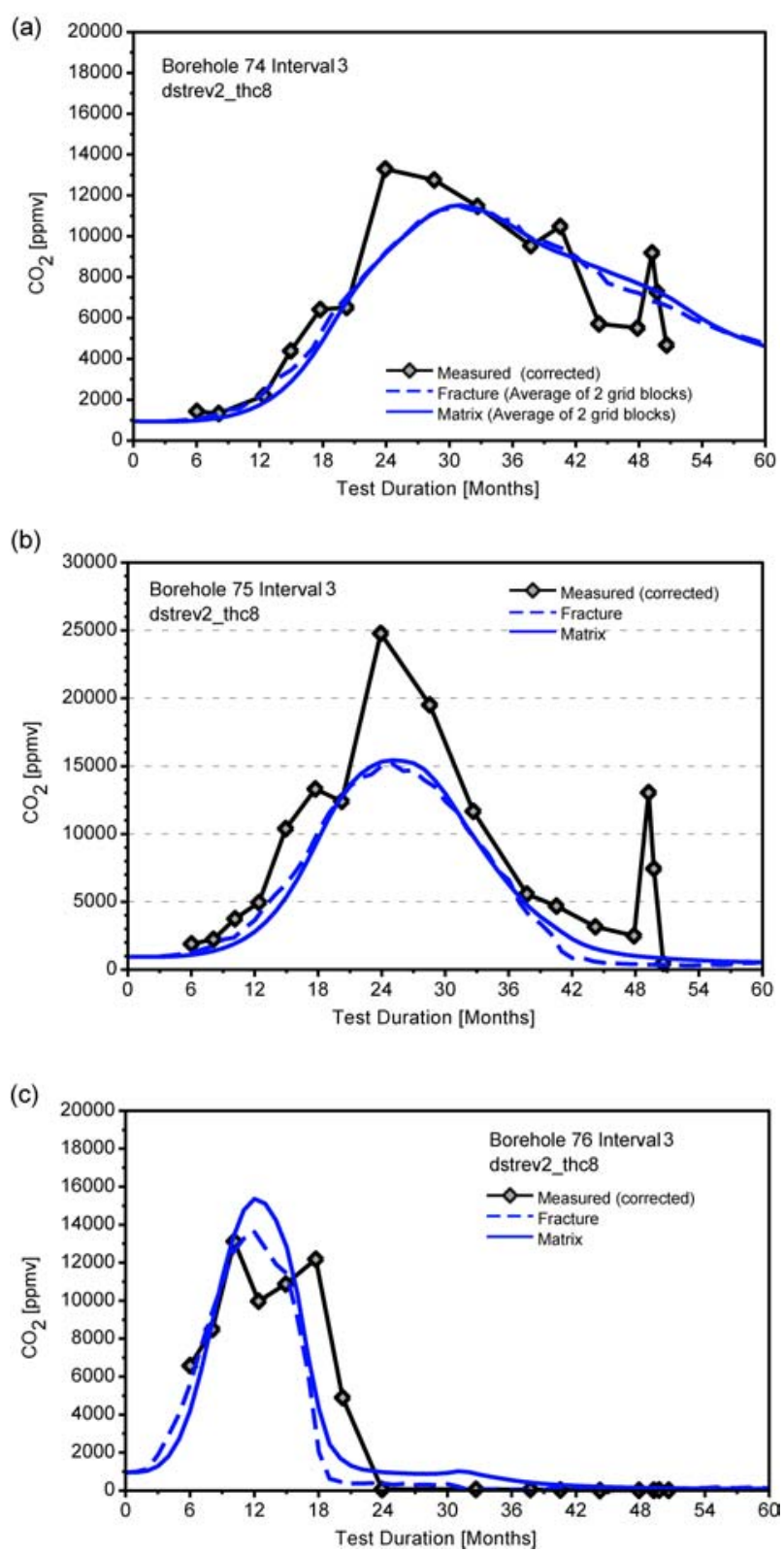

Figure 8.4.6. Modeled $\mathrm{CO}_{2}$ concentrations in fractures and matrix compared to measured values from boreholes (corrected for vapor condensation) (a) Borehole interval 74-3 (average of bounding grid blocks); (b) Borehole interval 75-3; (c) Borehole interval 76-3.

\section{Aqueous Species Evolution}

Aqueous species in waters collected in the DST exhibit small reductions in $\mathrm{pH}$, from about $\mathrm{pH} 8$ in the pore water to about 6-8 in condensate waters. The drop in $\mathrm{pH}$ is related to the local increases in $\mathrm{CO}_{2}$ concentrations. Figure 8.4.7 shows an example of the initial drop in $\mathrm{pH}$ 
during vapor condensation, followed by increasing $\mathrm{pH}$ as the zone is further heated and $\mathrm{CO}_{2}$ is diluted by water vapor.

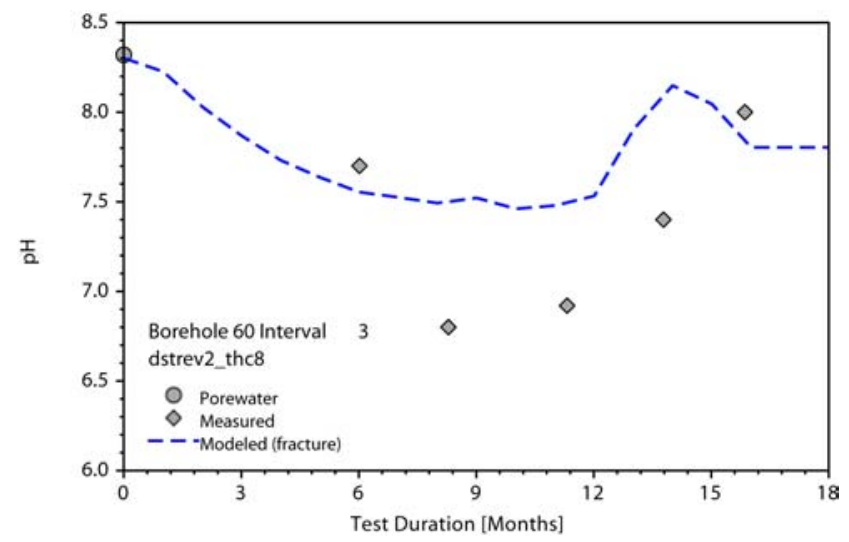

Figure 8.4.7. Measured and modeled $\mathrm{pH}$ (in fractures) for samples collected from borehole interval 60-3, located below the heaters.

Simulated and measured concentrations of conservative species in the fractures, such as chloride, are much lower than in the initial matrix pore water, indicating that fracture-matrix interaction has been negligible. However, reactive species, such as silica and potassium show significant effects of reaction with fracture-lining silicate minerals.

\section{Mineral Precipitation/Dissolution}

Model predictions, followed by analyses of in-situ sidewall core samples, showed that amorphous silica, calcite and lesser amounts of gypsum are the dominant precipitating phases expected in the boiling regions. The greatest amount of mineral precipitation is predicted to be above the heaters where reflux of water condensed in fractures dissolves fracture-lining minerals and is boiled. Simulations and measurements of amorphous silica and calcite, along with locations of observed mineralization are shown in Figures 8.4.8 and 8.4.9. Amorphous silica forms only where strong evaporation by boiling takes place. Calcite also forms in the boiling zones, however calcite that is originally present in fractures dissolves in the lower $\mathrm{pH}$ waters that formed in condensation zones around the boiling zone and in the drainage zones below the heaters. 


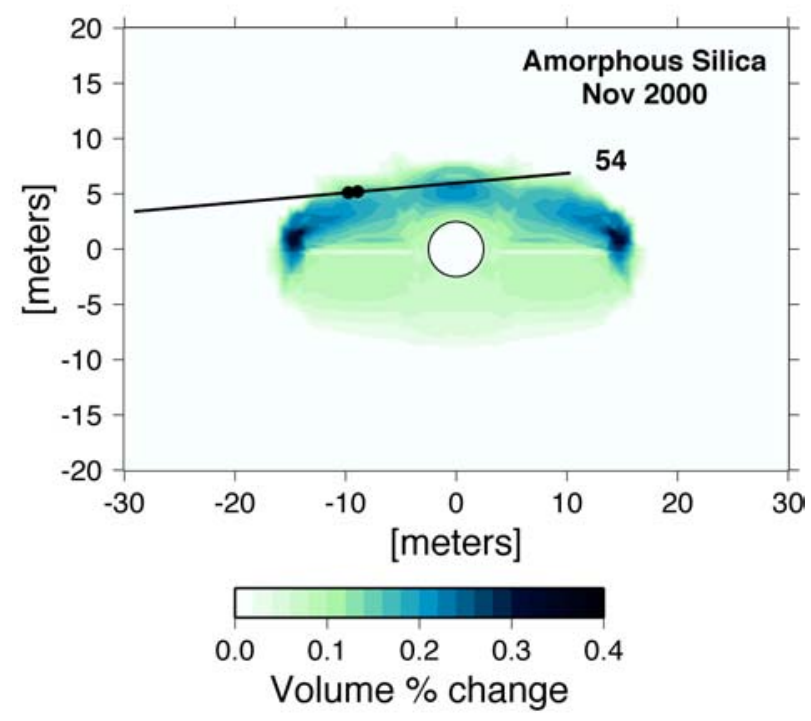

Figure 8.4.8. Volume percent change in amorphous silica abundance in fractures. Filled circle indicates sidewall core sample locations where it was observed.

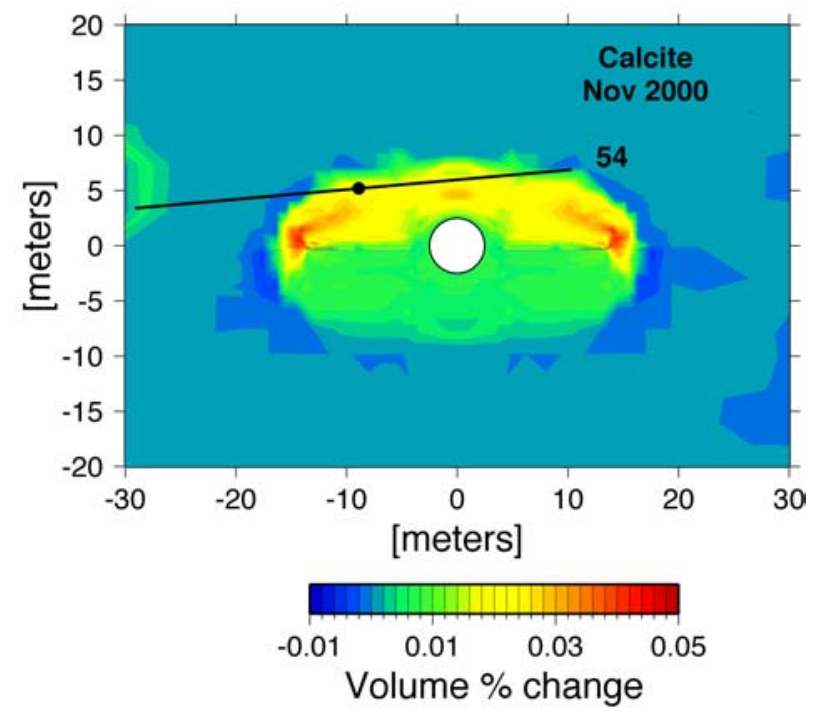

Figure 8.4.9. Volume percent change in calcite abundance in fractures. Filled circle indicates sidewall core sample locations where it was observed. 


\section{5. $\mathrm{CO}_{2}$ Disposal in Deep Saline Aquifers (ECO2N)}

\subsubsection{Problem statement}

The feasibility of storing $\mathrm{CO}_{2}$ in deep geologic formations has been discussed in the technical literature over the last decade. Studies include an evaluation of the feasibility of $\mathrm{CO}_{2}$ aquifer storage in The Netherlands (Lohuis, 1993) and in the Alberta Basin, Canada (Gunter et al., 1993; Bachu et al., 1994; Law and Bachu 1996; Gunter et al., 1996 and 1997). Furthermore, large-scale $\mathrm{CO}_{2}$ disposal in an aquifer is already being practiced in the Norwegian sector of the North Sea (Korbol and Kaddour, 1995).

Carbon dioxide is retained in geologic formations in three ways (Hitchon, 1996). First, $\mathrm{CO}_{2}$ can be trapped as a gas or supercritical fluid under a low-permeability caprock. This process, commonly called hydrodynamic trapping, will likely be, in the short term, the most important mechanism of retention. Second, $\mathrm{CO}_{2}$ can dissolve into the groundwater, referred to as a solubility trapping. The dissolution of $\mathrm{CO}_{2}$ in groundwater increases the acidity of water and affects the solubilities of minerals composing the host rock matrix. Third, $\mathrm{CO}_{2}$ can react directly or indirectly with minerals and organic matter in the geologic formation leading to the precipitation of secondary carbonates. The latter process, so-called "mineral trapping", is attractive because it could immobilize $\mathrm{CO}_{2}$ for long time scales, and prevent its easy return to the atmosphere. The interaction of $\mathrm{CO}_{2}$ with alkaline aluminosilicate minerals will also result in the formation of dissolved alkali carbonates and bicarbonates, thereby enhancing "solubility trapping".

Numerical modeling of geochemical processes is a necessary tool for investigating the long-term consequences of $\mathrm{CO}_{2}$ disposal in deep formations, because alteration of the predominant host rock aluminosilicate minerals is very slow and is not experimentally accessible under ambient deep-aquifer conditions. Johnson et al. (2001) simulated $\mathrm{CO}_{2}$ injection at Statoil's North-Sea Sleipner facility and analyzed the coupled process mechanisms that lead to hydrodynamic, solubility, and mineral trapping, as well as the relative effectiveness of the distinct sequestration processes as a function of key reservoir properties. McPherson and Lichtner (2001) used a sedimentary basin model, including multiphase flow of $\mathrm{CO}_{2}$, groundwater, and brine, to evaluate resident times in possible aquifer storage sites and migration patterns and rates away 
from such sites in the Powder River Basin of Wyoming. Xu et al. (2004a) performed batch geochemical modeling for three different formation mineralogies in the presence of $\mathrm{CO}_{2}$ at high pressure. The modeling included (1) redox processes that could be important in deep subsurface environments, (2) the presence of organic matter, (3) the kinetics of chemical interactions between the host rock minerals and the aqueous phase, and (4) $\mathrm{CO}_{2}$ solubility dependence on pressure, temperature and salinity of the system (see Eq. B.14 through B.17 in Appendix B).

During large-scale injection of $\mathrm{CO}_{2}$ into deep formations, geochemical processes are strongly affected by physical processes such as multiphase fluid flow and solute transport. Fluid pressures will rise as $\mathrm{CO}_{2}$ displaces formation water in which it partly dissolves. The dissolution of primary and precipitation of secondary minerals change formation porosity and permeability, and could alter fluid flow patterns. All coupled hydrologic and chemical processes affect the feasibility of $\mathrm{CO}_{2}$ injection and storage in deep formations. Uncoupled batch geochemical modeling and flow simulation are inadequate to describe the complex subsurface physical and chemical interactions expected to occur. A systematic process-based understanding of the coupled physical and chemical phenomena is required.

\subsubsection{Definition of test problem}

The response of deep formations to $\mathrm{CO}_{2}$ injection will depend on many factors, including formation permeability and porosity, the presence of heterogeneities such as faults and layers of high or low permeability, the physical and chemical characteristics of the brines, and the nature of the mineral phases that are present. A great deal of specific and detailed information will be required to assess the feasibility of disposing of $\mathrm{CO}_{2}$ in a brine formation at any particular site, and to develop engineering designs for $\mathrm{CO}_{2}$ disposal systems. A basic issue in geologic disposal of $\mathrm{CO}_{2}$ is the physical and chemical behavior in the vicinity of a $\mathrm{CO}_{2}$ injection well. Previous numerical studies have investigated simple models of one- and two-dimensional radial flow to examine the displacement of formation waters by injected $\mathrm{CO}_{2}$ (Pruess and Garcia, 2002; Pruess et al., 2003). These studies have provided initial insight into issues regarding volumetric sweep, $\mathrm{CO}_{2}$ storage capacity, and pressurization processes that would arise from large-scale $\mathrm{CO}_{2}$ injection. Exploratory studies of geochemical effects have also been conducted, using a zerodimensional batch reaction approach to model the chemical reactions that would take place when different mineral assemblages are exposed to $\mathrm{CO}_{2}$ at high pressures in the presence of brine 
(Perkins and Gunter, 1996; Gunter et al., 1997; Xu et al., 2004a). The present study combines the simple 1-D radial model previously investigated by Pruess et al. (2003) with the batch chemical reaction model of $\mathrm{Xu}$ et al. (2004a), to model the coupled processes of fluid flow and chemical reactions near a $\mathrm{CO}_{2}$ injection well.

\section{Geologic formation}

The setup of the problem is similar to that of $\mathrm{Xu}$ et al. (2003b), except using the following (1) a porosity of 0.3 not 0.1 , (2) a temperature of $75^{\circ} \mathrm{C}$ (at about $2000 \mathrm{~m}$ depth) instead of $40^{\circ} \mathrm{C}$, (3) improved mineralogical composition, and kinetic rate law and parameters.

The geologic formation is assumed to be infinitely long and homogeneous with a thickness of $100 \mathrm{~m}$, containing $1 \mathrm{M} \mathrm{NaCl}$ brine at a constant temperature of $75^{\circ} \mathrm{C}$. A 1-D radial model is used. This simplification does not consider non-uniform sweep that may occur due to formation heterogeneities, or due to buoyancy forces that would tend to drive $\mathrm{CO}_{2}$ towards the top of the aquifer. Some justification for a 1-D approach can be derived from the slow rates and long time scales of geochemical changes, which will cause processes to play out over time that will make the distribution of $\mathrm{CO}_{2}$ more uniform. Initially, injected $\mathrm{CO}_{2}$ will tend to accumulate and spread out near the top of permeable intervals, partially dissolving in the aqueous phase. $\mathrm{CO}_{2}$ dissolution causes the aqueous-phase density to increase by a few percent. This will give rise to buoyant convection where waters enriched in $\mathrm{CO}_{2}$ will tend to migrate downward (Weir et al., 1995; Garcia, 2001). The process of $\mathrm{CO}_{2}$ dissolution and subsequent aqueous phase convection will tend to mix aqueous $\mathrm{CO}_{2}$ in the vertical direction. The time scale for significant convective mixing is likely to be slow (of the order of hundreds of years or more; Ennis-King and Paterson, 2003), and may be roughly comparable to time scales for significant geochemical interactions of $\mathrm{CO}_{2}$.

The well field is modeled as a circular region of $10,000 \mathrm{~m}$ radius, at the center of which $\mathrm{CO}_{2}$ is injected uniformly at a constant rate of $90 \mathrm{~kg} / \mathrm{s}$. A 1-D radial grid was used with a spacing gradually increasing away from the well. The $\mathrm{CO}_{2}$ injection was assumed to continue for a period of 10 years. The fluid flow and geochemical transport simulation was run for a period of 1,000 years. 
Table 8.5.1. Hydrogeologic parameters for the radial fluid flow problem.

\begin{tabular}{|c|c|}
\hline $\begin{array}{l}\text { Aquifer thickness } \\
\text { Permeability } \\
\text { Porosity } \\
\text { Compressibility } \\
\text { Temperature } \\
\text { Pressure } \\
\text { Salinity } \\
\mathrm{CO}_{2} \text { injection rate }\end{array}$ & $\begin{array}{l}100 \mathrm{~m} \\
10^{-13} \mathrm{~m}^{2} \\
0.30 \\
4.5 \times 10^{-10} \mathrm{~Pa}^{-1} \\
75^{0} \mathrm{C} \\
200 \mathrm{bar} \\
0.06 \text { (mass fraction) } \\
90 \mathrm{~kg} / \mathrm{s}\end{array}$ \\
\hline \multicolumn{2}{|l|}{ Relative permeability } \\
\hline \multicolumn{2}{|l|}{ Liquid (van Genuchten, 1980): } \\
\hline $\mathrm{k}_{\mathrm{rl}}=\sqrt{\mathrm{S}^{*}}\left\{1-\left(1-\left[\mathrm{S}^{*}\right]^{1 / \mathrm{m}}\right)^{\mathrm{m}}\right\}^{2}$ & $\mathrm{~S}^{*}=\left(\mathrm{S}_{1}-\mathrm{S}_{\mathrm{lr}}\right) /\left(1-\mathrm{S}_{\mathrm{lr}}\right)$ \\
\hline $\begin{array}{l}\text { irreducible water saturation } \\
\text { exponent }\end{array}$ & $\begin{array}{l}\mathrm{S}_{1 \mathrm{r}}=0.30 \\
\mathrm{~m}=0.457\end{array}$ \\
\hline \multicolumn{2}{|l|}{ Gas (Corey, 1954): } \\
\hline $\mathrm{k}_{\mathrm{rg}}=(1-\widehat{\mathrm{S}})^{2}\left(1-\widehat{\mathrm{S}}^{2}\right)$ & $\widehat{\mathrm{S}}=\frac{\left(\mathrm{S}_{1}-\mathrm{S}_{\mathrm{lr}}\right)}{\left(\mathrm{S}_{1}-\mathrm{S}_{\mathrm{lr}}-\mathrm{S}_{\mathrm{gr}}\right)}$ \\
\hline irreducible gas saturation & $\mathrm{S}_{\mathrm{gr}}=0.05$ \\
\hline \multicolumn{2}{|l|}{ Capillary pressure } \\
\hline $\begin{array}{l}\text { van Genuchten }(1980) \\
\qquad \mathrm{P}_{\text {cap }}=-\mathrm{P}_{0}\left(\left[\mathrm{~S}^{*}\right]^{-1 / \mathrm{m}}-1\right)^{1-\mathrm{m}}\end{array}$ & $\mathrm{S}^{*}=\left(\mathrm{S}_{1}-\mathrm{S}_{\mathrm{lr}}\right) /\left(1-\mathrm{S}_{\mathrm{lr}}\right)$ \\
\hline $\begin{array}{l}\text { irreducible water saturation } \\
\text { exponent } \\
\text { strength coefficient }\end{array}$ & $\begin{array}{l}\mathrm{S}_{\mathrm{lr}}=0.00 \\
\mathrm{~m}=0.457 \\
\mathrm{P}_{0}=19.61 \mathrm{kPa}\end{array}$ \\
\hline
\end{tabular}

\section{Geochemical system}

A proxy for sediment from the United States Gulf Coast, modified from that originally presented by Apps (1996), was used for the reactive geochemical transport simulations. The mineralogy is similar to that commonly encountered in sedimentary basins. Apps (1996) presented a batch geochemical simulation of the evolution of Gulf Coast sediments as a basis for interpreting the chemical processes relating to the deep injection disposal of hazardous and industrial wastes.

The initial mineral abundances are shown in Table 8.5.2. The specification of formation mineralogy is determined in part by the availability of data. Most studies related to the Tertiary 
Gulf Coast sediments are concentrated in the state of Texas. The principal reservoir-quality sandstones within that region are respectively, the Frio, the Vicksberg and the Wilcox formations, all of which are found within the lower Tertiary. Of the three formations, the Frio was chosen as a representative candidate for the sequestration of supercritical carbon dioxide. It is the shallowest of the three formations, but over much of its areal extent, it is located at depths between 5,000 and 20,000 ft, depths sufficient to ensure adequate $\mathrm{CO}_{2}$ densities for effective storage.

Calcite was assumed to react with aqueous species at local equilibrium because its reaction rate is typically quite rapid. Dissolution and precipitation of other minerals are kinetically-controlled. Kinetic rates are a product of the rate constant and reactive surface area (Eq. B.5 in Appendix B). Multiple mechanisms (including neutral, acid and base) are used for dissoluton of minerals (Eqs. B.11 and B.12 in Appendix B). Kinetic parameters: rate constant $\left(\mathrm{k}_{25}\right)$, the activation energy $\left(\mathrm{E}_{\mathrm{a}}\right)$, and the power term $(\mathrm{n})$ for each mechanism are listed in Table 8.5.2. At any $\mathrm{pH}$ the total rate is the sum of the rates via each mechanism. Most of these parameters were taken from Palandri and Kharaka (2004) who compiled and fitted many experimental data reported by a large number of investigators. Parameters for illite were set to those of smectite. Acid $\mathrm{pH}$ parameters for siderite, ankerite, and dawsonite were set to those of dolomite. Neutral $\mathrm{pH}$ parameters for siderite were taken from Steefel (2001). Neutral pH parameters for ankerite and dawsonite are set to those of siderite.

Precipitation rate data do not exist for most minerals. Several aspects regarding precipitation are different from dissolution, including nucleation, crystal growth and Ostwald ripening processes, as well as the calculation of the reactive surface area (Steefel and van Capellen, 1990). These processes for mineral precipitation are not considered. Parameters for neutral $\mathrm{pH}$ in Table 8.5.2 were used for precipitation of the corresponding minerals. Notice that different sets of parameters for precipitation can be specified in the chemical input file of TOUGHREACT code.

The evolution of surface area in natural geologic media is complex, especially for multimineralic systems, and is not quantitatively understood at present. Mineral reactive surface areas (the third column of Table 8.5.2) were taken from Sonnenthal and Spycher (2001), which were calculated using a cubic array of truncated spheres that make up the framework of the rock. For clay minerals kaolinite, illite, and smectite, increased surface areas were based on the smaller grain sizes of these sheet silicate minerals (Nagy, 1995). A reactive surface area calculated from 
grain size may be a poor estimate of the hydrologically accessible mineral surface area. To account for this effect, surface areas listed in Table 8.5.2 were reduced by one order of magnitude in the present simulations. The magnitudes of surface areas are highly uncertain and cover a wide range of values. Sensitivity regarding the kinetic rate constants and reactive surface areas should be addressed in the future.

Prior to $\mathrm{CO}_{2}$ injection, a simulation of water-rock interaction was performed to obtain a nearly equilibrated water chemistry using a pure $1.0 \mathrm{M}$ solution of sodium chloride reacting with the primary minerals listed in Table 8.5.2 at a temperature of $75{ }^{\circ} \mathrm{C}$. The resulting water chemistry was used for the initial condition of reactive geochemical transport simulations under $\mathrm{CO}_{2}$ injection. 
Table 8.5.2. Initial mineral volume fractions, possible secondary mineral phases, and their kinetic properties. Note that: (1) all rate constants are listed for dissolution; (2) A is the reactive surface area (Eq. B.5 in Appendix B), $\mathrm{k}_{25}$ is the kinetic constant at $25^{\circ} \mathrm{C}, \mathrm{E}_{\mathrm{a}}$ is activation energy, and $\mathrm{n}$ is the power (Eq. B.11); (3) the power terms $\mathrm{n}$ for both acid and base mechanisms are with respect to $\mathrm{H}^{+}$, (4) for pyrite, the neutral mechanism has a $\mathrm{n}$ with respect to $\mathrm{O}_{2}(\mathrm{aq})$, the acid mechanism has two species involved: one $\mathrm{n}$ with respect to $\mathrm{H}^{+}$and another $\mathrm{n}$ with respect to $\mathrm{Fe}^{3+}$ (see Eq. B.12); (5) dolomite, Ca-smectite, and pyrite were included in the list of possible secondary mineral phases in the input but they were not formed during the simulation.

\begin{tabular}{|c|c|c|c|c|c|c|c|c|c|c|}
\hline \multirow{3}{*}{ Mineral } & \multirow{3}{*}{$\begin{array}{l}\text { Vol.\% } \\
\text { Of } \\
\text { solid }\end{array}$} & \multirow{3}{*}{$\begin{array}{l}\text { A } \\
\left(\mathrm{cm}^{2} / \mathrm{g}\right)\end{array}$} & \multicolumn{8}{|c|}{ Parameters for kinetic rate law } \\
\hline & & & \multicolumn{2}{|c|}{ Neutral mechanism } & \multicolumn{3}{|c|}{ Acid mechanism } & \multicolumn{3}{|c|}{ Base mechanism } \\
\hline & & & $\begin{array}{l}\mathrm{k}_{25} \\
\left(\mathrm{~mol} / \mathrm{m}^{2} / \mathrm{s}\right)\end{array}$ & $\begin{array}{l}\mathrm{E}_{\mathrm{a}} \\
(\mathrm{KJ} \\
/ \mathrm{mol})\end{array}$ & $\mathrm{k}_{25}$ & $\mathrm{E}_{\mathrm{a}}$ & $\mathrm{n}\left(\mathrm{H}^{+}\right)$ & $\mathrm{k}_{25}$ & $\mathrm{E}_{\mathrm{a}}$ & $\mathrm{n}\left(\mathrm{H}^{+}\right)$ \\
\hline \multicolumn{11}{|l|}{ Primary: } \\
\hline Quartz & 57.888 & 9.8 & $1.023 \times 10^{-14}$ & 87.7 & & & & & & \\
\hline Kaolinite & 2.015 & 151.6 & $6.918 \times 10^{-14}$ & 22.2 & $4.898 \times 10^{-12}$ & 65.9 & 0.777 & $8.913 \times 10^{-18}$ & 17.9 & -0.472 \\
\hline Calcite & 1.929 & \multicolumn{9}{|c|}{ Assumed at equilibrium } \\
\hline Illite & 0.954 & 151.6 & $1.660 \times 10^{-13}$ & 35 & $1.047 \times 10^{-11}$ & 23.6 & 0.34 & $3.020 \times 10^{-17}$ & 58.9 & -0.4 \\
\hline Oligoclase & 19.795 & 9.8 & $1.445 \times 10^{-13}$ & 69.8 & $2.138 \times 10^{-11}$ & 65 & 0.457 & & & \\
\hline K-feldspar & 8.179 & 9.8 & $3.890 \times 10^{-13}$ & 38 & $8.710 \times 10^{-11}$ & 51.7 & 0.5 & $6.310 \times 10^{-12}$ & 94.1 & -0.823 \\
\hline Na-smectite & 3.897 & 151.6 & $1.660 \times 10^{-13}$ & 35 & $1.047 \times 10^{-11}$ & 23.6 & 0.34 & $3.020 \times 10^{-17}$ & 58.9 & -0.4 \\
\hline Chlorite & 4.556 & 9.8 & $3.02 \times 10^{-13}$ & 88 & $7.762 \times 10^{-12}$ & 88 & 0.5 & & & \\
\hline Hematite & 0.497 & 12.9 & $2.512 \times 10^{-15}$ & 66.2 & $4.074 \times 10^{-10}$ & 66.2 & 1 & & & \\
\hline \multicolumn{11}{|l|}{ Secondary: } \\
\hline Magnesite & & 9.8 & $4.571 \times 10^{-10}$ & 23.5 & $4.169 \times 10^{-7}$ & 14.4 & 1 & & & \\
\hline Dolomite & & 9.8 & $2.951 \times 10^{-8}$ & 52.2 & $6.457 \times 10^{-4}$ & 36.1 & 0.5 & & & \\
\hline Low-albite & & 9.8 & $2.754 \times 10^{-13}$ & 69.8 & $6.918 \times 10^{-11}$ & 65 & 0.457 & $2.512 \times 10^{-16}$ & 71 & -0.572 \\
\hline Siderite & & 9.8 & $1.260 \times 10^{-9}$ & 62.76 & $6.457 \times 10^{-4}$ & 36.1 & 0.5 & & & \\
\hline Ankerite & & 9.8 & $1.260 \times 10^{-9}$ & 62.76 & $6.457 \times 10^{-4}$ & 36.1 & 0.5 & & & \\
\hline Dawsonite & & 9.8 & $1.260 \times 10^{-9}$ & 62.76 & $6.457 \times 10^{-4}$ & 36.1 & 0.5 & & & \\
\hline Ca-smectite & & 151.6 & $1.660 \times 10^{-13}$ & 35 & $1.047 \times 10^{-11}$ & 23.6 & 0.34 & $3.020 \times 10^{-17}$ & 58.9 & -0.4 \\
\hline Pyrite & & 12.9 & $\begin{array}{l}\mathrm{k}_{25}=2.818 \times 1 \\
\mathrm{E}_{\mathrm{a}}=56.9 \\
\mathrm{n}\left(\mathrm{O}_{2}(\mathrm{aq})\right)=0\end{array}$ & & $\begin{array}{l}\mathrm{k}_{25}=3.02 \times 10 \\
\mathrm{E}_{\mathrm{a}}=56.9 \\
\mathrm{n}\left(\mathrm{H}^{+}\right)=-0.5,\end{array}$ & $\mathrm{n}(\mathrm{F}$ & $+{ }^{+}=0.5$ & & & \\
\hline
\end{tabular}

A new fluid property module, $\mathrm{ECO} 2 \mathrm{~N}$, was used for this $\mathrm{CO}_{2}$ disposal problem. $\mathrm{ECO} 2 \mathrm{~N}$ is based on work by Spycher and Pruess (2005), and provides an accurate description of the thermophysical properties of mixtures of water and $\mathrm{CO}_{2}$ under conditions typically encountered in saline aquifers of interest for $\mathrm{CO}_{2}$ disposal $\left(10{ }^{\circ} \mathrm{C} \leq \mathrm{T} \leq 110{ }^{\circ} \mathrm{C} ; \mathrm{P} \leq 600\right.$ bars $)$. Details on this new fluid property module can be found in $\mathrm{ECO} 2 \mathrm{~N}$ manual (in the distribution $\mathrm{CD}$ : subdirectory: $\sim$ documents/ECO2N_manual.pdf). 
As mentioned above, the reactive transport simulation was performed for a time period of 1,000 years. To demonstrate the RESTART feature, we performed a series of two TOUGHREACT runs. The first run was performed for 10 years. The input and major output files for the first run are given in the distribution CD (subdirectory: /sample-problems/P5_ECO2N1Dradial). Parts of output files for fluid flow, aqueous chemical concentrations, and changes of mineral abundances are given in Figures 8.5.1, 8.5.2 and 8.5.3. For the continuation run (restart) to $1,000 \mathrm{yr}$, we create a new subdirectory $\sim / \mathrm{P} 5$ _ECO2N-1Dradial/restart, into which we copy the input files (flow.inp, solute.inp, chemical.inp, databas1.dat), the $\mathrm{CO} 2$ property file (CO2TAB), and the files SAVE and savechem from the first run. File SAVE is renamed INCON, savechem is renamed inchem, and the following minor changes are made in flow.inp: delete the INCON input block, and change the final simulation time from 3.15576E08 (10 years) to $3.15576 \mathrm{E} 10(1,000$ years) in the PARAM input block. Now we can perform the restart run. Major output files from the restart run are also in subdirectory: / P5_ECO2N-1Dradial/restart. Changes in porosity and permeability due to mineral dissolution and precipitation, consumption of $\mathrm{CO}_{2}$ due to formation of carbonate minerals, consumption of $\mathrm{H}_{2} \mathrm{O}$ due to hydroration reactions affect the multiphase fluid flow. For longer time simulation, these feedback effects should be coupled. This option can be used by specifying $\mathrm{kcpl}=1$ (porosity and permeability coupling) and Ico2h2o $=2\left(\mathrm{CO}_{2}\right.$ and $\mathrm{H}_{2} \mathrm{O}$ coupling) in input file solute.inp. However, if the coupling options are used, the convergence for solving flow equations could be slower.

An important feature for ECO2N module (and also EOS2) from other modules is that partial pressures of $\mathrm{CO}_{2}$ gas are calculated from fluid flow calculations and then fed to geochemistry. In contrast, with the EOS3 and EOS4 modules, $\mathrm{CO}_{2}$ is assumed to be a trace gas and transported with the bulk gas phase by advection and diffusion. With $\mathrm{EOS} 9, \mathrm{CO}_{2}$ is also assumed to be a trace gas but is transported only by diffusion because the bulk gas phase is not considered. With the ECO2N (or EOS2), if the $\mathrm{CO}_{2}$ partial pressure in block 'INITIAL gas ZONES' of chemical.inp (see the file chemical.inp in the distribution $\mathrm{CD}$ ) is greater than zero, this partial pressure is taken as the background partial pressure (regions not flooded with the injected $\mathrm{CO}_{2}$ ). If this value is set to zero, no background $\mathrm{CO}_{2}$ partial pressure buffer is allowed. 
Figure 8.5.1. Part of file flow.out for problem no. $5\left(\mathrm{CO}_{2}\right.$ disposal $)$.

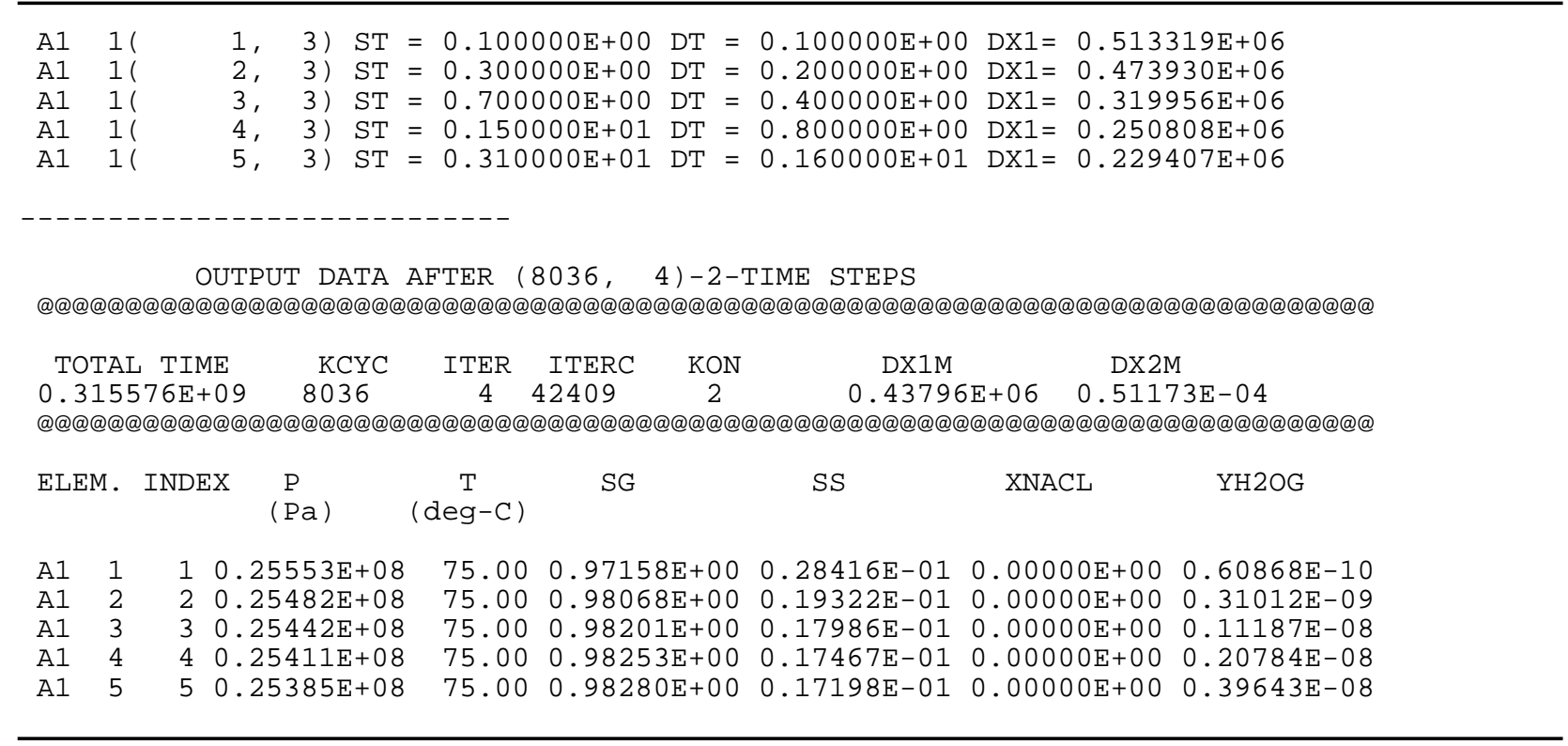

Figure 8.5.2. Part of file co $2 \mathrm{~d}$ _conc.dat for problem no. 5 after $\mathrm{t}=10 \mathrm{yr}$. (For coordinates from $\mathrm{x}$ $=0.50 .95$ to $\mathrm{x}=1150 \mathrm{~m}$, concentrations of aqueous species are marked as " $0.0000 \mathrm{E}+00$ " that indicates a zero water saturation, which are not shown here)

\begin{tabular}{rcccccc}
\hline $\mathrm{X}$ & $\mathrm{Sg}$ & $\mathrm{pH}$ & $\mathrm{ca}+2$ & $\mathrm{mg}+2$ & $\mathrm{na}$ & $\mathrm{k}+$ \\
50.950 & 0.871 & $0.4885 \mathrm{E}+01$ & $0.3602 \mathrm{E}-01$ & $0.1797 \mathrm{E}-01$ & $0.2714 \mathrm{E}+01$ & $0.1137 \mathrm{E}-01$ \\
69.350 & 0.478 & $0.4804 \mathrm{E}+01$ & $0.3826 \mathrm{E}-01$ & $0.6995 \mathrm{E}-02$ & $0.9272 \mathrm{E}+00$ & $0.3626 \mathrm{E}-02$ \\
94.300 & 0.432 & $0.4804 \mathrm{E}+01$ & $0.3825 \mathrm{E}-01$ & $0.6937 \mathrm{E}-02$ & $0.9195 \mathrm{E}+00$ & $0.3591 \mathrm{E}-02$ \\
128.100 & 0.402 & $0.4805 \mathrm{E}+01$ & $0.3824 \mathrm{E}-01$ & $0.6927 \mathrm{E}-02$ & $0.9197 \mathrm{E}+00$ & $0.3587 \mathrm{E}-02$ \\
173.900 & 0.375 & $0.4805 \mathrm{E}+01$ & $0.3822 \mathrm{E}-01$ & $0.6910 \mathrm{E}-02$ & $0.9200 \mathrm{E}+00$ & $0.3580 \mathrm{E}-02$ \\
236.000 & 0.349 & $0.4806 \mathrm{E}+01$ & $0.3821 \mathrm{E}-01$ & $0.6871 \mathrm{E}-02$ & $0.9203 \mathrm{E}+00$ & $0.3567 \mathrm{E}-02$ \\
320.200 & 0.323 & $0.4807 \mathrm{E}+01$ & $0.3822 \mathrm{E}-01$ & $0.6796 \mathrm{E}-02$ & $0.9205 \mathrm{E}+00$ & $0.3540 \mathrm{E}-02$ \\
434.300 & 0.296 & $0.4808 \mathrm{E}+01$ & $0.3829 \mathrm{E}-01$ & $0.6645 \mathrm{E}-02$ & $0.9207 \mathrm{E}+00$ & $0.3478 \mathrm{E}-02$ \\
550.000 & 0.281 & $0.4809 \mathrm{E}+01$ & $0.3840 \mathrm{E}-01$ & $0.6453 \mathrm{E}-02$ & $0.9209 \mathrm{E}+00$ & $0.3392 \mathrm{E}-02$ \\
650.000 & 0.267 & $0.4809 \mathrm{E}+01$ & $0.3862 \mathrm{E}-01$ & $0.6173 \mathrm{E}-02$ & $0.9209 \mathrm{E}+00$ & $0.3233 \mathrm{E}-02$ \\
750.000 & 0.255 & $0.4808 \mathrm{E}+01$ & $0.3896 \mathrm{E}-01$ & $0.5743 \mathrm{E}-02$ & $0.9209 \mathrm{E}+00$ & $0.2989 \mathrm{E}-02$ \\
850.000 & 0.243 & $0.4806 \mathrm{E}+01$ & $0.3943 \mathrm{E}-01$ & $0.5184 \mathrm{E}-02$ & $0.9208 \mathrm{E}+00$ & $0.2637 \mathrm{E}-02$ \\
950.000 & 0.230 & $0.4804 \mathrm{E}+01$ & $0.4001 \mathrm{E}-01$ & $0.4500 \mathrm{E}-02$ & $0.9207 \mathrm{E}+00$ & $0.2175 \mathrm{E}-02$ \\
1050.000 & 0.214 & $0.4802 \mathrm{E}+01$ & $0.4062 \mathrm{E}-01$ & $0.3699 \mathrm{E}-02$ & $0.9205 \mathrm{E}+00$ & $0.1623 \mathrm{E}-02$ \\
1150.000 & 0.179 & $0.4800 \mathrm{E}+01$ & $0.4121 \mathrm{E}-01$ & $0.2791 \mathrm{E}-02$ & $0.9201 \mathrm{E}+00$ & $0.1080 \mathrm{E}-02$ \\
\hline
\end{tabular}


Figure 8.5.3. Part of file co2d_min.dat for problem no. 5, giving changes in mineral abundances (volume fraction) after $\mathrm{t}=10 \mathrm{yr}$.

\begin{tabular}{rcccccc}
\hline $\mathrm{X}$ & calcite & quartz & kaolinite & illite & oligoclase & smectite-na \\
50.950 & $-0.2251 \mathrm{E}-03$ & $0.1507 \mathrm{E}-04$ & $0.4499 \mathrm{E}-05$ & $0.1087 \mathrm{E}-03$ & $-0.3909 \mathrm{E}-03$ & $0.3380 \mathrm{E}-03$ \\
69.350 & $-0.3572 \mathrm{E}-03$ & $0.1722 \mathrm{E}-04$ & $0.5478 \mathrm{E}-05$ & $0.1362 \mathrm{E}-03$ & $-0.4832 \mathrm{E}-03$ & $0.4165 \mathrm{E}-03$ \\
94.300 & $-0.3550 \mathrm{E}-03$ & $0.1812 \mathrm{E}-04$ & $0.5626 \mathrm{E}-05$ & $0.1434 \mathrm{E}-03$ & $-0.5087 \mathrm{E}-03$ & $0.4384 \mathrm{E}-03$ \\
128.100 & $-0.3510 \mathrm{E}-03$ & $0.1889 \mathrm{E}-04$ & $0.5680 \mathrm{E}-05$ & $0.1500 \mathrm{E}-03$ & $-0.5308 \mathrm{E}-03$ & $0.4571 \mathrm{E}-03$ \\
173.900 & $-0.3483 \mathrm{E}-03$ & $0.1961 \mathrm{E}-04$ & $0.5637 \mathrm{E}-05$ & $0.1567 \mathrm{E}-03$ & $-0.5519 \mathrm{E}-03$ & $0.4745 \mathrm{E}-03$ \\
236.000 & $-0.3431 \mathrm{E}-03$ & $0.2029 \mathrm{E}-04$ & $0.5440 \mathrm{E}-05$ & $0.1636 \mathrm{E}-03$ & $-0.5724 \mathrm{E}-03$ & $0.4906 \mathrm{E}-03$ \\
320.200 & $-0.3370 \mathrm{E}-03$ & $0.2092 \mathrm{E}-04$ & $0.5049 \mathrm{E}-05$ & $0.1708 \mathrm{E}-03$ & $-0.5920 \mathrm{E}-03$ & $0.5046 \mathrm{E}-03$ \\
434.300 & $-0.3318 \mathrm{E}-03$ & $0.2151 \mathrm{E}-04$ & $0.4479 \mathrm{E}-05$ & $0.1781 \mathrm{E}-03$ & $-0.6101 \mathrm{E}-03$ & $0.5145 \mathrm{E}-03$ \\
550.000 & $-0.2960 \mathrm{E}-03$ & $0.2171 \mathrm{E}-04$ & $0.3754 \mathrm{E}-05$ & $0.1814 \mathrm{E}-03$ & $-0.6151 \mathrm{E}-03$ & $0.5101 \mathrm{E}-03$ \\
650.000 & $-0.2899 \mathrm{E}-03$ & $0.2159 \mathrm{E}-04$ & $0.3159 \mathrm{E}-05$ & $0.1836 \mathrm{E}-03$ & $-0.6154 \mathrm{E}-03$ & $0.4970 \mathrm{E}-03$ \\
750.000 & $-0.2873 \mathrm{E}-03$ & $0.2127 \mathrm{E}-04$ & $0.2598 \mathrm{E}-05$ & $0.1838 \mathrm{E}-03$ & $-0.6115 \mathrm{E}-03$ & $0.4743 \mathrm{E}-03$ \\
850.000 & $-0.2887 \mathrm{E}-03$ & $0.2051 \mathrm{E}-04$ & $0.2049 \mathrm{E}-05$ & $0.1831 \mathrm{E}-03$ & $-0.6038 \mathrm{E}-03$ & $0.4434 \mathrm{E}-03$ \\
950.000 & $-0.2917 \mathrm{E}-03$ & $0.1930 \mathrm{E}-04$ & $0.1440 \mathrm{E}-05$ & $0.1811 \mathrm{E}-03$ & $-0.5919 \mathrm{E}-03$ & $0.4045 \mathrm{E}-03$ \\
1050.000 & $-0.2958 \mathrm{E}-03$ & $0.1761 \mathrm{E}-04$ & $0.6577 \mathrm{E}-06$ & $0.1772 \mathrm{E}-03$ & $-0.5731 \mathrm{E}-03$ & $0.3575 \mathrm{E}-03$ \\
1150.000 & $-0.3022 \mathrm{E}-03$ & $0.1552 \mathrm{E}-04$ & $-0.6901 \mathrm{E}-06$ & $0.1688 \mathrm{E}-03$ & $-0.5351 \mathrm{E}-03$ & $0.2984 \mathrm{E}-03$ \\
\hline
\end{tabular}

\subsubsection{Results and discussion}

Figure 8.5.4a shows $\mathrm{CO}_{2}$ gas (supercritical fluid) saturations along the radial distance (water saturations are complementary to gas saturations, or $\mathrm{S}_{1}=1-\mathrm{S}_{\mathrm{g}}$ ). After 10 years, the region close to the well in about $40 \mathrm{~m}$ radial distance is completely dryout. The $\mathrm{CO}_{2}$ plume (two-phase region) extends to a radial distance of 1,250 m. Later, the gas saturation gradually decreases due to formation of secondary carbonate minerals (see Figures 8.5.5 and 8.5.6). In the $\mathrm{CO}_{2}$ plume region, $\mathrm{pH}$ is mainly buffered by $\mathrm{CO}_{2}$ gas dissolution and calcite dissolution, values close to 5 are maintained as long as both $\mathrm{CO}_{2}$ gas and calcite mineral are present. $\mathrm{pH}$ gradually increases with time due to mineral alteration. After 1,000 years, a value close to 6 was attained. 


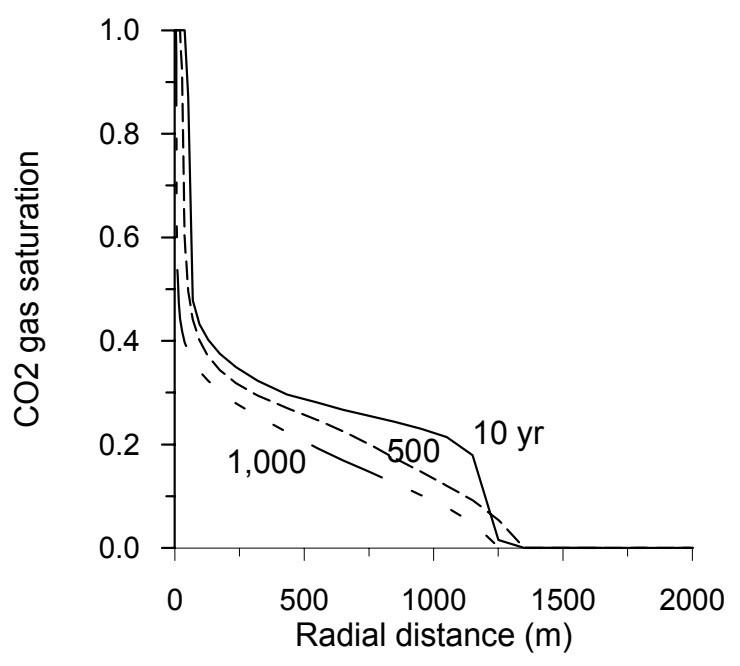

(a) $\mathrm{CO}_{2}$ saturation

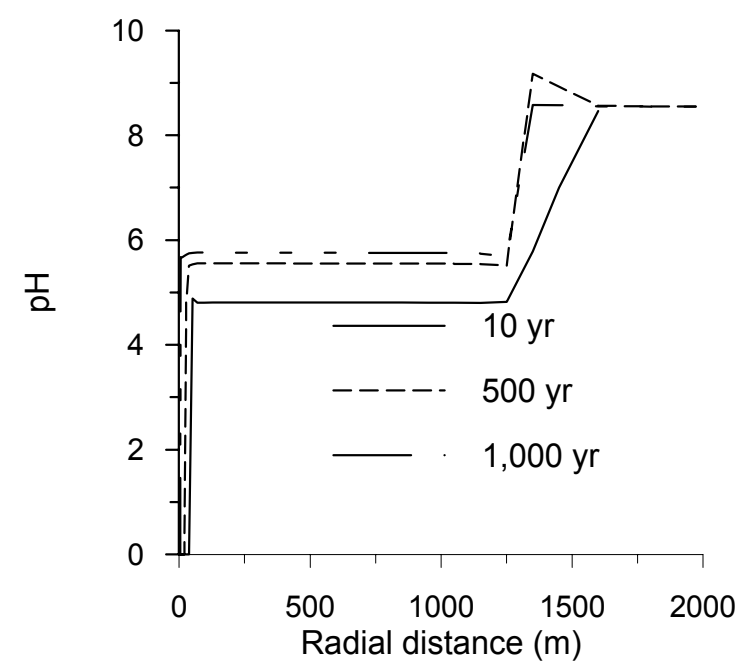

(b) $\mathrm{pH}$

Figure 8.5.4. Distributions of $\mathrm{CO}_{2}$ gas saturation (a) and $\mathrm{pH}$ at different times for the 1-D radial flow problem (in the region close to the well in about $160 \mathrm{~m}$ distance, water is completely removed).

Significant ankerite precipitates due to $\mathrm{CO}_{2}$ injection and dissolution of alumino-silicate minerals (Figure 8.5.5a). After 1,000 years, a maximum volume fraction of $0.02(2 \%)$ formed at 1,250 $\mathrm{m}$ distance. Calcite dissolves rather than precipitates in the injected $\mathrm{CO}_{2}$ plume region because a slightly low $\mathrm{pH}$. Some dawsonite precipitates (Figure 8.5.5b) with a maximum volume fraction of $0.003(0.3 \%)$. A small amount precipitation of magnesite and siderite occurs. No dolomite precipitation is observed in the simulation. The cumulative sequestration of $\mathrm{CO}_{2}$ by carbonate mineral precipitation is given in Figure 8.5.6a. After 1,000 years, a maximum of $20 \mathrm{~kg}$ $\mathrm{CO}_{2}$ per cubic meter medium could be sequestrated by carbonate precipitation. Addition of $\mathrm{CO}_{2}$ mass to the solid matrix as secondary carbonate minerals decreases porosity (Figure 8.5.6b). More results on mineral alteration and on aqueous concentrations are given in the files, co2d_min.dat and co2d_conc.dat in the distribution CD. 


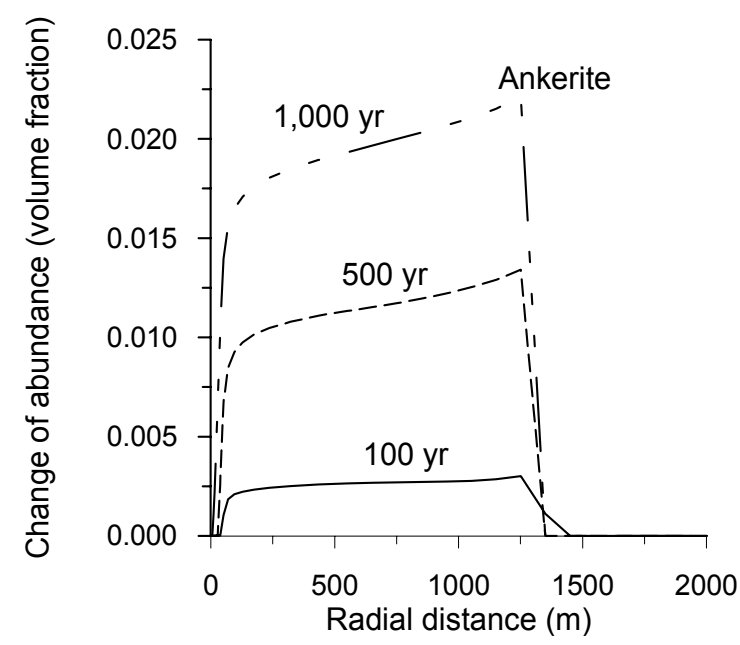

(a) Ankerite

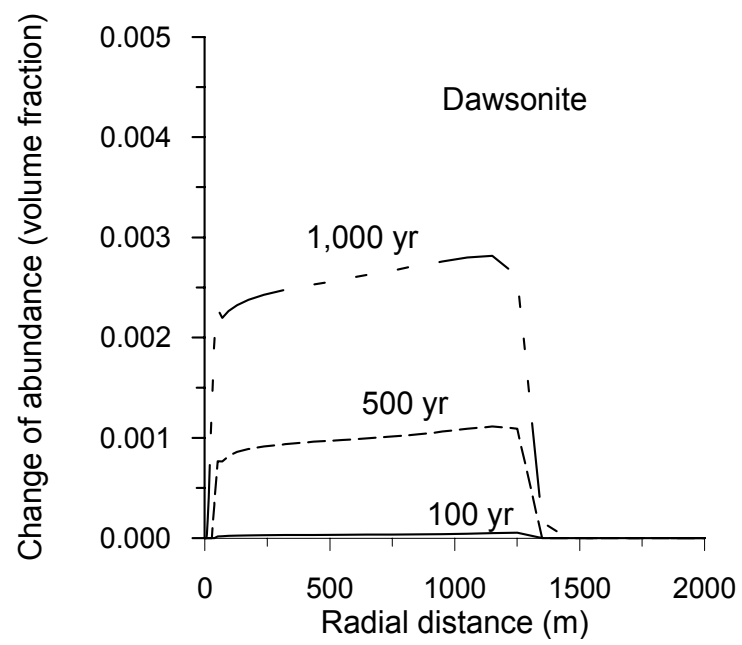

(b) Dawsonite

Figure 8.5.5. Change in mineral abundance (in volume fraction, positive values indicate precipitation and negative dissolution) after different times for the 1-D radial flow problem.

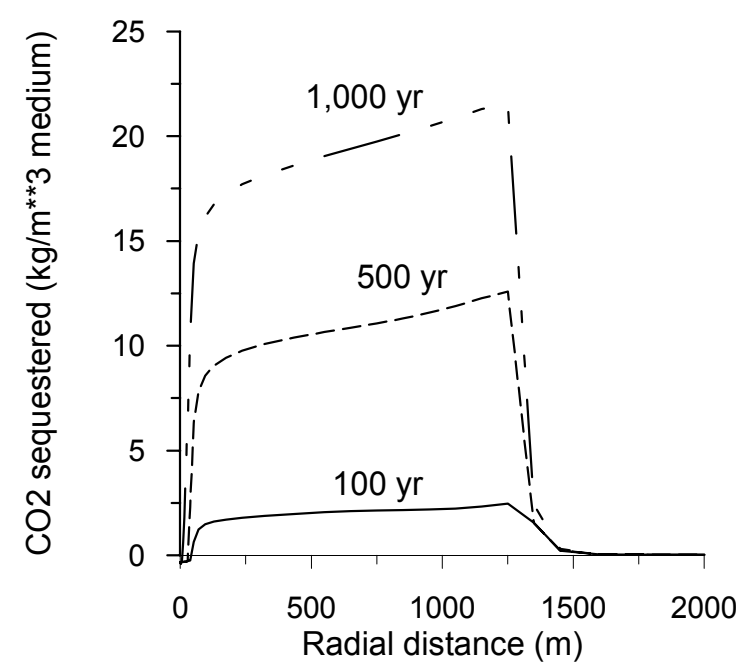

(a) $\mathrm{CO}_{2}$ sequestered

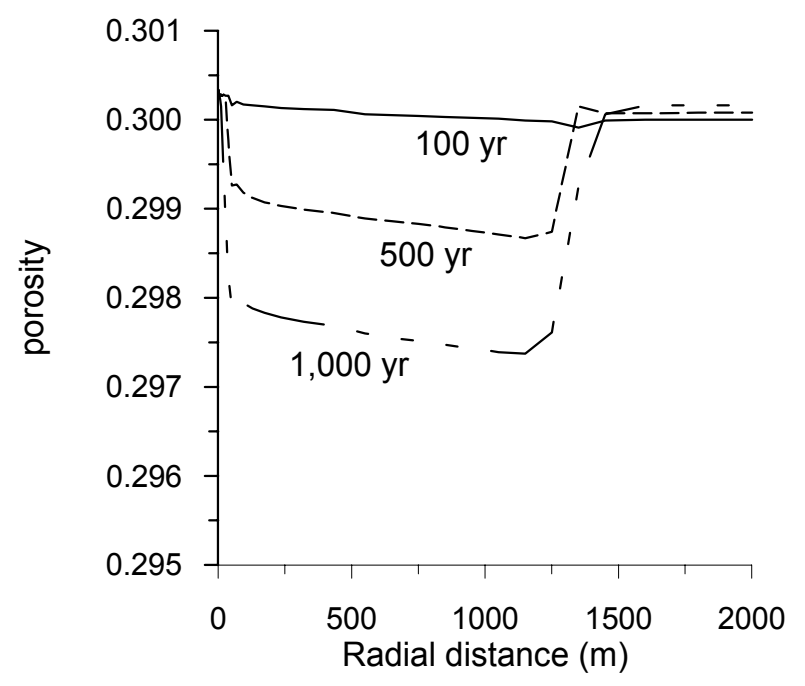

(b) Porosity

Figure 8.5.6. Cumulative $\mathrm{CO}_{2}$ sequestration by carbonate mineral precipitation for different times. 


\subsection{Supergene Copper Enrichment (EOS9)}

\subsubsection{Problem statement}

This simulation problem was published in Xu et al. (2001). Supergene copper enrichment (SCE) involves hydrochemical differentiation by near-surface weathering processes in which water transports metals from a source region or leached zone (Brimhall et al., 1985; Brimhall and Dietrich, 1987; Ague and Brimhall, 1989) to an enrichment blanket zone where they are reprecipitated as secondary ore compounds conserving mass (Figure 8.6.1). The schematic system shown in Figure 8.6.1 captures, in a simplified manner, conditions of desertification in Northern Chile that led to oxidation and chemical enrichment of copper deposits at certain times in the past (of order $15 \mathrm{Ma}$ ) when a decline of the ground water table exposed sulfides to unsaturated conditions (Brimhall et al., 1985; Brimhall and Dietrich, 1987; Alpers and Brimhall, 1989; Ague and Brimhall, 1989).

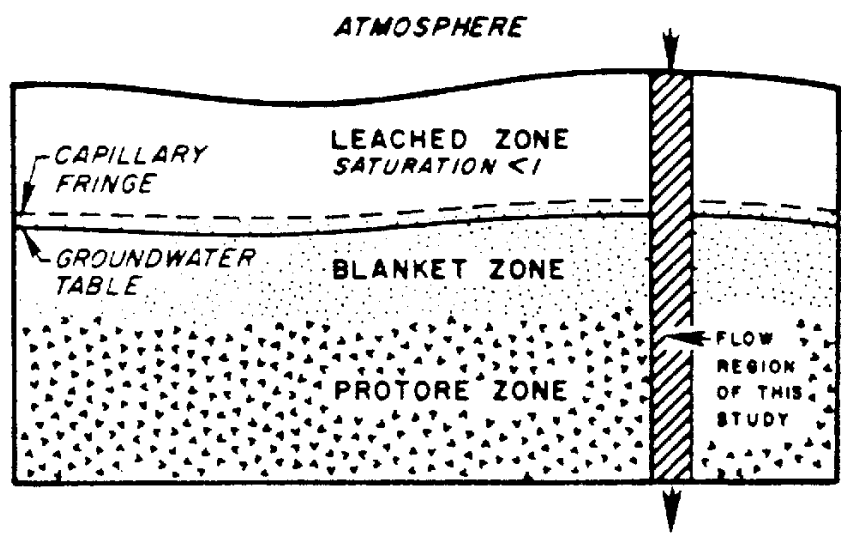

Figure 8.6.1. A schematic representation of a supergene copper enrichment system according to Ague and Brimhall (1989).

Oxidative weathering of pyrite $\left(\mathrm{FeS}_{2}\right)$ and chalcopyrite $\left(\mathrm{CuFeS}_{2}\right)$ causes acidification and mobilization of metals in the oxidizing zone and intense alteration of primary minerals, with subsequent formation of enriched secondary copper bearing sulfide mineral deposits (enrichment blanket) in the reducing conditions below the water table. Such oxidative weathering-driven processes have produced some of the world's largest copper deposits (Ague and Brimhall, 1989). 
The present investigation on geochemical transport in SCE systems is not specific to any field site, but the geochemistry for this work was based on field and laboratory studies of SCE systems as carried out by Brimhall et al. (1985), and Ague and Brimhall (1989). The coupled modeling study is intended to provide a better understanding of the complex interplay of oxygen diffusion, sulfide mineral oxidation, subsequent intense alteration of primary minerals and reprecipitation of secondary minerals. The SCE processes typically took place in a fractured porous medium such as at the El Salvador mine, Chile (Mote et al., 2001). To gain better insight into the processes involved, we first considered a problem in a one-dimensional unsaturated-saturated porous medium. Then we considered the case of SCE processes in a variably saturated fractured rock system using the "multiple interacting continua" (MINC) method. Here we only present the case of SCE processes in a variably saturated fractured rock. The simple porous medium case is given in Xu et al. (2001)

\subsubsection{Problem setup}

The method of "multiple interacting continua" (MINC) is used to resolve "global" flow and diffusion of chemicals in the fractured rock and its interaction with "local" exchange between fractures and matrix rock. This method was developed by Pruess and Narasimhan (1985) for fluid and heat flow in fractured porous media. The extension of the MINC method to reactive geochemical transport is described in detail by Xu and Pruess (2001b). It is well-known that in the case of reactive chemistry diffusive fluxes may be controlled by reactions occurring near (within millimeters) the fracture walls. The resolution of concentration gradients in matrix blocks is achieved by appropriate subgridding. The MINC concept is based on the notion that changes in fluid pressures and chemical concentrations propagate rapidly through the fracture system, while invading the tight matrix blocks only slowly. Therefore, changes in matrix conditions will be (locally) controlled by the distance from the fractures and can then be modeled by means of onedimensional strings of nested grid blocks (Figure 8.6.2).

In general it is not necessary to consider explicitly subgrids in all the matrix blocks separately. Within a certain subdomain (corresponding to a finite difference grid block), all fractures will be lumped into continuum \# 1, all matrix material within a certain distance from the fractures will be lumped into continuum \# 2, matrix material at larger distance becomes continuum \# 3, and so on. Quantitatively, the subgridding is specified by means of a set of 
volume fractions $\operatorname{VOL}(\mathrm{j}), \mathrm{j}=1, \ldots, \mathrm{J}$, into which the "primary" porous medium grid blocks are partitioned. The information on fracturing (spacing, number of sets, shape of matrix blocks) required for this is provided by a "proximity function" PROX(x) which expresses, for a given domain $\mathrm{V}_{0}$, the total fraction of matrix material within a distance $\mathrm{x}$ from the fractures (Pruess and Karasaki, 1982). If only two continua are specified (one for fractures, one for matrix), the MINC approach reduces to the conventional double-porosity or dual permeability methods.

We consider an idealized fractured porous medium with two perpendicular sets of plane, parallel, vertical fractures of equal aperture and spacing. Because of symmetry only one column of matrix blocks needs to be modeled. Figure 8.6.2 shows an areal view of a rock matrix column that is surrounded by vertical fractures with a spacing of $0.5 \mathrm{~m}$, with subgridding of the matrix according to the MINC method. Subgrid 1 represents the fracture domain that is defined to include 50 percent by volume of wall rock. Subgrids 2 through 7 represent the rock matrix. In the vertical direction, a total of 10 model layers are used with a thickness of $2 \mathrm{~m}$. A net rainwater infiltration rate of $0.015 \mathrm{~m} \mathrm{yr}^{-1}$ over the entire area was applied to the fractures. Water pressure is held constant at 2 bars at the bottom $(z=-20 \mathrm{~m})$, so that the water table is located at a depth of approximately $10 \mathrm{~m}$. In addition to global water flow and chemical transport in the fracture network, the model considers flow and transport between fractures and matrix, as well as vertical matrix-matrix water flow and chemical transport. The steady-state water saturations obtained without chemical reactions are used as initial conditions for the calculation of reactive geochemical transport. Hydrological parameters for the fracture and matrix are listed in Table 8.6.1. 


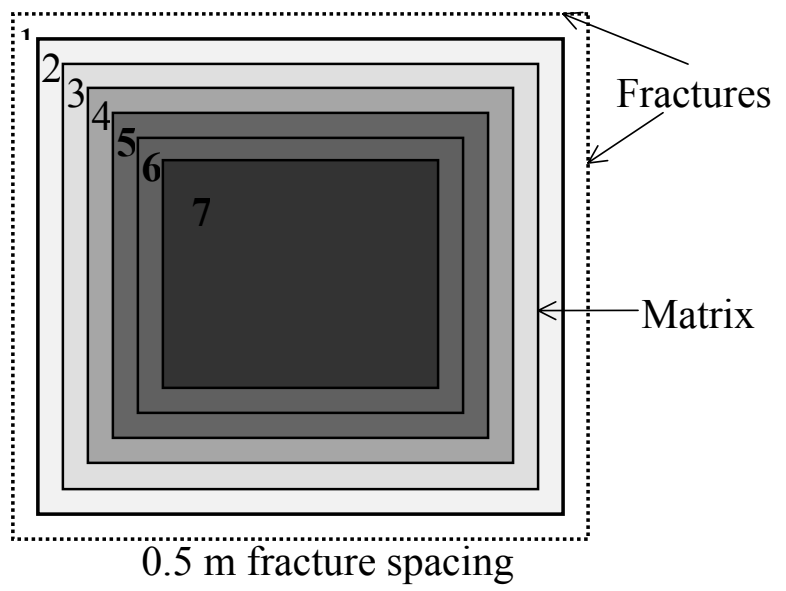

Figure 8.6.2 Subgridding of a rock matrix in the method of "multiple interacting continua" (MINC). The figure represents an areal view of a rock matrix column that is surrounded by vertical fractures.

Table 8.6.1. Hydrological parameters used for supergene copper enrichment in the fractured rock

\begin{tabular}{lcc}
\hline Parameter & Matrix & Fracture \\
\hline Permeability $\left(\mathrm{m}^{2}\right)$ & $10^{-16}$ & $10^{-12}$ \\
Fracture domain volume fraction, $\mathrm{v}^{*}$ & & 0.01 \\
Fracture spacing $(\mathrm{m})$ & \multicolumn{2}{c}{0.5} \\
Porosity & 0.08 & 0.5 \\
Relative permeability and capillary pressure (van Genuchten, 1980$)$ \\
$\quad \lambda$ & 0.457 & 0.457 \\
$\mathrm{~S}_{\mathrm{lr}}$ & 0.1 & 0.05 \\
$\mathrm{~S}_{\mathrm{ls}}$ & 1.0 & 1.0 \\
$\mathrm{P}_{0}(\mathrm{pa})$ & $2.17 \times 10^{5}$ & $6.2 \times 10^{3}$ \\
\hline
\end{tabular}

${ }^{*} \mathrm{~V}=\mathrm{V}_{\mathrm{f}} /\left(\mathrm{V}_{\mathrm{f}}+\mathrm{V}_{\mathrm{m}}\right)$ where $\mathrm{V}_{\mathrm{f}}$ and $\mathrm{V}_{\mathrm{m}}$ are fracture and matrix domain volumes.

The geochemical transport simulation considers unsaturated-saturated liquid phase flow and diffusive supply of oxygen to the protore. The domain modeled is initially filled entirely with a protore mineral assemblage as listed in Table 8.6.2. The dissolution of the primary minerals is 
considered to be kinetically-controlled. The kinetic rate constants and reactive surface areas are also given in Table 8.6.2. Precipitation of secondary minerals (Table 8.6.2 with initial $V_{f}=0$ where $V_{f}$ is mineral volume fraction) is represented using the same expression as dissolution. To simplify the description of precipitation kinetics, in the present study all secondary minerals are assigned the same kinetic rate constant $\left(2.0 \times 10^{-10} \mathrm{~mol} \mathrm{~m}^{-2} \mathrm{~s}^{-1}\right)$ and reactive surface areas $\left(0.1 \mathrm{~m}^{2}\right.$ per $\mathrm{dm}^{3}$ bulk medium). Because the rate constants assumed for precipitation reactions are larger than those for dissolution of primary minerals, formation of secondary minerals occurs effectively at conditions close to local equilibrium. The kinetic rate of sulfide mineral oxidation can be strongly influenced by catalytic effects of bacteria (Singer and Stumm, 1970; Olson, 1991; Nordstrom and Alpers, 1997), which are not considered in the present study. Estimates of field oxidation rate cover a wide range of values (Nordstrom and Alpers, 1997). The rate determining process is commonly the transport of oxygen or other reactants to the reaction site. This process is the main focus of the simulation. Heat generation by pyrite oxidation may change temperature, but this effect is not considered in the simulations. Calculations are carried out at a constant temperature of $25^{\circ} \mathrm{C}$. Thermodynamic data used in the simulations were taken from the EQ3/6 V8.2b database (Wolery, 1992), which were derived using SUPCRT92 (Johnson et al., 1992). 
Table 8.6.2. Initial protore mineral volume fractions $\left(\mathrm{V}_{\mathrm{f}}\right)$ and possible secondary mineral phases $\left(\mathrm{V}_{\mathrm{f}}=0.0\right)$ considered in the supergene copper enrichment problem. Kinetic data for primary minerals are based on Ague and Brimhall (1989) and Gérard and others (1997).

\begin{tabular}{|c|c|c|c|c|}
\hline Mineral & Composition & $\begin{array}{l}\text { Volume } \\
\text { fraction, } V_{f}\end{array}$ & $\begin{array}{l}\text { Rate constant at } \\
25^{\circ} \mathrm{C}\left(\mathrm{mol} \mathrm{m}^{-2} \mathrm{~s}^{-1}\right)\end{array}$ & $\begin{array}{l}\text { Surface area } \\
\left(\mathrm{m}^{2} \mathrm{dm}^{-3} \text { medium }\right)\end{array}$ \\
\hline \multicolumn{5}{|l|}{ Primary: } \\
\hline pyrite & $\mathrm{FeS}_{2}$ & 0.090 & $4.0 \times 10^{-11}$ & 0.0587 \\
\hline chalcopyrite & $\mathrm{CuFeS}_{2}$ & 0.045 & $4.0 \times 10^{-11}$ & 0.0587 \\
\hline magnetite & $\mathrm{Fe}_{3} \mathrm{O}_{4}$ & 0.045 & $2.0 \times 10^{-11}$ & 0.0787 \\
\hline $\mathrm{k}$-feldspar & $\mathrm{KAlSi}_{3} \mathrm{O}_{8}$ & 0.180 & $3.1 \times 10^{-12}$ & 0.2710 \\
\hline albite & $\mathrm{NaAlSi}_{3} \mathrm{O}_{8}$ & 0.090 & $3.1 \times 10^{-12}$ & 0.1360 \\
\hline anorthite & $\mathrm{CaAl}_{2} \mathrm{Si}_{2} \mathrm{O}_{8}$ & 0.090 & $1.5 \times 10^{-12}$ & 0.1420 \\
\hline annite & $\mathrm{KFe}_{3} \mathrm{AlSi}_{3} \mathrm{O}_{10}(\mathrm{OH})_{2}$ & 0.045 & $2.4 \times 10^{-14}$ & 0.0587 \\
\hline muscovite & $\mathrm{KAl}_{3} \mathrm{Si}_{3} \mathrm{O}_{10}(\mathrm{OH})_{2}$ & 0.090 & $2.4 \times 10^{-14}$ & 0.0123 \\
\hline quartz & $\mathrm{SiO}_{2}$ & 0.180 & $4.3 \times 10^{-14}$ & 0.0850 \\
\hline anhydrite & $\mathrm{CaSO}_{4}$ & $\begin{array}{l}0.045 \\
\text { total }=0.9 \\
\text { porosity }=0.1\end{array}$ & $1.5 \times 10^{-12}$ & 0.0510 \\
\hline \multicolumn{5}{|l|}{ Secondary: } \\
\hline $\begin{array}{l}\text { covellite } \\
\text { chalcocite }\end{array}$ & $\begin{array}{l}\mathrm{Cus} \\
\mathrm{Cu}_{2} \mathrm{~S}\end{array}$ & $\begin{array}{l}0.0 \\
0.0\end{array}$ & $\begin{array}{l}2.0 \times 10^{-10} \\
2.0 \times 10^{-10}\end{array}$ & $\begin{array}{l}0.1 \\
0.1\end{array}$ \\
\hline bornite & $\mathrm{Cu}_{5} \mathrm{FeS}_{4}$ & 0.0 & $2.0 \times 10^{-10}$ & 0.1 \\
\hline goethite & $\mathrm{FeOOH}$ & 0.0 & $2.0 \times 10^{-10}$ & 0.1 \\
\hline hematite & $\mathrm{Fe}_{2} \mathrm{O}_{3}$ & 0.0 & $2.0 \times 10^{-10}$ & 0.1 \\
\hline kaolinite & $\mathrm{Al}_{2} \mathrm{Si}_{2} \mathrm{O}_{5}(\mathrm{OH})_{4}$ & 0.0 & $2.0 \times 10^{-10}$ & 0.1 \\
\hline alunite & $\mathrm{KAl}_{3}(\mathrm{OH})_{6}\left(\mathrm{SO}_{4}\right)_{2}$ & 0.0 & $2.0 \times 10^{-10}$ & 0.1 \\
\hline amorphous silica & $\mathrm{SiO}_{2}$ & 0.0 & $2.0 \times 10^{-10}$ & 0.1 \\
\hline
\end{tabular}

Oxygen is treated as an ideal gas, and its interaction with the aqueous solution is assumed to be at equilibrium. The oxygen partial pressure at the land surface boundary is assumed to be constant at 0.2 bars. A dilute oxidized water that was equilibrated with an oxygen partial pressure of 0.2 bars is initially placed in the unsaturated zone, while a reducing water is assumed for the saturated zone. The infiltrating water composition is the same as the initial unsaturated water. The aqueous complexation is assumed at equilibrium, even though some aqueous redox pairs such as sulfite and sulfide species may not be at equilibrium (Stumm and Morgan, 1981). Whether a particular reaction should be described as governed by the local equilibrium approximation (LEA) or by kinetic rates depends not only on the reaction itself but also on the rates of hydrodynamic transport processes (Domenico and Schwarz, 1990). The LEA is applicable when the characteristic time for transport of reactants is longer than the time required to reach chemical 
equilibrium. In the present simulations for reactive geochemical transport, the choice of equilibrium depends mainly on kinetic rate, infiltration rate, oxygen availability, and space discretization.

The EOS9 flow module was used for this ambient mineral deposition problem. The input and output files for the problem are given in the distribution CD (subdirectory: / sampleproblems/P6_EOS9_copper). To shorten the run time for benchmarking purposes, the simulation time in the PARAM input block of flow.inp is specified as 3.15576E08 s (or 10 years). Users can reset this variable to their desired time. Parts of output files for fluid flow, aqueous chemical concentrations, and changes of mineral abundances are given in Figures 8.6.3, 8.6.4 and 8.6.5. 
Figure 8.6.3. Part of file flow.out for problem no. 6 (copper enrichment).

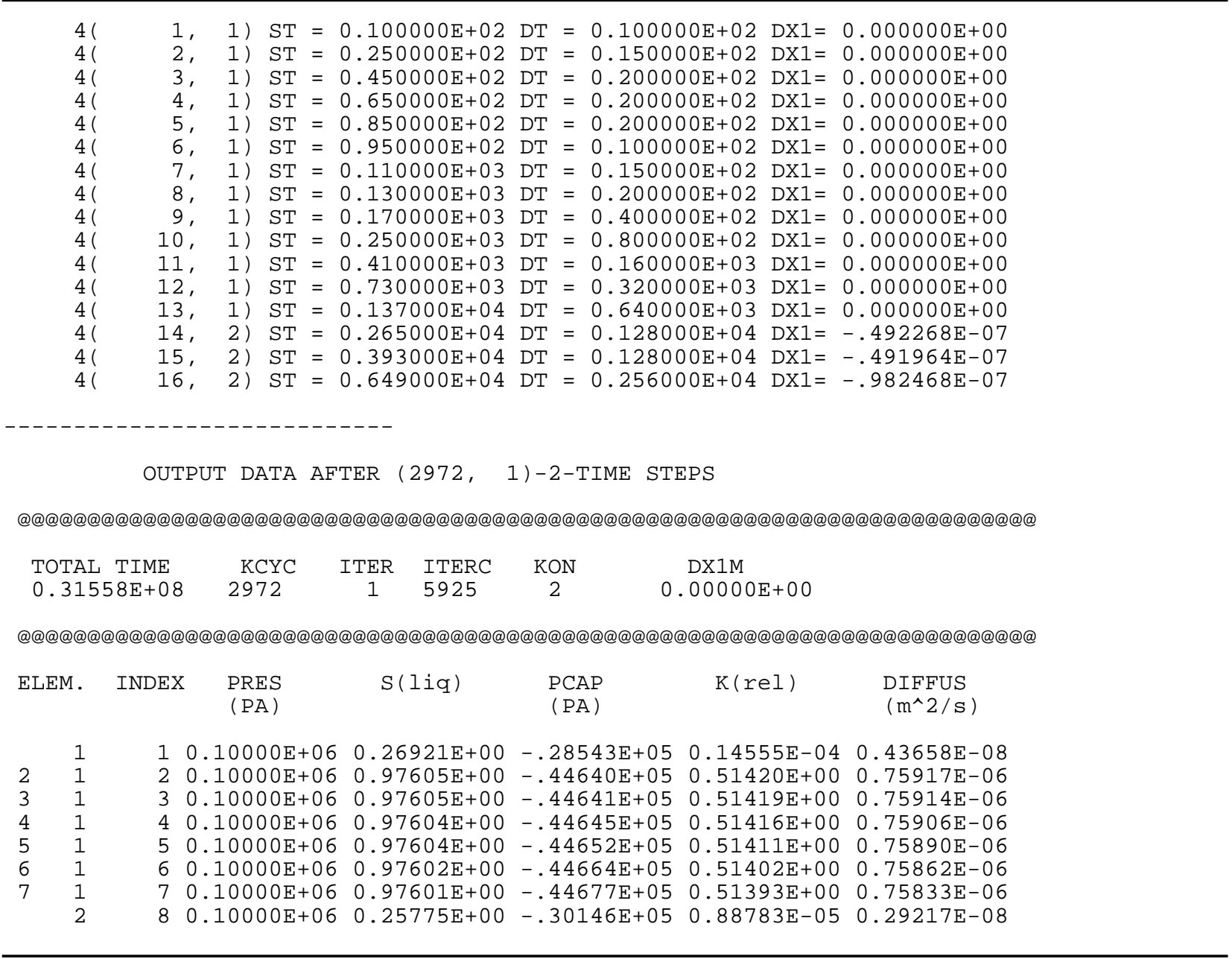

Figure 8.6.4. Part of file Amic_aqu.dat for problem no. 6 after $\mathrm{t}=1 \mathrm{yr}$ ( $\mathrm{S} l$ is water saturation, unit of concentrations is $\mathrm{mol} / \mathrm{l})$.

\begin{tabular}{rccccccc}
\hline $\mathrm{X}$ & $\mathrm{Y}$ & $\mathrm{SI}$ & $\mathrm{pH}$ & $\mathrm{s} 04-2$ & $\mathrm{fe}+2$ & $\mathrm{cu}+2$ & $\mathrm{nat}$ \\
0.000 & -1.000 & $0.2692 \mathrm{E}+00$ & 3.7975 & $0.2208 \mathrm{E}-03$ & $0.1236 \mathrm{E}-08$ & $0.3676 \mathrm{E}-04$ & $0.7787 \mathrm{E}-04$ \\
0.254 & -1.000 & $0.9760 \mathrm{E}+00$ & 3.7892 & $0.2260 \mathrm{E}-03$ & $0.1276 \mathrm{E}-08$ & $0.3762 \mathrm{E}-04$ & $0.7946 \mathrm{E}-04$ \\
0.900 & -1.000 & $0.9760 \mathrm{E}+00$ & 3.7613 & $0.2465 \mathrm{E}-03$ & $0.1367 \mathrm{E}-08$ & $0.4105 \mathrm{E}-04$ & $0.8578 \mathrm{E}-04$ \\
2.247 & -1.000 & $0.9760 \mathrm{E}+00$ & 3.7187 & $0.2820 \mathrm{E}-03$ & $0.1517 \mathrm{E}-08$ & $0.4695 \mathrm{E}-04$ & $0.9667 \mathrm{E}-04$ \\
5.215 & -1.000 & $0.9760 \mathrm{E}+00$ & 3.6750 & $0.3245 \mathrm{E}-03$ & $0.1692 \mathrm{E}-08$ & $0.5403 \mathrm{E}-04$ & $0.1097 \mathrm{E}-03$ \\
10.790 & -1.000 & $0.9760 \mathrm{E}+00$ & 3.6581 & $0.3429 \mathrm{E}-03$ & $0.1765 \mathrm{E}-08$ & $0.5709 \mathrm{E}-04$ & $0.1154 \mathrm{E}-03$ \\
14.340 & -1.000 & $0.9760 \mathrm{E}+00$ & 3.6561 & $0.3452 \mathrm{E}-03$ & $0.1774 \mathrm{E}-08$ & $0.5747 \mathrm{E}-04$ & $0.1161 \mathrm{E}-03$ \\
0.000 & -3.000 & $0.2578 \mathrm{E}+00$ & 3.6961 & $0.3032 \mathrm{E}-03$ & $0.1586 \mathrm{E}-08$ & $0.5048 \mathrm{E}-04$ & $0.1032 \mathrm{E}-03$ \\
0.254 & -3.000 & $0.9832 \mathrm{E}+00$ & 3.6944 & $0.3049 \mathrm{E}-03$ & $0.1612 \mathrm{E}-08$ & $0.5076 \mathrm{E}-04$ & $0.1037 \mathrm{E}-03$ \\
0.900 & -3.000 & $0.9832 \mathrm{E}+00$ & 3.6880 & $0.3113 \mathrm{E}-03$ & $0.1638 \mathrm{E}-08$ & $0.5182 \mathrm{E}-04$ & $0.1057 \mathrm{E}-03$ \\
2.247 & -3.000 & $0.9832 \mathrm{E}+00$ & 3.6767 & $0.3228 \mathrm{E}-03$ & $0.1685 \mathrm{E}-08$ & $0.5373 \mathrm{E}-04$ & $0.1092 \mathrm{E}-03$ \\
5.215 & -3.000 & $0.9832 \mathrm{E}+00$ & 3.6628 & $0.3378 \mathrm{E}-03$ & $0.1745 \mathrm{E}-08$ & $0.5623 \mathrm{E}-04$ & $0.1138 \mathrm{E}-03$ \\
10.790 & -3.000 & $0.9832 \mathrm{E}+00$ & 3.6567 & $0.3445 \mathrm{E}-03$ & $0.1772 \mathrm{E}-08$ & $0.5736 \mathrm{E}-04$ & $0.1159 \mathrm{E}-03$ \\
14.340 & -3.000 & $0.9832 \mathrm{E}+00$ & 3.6560 & $0.3453 \mathrm{E}-03$ & $0.1775 \mathrm{E}-08$ & $0.5748 \mathrm{E}-04$ & $0.1161 \mathrm{E}-03$ \\
\hline
\end{tabular}


Figure 8.6.5. Part of file Amic_sod.dat for problem no. 6, giving changes in mineral abundances (in volume fraction, positive values indicate precipitation and negative dissolution) after $\mathrm{t}=1 \mathrm{yr}$.

\begin{tabular}{|c|c|c|c|c|c|c|}
\hline $\mathrm{X}$ & $\mathrm{Y}$ & pyrite & chalcopyrit & magnetite & $\mathrm{k}$-feldspar & albite \\
\hline 0.000 & -1.000 & $-0.1611 E-07$ & $-0.1441 \mathrm{E}-07$ & $-0.7491 E-08$ & $-0.1136 \mathrm{E}-08$ & $-0.6222 E-07$ \\
\hline 0.254 & -1.000 & $-0.2149 \mathrm{E}-06$ & $-0.1923 E-06$ & $-0.9993 E-07$ & $-0.1515 E-07$ & $-0.8300 E-06$ \\
\hline 0.900 & -1.000 & $-0.2149 E-06$ & $-0.1923 E-06$ & $-0.9993 E-07$ & $-0.1515 E-07$ & $-0.8300 E-06$ \\
\hline 2.247 & -1.000 & $-0.2149 E-06$ & $-0.1923 E-06$ & $-0.9993 E-07$ & $-0.1515 E-07$ & $-0.8300 E-06$ \\
\hline 5.215 & -1.000 & $-0.2149 E-06$ & $-0.1923 E-06$ & $-0.9993 E-07$ & $-0.1515 E-07$ & $-0.8300 \mathrm{E}-06$ \\
\hline 10.790 & -1.000 & $-0.2149 E-06$ & $-0.1923 E-06$ & $-0.9993 E-07$ & $-0.1515 E-07$ & $-0.8300 \mathrm{E}-06$ \\
\hline 14.340 & -1.000 & $-0.2149 E-06$ & $-0.1923 E-06$ & $-0.9993 E-07$ & $-0.1515 E-07$ & $-0.8300 E-06$ \\
\hline 0.000 & -3.000 & $-0.1543 E-07$ & $-0.1380 \mathrm{E}-07$ & $-0.7173 E-08$ & $-0.1087 \mathrm{E}-08$ & $-0.5958 E-07$ \\
\hline 0.254 & -3.000 & $-0.2165 E-06$ & $-0.1937 E-06$ & $-0.1007 E-06$ & $-0.1526 E-07$ & $-0.8361 E-06$ \\
\hline 0.900 & -3.000 & $-0.2165 E-06$ & $-0.1937 E-06$ & $-0.1007 E-06$ & $-0.1526 E-07$ & $-0.8361 E-06$ \\
\hline 2.247 & -3.000 & $-0.2165 E-06$ & $-0.1937 E-06$ & $-0.1007 E-06$ & $-0.1526 E-07$ & $-0.8361 E-06$ \\
\hline 5.215 & -3.000 & $-0.2165 E-06$ & $-0.1937 E-06$ & $-0.1007 E-06$ & $-0.1526 E-07$ & $-0.8361 E-06$ \\
\hline 10.790 & -3.000 & $-0.2165 E-06$ & $-0.1937 E-06$ & $-0.1007 E-06$ & $-0.1526 E-07$ & $-0.8361 E-06$ \\
\hline 14.340 & -3.000 & $-0.2165 E-06$ & $-0.1937 E-06$ & $-0.1007 E-06$ & $-0.1526 \mathrm{E}-07$ & $-0.8361 E-06$ \\
\hline
\end{tabular}

\subsubsection{Results}

Some selected plots of simulation results are presented in Figures 8.6.6, 8.6.7, and 8.6.8. More results and discussion are presented in Xu et al. (2001).

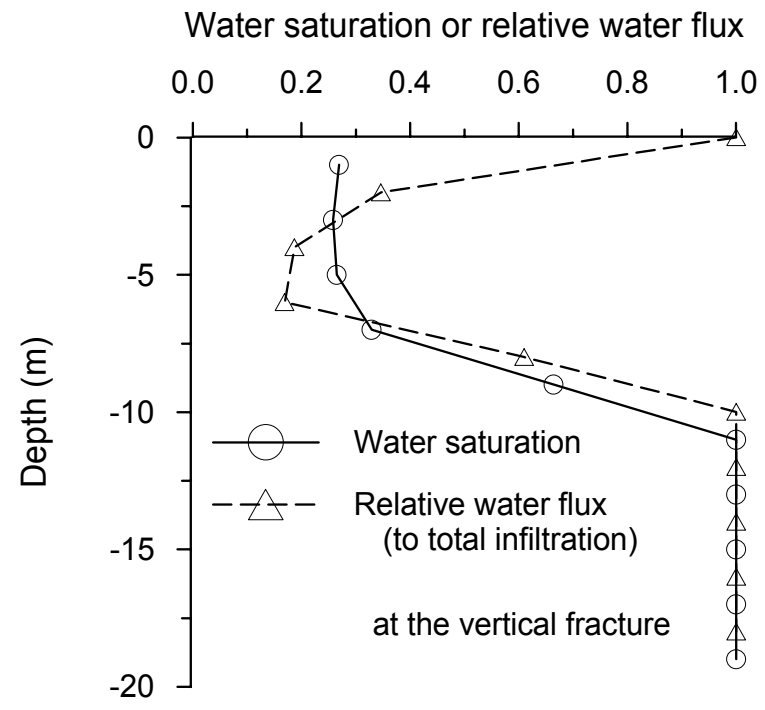

Figure 8.6.6. Steady-state water saturation and water flux (relative to total infiltration) passed through the fractures 


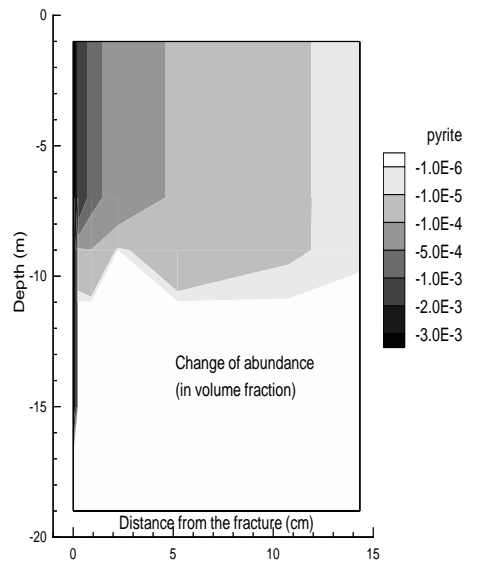

(A)

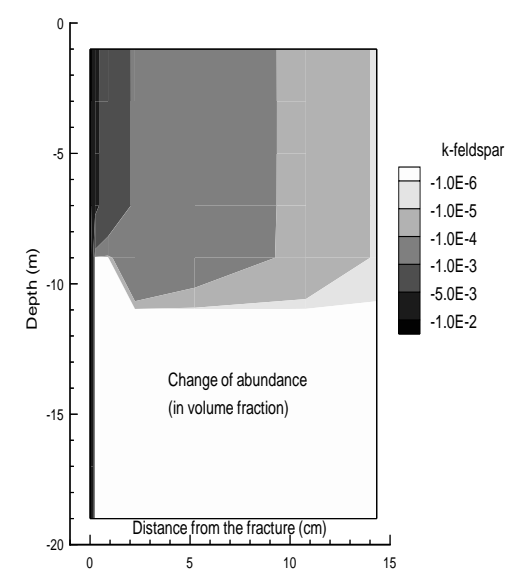

(C)

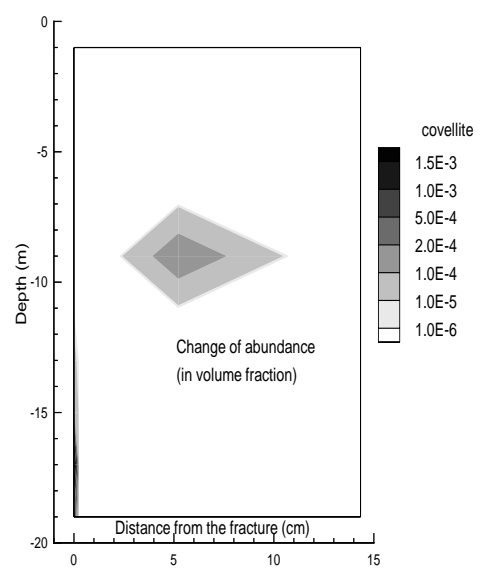

(E)

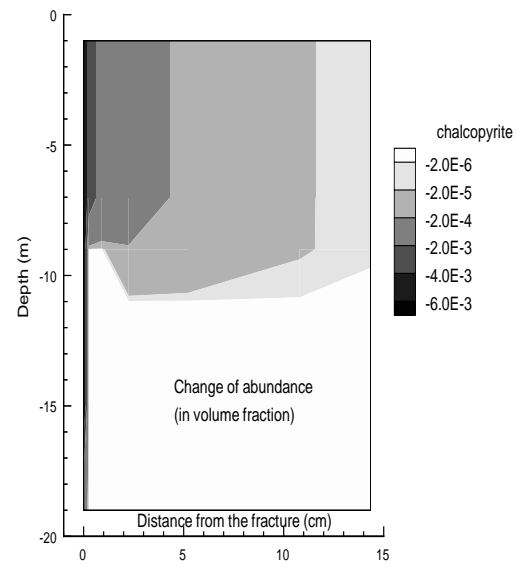

(B)

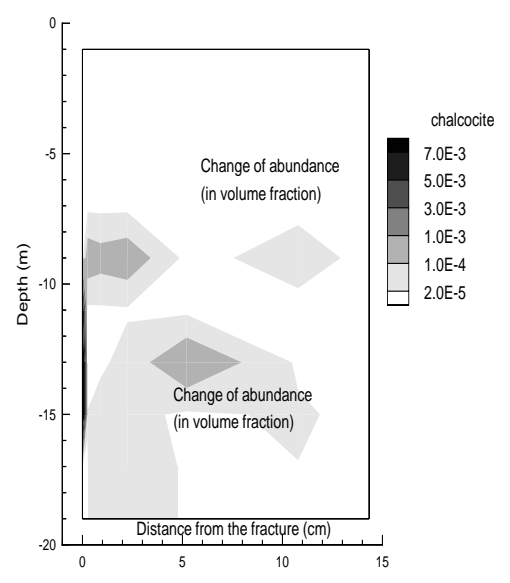

(D)

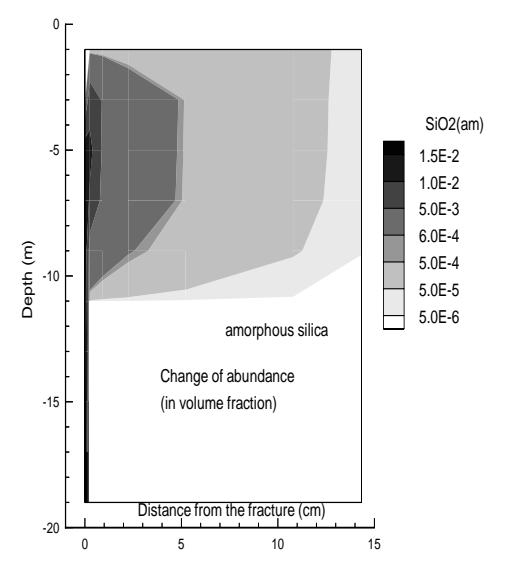

(F)

Figure 8.6.7. Change of mineral abundance (positive values indicate precipitation and negative dissolution) after 20,000 yrs in the fractured rock. 


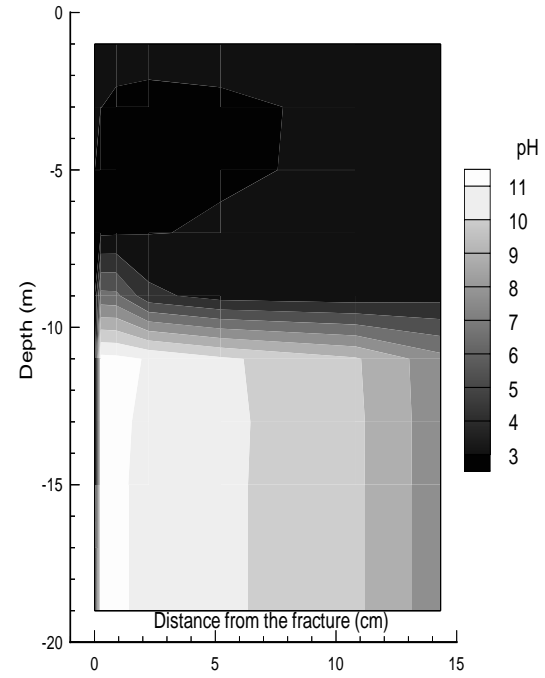

(A)

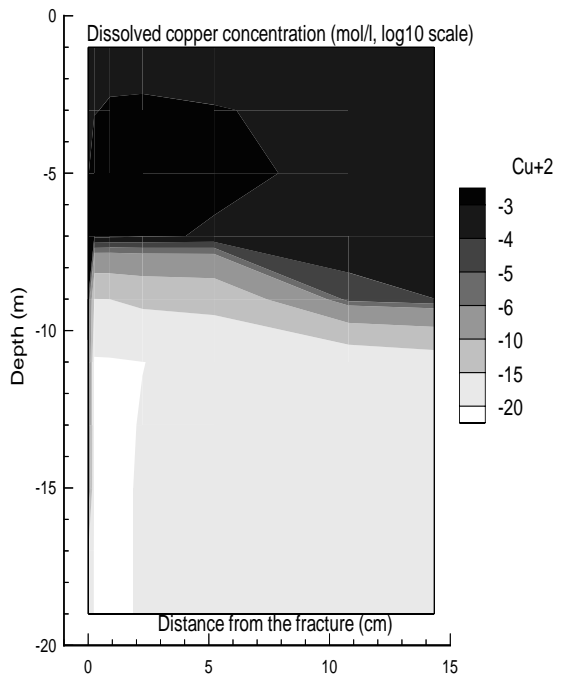

(B)

Figure 8.6.8. $\mathrm{pH}$ and dissolved copper concentration at 20,000 yrs in the fractured rock. 


\subsection{Caprock Alteration (EOS2)}

\subsubsection{Problem statement}

This problem was published in $\mathrm{Xu}$ and Pruess (2001a). The interaction between hydrothermal fluids and the rocks through which they migrate alters the earlier formed primary minerals and leads to the formation of secondary minerals, resulting in changes in physical and chemical properties of the system. Here, we consider the following processes: (1) detailed fracture-matrix interaction for fluid, heat and chemical constituents; (2) gas phase participation in multiphase fluid flow and geochemical reactions; (3) the kinetics of fluid-rock chemical interaction, and (4) heat effects on thermophysical and chemical properties and processes, which include water and $\mathrm{CO}_{2}$ partitioning between liquid and gas phases, temperature-dependent phase density and viscosity, and thermodynamic chemical equilibrium and kinetic rate constants. The range of problems concerning the interaction of hydrothermal fluids with rocks is very broad. We confine our attention to the evolution of geothermal fields associated with magmatic activity, such as are encountered in the Long Valley Caldera (LVC), California (Sorey, 1985; White and Peterson, 1991; and Sorey et al., 1998) and in the Taupo Volcanic Zone, New Zealand (White and Christenson, 1998). In the hydrothermal fluids in these areas, water vapor and $\mathrm{CO}_{2}$ are the dominant gas phase constituents. The present study uses, as an example, water and gas chemistry data from the hydrothermal system in the LVC (Sorey, 1985; White and Peterson, 1991; and Flexser, 1991). The flow system studied in this paper is intended to capture realistic features of hydrothermal systems such as the LVC.

\subsubsection{Problem setup}

The Long Valley Caldera (LVC) is a $450 \mathrm{~km}^{2}$ elliptical depression located along the eastern front of the Sierra Nevada in east-central California (Sorey, 1985; White and Peterson, 1991; and Sorey et al., 1998). Many hot springs in and around LVC occur along north to northwest trending normal faults, and are derived from hydrothermal reservoirs. Hot water is transported upward along fault systems into shallow aquifers (Sorey, 1985; White and Peterson, 1991). In these aquifers, the hydrothermal fluids mix with varying proportions of cold meteoric 
water before discharging in hot springs. The present LVC hydrothermal system has been active for perhaps 40, 000 years (Flexser, 1991).

For the sake of simplification and interpretation of results, we consider an idealized fractured rock with a set of plane, parallel vertical fracture zones (faults) of equal aperture $(0.1 \mathrm{~m})$ and spacing $(3.5 \mathrm{~m})$. Because of the symmetry of this fractured rock, only one column of matrix blocks needs to be modeled (Figure 8.7.1). We simulated a vertical column extending from the atmosphere (top boundary) through the fracture-matrix system to the hydrothermal reservoir (bottom boundary). The depth of the hydrothermal reservoir varies from site to site. For example, according to the data presented in White and Peterson (1991) for the LVC, the reservoir depth varies from several tens of meters to near 1000 meters. In this study, we use a single depth of 280 $\mathrm{m}$ for simplicity. A 1-m-thick vertical slice is modeled, where a total depth of $280 \mathrm{~m}$ is discretized into 56 layers of $5 \mathrm{~m}$ thickness. The fracture is considered as one model grid zone. The rock matrix is further discretized into 6 grid zones with permeability decreasing away from the fracture (Table 8.7.1). A thermal conductivity of $2.1 \mathrm{~W} / \mathrm{m}^{\circ} \mathrm{C}$, a specific heat of $920 \mathrm{~J} / \mathrm{kg}^{\circ} \mathrm{C}$, and an aqueous chemical diffusion coefficient of $1 \times 10^{-10} \mathrm{~m}^{2} / \mathrm{s}$ are used. Other parameters for the fracture and matrix are listed in Table 8.7.1. The top atmosphere and bottom hydrothermal reservoir boundaries are modeled as constant pressure boundaries with properties shown in Figure 8.7.1. At a depth of $88.4 \mathrm{~m}$ the rising hot water mixes with shallow cold meteoric water. The cold water (11 ${ }^{\circ} \mathrm{C}$ ) recharge is assumed to occur only in the fracture grid block at a rate of $3 \times 10^{-5} \mathrm{~kg} / \mathrm{s}$, and is treated as a source term for fluid, heat and chemical constituents, the concentrations of which are given in Table 8.7.2. The bottom reservoir is assigned the same thermophysical properties as the fracture zone. 


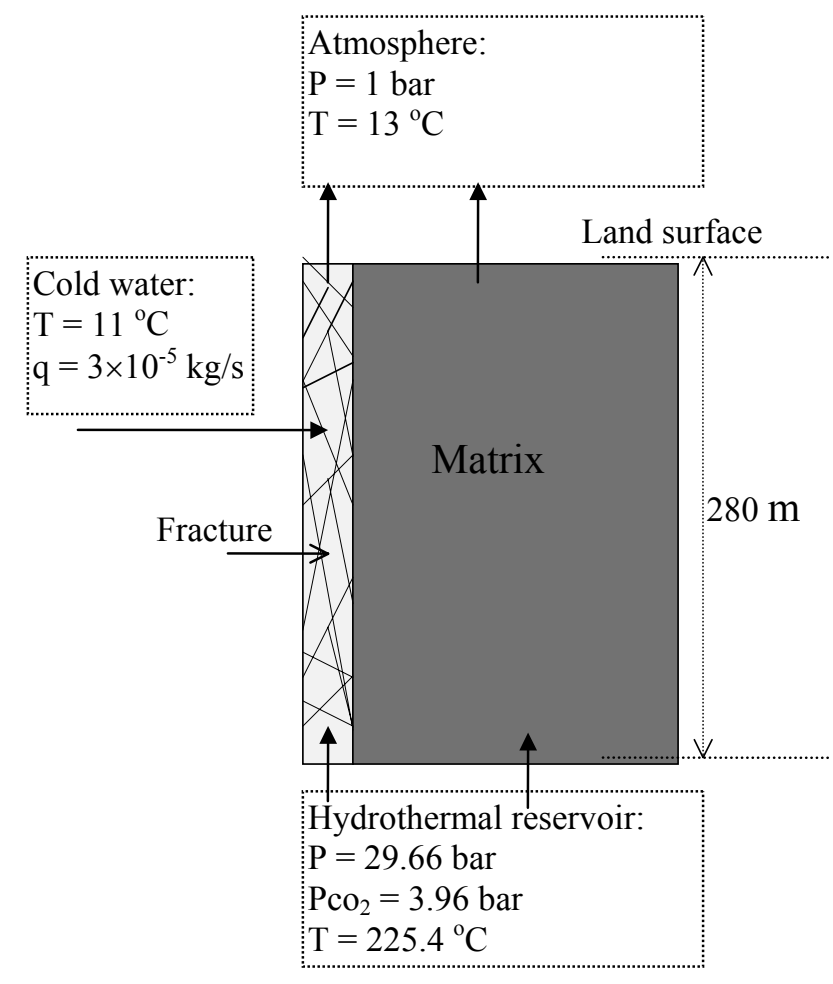

Figure 8.7.1. Vertical 2-D section model for hydrothermal fluid flow and rock alteration in a fractured rock.

Table 8.7.1. Some parameters used in the simulation for the fracture-matrix system

\begin{tabular}{lllll}
\hline medium & fracture & matrix & matrix & matrix \\
\hline symbol & $\mathrm{F}$ & $\mathrm{M} 1$ & $\mathrm{M} 2$ & $\mathrm{M} 3, \mathrm{M} 4, \mathrm{M} 5, \mathrm{M} 6$ \\
\hline grid spacing $(\mathrm{m})$ & 0.05 & 0.1 & 0.15 & $0.2,0.3,0.4,0.55$ \\
\hline permeability $\left(\mathrm{m}^{2}\right)$ & $1 \times 10^{-12}$ & $1 \times 10^{-14}$ & $1 \times 10^{-15}$ & $1 \times 10^{-16}$ \\
\hline parameters for relative & permeability and capillary & pressure & functions (van & Genuchten, 1980): \\
$\lambda$ & 0.457 & 0.457 & 0.457 & 0.457 \\
$\mathrm{~S}_{\mathrm{lr}}$ & 0.15 & 0.20 & 0.30 & 0.40 \\
$\mathrm{~S}_{\mathrm{ls}}$ & 1.0 & 1.0 & 1.0 & 1.0 \\
$\mathrm{P}_{0}(\mathrm{~Pa})$ & $6.195 \times 10^{3}$ & $6.195 \times 10^{4}$ & $1.959 \times 10^{5}$ & $6.195 \times 10^{5}$ \\
\hline porosity & 0.5 & 0.1 & 0.09 & 0.08 \\
\hline
\end{tabular}


Table 8.7.2. Aqueous chemical concentrations $\left(\mathrm{mol} / \mathrm{kgH}_{2} \mathrm{O}\right)$ of hot reservoir water and cold meteoric water used for the simulation study.

\begin{tabular}{lll}
\hline Component & hot water & cold water \\
\hline $\mathrm{Ca}^{2+}$ & $4.49 \times 10^{-4}$ & $1.27 \times 10^{-4}$ \\
$\mathrm{Mg}^{2+}$ & $1.44 \times 10^{-5}$ & $2.43 \times 10^{-4}$ \\
$\mathrm{Na}^{+}$ & $1.65 \times 10^{-2}$ & $1.00 \times 10^{-3}$ \\
$\mathrm{~K}^{+}$ & $1.23 \times 10^{-3}$ & $1.00 \times 10^{-4}$ \\
$\mathrm{HCO}^{-}$ & $8.82 \times 10^{-3}$ & $1.21 \times 10^{-3}$ \\
$\mathrm{SO}_{4}^{2-}$ & $1.86 \times 10^{-3}$ & $8.33 \times 10^{-5}$ \\
$\mathrm{Al}^{++}$ & $1.00 \times 10^{-6}$ & $1.00 \times 10^{-6}$ \\
$\mathrm{SiO}_{2}(\mathrm{aq})$ & $4.61 \times 10^{-3}$ & $9.65 \times 10^{-4}$ \\
$\mathrm{Cl}^{-}$ & $8.31 \times 10^{-3}$ & $1.61 \times 10^{-4}$ \\
$\mathrm{pH}$ & 6.6 & 6.8 \\
$\mathrm{~T}\left({ }^{\circ} \mathrm{C}\right)$ & 225 & 11 \\
& & \\
\end{tabular}

The aqueous phase chemical composition is based on data reported by White and Peterson (1991). The concentrations of major chemical species in samples at various wells are similar, and we arbitrarily chose data from well RDO-8 (Table 8.7.2) for our simulation. $\mathrm{CO}_{2}$ is the dominant gaseous species in the hydrothermal system, and its partial pressures range from 1 to 9 bars (1 bar $\equiv 10^{5} \mathrm{~Pa}$ ). We use an intermediate partial pressure value of approximately 4 bars. The cold recharge water chemical composition is taken from Sorey (1985) for cold Big Springs of LVC (Table 7) that is assumed to be representative of the shallow aquifer meteoric water. The initial fracture-matrix system is assumed to be liquid-water saturated.

The caprock mineral composition is highly variable in geothermal reservoirs. For the purpose of our study, we chose an initial rock mineral assemblage as listed in Table 8.7.3 throughout the column, which is based on the studies carried out by Steefel and Lasaga (1994) and White and Christenson (1998). The dissolution of the primary minerals proceeds subject to kinetic controls. The precipitation of secondary minerals (also given in Table 8.7.3) is represented using the same kinetic expression as that for dissolution. However, several aspects regarding precipitation are different, including nucleation, crystal growth and Ostwald ripening processes, as well as the calculation of the reactive surface area (Steefel and van Capellen, 1990). To simplify the description of precipitation kinetics, a constant reactive surface area of $0.01 \mathrm{~m}^{2}$ per $\mathrm{dm}^{3}$ (cubic decimeter) medium is used for the entire simulation time. Kinetic rates of precipitation depend on the activities of reactants supplied by dissolution. 
Table 8.7.3. Initial caprock mineral volume fractions (with $\mathrm{V}_{f}>0$ where $\mathrm{V}_{f}$ is mineral volume fraction) and secondary mineral phases $\left(\mathrm{V}_{\mathrm{f}}=0.0\right)$ formed in the simulation. The kinetic rate law used is given in Eq. B.5 (in Appendix B) using two exponential parameters $\mu$ and $\mathrm{n}$ set equal to one (first order kinetics). Rate constants are calculated from Eq. B.6, and kinetic constant at $25^{\circ} \mathrm{C}$ $\left(\mathrm{k}_{25}\right)$ and activation energy $\left(\mathrm{E}_{\mathrm{a}}\right)$ are taken from Steefel and Lasaga (1994), and Johnson et al. (1998).

\begin{tabular}{llllll}
\hline Mineral & $\begin{array}{l}\text { Chemical } \\
\text { composition }\end{array}$ & $\begin{array}{l}\text { Volume } \\
(\%)\end{array}$ & $\begin{array}{l}\text { Surface area } \\
\left(\mathrm{m}^{2} / \mathrm{dm}^{3}\right. \\
\text { medium })\end{array}$ & $\begin{array}{l}\mathrm{k}_{25} \\
\left(\mathrm{moles} \mathrm{m}^{-2} \mathrm{~s}^{-1}\right)\end{array}$ & $\begin{array}{l}\mathrm{E}_{\mathrm{a}} \\
(\mathrm{KJ} / \mathrm{mol})\end{array}$ \\
\hline $\begin{array}{l}\text { Primary: } \\
\text { quartz } \\
\text { cristobalite }\end{array}$ & $\mathrm{SiO}_{2}$ & 35 & 0.035 & $4.30 \times 10^{-14}$ & 75.00 \\
$\begin{array}{l}\text { K-feldspar } \\
\text { albite }\end{array}$ & $\mathrm{SiO}_{2}$ & 23 & 0.023 & $3.16 \times 10^{-13}$ & 69.08 \\
anorthite & $\mathrm{KAlSi}_{3} \mathrm{O}_{8}$ & 30 & 0.03 & $1.00 \times 10^{-12}$ & 68.73 \\
porosity & $\mathrm{NaAlSi}_{3} \mathrm{O}_{8}$ & 2 & 0.002 & $1.00 \times 10^{-12}$ & 68.73 \\
total & $\mathrm{CaAl}_{2} \mathrm{Si}_{2} \mathrm{O}_{8}$ & 2 & 0.002 & $1.00 \times 10^{-12}$ & 68.73 \\
& & 8 & ---- & --- & -- \\
$\begin{array}{l}\text { Secondary: } \\
\text { kaolinite }\end{array}$ & & 100 & ---- & - & - \\
muscovite & & & & & \\
pyrophyllite & $\mathrm{Al}_{2} \mathrm{Si}_{2} \mathrm{O}_{5}(\mathrm{OH})_{4}$ & 0 & 0.01 & $1.00 \times 10^{-13}$ & 62.76 \\
paragonite & $\mathrm{KAl}_{3} \mathrm{Si}_{3} \mathrm{O}_{10}(\mathrm{OH})_{2}$ & 0 & 0.01 & $1.00 \times 10^{-14}$ & 58.48 \\
calcite & $\mathrm{Al}_{2} \mathrm{Si}_{4} \mathrm{O}_{10}(\mathrm{OH})_{2}$ & 0 & 0.01 & $1.00 \times 10^{-13}$ & 62.76 \\
Amorphous silica & $\mathrm{NaAl}_{3} \mathrm{Si}_{3} \mathrm{O}_{10}(\mathrm{OH})_{2}$ & 0 & 0.01 & $1.00 \times 10^{-14}$ & 58.48 \\
\hline
\end{tabular}

The simulation is run for 1000 years. Initially, we limit the simulation to only fluid and heat flow until a steady-state is attained. Then we simulate chemical transport and fluid-rock interactions using the steady-state fluid and heat flow as the initial condition. Modeling the transport of a chemically reactive multi-component fluid is computationally intensive, and requires that a balance be struck between fluid and chemical complexity and calculation time. The described two-step approach can significantly save on computational time and give a detailed description of geochemical evolution of the system. In addition, the interpretation of results is easier when flow is decoupled from reactive transport. Although this case considers an idealized fractured rock, generally any fracture geometry can be considered in TOUGH2/TOUGHREACT. Furthermore, we should point out that $\mathrm{CO}_{2}$ consumed by mineral precipitation such as calcite is assumed not to affect its partial pressure and then fluid flow. If at the bottom boundary (geothermal reservoir) the partial pressure remains constant as in the case simulated here, this 
assumption is justified. A 1-D vertical column is tested first with the bottom and top boundary conditions as shown in Figure 8.7.1. The effect of $\mathrm{CO}_{2}$ consumed by calcite precipitation on fluid flow is negligible in this kinetically-controlled chemical system. Most calcite precipitation occurs close to the bottom reservoir. $\mathrm{CO}_{2}$ consumed by calcite precipitation is replenished by enhanced physical transport from the reservoir.

The EOS2 flow module was used for this problem. The input and output files for the problem are given in the distribution CD (subdirectory: /sample-problems/P7_EOS2-LVC). To shorten the simualation time for benchmarking purposes, the time in the PARAM input block of flow.inp is specified as 3.15576E08 (s, or 10 years). Users can reset this variable to their desired time.

\subsubsection{Results}

Contour plots of steady-state liquid water saturation and temperature are presented in Figure 8.7.2. Some results for changes of mineral abundances are given in Figures 8.7.3 and 8.7.4. More results can be found in Xu and Pruess (2001a).

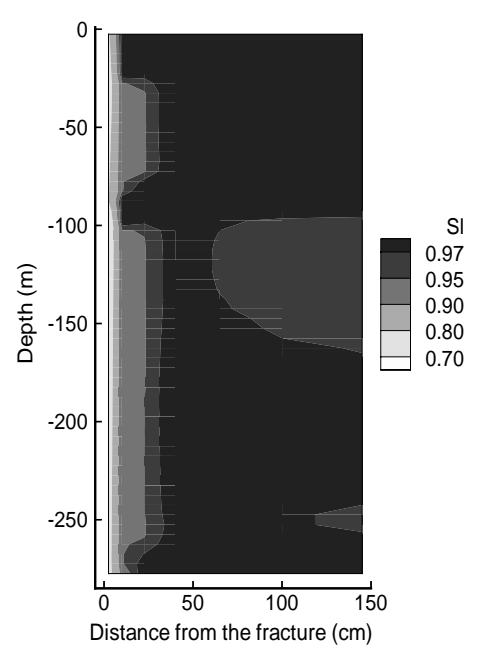

(a)

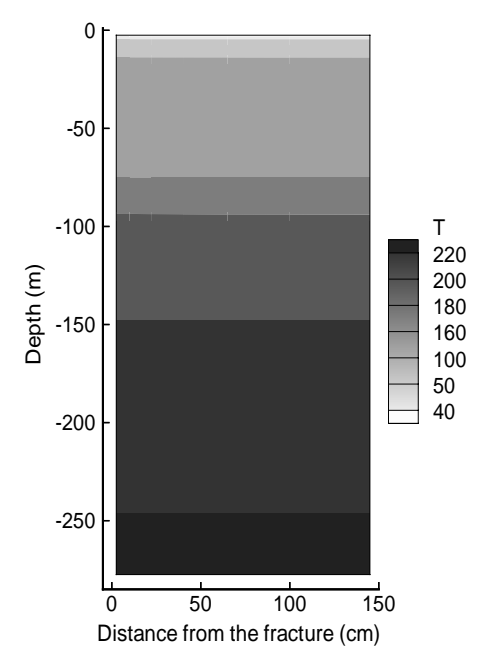

(b)

Figure 8.7.2. Liquid saturation (a) and temperature $\left(b\right.$, in $\left.{ }^{\circ} \mathrm{C}\right)$ in the fracture-matrix system. This and subsequent contour plots extend to a distance of $145 \mathrm{~cm}$, which is the distance between the center of the fracture zone, and the nodal point at the center of the innermost matrix grid block. The overall size of the model domain is $175 \mathrm{~cm}$ (sum of all grid spacings; see Table 8.7.1). 


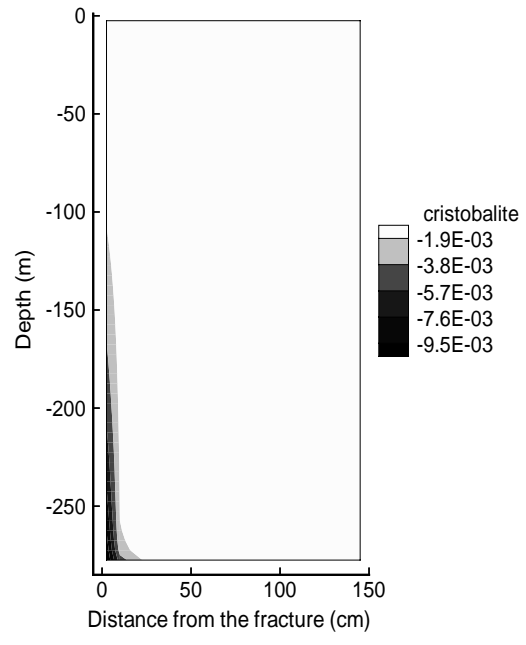

(a)

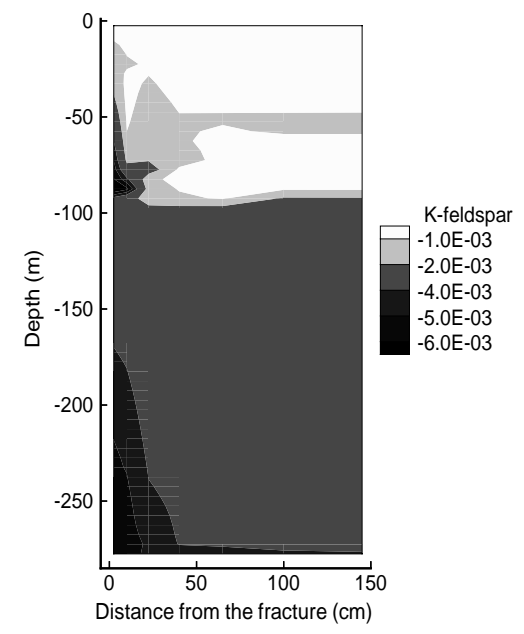

(c)

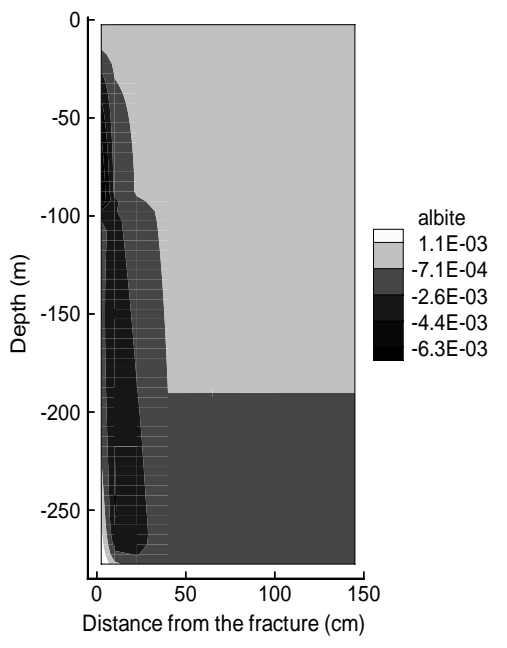

(b)

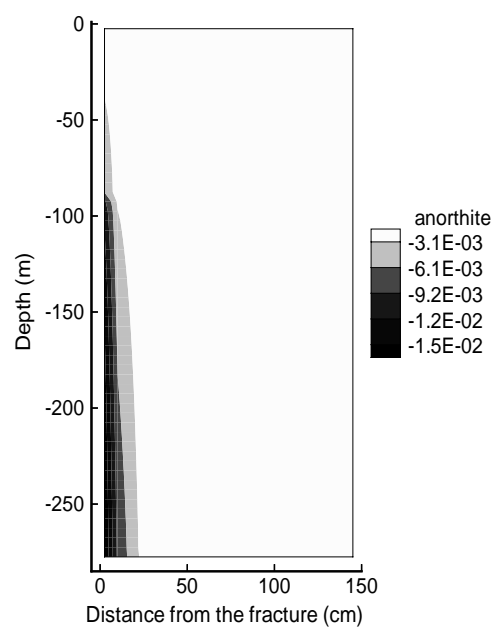

(d)

Figure 8.7.3. Change of primary mineral abundance (in volume fraction) after 1000 years. The inflection points in the figures result from (1) grid discretization and (2) highly non-linear nature of heterogeneous reactions. The space discretization in the simulation is not fine enough to give an accurate definition of mineral abundances near inflection points. 


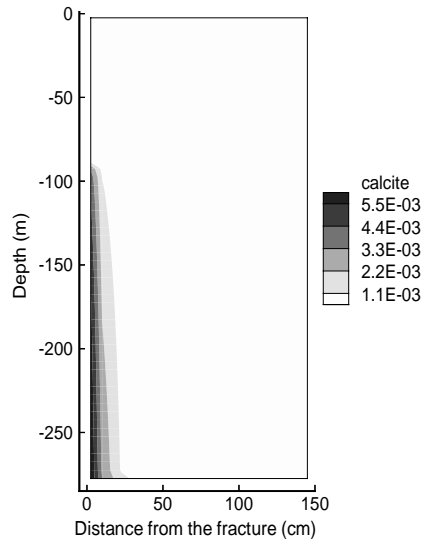

(a)

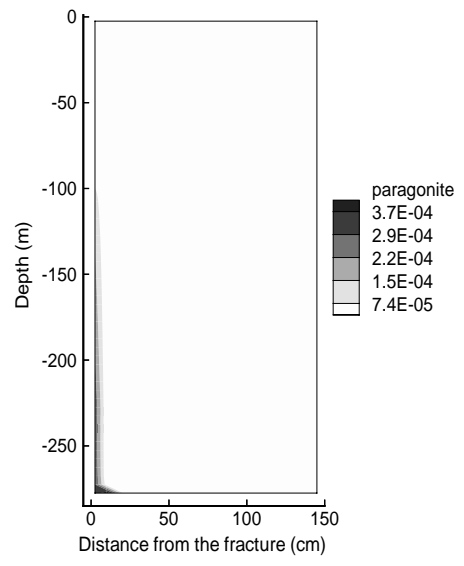

(d)

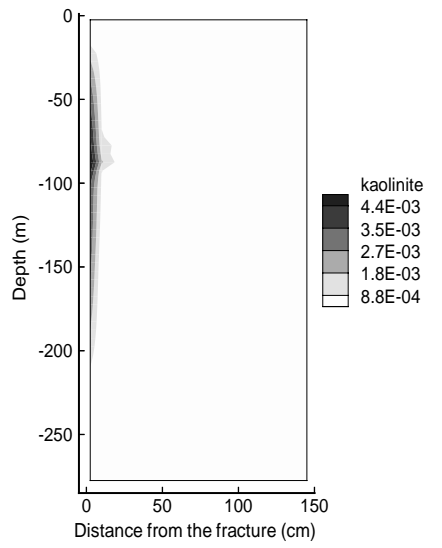

(b)

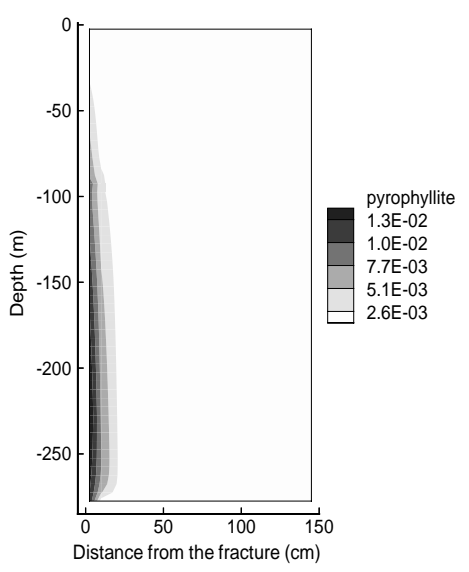

(e)

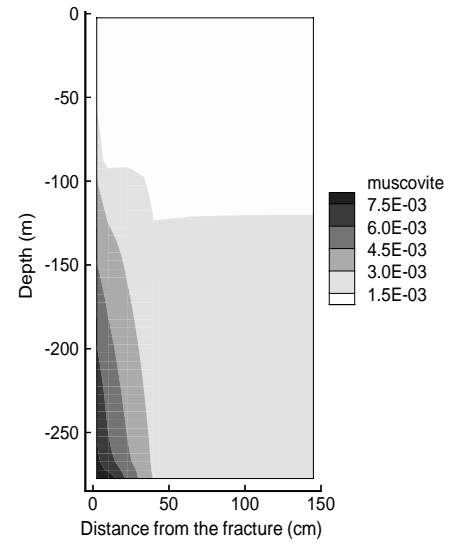

(c)

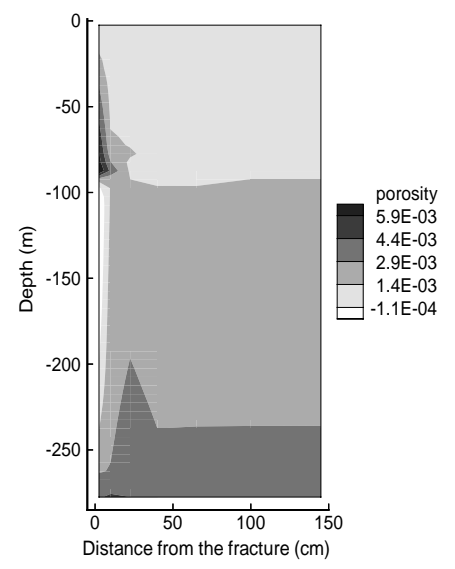

(f)

Figure 8.7.4. Change of mineral abundance (secondary phases, in volume fraction) and porosity after 1000 years. 


\subsection{Injection Well Scaling and Acidizing at Tiwi Field, Philippines (EOS1)}

\subsubsection{Problem statement}

Nag-67 is one of the hot brine injectors located to the south-east of the Tiwi geothermal field, Philippines. The well was completed in March 1987. The injectivity of the well decreased significantly with time. The drop in injection capacity was attributed to scaling inside the wellbore as early as October 1992.

Records of injection history (Figure 8.8.1) and fluid chemistry for Nag-67 were reviewed to determine the nature of the deposited scale and to estimate the amount and location of the deposits. The well was acidized in January 1989 primarily to clear the near-wellbore formation of drilling mud damage and to improve its injectivity. Injection capacity of the well after the stimulation was $126 \mathrm{~kg} / \mathrm{s}$ at a wellhead pressure of $1.38 \mathrm{MPa}$. In 1996, the well was found to accept only $38 \mathrm{~kg} / \mathrm{s}$ at an injection wellhead pressure of about $1 \mathrm{MPa}$. In 1999, an injectivity test indicated that the capacity of the well had dropped to $17 \mathrm{~kg} / \mathrm{s}$ at an injection wellhead pressure of 1.31 MPa. In March 2000, the recorded injection rate in Nag-67 suddenly decreased to $3.8 \mathrm{~kg} / \mathrm{s}$.

In January 2001, the scale inside the Nag-67 wellbore was drilled-out, and the scale deposited in the near-well formation was dissolved by acid. Measurements after the scale drillout indicated that the capacity of the injector went up to $25.2 \mathrm{~kg} / \mathrm{s}$, and another test after the acid stimulation showed a further increase to $113.4 \mathrm{~kg} / \mathrm{s}$. These results strongly suggested that the decline in injectivity of the well was caused primarily by scale deposition in the near-well formation. Based on the chemistry of the brine injected and analysis of deposited scale, it was determined that most of the scale in Nag -67 was amorphous silica.

The silica concentration and $\mathrm{pH}$ of the brine being supplied to the Nag-67 injector were monitored between 1989 and 2000. Complete brine analyses were also available for every year except 1999 and were used to characterize the saturation state of the brine with respect to other minerals. From this historical chemical record, the degree of amorphous silica saturation in each analyzed water sample was determined. 


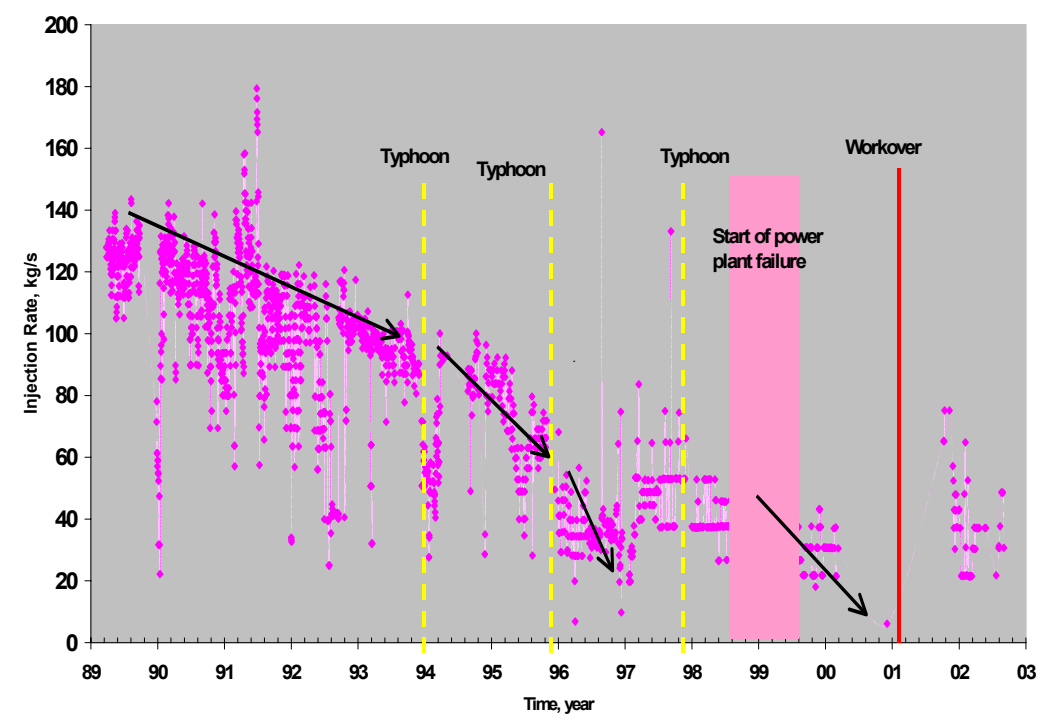

Figure 8.8.1. Historical injection rates $(\mathrm{kg} / \mathrm{s})$ in Nag-67.

The estimated amount of silica (in the formation) dissolved by acid stimulation was calculated by assuming that the acid dissolved a stoichiometrically equivalent amount of silica. The silica scale volume calculated in this way was only $1.4 \mathrm{~m}^{3}$. The dissolution of this seemingly small amount of amorphous silica nevertheless increased the injection capacity of the well to near original capacity. Therefore, it would appear that a significant part of the injectivity loss was related to silica deposition in the formation close to the wellbore, as opposed to in the wellbore itself.

To understand the scaling process and loss of injectivity in hot brine injectors, Ontoy et al. (2003) identified factors that cause the deposition of amorphous silica in the near-well formation and the extent of their effect using TOUGHREACT. These factors include the silica concentration in the hot brine injectate, the temperature of the injectate, the flowrate of the injectate, the $\mathrm{pH}$ of the injectate, and the temperature and pressure conditions of the reservoir in the vicinity of the injector.

$\mathrm{Xu}$ et al. (2004b) conducted a large number of numerical simulations to reproduce the loss of injectivity and its recovery by acid injection. A porosity-permeability relationship (Verma and 
Pruess, 1988; see Eq. F.8 in Appendix F) was calibrated by comparing predicted injection indexes with field observed data. Here we give brief description of the work of Xu et al. (2004b).

\subsubsection{Problem setup}

\section{Grid and fluid flow parameters}

A $120 \mathrm{~m}$ thick reservoir formation at the bottommost permeable zone of the injection well (Nag-67) was modeled. A simple one-dimensional radial flow model was used, consisting of 50 radial blocks with logarithmically increasing radii (Figure 8.8.2). The 50 blocks represent a distance of $1000 \mathrm{~m}$ from the wall of the drilled open hole. A fracture porosity of 1\% (ratio of fracture volume over the total formation volume) was assumed. The initial bulk permeability has been estimated at $8.5 \times 10^{-14} \mathrm{~m}^{2}$, to be consistent with the observed initial injectivity index of the well. Conductive heat exchange with rocks of low permeability above and below this zone is an important process. The confining layers are modeled as semi-infinite half spaces, and heat exchange is treated with a semi-analytical technique due to Vinsome and Westerveld (1980).

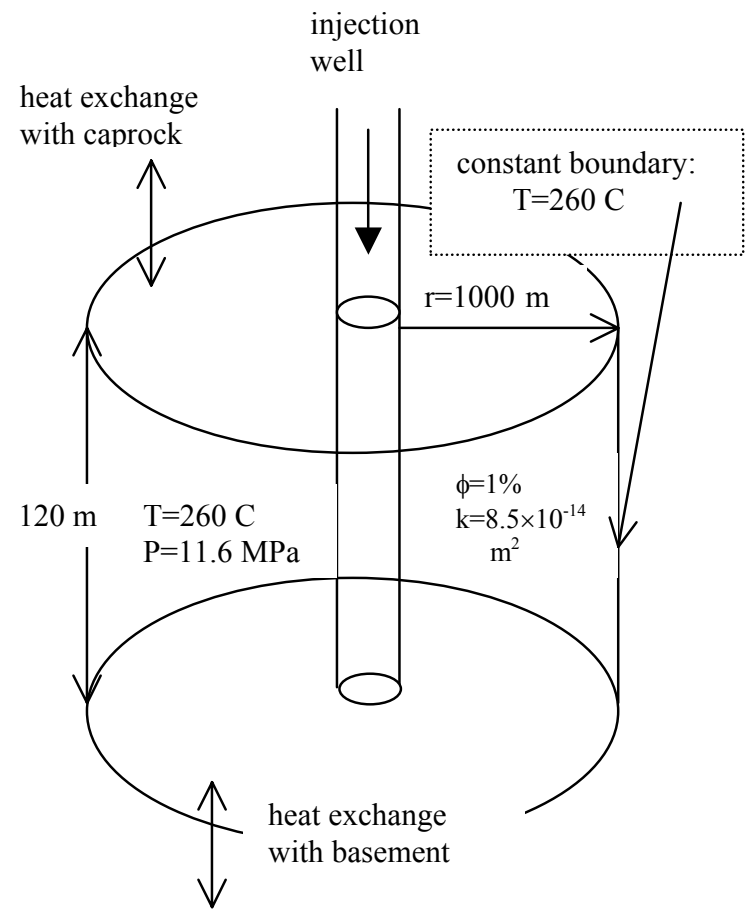

Figure 8.8.2. Simplified conceptual model for injection well Nag-67. 
Only the fracture network is considered in the flow simulation, with the assumption that the fluid exchange with the surrounding low permeability matrix is insignificant. To allow for chemical reaction with the rock, $50 \%$ porosity was assigned to the blocks, and the total volume was accordingly doubled. The simulation zone was therefore "compressed" into a $2.4 \mathrm{~m}$ thick layer with $50 \%$ pore volume and $50 \%$ rock volume. A fracture permeability of $4.3 \times 10^{-12} \mathrm{~m}^{2}$ was used in the simulation (corresponding to a bulk fracture permeability value of $8.5 \times 10^{-14} \mathrm{~m}^{2}$ for the whole formation thickness with $1 \%$ fracture porosity). For consistency, bulk fracture porosity and permeability are reported here.

Initial reservoir temperature and pressure were assumed as $260^{\circ} \mathrm{C}$ and $11.6 \mathrm{MPa}$, respectively. The injection history of the well was used to define the amount of injected mass versus time (Figure 8.8.1): 50\% of the total injection rate in Nag-67 was used because spinner surveys showed that the bottommost permeable zone accepted about $50 \%$ of the injectate. A constant injection temperature of $160^{\circ} \mathrm{C}$ was used because measured temperature fluctuations were generally small and with a relatively flat average trend (Figure 8.8.3).

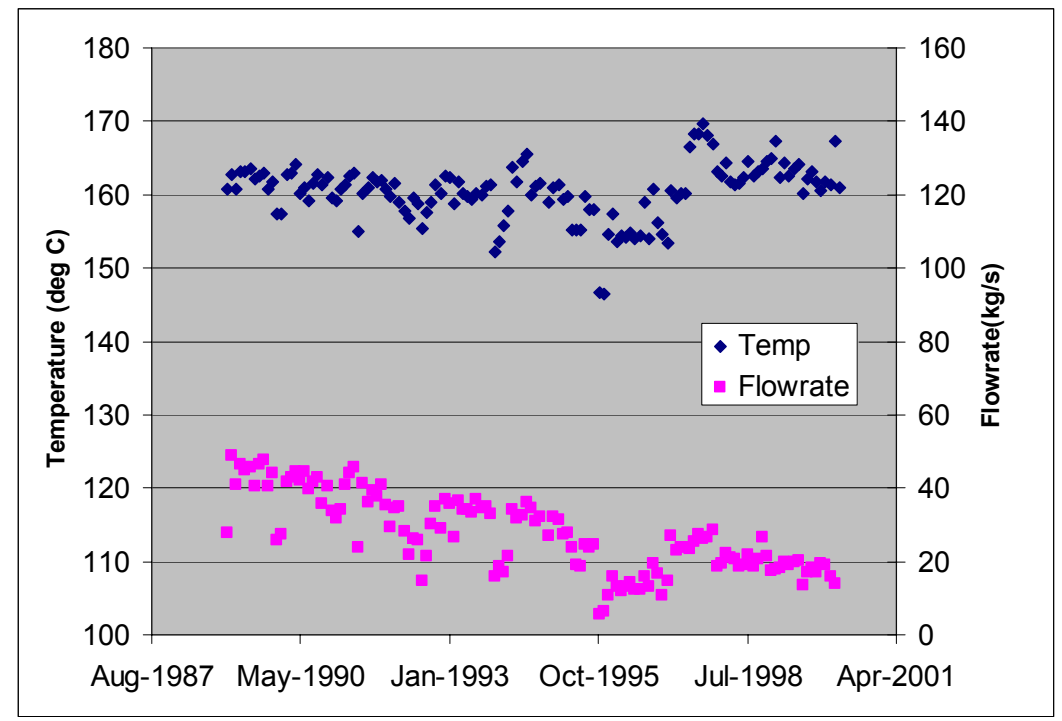

Figure 8.8.3. Measured temperature of the injected water. 


\section{Geochemical data}

The types and initial abundances of primary minerals were determined from the reported Nag-67 alteration mineralogy at the 1798-1920 m MD permeable zone (propylitic/phyllic rock). Secondary minerals were also determined from field observations (Table 8.8.1).

Table 8.8.1. List of minerals and aqueous species considered in the simulations

\begin{tabular}{llc|c}
\hline Mineral & $\begin{array}{c}\text { Mineral } \\
\text { Precipitation } \\
\text { /Dissolution }\end{array}$ & $\begin{array}{c}\text { Mineral } \\
\text { Initial } \\
\text { Volume } \\
\text { fraction }\end{array}$ & $\begin{array}{c}\text { Primary } \\
\text { Aqueous } \\
\text { Components }\end{array}$ \\
\hline $\begin{array}{l}\text { Primary: } \\
\text { albite-low }\end{array}$ & Kinetic & 0.18 & $\mathrm{H}_{2} \mathrm{O}$ \\
anorthite & Kinetic & 0.02 & $\mathrm{H}^{+}$ \\
illite & Kinetic & 0.05 & $\mathrm{Ca}^{+2}$ \\
quartz & Kinetic & 0.14 & $\mathrm{Mg}^{+2}$ \\
muscovite & Kinetic & 0.16 & $\mathrm{Na}^{+}$ \\
clinochlore-7a \\
clinozoisite & Kinetic & 0.08 & $\mathrm{Cl}^{-}$ \\
calcite & Kinetic & 0.01 & $\mathrm{SiO}_{2(\mathrm{aq})}$ \\
$\begin{array}{l}\text { Secondary: } \\
\text { amorphous silica } \\
\text { microcline }\end{array}$ & $\begin{array}{l}\text { Kinetic } \\
\text { Kinetic }\end{array}$ & & $\mathrm{HCO}_{3}^{-}$ \\
$\begin{array}{l}\text { kaolinite } \\
\text { anhydrite }\end{array}$ & Kinetic & & $\mathrm{K}^{-2}$ \\
$\mathrm{AlO}_{2}^{-}$ & \\
\hline
\end{tabular}

The composition of the injected brine was provided from historical analytical data. The formation water was reconstituted from the known brine composition as follows. First, the brine was diluted to yield saturation with quartz at the observed reservoir temperature of $260^{\circ} \mathrm{C}$ (thus reversing the concentrative effect of flashing). The resulting water was then equilibrated with minerals identified in the well mineralogy log (calculating the aluminum concentration using equilibrium with microcline, sodium using albite, $\mathrm{pH}$ using calcite, calcium using clinozoisite, and magnesium using clinochlore). Calcite and anhydrite were assumed to react at equilibrium because their reaction rate is typically quite rapid. Other minerals were set to react under kinetic constraints (Table 8.8.1). Thermodynamic and kinetic data for amorphous silica were taken from Carroll et al. (1998), and Gunnarsson and Arnorsson (2000). For other minerals, thermodynamic and kinetic data were taken from various other literature sources.

For all minerals except amorphous silica, input surface areas were estimated from the geometry of the modeled fracture (around $130 \mathrm{~m}^{2} / \mathrm{m}^{3}$ medium). For amorphous silica, a large 
surface area was estimated $\left(10^{7} \mathrm{~cm}^{2} / \mathrm{g}\right)$ from Parks (1990, Fig. 16). Such a large value takes into account the very small size of amorphous silica particles in solution. Silica concentrations of 705 and $710 \mathrm{ppm}$ were used, within the range of observed values (Figure 8.8.4).

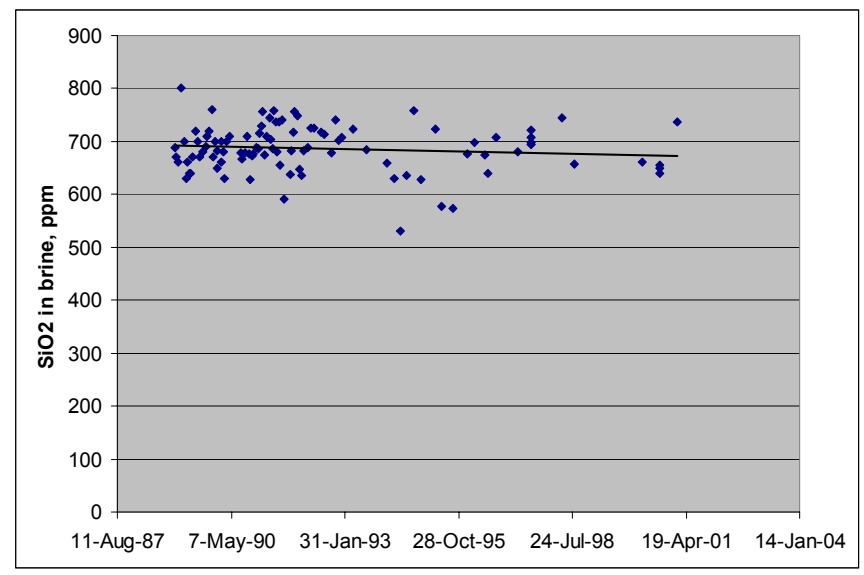

Figure 8.8.4. Evolution of silica concentrations in the injected water.

Parameters $\phi_{\mathrm{c}}$ and $\mathrm{n}$ in Eq. (F. 8) in Appendix F were calibrated by comparing simulated injection indexes with measured data. The injection index is defined as

$$
I I=\frac{\text { Flowrate }}{P_{b}-P_{i}}
$$

where, $\mathrm{P}_{\mathrm{b}}$ is the borehole pressure and $\mathrm{P}_{\mathrm{i}}$ is the initial reservoir pressure (116 bar). A total of 18 simulations were performed using the silica concentrations and values of parameters $\phi_{\mathrm{c}}$ and $\mathrm{n}$ as listed in Table 8.8.2. The simulated time of injection was approximately 12 years, corresponding to the time from the initial acidization of the well in January, 1989, to the time of the well workover in January, 2001. 
Table 8.8.2. List of simulations using different injection silica concentrations and values of parameters $\phi_{\mathrm{c}}$ and $\mathrm{n}$.

\begin{tabular}{|c|c|c|c|}
\hline $\begin{array}{l}\text { Silica concentration } \\
\text { (ppm) }\end{array}$ & $\phi_{c}(\%)$ & $\mathrm{n}$ & Simulation number \\
\hline \multirow[t]{12}{*}{705} & \multirow[t]{3}{*}{0.88} & 9 & 1 \\
\hline & & 11 & 2 \\
\hline & & 13 & 3 \\
\hline & \multirow[t]{3}{*}{0.90} & 7 & 4 \\
\hline & & 9 & 5 \\
\hline & & 11 & 6 \\
\hline & \multirow[t]{3}{*}{0.92} & 6 & 7 \\
\hline & & 8 & 8 \\
\hline & & 10 & 9 \\
\hline & \multirow[t]{3}{*}{0.94} & 3 & 10 \\
\hline & & 5 & 11 \\
\hline & & 6 & 12 \\
\hline \multirow[t]{6}{*}{710} & \multirow[t]{3}{*}{0.90} & 3 & 13 \\
\hline & & 4 & 14 \\
\hline & & 5 & 15 \\
\hline & \multirow[t]{3}{*}{0.92} & 2 & 16 \\
\hline & & 3 & 17 \\
\hline & & 4 & 18 \\
\hline
\end{tabular}

\subsubsection{Results and discussion}

The injection indexes can be reproduced by different sets of parameter combinations in the porosity-permeability relationship, Eq. (F.8) in Appendix F. For an injection silica concentration of $705 \mathrm{ppm}$, reasonable fits are obtained for the following combinations of $\phi_{\mathrm{c}}$ and $\mathrm{n}$ values: (1) $\phi_{\mathrm{c}}=0.88 \%$ and $\mathrm{n}=13,(2) \phi_{\mathrm{c}}=0.9 \%$ and $\mathrm{n}=11$, (3) $\phi_{\mathrm{c}}=0.92 \%$ and $\mathrm{n}=10$, and (4) $\phi_{\mathrm{c}}$ $=0.94 \%$ and $\mathrm{n}=6$. Here results obtained with only two sets of $\phi_{\mathrm{c}}$ and $\mathrm{n}$ values are presented in Figure 8.8.5. More results can be found in Xu et al. (2004b). A smaller critical porosity $\phi_{c}$ 
requires a larger power term $\mathrm{n}$. For a silica concentration of $710 \mathrm{ppm}$, the matching parameter combinations are (1) $\phi_{\mathrm{c}}=0.9 \%$ and $\mathrm{n}=5$, and (2) $\phi_{\mathrm{c}}=0.92 \%$ and $\mathrm{n}=4$. The simulated results show that small decreases in porosity result in steep reductions in permeability. This is consistent with a permeability experiment of Moore et al. (1983) in which a heated aqueous fluid was passed down a temperature gradient through Westerly Granite. The experiment showed a reduction in permeability of $96 \%$ with an $8 \%$ reduction of the initial porosity over a two-week period.

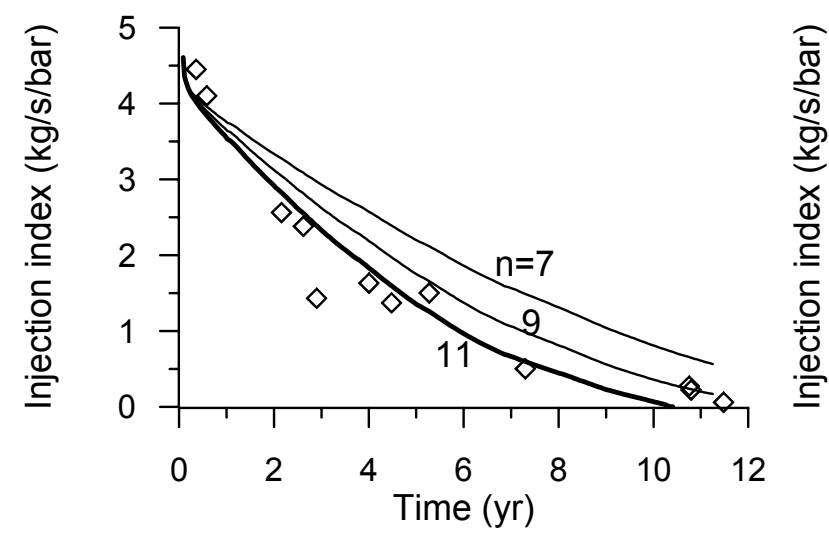

(a) $\phi_{\mathrm{c}}=0.90 \%$

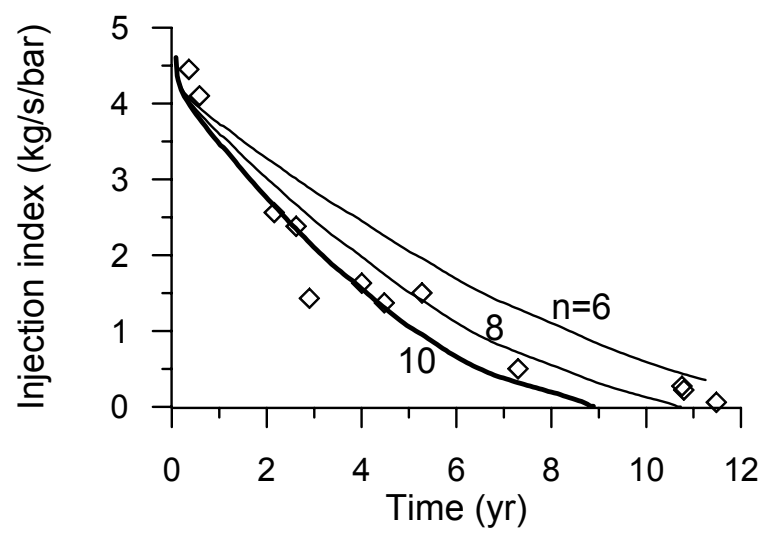

(b) $\phi_{\mathrm{c}}=0.92 \%$

Figure 8.8.5. Simulated injection indexes using an injection silica concentration of $705 \mathrm{ppm}$, together with measured data.

An injection silica concentration of $705 \mathrm{ppm}$ results in a total amorphous silica precipitation of $5.9 \mathrm{~m}^{3}$ in the reservoir formation, while a silica concentration of $710 \mathrm{ppm}$ results in $19.5 \mathrm{~m}^{3}$. The estimated amount of amorphous silica in the formation dissolved by acid is about $1.4 \mathrm{~m}^{3}$. Therefore, an injection silica concentration of $705 \mathrm{ppm}$ could be a reasonable number for capturing total silica precipitation.

Further review of Figure 8.8.5 shows that the simulated injection indexes reach zero at earlier times than observed. Figure 8.8.3 indicates that after January 1996 (seven years after the simulation start) temperatures increase significantly above $160^{\circ} \mathrm{C}$. We then performed an additional simulation using an injection temperature of $161^{\circ} \mathrm{C}$ for the later time period. Other parameters for the additional simulation are an injection silica concentration of $705 \mathrm{ppm}, \phi_{\mathrm{c}}=$ $0.92 \%$ and $n=10$. Results of the additional simulation are presented in Figure 8.8.6, showing that the match of injection indexes to observations for the later period was improved. The higher 
temperature results in some early precipitated silica dissolving at later time. At the end of the simulation, a total of $2 \mathrm{~m}^{3}$ of amorphous silica remains in the formation, similar to the actual amount of $1.4 \mathrm{~m}^{3}$ estimated to have been dissolved by acid.

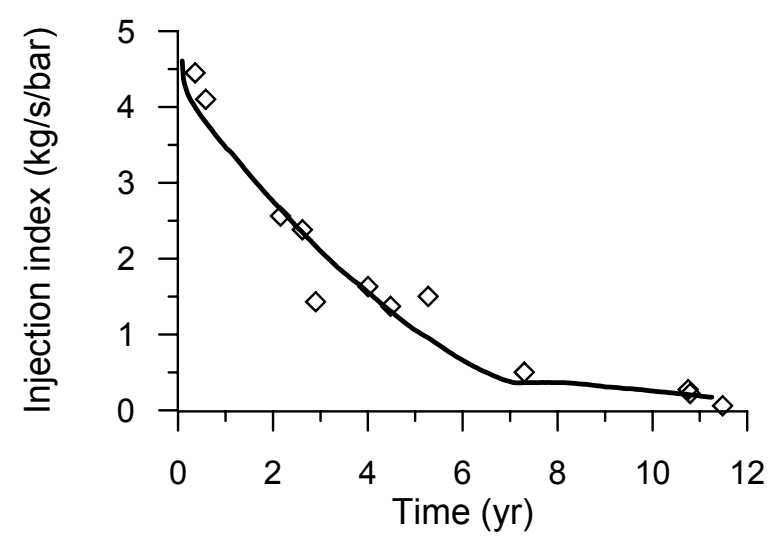

Figure 8.8.6. Simulated injection indexes using an injection temperature of $161^{\circ} \mathrm{C}$ for the later time period, together with measured data ( silica concentration $=705 \mathrm{ppm}, \phi_{\mathrm{c}}=0.92 \%$, and $\mathrm{n}=$ $10)$.

Significant reductions in porosity and permeability occur within a $10 \mathrm{~m}$ radius of the well (Figure 8.8.7). The pattern of permeability change on a logarithmic scale is similar to porosity change on a linear scale. The porosity reduction is mainly due to precipitation of amorphous silica (Figure 8.8.8). Some low-albite precipitation and minor illite precipitation and calcite dissolution occur in the simulations. 


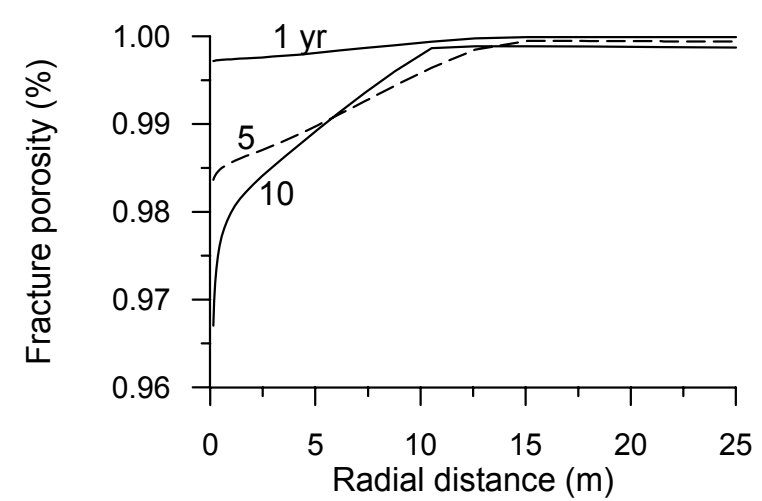

(a) Porosity
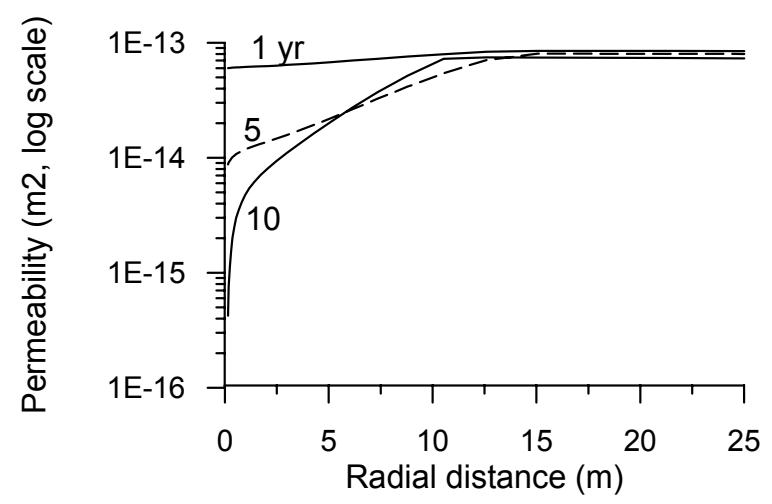

(b) Permeability

Figure 8.8.7. Distribution of porosity and permeability along the well radius for the simulation shown in Figure 8.8.6.

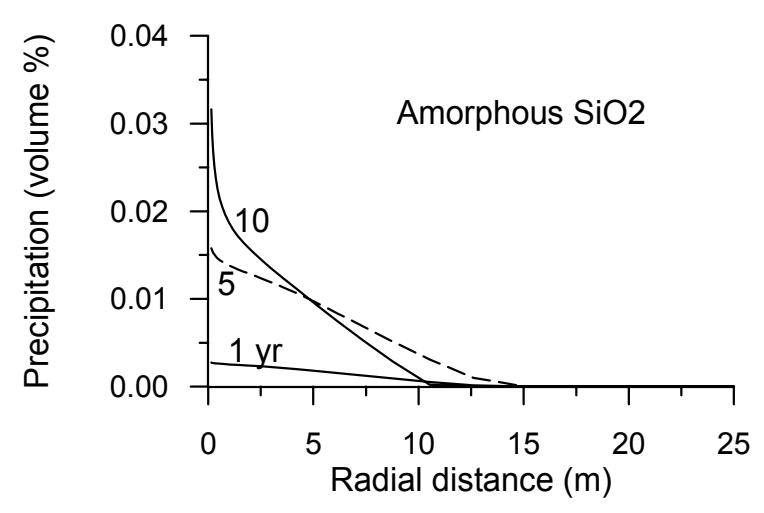

Figure 8.8.8. Amorphous silica precipitated along the well radius for the simulation shown in Figure 8.8.6.

For only one simulation corresponding to Figure 8.8.6, input and output files are given in the distribution CD (subdirectory: /sample-problems/P8_EOS1-scaling). To shorten the simulation time for benchmarking purposes, the time in the PARAM input block of flow.inp is specified as $3.5478 \mathrm{e}+07 \mathrm{~s}(1 / 10$ of the entire simulation time and slightly longer than 1 year). Users can reset this variable to their desired time. Parts of output files for fluid flow, aqueous chemical concentrations, and changes of mineral abundances are given in Figures 8.8.9, 8.8.10 and 8.8.11. 
Figure 8.8.9. Part of file flow.out for problem no. 8 (injection well scaling).

\begin{tabular}{|c|c|c|c|c|c|c|c|c|c|}
\hline A1 & 5( & 1, & 4) & ST & $=0.262800 \mathrm{E}+07$ & $\mathrm{DT}$ & $=0.100000 \mathrm{E}+01$ & $\mathrm{DX} 1=$ & $0.191361 \mathrm{E}+06$ \\
\hline A1 & 4( & 2 , & 3) & ST & $262800 \mathrm{E}+07$ & DT & $.100000 \mathrm{E}+01$ & $\mathrm{DX} 1=$ & $228790 \mathrm{E}+0$ \\
\hline A1 & 4( & 3, & 3) & ST & $0.262800 \mathrm{E}+07$ & DT & $0.100000 \mathrm{E}+01$ & $\mathrm{DX1}=$ & $.152136 \mathrm{E}+$ \\
\hline A1 & 4( & 4, & 3) & ST & $=0.262800 \mathrm{E}+07$ & DT & $0.100000 \mathrm{E}+01$ & $\mathrm{DX1}=$ & $0.100274 \mathrm{E}+0$ \\
\hline A1 & 4( & 5, & 3) & ST & $=0.262800 \mathrm{E}+07$ & DT & $=0.100000 \mathrm{E}+01$ & $\mathrm{DX} 1=$ & $0.778482 \mathrm{E}+0$ \\
\hline
\end{tabular}

OUTPUT DATA AFTER (1500, 2)-2-TIME STEPS

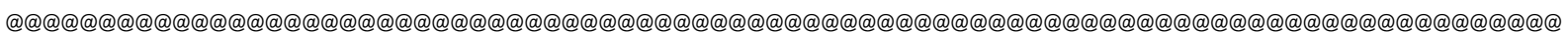

TOTAL TIME KCYC ITER ITERC KON DX1M DX2M DX3M

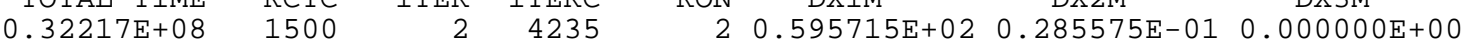

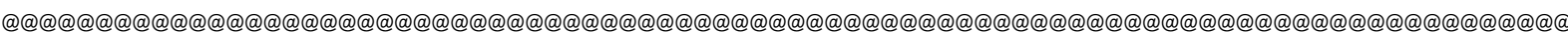

$\begin{array}{lllllll}\text { ELEM. INDEX } & \mathrm{P} & \mathrm{T} & \mathrm{SG} & \mathrm{SW} & \mathrm{X} 1 & \mathrm{X} 2\end{array}$

$(\mathrm{PA}) \quad(\mathrm{DEG}-\mathrm{C})$

$\begin{array}{llllllllllll}\text { A1 } 3 & 1 & 0.12345 \mathrm{E}+08 & 0.16041 \mathrm{E}+03 & 0.00000 \mathrm{E}+00 & 0.10000 \mathrm{E}+01 & 0.10000 \mathrm{E}+01 & 0.00000 \mathrm{E}+00\end{array}$

$\begin{array}{lllllllllll}\mathrm{A} 1 & 4 & 2 & 0.12318 \mathrm{E}+08 & 0.16041 \mathrm{E}+03 & 0.00000 \mathrm{E}+00 & 0.10000 \mathrm{E}+01 & 0.10000 \mathrm{E}+01 & 0.00000 \mathrm{E}+00\end{array}$

A1 $5530.12293 \mathrm{E}+08 \quad 0.16042 \mathrm{E}+03 \quad 0.00000 \mathrm{E}+00 \quad 0.10000 \mathrm{E}+01 \quad 0.10000 \mathrm{E}+01 \quad 0.00000 \mathrm{E}+00$

$\begin{array}{lllllllllll}\mathrm{A} 1 & 6 & 4 & 0.12269 \mathrm{E}+08 & 0.16042 \mathrm{E}+03 & 0.00000 \mathrm{E}+00 & 0.10000 \mathrm{E}+01 & 0.10000 \mathrm{E}+01 & 0.00000 \mathrm{E}+00\end{array}$

$\begin{array}{llllllllll}\text { A } 7 & 5 & 0.12246 \mathrm{E}+08 & 0.16042 \mathrm{E}+03 & 0.00000 \mathrm{E}+00 & 0.10000 \mathrm{E}+01 & 0.10000 \mathrm{E}+01 & 0.00000 \mathrm{E}+00\end{array}$

Figure 8.8.10. Part of file sca_conc.dat for problem no. 8 after $t=1 \mathrm{yr}\left(\mathrm{T}\right.$ is temperature in ${ }^{\circ} \mathrm{C}$, unit of concentrations is $\mathrm{mol} / \mathrm{l})$.

\begin{tabular}{cccccccc}
\hline $\mathrm{X}$ & $\mathrm{T}(\mathrm{C})$ & $\mathrm{pH}$ & $\mathrm{ca}+2$ & $\mathrm{mg}+2$ & $\mathrm{n}$ & & \\
0.139 & 160.409 & 6.7458 & $0.1033 \mathrm{E}-02$ & $0.1728 \mathrm{E}-04$ & $0.1273 \mathrm{E}+00$ & $0.1164 \mathrm{E}-01$ & $0.1043 \mathrm{E}-02$ \\
0.179 & 160.413 & 6.7458 & $0.1033 \mathrm{E}-02$ & $0.1729 \mathrm{E}-04$ & $0.1273 \mathrm{E}+00$ & $0.1164 \mathrm{E}-01$ & $0.1043 \mathrm{E}-02$ \\
0.228 & 160.417 & 6.7458 & $0.1033 \mathrm{E}-02$ & $0.1730 \mathrm{E}-04$ & $0.1273 \mathrm{E}+00$ & $0.1164 \mathrm{E}-01$ & $0.1043 \mathrm{E}-02$ \\
0.286 & 160.420 & 6.7459 & $0.1033 \mathrm{E}-02$ & $0.1731 \mathrm{E}-04$ & $0.1273 \mathrm{E}+00$ & $0.1164 \mathrm{E}-01$ & $0.1043 \mathrm{E}-02$ \\
0.356 & 160.423 & 6.7459 & $0.1033 \mathrm{E}-02$ & $0.1734 \mathrm{E}-04$ & $0.1273 \mathrm{E}+00$ & $0.1164 \mathrm{E}-01$ & $0.1043 \mathrm{E}-02$ \\
0.440 & 160.426 & 6.7460 & $0.1033 \mathrm{E}-02$ & $0.1737 \mathrm{E}-04$ & $0.1273 \mathrm{E}+00$ & $0.1164 \mathrm{E}-01$ & $0.1043 \mathrm{E}-02$ \\
0.539 & 160.429 & 6.7460 & $0.1033 \mathrm{E}-02$ & $0.1742 \mathrm{E}-04$ & $0.1273 \mathrm{E}+00$ & $0.1164 \mathrm{E}-01$ & $0.1043 \mathrm{E}-02$ \\
0.658 & 160.432 & 6.7461 & $0.1033 \mathrm{E}-02$ & $0.1748 \mathrm{E}-04$ & $0.1273 \mathrm{E}+00$ & $0.1164 \mathrm{E}-01$ & $0.1043 \mathrm{E}-02$ \\
0.801 & 160.436 & 6.7463 & $0.1033 \mathrm{E}-02$ & $0.1758 \mathrm{E}-04$ & $0.1273 \mathrm{E}+00$ & $0.1164 \mathrm{E}-01$ & $0.1043 \mathrm{E}-02$ \\
0.971 & 160.439 & 6.7464 & $0.1033 \mathrm{E}-02$ & $0.1771 \mathrm{E}-04$ & $0.1273 \mathrm{E}+00$ & $0.1164 \mathrm{E}-01$ & $0.1043 \mathrm{E}-02$ \\
1.174 & 160.442 & 6.7467 & $0.1033 \mathrm{E}-02$ & $0.1791 \mathrm{E}-04$ & $0.1273 \mathrm{E}+00$ & $0.1165 \mathrm{E}-01$ & $0.1043 \mathrm{E}-02$ \\
1.417 & 160.446 & 6.7471 & $0.1033 \mathrm{E}-02$ & $0.1818 \mathrm{E}-04$ & $0.1273 \mathrm{E}+00$ & $0.1165 \mathrm{E}-01$ & $0.1043 \mathrm{E}-02$ \\
1.708 & 160.450 & 6.7476 & $0.1033 \mathrm{E}-02$ & $0.1857 \mathrm{E}-04$ & $0.1273 \mathrm{E}+00$ & $0.1165 \mathrm{E}-01$ & $0.1043 \mathrm{E}-02$ \\
2.056 & 160.454 & 6.7484 & $0.1033 \mathrm{E}-02$ & $0.1912 \mathrm{E}-04$ & $0.1273 \mathrm{E}+00$ & $0.1165 \mathrm{E}-01$ & $0.1043 \mathrm{E}-02$ \\
2.471 & 160.459 & 6.7495 & $0.1033 \mathrm{E}-02$ & $0.1988 \mathrm{E}-04$ & $0.1273 \mathrm{E}+00$ & $0.1165 \mathrm{E}-01$ & $0.1043 \mathrm{E}-02$ \\
2.967 & 160.465 & 6.7509 & $0.1033 \mathrm{E}-02$ & $0.2092 \mathrm{E}-04$ & $0.1273 \mathrm{E}+00$ & $0.1165 \mathrm{E}-01$ & $0.1043 \mathrm{E}-02$ \\
3.561 & 160.472 & 6.7528 & $0.1033 \mathrm{E}-02$ & $0.2232 \mathrm{E}-04$ & $0.1273 \mathrm{E}+00$ & $0.1165 \mathrm{E}-01$ & $0.1043 \mathrm{E}-02$ \\
4.271 & 160.481 & 6.7553 & $0.1033 \mathrm{E}-02$ & $0.2414 \mathrm{E}-04$ & $0.1273 \mathrm{E}+00$ & $0.1165 \mathrm{E}-01$ & $0.1043 \mathrm{E}-02$ \\
\hline
\end{tabular}


Figure 8.8.11. Part of file sca_min.dat for problem no. 8 after $\mathrm{t}=1 \mathrm{yr}$ (unit of permeability is $\mathrm{m}^{2}$; mineral abundances are expressed as changes in volume fraction, positive values indicate precipitation and negative dissolution).

\begin{tabular}{ccccccl}
\hline $\mathrm{X}$ & Porosity & Perm(m^2) & calcite & albite-low & illite & sio2(amor.) \\
0.139 & 0.49868 & $0.30712 \mathrm{E}-11$ & $-0.1649 \mathrm{E}-04$ & $0.7853 \mathrm{E}-03$ & $0.9436 \mathrm{E}-04$ & $0.1271 \mathrm{E}-02$ \\
0.179 & 0.49869 & $0.30803 \mathrm{E}-11$ & $-0.1649 \mathrm{E}-04$ & $0.7854 \mathrm{E}-03$ & $0.9434 \mathrm{E}-04$ & $0.1260 \mathrm{E}-02$ \\
0.228 & 0.49870 & $0.30888 \mathrm{E}-11$ & $-0.1649 \mathrm{E}-04$ & $0.7854 \mathrm{E}-03$ & $0.9432 \mathrm{E}-04$ & $0.1249 \mathrm{E}-02$ \\
0.286 & 0.49871 & $0.30970 \mathrm{E}-11$ & $-0.1650 \mathrm{E}-04$ & $0.7854 \mathrm{E}-03$ & $0.9430 \mathrm{E}-04$ & $0.1239 \mathrm{E}-02$ \\
0.356 & 0.49872 & $0.31053 \mathrm{E}-11$ & $-0.1650 \mathrm{E}-04$ & $0.7854 \mathrm{E}-03$ & $0.9428 \mathrm{E}-04$ & $0.1229 \mathrm{E}-02$ \\
0.440 & 0.49873 & $0.31136 \mathrm{E}-11$ & $-0.1650 \mathrm{E}-04$ & $0.7854 \mathrm{E}-03$ & $0.9425 \mathrm{E}-04$ & $0.1218 \mathrm{E}-02$ \\
0.539 & 0.49874 & $0.31213 \mathrm{E}-11$ & $-0.1650 \mathrm{E}-04$ & $0.7853 \mathrm{E}-03$ & $0.9420 \mathrm{E}-04$ & $0.1209 \mathrm{E}-02$ \\
0.658 & 0.49875 & $0.31301 \mathrm{E}-11-0.1649 \mathrm{E}-04$ & $0.7852 \mathrm{E}-03$ & $0.9415 \mathrm{E}-04$ & $0.1198 \mathrm{E}-02$ \\
0.801 & 0.49876 & $0.31395 \mathrm{E}-11-0.1649 \mathrm{E}-04$ & $0.7850 \mathrm{E}-03$ & $0.9407 \mathrm{E}-04$ & $0.1186 \mathrm{E}-02$ \\
0.971 & 0.49877 & $0.31489 \mathrm{E}-11-0.1649 \mathrm{E}-04$ & $0.7846 \mathrm{E}-03$ & $0.9396 \mathrm{E}-04$ & $0.1175 \mathrm{E}-02$ \\
1.174 & 0.49879 & $0.31605 \mathrm{E}-11-0.1649 \mathrm{E}-04$ & $0.7841 \mathrm{E}-03$ & $0.9381 \mathrm{E}-04$ & $0.1161 \mathrm{E}-02$ \\
1.417 & 0.49880 & $0.31731 \mathrm{E}-11$ & $-0.1649 \mathrm{E}-04$ & $0.7834 \mathrm{E}-03$ & $0.9360 \mathrm{E}-04$ & $0.1145 \mathrm{E}-02$ \\
1.708 & 0.49882 & $0.31893 \mathrm{E}-11$ & $-0.1648 \mathrm{E}-04$ & $0.7822 \mathrm{E}-03$ & $0.9329 \mathrm{E}-04$ & $0.1126 \mathrm{E}-02$ \\
2.056 & 0.49885 & $0.32086 \mathrm{E}-11-0.1647 \mathrm{E}-04$ & $0.7806 \mathrm{E}-03$ & $0.9286 \mathrm{E}-04$ & $0.1102 \mathrm{E}-02$ \\
2.471 & 0.49888 & $0.32342 \mathrm{E}-11-0.1646 \mathrm{E}-04$ & $0.7782 \mathrm{E}-03$ & $0.9224 \mathrm{E}-04$ & $0.1072 \mathrm{E}-02$ \\
2.967 & 0.49892 & $0.32675 \mathrm{E}-11$ & $-0.1645 \mathrm{E}-04$ & $0.7747 \mathrm{E}-03$ & $0.9136 \mathrm{E}-04$ & $0.1032 \mathrm{E}-02$ \\
3.561 & 0.49897 & $0.33113 \mathrm{E}-11$ & $-0.1642 \mathrm{E}-04$ & $0.7696 \mathrm{E}-03$ & $0.9009 \mathrm{E}-04$ & $0.9805 \mathrm{E}-03$ \\
4.271 & 0.49904 & $0.33705 \mathrm{E}-11$ & $-0.1639 \mathrm{E}-04$ & $0.7623 \mathrm{E}-03$ & $0.8827 \mathrm{E}-04$ & $0.9118 \mathrm{E}-03$ \\
\hline
\end{tabular}

Other simulations can be achieved by modifying the $\phi_{\mathrm{c}}$ and $\mathrm{n}$ values in file chemical.inp (under key word 'Permeability-Porosity Zones'). As mentioned before, only the fracture network is considered in the simulation. To allow for chemical reaction with the rock, $50 \%$ porosity was assigned to the blocks (with $50 \%$ pore volume and 50\% rock volume). Therefore, an intrinsic porosity of 0.46 (in file chemical.inp) corresponds to bulk $\phi_{\mathrm{c}}=0.46 \times 2 \%=0.92 \%$.

After the first phase of simulations of injectivity loss due to silica scaling, a simulation of acidizing for the injectivity recovery was performed. For the actual acidizing, a $5 \mathrm{wt} \%$ (about 2.5 $\mathrm{mol} / \mathrm{kg}$ ) HF acid was injected for five hours at an average rate of $18.2 \mathrm{~kg} / \mathrm{s}$. In the recovery simulation, a HF concentration of $1.25 \mathrm{~mol} / \mathrm{kg}$ was used to account for some dilution by wellbore and formation waters. The predicted amount of amorphous silica dissolved by acid was also consistent with the estimated amount. Detailed results are given in Xu et al. (2004b).

\subsubsection{Summary}

A review of historical injection records, fluid chemistry data, and analyses of scale materials suggest silica scaling at Nag-67 occurred mainly in the rock formation immediately adjacent to the wellbore. Silica scaling (precipitation) decreases porosity, and in turn permeability and injectivity. A reactive transport numerical model, including the porosity-permeability relationship of Verma and Pruess (1988) was used to simulate injection loss and recovery. The 
porosity-permeability relationship involves two parameters: a "critical" porosity $\phi_{\mathrm{c}}$ (which is the value of porosity at which permeability goes to zero) and a power term n (Eq. F.8). A number of simulations were performed using different combinations of values of $\phi_{\mathrm{c}}$ and $\mathrm{n}$ under two different injection silica concentrations.

Significant precipitation of amorphous silica, and reductions of porosity and permeability occur within a $10 \mathrm{~m}$ radius from the well. The pattern of $\log 10$ scale of permeability is similar to linear scale of porosity. The simulated injection indexes were compared to measured data for each simulation. A good match was obtained using different parameter combinations; a smaller critical porosity $\phi_{\mathrm{c}}$ requires a larger power term $\mathrm{n}$. The porosity-permeability relationship is well suited for capturing the steep loss of injectivity at Nag-67. A steep reduction in permeability with a small decrease in porosity is consistent with a published permeability experiment. Taking an injection silica concentration of $705 \mathrm{ppm}$, within the range of observed values, results in a total amorphous silica precipitation of $2 \mathrm{~m}^{3}$ in the reservoir formation, close to the amount of $1.4 \mathrm{~m}^{3}$ estimated from the quantity of acid used to recover injectivity. 


\section{Concluding Remarks}

TOUGHREACT is a comprehensive computer program for non-isothermal multiphase fluid flow and geochemical transport. The gas phase is considered active for multiphase fluid flow, species transport, and chemical reactions. The code is applicable to porous media as well as to fractured rocks. An integral finite difference (IFD) technique is employed for space discretization. The IFD methodology can deal with irregular grids, does not require reference to a global system of coordinates, and includes classical dual-continua, multiple interacting continua, and multi-region models for heterogeneous and fractured rocks. Non-isothermal effects are considered, including water-vapor phase change and air partitioning between the liquid and gas phases, temperature-dependence of thermophysical properties such as phase density and viscosity, and chemical properties such as thermodynamic and kinetic parameters. Chemical reactions considered under the local equilibrium assumption include aqueous complexation, acid-base, redox, gas dissolution/exsolution, cation exchange, and surface complexation. Mineral dissolution/precipitation can proceed either subject to local equilibrium or kinetic conditions.

TOUGHREACT is applicable to one-, two-, or three-dimensional geologic domains with physical and chemical heterogeneity, and can be applied to a wide range of subsurface conditions. Temperatures can range from 0 to $300{ }^{\circ} \mathrm{C}$, limited at present by available geochemical databases such as EQ3/6 (Wolery, 1992). Pressures of 1 bar (atmospheric pressure) to several hundred bars (at several thousand meter depth) can be considered. Water saturation can range from completely dry to fully water saturated. The code can handle ionic strengths from dilute to saline waters with up to $6 \mathrm{~mol} / \mathrm{kg}$ for an NaCl-dominant solution.

TOUGHREACT applications have been demonstrated for a variety of reactive fluid and geochemical transport systems, including (1) contaminant transport with linear Kd adsorption and decay, (2) natural groundwater quality evolution under ambient conditions, (3) assessment of nuclear waste disposal sites, (4) sedimentary diagenesis and $\mathrm{CO}_{2}$ disposal in deep formations, (5) mineral deposition such as supergene copper enrichment, and (6) mineral alteration and silica scaling in hydrothermal systems under natural and production conditions. Of course, many other potential geologic, experimental, and engineered systems could be analyzed using similar methodologies as given in these examples. 
Acknowledgements. We are grateful to Keni Zhang for a review of the manuscript and suggestions for improvements. We thank Tom Wolery for allowing us to use the EQ3/6 database. The development of TOUGHREACT was initiated with funding from the Laboratory Directed Research and Development Program of the Ernest Orlando Lawrence Berkeley National Laboratory. Subsequent development was supported by the Assistant Secretary for Energy Efficiency and Renewable Energy, Office of Geothermal Technologies; by the Director, Office of Science, Office of Basic Energy Sciences; by the Director, Office of Civilian Radioactive Waste Management; and by the Zero Emission Research and Technology project (ZERT), of the U.S. Department of Energy, under Contract No. DE-AC02-05CH11231. Documentation and public release of the code were funded by the Assistant Secretary for Energy Efficiency and Renewable Energy, Office of Geothermal Technologies, and by the Director, Office of Science, Office of Basic Energy Sciences, of the U.S. Department of Energy, under Contract No. DE-AC0376SF00098. For sample problem no. 4 (Yucca Mountain heater test), geochemical data from the Drift Scale Test discussed in this report were reported by Laura DeLoach (aqueous species), Schon Levy (mineralogy), and Mark Conrad $\left(\mathrm{CO}_{2}\right)$. Sumit Mukhopadhyay and Jens Birkholzer developed the initial TH grid. John Apps worked on initial development of the thermodynamic database and Sonia Salah worked on a refinement of the kinetic database. This sample problem (problem no. 4) and also problem no. 3 are based on work supported by the Director, Office of Civilian Radioactive Waste Management, U.S. Department of Energy, through Memorandum Purchase Order QA-B004220RB3X between Bechtel SAIC Company, LLC and the Ernest Orlando Lawrence Berkeley National Laboratory (Berkeley Lab).

\section{References}

Ague, J. J., and Brimhall, G. H., Geochemical modeling of steady state and chemical reaction during supergene enrichment of porphyry copper deposits: Economic Geology, v. 84, p. 506$528,1989$.

Ahlers, C. F., and Liu, H. H., Calibrated properties model, MDL-NBS-HS-000003 REV00., Yucca Mountain Project, Lawrence Berkeley National Laboratory, Berkeley, California, 2000. 
Alpers, C. A., and Brimhall, G. H, Paleohydrologic evolution and geochemical dynamics of cumulative supergene metal enrichment at La Escondida, Atacama Desert, Northern Chile: Economic Geology, v. 84, p. 229-255, 1989.

Appelo, C. A. J., and Postma, D., Geochemistry, groundwater and pollution, Rotterdam, The Netherlands, Balkema, 536 pp., 1993.

Appelo, C. A. J., Cation and proton exchange, $\mathrm{pH}$ variations and carbonate reactions in a freshening aquifer, Water Resour. Res., v. 30(10), p. 2793-2805, 1994.

Apps, J. A., An approach to modeling of the chemistry of waste fluid disposal in deep saline aquifers, In Apps, J. A., and Tsang, C. F. (eds.), Deep injection disposal of hazardous and industrial waste: Scientific and Engineering Aspects, p. 465-488, Academic Press, San Diego, California, 1996.

Bachu, S., Gunter, W. D., and Perkins, E. H., Aquifer disposal of $\mathrm{CO}_{2}$ : hydrodynamic and mineral trapping, Energy Convers. Mgmt., v. 35, p. 269-279, 1994.

Birkholzer, J. T., and Tsang, Y. W., Pretest analysis of the thermal-hydrological conditions of the ESF Drift Scale Test, Yucca Mountain Project Level 4 Milestone SP9322M4, Lawrence Berkeley National Laboratory, Berkeley, California, 1997.

Birkholzer, J. T., and Tsang, Y. W., Interpretive analysis of the thermo-hydrological processes of the Drift Scale Test, In Drift Scale Test Progress Report, Chapter 6., Yucca Mountain Project Level 4 Milestone SP2930M4, Lawrence Berkeley National Laboratory, Berkeley, California, 1998.

Bodvarsson, G. S., Scientific Notebooks Referenced in AMR N0120/U0110, Drift-Scale Coupled Processes (Drift-Scale Test and THC Seepage) Models DI: MDL-NBS-HS-000001 Rev01, Interoffice correspondence from G.S. Bodvarsson (CRWMS M\&O) to File, February 1, 2001.

Brimhall, G. H., Alpers, C. N., and Cunningham, A. B., Analysis of supergene ore-forming processes and ground water solute transport using mass balance principles: Economic Geology, v. 80 , p. 1227-1256, 1985.

Brimhall, G. H., and Dietrich, W. E., Constitutive mass balance relations between chemical composition, volume, density, porosity, and strain in metasomatic hydrochemical systems: Results on weathering and pedogenesis, Geochim. Cosmochim. Acta, v. 51, p. 567-588, 1987. 
Carey, J. W., Chipera, S. J., Vaniman, D. T., Bish, D. L., Three-dimensional mineralogic model of Yucca Mountain, Nevada, Rev 2.0., Los Alamos National Laboratory, Los Alamos, New Mexico, 1998.

Carlos, B. A., Chipera, S. J., Bish, D. L., Calcite and zeolite fracture coating in Topopah Spring Tuff along Drill Hole Wash, Yucca Mountain (Nevada), Proc. $6^{\text {th }}$ Intl. Conf. High Level Rad. Waste Mgmt., p. 100-102, 1995.

Carroll, S., Mroczek, E., Alai, M., and Ebert, M., Amorphous Silica Precipitation (60 to $\left.120^{\circ} \mathrm{C}\right)$ : Comparison of Laboratory and Field Rates, Geochim. Cosmochim. Acta, v. 62, p. 1379-1396, 1998.

Chapelle, F. H., and Drummond, D. D., Hydrogeology, digital simulation, and geochemistry of the Aquia and Piney Point-Nanjemoy aquifer system in southern Maryland, Rep. Invest. 38, Md. Geol. Surv., Baltimore, Maryland, 1983.

Chapelle, F. H., and Knobel, L. L., Aqueous geochemistry and exchangeable cation composition of glauconite in the Aquia aquifer, Maryland, Groundwater, v. 21, p. 343-352, 1983.

Chesnut, D. A., Dispersivity in heterogeneous permeable media, Proceedings, Fifth annual international high-level radioactive waste management conference, Las Vegas, NV, v. 4, p. 1822-1841, American Nuclear Society, La Grange Park, IL, May, 1994.

Corey, A. T., The interrelation between gas and oil relative permeabilities, Producers Monthly, p. 38-41, 1954.

Dobson, P. F., Salah, S., Spycher, N., and Sonnenthal, E. L., Simulation of water-rock interaction in the Yellowstone geothermal system using TOUGHREACT, Geothermics, v. 33, p. 493-502, 2004.

Domenico, P. A., and Schwartz, F. W., Physical and Chemical Hydrogeology, John Wiley and Sons, New York, 824 pp., 1990.

Drever, J. I., Geochemistry of Natural Waters, $3^{\text {rd }}$ Edition, Upper Saddle River, New Jersey: Prentice Hall, 436pp., 1997.

Drummond, J. M., Jr., Boiling and mixing of hydrothermal fluids: Chemical effects on mineral precipitation, Ph.D. thesis, The Pennsylvania State University, University Park, Pennsylvania, 1981.

Dzombak, D. A., and Morel, F. M. M., Surface complexation modeling: New York, Wiley Interscience, 431 pp., 1990. 
Engesgaard, P., and Kipp, K. L., A geochemical transport model for redox-controlled movement of mineral fronts in groundwater flow systems, A case of nitrate removal by oxidation of pyrite, Water Resour. Res., v. 28, p. 2829-2843, 1992.

Ennis-King, J., and Paterson, L., Role of convective mixing of the long-term storage of carbon dioxide in deep saline formations, Paper SPE 84344, Presented at Society of Petroleum Engineers Annual Fall Technical Conference and Exhibition, Denver, CO, October 2003.

Flexser, S., Hydrothermal alteration and past and present thermal regimes in the western moat of Long Valley Cadera (California), J. Volcanol. and Geotherm. Res., v. 48, p. 303-318, 1991.

Gelhar, L. W., Welty, C., and Remfeldt, K. R., A critical review of data on field-scale dispersion in aquifers, Water Resour. Res., v. 28, p. 1955-1974, 1992.

Gérard, F., Xu, T., Brimhall, G., and Pruess, K., Modeling reactive chemical transport problems with the codes EQ3/6 and TRANQUI: Lawrence Berkeley Laboratory Report LBL-40505, Berkeley, California, 1997.

Gunnarsson, I. and Arnórsson, S., Amorphous Silica Solubility and the Thermodynamic Properties of $\mathrm{H}_{4} \mathrm{SiO}_{4}$ in the Range of $0^{\circ}$ to $350^{\circ} \mathrm{C}$ at $\mathrm{P}_{\text {sat }}$, Geochim. Cosmochim. Acta, v. 64, p. 2295-2307, 2000.

Gunter W. D., Perkins, E. H., and McCann, T. J., Aquifer disposal of $\mathrm{CO}_{2}$-rich gases: Reaction design for added capacity. Energy Convers. Mgmt., v. 34, p. 941-948, 1993.

Gunter W. D., Bachu, S., Law, D. H. S., Marwaha, V., Drysdale, D. L., MacDonald, D. E., and McCann, T. J., Technical and economic feasibility of $\mathrm{CO}_{2}$ disposal in aquifers within the Alberta Sedimentary Basin, Canada, Energy Convers. Mgmt. v. 37, p. 1135-1142, 1996.

Gunter W. D., Wiwchar, B., and Perkins, E. H., Aquifer disposal of $\mathrm{CO}_{2}$-rich greenhouse gases: extension of the time scale of experiment for $\mathrm{CO}_{2}$-sequestering reactions by geochemical modeling, Mineral. and Petrol., v. 59, p. 121-140, 1997.

Gwo, J. P., Jardine, P. M., Wilson, G. V., and Yeh, G. T., Using a multiregion model to study the effects of advective and diffusive mass transfer on local physical nonequilibrium and solute mobility in a structured soil, Water Resour. Res., v. 32, p. 561-570, 1996.

Helgeson, H. C., Kirkham, D. H., Flowers, D. C., Theoretical prediction of the thermodynamic behavior of aqueous electrolytes at high pressures and temperatures: IV. Calculation of activity coefficients, osmotic coefficients, and apparent molal and standard and relative partial molal properties to 600 C and 5 kb. Am. J. Sci., v. 281, p. 1249-1516, 1981. 
Hitchon, B. (ed.)., Aquifer Disposal of Carbon Dioxide, Geoscience Publishing, Ltd., Sherwood Park, Alberta, Canada, 1996.

Javandel, J., Doughty, C., and Tsang, C. F., Groundwater transport: Handbook of mathematical models, American Geophysical Union, Washington D. C., pp. 228, 1984.

Johnson, J. W., Oelkers, E. H., and Helgeson, H. C., SUPCRT92: A software package for calculating the standard molal thermodynamic properties of minerals, gases, aqueous species, and reactions from 1 to 5000 bars and 0 to 1000 degrees C: Computers and Geosciences, v. 18, p. 899-948, 1992.

Johnson J. W., Knauss, K. J., Glassley, W. M., Deloach, L. D., Tompson, A. F. B., Reactive transport modeling of plug-flow reactor experiments: Quartz and tuff dissolution at $240^{\circ} \mathrm{C} . J$. Hydrol., v. 209, p. 81-111, 1998.

Johnson. J. W., Nitao, J. J., Steefel, C. I., and Knaus, K. G., Reactive transport modeling of geologic $\mathrm{CO}_{2}$ sequestration in saline aquifers: The influence of intra-aquifer shales and the relative effectiveness of structural, solubility, and mineral trapping during prograde and retrograde sequestration, In proceedings: First National Conference on Carbon Sequestration, Washington, DC, May 14-17, 2001.

Kapoor, V., Gelhar, L. W., and Miralles-Willem, F., Bimolecular second-order reactions in spatially varying flows, Segregation induced scale-dependent transformation rates, Water Resour. Res., v. 33, p. 527-536, 1997.

Korbol, R., and Kaddour, A., Sleipner vest $\mathrm{CO}_{2}$ disposal - injection of removed $\mathrm{CO}_{2}$ into the Utsira Formation, Energy Convers. Mgmt., v. 36(6-9), p. 509-512, 1995.

Langmuir, D., Aqueous Environmental Geochemistry, Prentice Hall, Upper Saddle River, New Jersey, 600pp, 1997.

Lasaga, A. C., Chemical kinetics of water-rock interactions, J. Geophys. Res., v. 89, p. 4009-4025, 1984.

Lasaga, A. C., Soler, J. M., Ganor, J., Burch, T. E., Nagy, K. L., Chemical weathering rate laws and global geochemical cycles. Geochim. Cosmochim. Acta, v. 58, p. 2361-2386, 1994.

Lasaga, A. C., Kinetic Theory in the Earth Sciences, Princeton University Press, Princeton, New Jersey, 1998.

Lichtner, P. C., The quasi-stationary state approximation to coupled mass transport and fluid-rock interaction in a porous medium, Geochim. Cosmochim. Acta, v. 52, p. 143-165, 1988. 
Lichtner, P. C., Continuum formulation of multicomponent-multiphase reactive transport, in Lichtner, P. C., Steefel, C. I., and Oelkers, E. H. (eds.), Reactive transport in porous media, Reviews in Mineralogy, Mineral Society of America, v. 34, p. 1-79, 1996.

Liu, H. H.; Doughty, C.; and Bodvarsson, G. S. An Active Fracture Model for Unsaturated Flow and Transport in Fractured Rocks. Water Resour. Res., v. 34, p. 2633-2646, 1998.

Lohuis, J. A. O., Carbon dioxide disposal and sustainable development in The Netherlands, Energy Convers. Mgmt., v. 34(9-11), p. 815-821, 1993.

Marshall, B. D., Paces, J. B., Neymark, L. A., Whelan, J. F., and Peterman, Z. E., Secondary minerals record past percolation flux at Yucca Mountain, Nevada, In: Proceedings of the 8th International High-level Radioactive Waste Management Conference, May 11-14, Las Vegas, Nevada, USA, 1998.

Marshall, B. D., Neymark, L. A., Paces, J. B., Peterman, Z. E., Whelan, J. F., Seepage flux conceptualized from secondary calcite in lithophysal cavities in the Topopah Spring Tuff, Yucca Mountain, Nevada. The society for Mining, Metallurgy, and Exploration, Inc. Annual Meeting 2000, USGS, Denver, Colorado, 1999.

McPherson, B. J. O. L., and P. C. Lichtner, $\mathrm{CO}_{2}$ sequestration in deep aquifers, In proceedings: First National Conference on Carbon Sequestration, Washington, DC, May 14-17, 2001.

Montazer, P. and Wilson, W. E., Conceptual hydrologic model of flow in the unsaturated zone, Yucca Mountain, Nevada, Water Resources Investigations Report 84-4355, USGS, Denver, Colorado, 1984.

Moore, D. E., Morrow, C. A., and Byerlee, J. D., Chemical reactions accompanying fluid flow through granite held in a temperature gardient. Geochim. Cosmochim. Acta, v. 47, p. 445-453, 1983.

Moridis, G., and Pruess, K., T2SOLV: An enhanced package of solvers for the TOUGH2 family of reservoir simulation codes, Geothermics, v. 27, p. 415-444, 1998.

Mote T. I., Brimhall, G. H., Tidy-Finch, E., Muller, G., and Carrasco, P., Application of mass-balance modeling of sources, pathways, and sinks of supergene enrichment to exploration and discovery of the Quebrada Turquesa Exotic Copper Orebody, El Salvador District, Chile, Economic Geology \& the Bulletin of the Society of Economic Geologists, v. 96 (No. 2), p. 367-386, 2001.

Millington, R. J., and Quirk, J. P., Permeability of porous solids, Trans. Faraday Soc., v. 57, p. 12001207, 1961. 
Nagy, K. L., Dissolution and precipitation kinetics of sheet silicates, Chemical Weathering Rates of Silicate Minerals, v. 31, p. 291-351, 1995.

Narasimhan, T. N., and Witherspoon, P. A., An integrated finite difference method for analyzing fluid flow in porous media, Water Resour. Res., v. 12, p. 57-64, 1976.

Neymark, L. A., Amelin, Y. V., Paces, J. B., Peterman, Z. E., Whelan, J. F., Age constraints on fluid inclusions in calcite at Yucca Mountain, In: Proceedings of the 9th International High-level Radioactive Waste Management Conference, Las Vegas, Nevada, USA, April 29-May 3, 2001.

Nordstrom, D. K., and Muñoz, J. L., Geochemical Thermodynamics, The Benjamin/Cummings Pub. Co., Menlo Park, California, 477 pp., 1986.

Nordstrom, D. K., and Alpers, C. N., The Environmental geochemistry of mineral deposits. Part A. Processes, methods and health Issues. (Plumlee, G. S., Logsdon, M. J. (Eds) ), Reviews in Economic Geology, v. 6, Society of Economic Geologists, 1997.

Oldenburg C. M., and Pruess, K., EOS7R: Radionuclide transport for TOUGH2, Lawrence Berkeley National Laboratory Report LBNL-34868, Berkeley, California, 1995.

Olson, G. J., Rate of pyrite bioleaching by Thiobacillus ferrooxidans - Results of an interlaboratory comparison, Applied and Environmental Microbiology, v. 57, p. 642-644, 1991.

Ontoy, Y., Molling, P. L., Xu, T., Spycher, N., Parini, M. and Pruess, K., Scaling of hot brine injection wells: supplementing field studies with reactive transport modeling. In Proceedings of TOUGH Symposium 2003, Lawrence Berkeley National Laboratory, Berkeley, California, May 12-14, 2003.

Paces, J. B., Marshall, B. D., Whelan, J. F., Neymark, L. A., Peterman, Z. E., Summary of subsurface calcite and opal deposits and estimates of the probable distribution and isotopic compositions of hydrogenic minerals along the East-West Cross Drift, Yucca Mountain, Nevada. U.S. Geol. Surv. Open File Rep., Denver, Colorado, 1998.

Palandri, J., and Kharaka, Y. K., A compilation of rate parameters of water-mineral interaction kinetics for application to geochemical modeling, US Geol. Surv. Open File Report 2004-1068, 64 pp., 2004.

Pape, H., Clauser C., and Iffland J., Permeability prediction based on fractural pore-space geometry, Geophysics, v. 64(5), p. 1447-1460, 1999.

Parks, G. A., Surface energy and absorption at mineral-water interfaces: an introduction, Review of Mineralogy, v. 23 (Miner.-Water Interface Geochem.), p. 133-75, 1990. 
Parkhurst, D. L., Thorstenson, D. C., and Plummer, L. N., PHREEQE: A computer program for geochemical calculations, US Geol. Surv. Water Resour. Invest. 80-96, 174 pp., 1980.

Perkins, E. H., and Gunter, W. D., Mineral Traps for Carbon Dioxide, in: Hitchon, B. (ed.), Aquifer Disposal of Carbon Dioxide, Geoscience Publishing, Ltd., Alberta, Canada, p. 93-113, 1996.

Pruess, K., and Karasaki, K., Proximity functions for modeling fluid and heat flow in reservoirs with stochastic fracture distributions, in Proceedings, Eighth workshop on geothermal reservoir engineering: p. 219-224, Stanford University, Stanford, California, 1982.

Pruess, K., and Narasimhan, T. N., A practical method for modeling fluid and heat flow in fractured porous media: Society of Petroleum Engineers Journal, v. 25, p. 14-26, 1985.

Pruess, K., TOUGH user's guide, Nuclear Regulatory Commission, report NUREG/CR-4645 (also Lawrence Berkeley Laboratory Report LBL-20700, Berkeley, California), 1987.

Pruess, K., TOUGH2: A general numerical simulator for multiphase fluid and heat flow, Lawrence Berkeley Laboratory Report LBL-29400, Berkeley, California, 1991.

Pruess, K., Oldenburg, C., and Moridis, G., TOUGH2 user's guide, Version 2.0, Lawrence Berkeley Laboratory Report LBL-43134, Berkeley, California, 1999.

Pruess, K., and García, J., Multiphase flow dynamics during CO2 disposal into saline aquifers, Environmental Geology, v. 42, p. 282-295, 2002.

Pruess, K., Xu, T., Apps, J., and García, J., Numerical modeling of aquifer disposal of CO2, Paper SPE-83695, SPE Journal, p. 49-60, 2003. Pruess, K., ECO2N: A TOUGH2 Fluid Property Module for Mixtures of Water, $\mathrm{NaCl}$, and CO2, Lawrence Berkeley National Laboratory Report LBNL-57592, Berkeley, California, 2005.

Raffensperger, J. P., Numerical simulation of sedimentary basin-scale hydrochemical processes, In Advances in Porous Media, Corapcioglu, Y. C., (ed.), Amsterdam, The Netherlands, Elsevier Science, 440 pp., 1996.

Reed, M. H., Calculation of multicomponent chemical equilibria and reaction processes in systems involving minerals, gases and aqueous phase, Geochim. Cosmochim. Acta, v. 46, p. 513-528, 1982.

Richards, L. A., Capillary conduction of liquids through porous mediums, Physics, v. 1, p. 318$333,1931$. 
Rimstidt, J. D. and Barnes, H. L., The kinetics of silica-water reactions, Geochim. Cosmochim. Acta, v. 44, p. 1683-1699, 1980.

Robinson, R. A., and Stokes, R. H., Electrolyte Solutions, the Measurement and Interpretation of Conductance, Chemical Potential and Diffusion in Solutions of Simple Electrolytes, $2^{\text {nd }}$ Edition, London, England: Butterworths \& Company, 1965.

Shock, E. L., Helgeson, H. C., and Sverjensky, D. A., Calculation of the thermodynamic and transport properties of aqueous species at high pressures and temperatures: Standard partial molal properties of inorganic neutral species, Geochim. Cosmochim. Acta, v. 53 (9), p. 21572183, 1989.

Simunek, J., and Suares, D. L., Two-dimensional transport model for variably saturated porous media with major ion chemistry, Water Resour. Res., v. 30, p. 1115-1133, 1994.

Singer, P. C., and Stumm, W., Acid mine drainage - The rate determining step: Science, v. 167, p. 1121-1123, 1970.

Slider, H. C., Practical petroleum reservoir engineering methods, An Energy Conservation Science. Tulsa, Oklahoma, Petroleum Publishing Company, 1976.

Sonnenthal, E. and Ortoleva, P. J., Numerical simulations of overpressured compartments in sedimentary Basins, Basin Compartments and Seals. Ortoleva, P.J., ed., AAPG Memoir v. 61, p. 403-416, Tulsa, Oklahoma, American Association of Petroleum Geologists, 1994.

Sonnenthal, E. L., and Bodvarsson, G. S., Percolation flux estimates from geochemical and thermal modeling. Proceedings of the Eighth International Conference on High-Level Radioactive Waste Management, American Nuclear Society, p. 130-132, 1998.

Sonnenthal, E., Spycher, N., Apps, J. A., and Simmons, A., 1998, Thermo-hydro-chemical predictive analysis for the Drift-Scale Heater Test, Yucca Mountain Project Level 4 Milestone SPY289M4, Lawrence Berkeley National Laboratory, Berkeley, California, 1998.

Sonnenthal, E. L., Bodvarsson, G. S., 1999. Constraints on the hydrology of the unsaturated zone at Yucca Mountain, NV from three-dimensional models of chloride and strontium geochemistry. $J$. Contam. Hydrol., v. 38, p. 107-156, 1999.

Sonnenthal, E., and Spycher, N., Drift-scale coupled processes model, Analysis and model report (AMR) N0120/U0110, Yucca Mountain Nuclear Waste Disposal Project, Lawrence Berkeley National Laboratory, Berkeley, California, 2000. 
Sonnenthal, E. L., Spycher, N., Drift-Scale coupled processes (DST and THC seepage) models. AMR N0120/U0110 Rev.01, Yucca Mountain Project, Lawrence Berkeley National Laboratory, Berkeley, California, 2001.

Sonnenthal, E., N. Spycher, and T. Xu, 2003. Linking Reaction, Transport, and Hydrological Parameters in Unsaturated Fractured Rock: TOUGHREACT Implementation and Application. Proceedings, TOUGH Symposium, 2003.

Sorey, M. L., Evolution and present state of the hydrothermal system in Long Valley Cadera, $J$. Geophys. Res., v. 90, p. 11219-11228, 1985.

Sorey, M. L, Evans, W. C., Kennedy, B. M., Farrar, C. D., Hainsworth, L. J., and Hausback, B., Carbon dioxide and helium emissions from a reservoir of magmatic gas beneath Mammoth Mountain (California), J. Geophys. Res., v. 103, p. 15303-15323, 1998.

Spycher, N. F., and Reed, M. H., Fugacity coefficients of $\mathrm{H}_{2}, \mathrm{CO}_{2}, \mathrm{CH}_{4}, \mathrm{H}_{2} \mathrm{O}$ and of $\mathrm{H}_{2} \mathrm{O}-\mathrm{CO}_{2}-$ $\mathrm{CH}_{4}$ mixtures: A virial equation treatment for moderate pressures and temperatures applicable to calculations of hydrothermal boiling, Geochim. Cosmochim. Acta, v. 52, p. 739-749, 1988.

Spycher N. F., Sonnenthal, E. L., and Apps, J. A., Fluid flow and reactive transport around potential nuclear waste emplacement tunnels at Yucca Mountain, Nevada, J. Contam. Hydrol., v.62-63, p. 653-673, 2003a.

Spycher, N., Sonnenthal, E. L., Dobson, P. F., Kneafsey, T., and Salah, S., Drift-scale coupled processes (DST and THC seepage) models, MDL-NBS-HS-000001 REV02, BSC: Las Vegas, NV, Report number LBID-2478, Lawrence Berkeley National Laboratory, Berkeley, California, $2003 b$.

Spycher, N., Pruess, K., $\mathrm{CO}_{2}-\mathrm{H}_{2} \mathrm{O}$ mixtures in the geological sequestration of $\mathrm{CO}$ 2: II. Partitioning in chloride brines at $12-100^{\circ} \mathrm{C}$ and up to 600 bar, Geochimica et Cosmochimica Acta, v. 69, p. 3309-3320, 2005.

Steefel, C. I., and van Cappellen, P., A new kinetic approach to modeling water-rock interaction: The role of nucleation, precursors and Ostwald ripening, Geochim. Cosmochim. Acta, v. 54, p. 2657-2677, 1990.

Steefel, C. I., and Lasaga, A. C., A coupled model for transport of multiple chemical species and kinetic precipitation/dissolution reactions with applications to reactive flow in single phase hydrothermal system, Am. J. Sci., v. 294, p. 529-592, 1994. 
Steefel, C. I., and MacQuarrie, K. T. B., Approaches to modeling of reactive transport in porous media, In Lichtner, P. C., Steefel, C. I., and Oelkers, E. H. (eds.), Reactive transport in porous media, Reviews in Mineralogy, Mineral Society of America, v. 34, p. 83-129, 1996.

Steefel, C. I., CRUNCH, Lawrence Livermore National Laboratory, pp. 76, 2001.

Stumm, W., and Morgan, J. J., Aquatic chemistry: An Introduction Emphasizing Chemical Equilibria in Natural Waters, John Wiley \& Sons, New York, 780 pp., 1981.

Van Genuchten, M. T., A closed-form equation for predicting the hydraulic conductivity of unsaturated soils, Soil Sci. Soc. Am. J., v. 44, p. 892-898, 1980.

Vaniman, D. T., Chipera, S. J., Paleotransport of lanthanides and strontium recorded in calcite compositions from tuffs at Yucca Mountain, Nevada, USA. Geochim. Cosmochim. Acta, v.60(22), p.4417-4433, 1996.

Vaniman, D. T., Chipera, S. J., Bish, D. L., Carey, J. W., and Levy, S. S., Quantification of unsaturated-zone alteration and cation exchange in zeolitized tuffs at Yucca Mountain, Nevada, USA. Geochim. Cosmochim. Acta, v. 65(20), p. 3409-3433, 2001.

Vaughan, P. J., Analysis of permeability reduction during flow of heated, aqueous fluid through Westerly Granite, in C.F. Tsang (ed.), Coupled processes associated with nuclear waste repositories, pp. 529-539, Academic Press, New York, 1987.

Verma, A., and Pruess, K., Thermohydrological conditions and silica redistribution near highlevel nuclear wastes emplaced in saturated geological formations, J. Geophys. Res., v. 93, p. 1159-1173, 1988.

Vinsome, P. K. W. and Westerveld, J., A simple method for predicting cap and base rock heat losses in thermal reservoir simulators, J. Canadian Pet. Tech., v. 19 (3), p. 87-90, 1980.

Walter, A. L., Frind, E. O., Blowes, D. W., Ptacek, C. J., and Molson, J. W., Modeling of multicomponent reactive transport in groundwater: 1, Model development and evaluation, Water Resour. Res., v. 30, p. 3137-3148, 1994.

Weir, G. J., White, S. P., and Kissling, W. M., Reservoir Storage and Containment of Greenhouse Gases, in: K. Pruess (ed.), Proceedings of the TOUGH Workshop '95, Lawrence Berkeley National Laboratory Report LBL-37200, p. 233-238, Berkeley, CA, 1995.

White, S. P., Multiphase non-isothermal transport of systems of reacting chemicals, Water Resour. Res., v. 31, p. 1761-1772, 1995. 
White, S. P., and Christenson, B. W., Modeling the alteration halo of a diorite intrusion, New Zealand Geothermal Congress, 1998.

White, A. F., and Peterson, M. L., Chemical equilibrium and mass balance relationships associated with Long Valley hydrothermal system, California, USA, J. Volcanol. and Geotherm. Res., v. 48, p. 283-302, 1991.

Wolery, T. J., EQ3/6: Software package for geochemical modeling of aqueous systems: Package overview and installation guide (version 8.0), Lawrence Livermore National Laboratory Report UCRL-MA-110662 PT I, Livermore, California, 1992.

Wu, Y.-S., and Mishra, A.,K., Modifications and additions to the selected TOUGH2 modules. Lawrence Berkeley National Laboratory Report LBNL-41870, Berkeley, California, 58 pp., 1998.

Wu, Y.-S., Haukwa, C., and Mukhopadhay, S., TOUGH2 V1.4 and T2R3D V1.4: Verification and Validation Report, Rev.00, Revised 10/11/99, 1999. MOL.20000216.0111.

$\mathrm{Xu}, \mathrm{T}$., and Pruess, K., Coupled modeling of non-isothermal multiphase flow, solute transport and reactive chemistry in porous and fractured media: 1. Model development and validation, Lawrence Berkeley National Laboratory Report LBNL-42050, Berkeley, California, 38 pp., 1998.

Xu, T., Samper, J., Ayora, C., Manzano, M., and Custodio, E., Modeling of non-isothermal multicomponent reactive transport in field-scale porous media flow system, J. Hydrol., v. 214, p. 144164, 1999a.

Xu, T., Pruess, K., and Brimhall, G., An improved equilibrium-kinetics speciation algorithm for redox reactions in variably saturated flow systems, Computers \& Geosciences, v. 25, p. 655$666,1999 b$.

Xu, T., White, S. P., Pruess, K., Brimhall, G. H., and Apps, J., Modeling of pyrite oxidation in saturated and unsaturated subsurface flow systems, Transport in Porous Media, v. 39, p. 25-56, 2000 .

$\mathrm{Xu}, \mathrm{T}$., and Pruess, K., On fluid flow and mineral alteration in fractured caprock of magmatic hydrothermal systems, J. Geophys. Res., v. 106, p. 2121-2138, $2001 \mathrm{a}$.

$\mathrm{Xu}, \mathrm{T}$., and Pruess, K., Modeling multiphase fluid flow and reactive geochemical transport in variably saturated fractured rocks: 1. Methodology, Am. J. Sci., v. 301, p. 16-33, 2001b. 
Xu, T., Sonnenthal, E., Spycher, N., Pruess, K., Brimhall, G., Apps, J., Modeling multiphase fluid flow and reactive geochemical transport in variably saturated fractured rocks: 2. Applications to supergene copper enrichment and hydrothermal flows, Am. J. Sci., v. 301, p. 34-59, 2001.

$\mathrm{Xu}, \mathrm{T} .$, Sonnenthal, E., and Bodvarsson G., A reaction-transport model for calcite precipitation and evaluation of infiltration-percolation fluxes in unsaturated fractured rock, J. Contam. Hydrol., v. 64(1-2) p. 113 - 127, $2003 a$.

Xu, T., Apps, J. A., and Pruess, K., Reactive geochemical transport simulation to study mineral trapping for $\mathrm{CO}_{2}$ disposal in deep arenaceous formations, J. Geophys. Res., v. 108 (B2), 2071, doi:10.1029/2002JB001979, 2003b.

$\mathrm{Xu}, \mathrm{T}$, Apps, J. A., and Pruess, K., Numerical simulation of $\mathrm{CO}_{2}$ disposal by mineral trapping in deep aquifers, Applied Geochemistry, v. 19, p. 917-936, 2004a.

Xu, T., Ontoy, Y., Molling, P., Spycher, N., Parini, M., and Pruess, K., Reactive transport modeling of injection well scaling and acidizing at Tiwi Field Philippines, Geothermics, v. 33(4), p. 477-491, $2004 b$.

Yeh, G. T., and Tripathi, V. S., A model for simulating transport of reactive multispecies components: model development and demonstration, Water Resour. Res., v. 27, p. 3075-3094, 1991. 


\section{Appendix A. Mathematical Equations for Flow and Transport}

All flow and transport equations have the same structure, and can be derived from the principle of mass (or energy) conservation. Table A.1 summarizes these equations and Table A.2 gives the meaning of symbols used. The models for fluid and heat flow have been discussed in detail by Pruess (1987 and 1991) and Pruess et al. (1999). Aqueous species are subject to transport in the liquid phase as well as to local chemical interactions with the solid and gaseous phases. Chemical transport equations are written in terms of total dissolved concentrations of chemical components that are concentrations of their basis species plus their associated aqueous secondary species (Yeh and Tripathi, 1991; Steefel and Lasaga, 1994; Walter et al., 1994). Advection and diffusion processes are considered for chemical transport, and diffusion coefficients are assumed to be the same for all aqueous species.

Table A.1. Governing equations for fluid and heat flow, and chemical transport. Symbol meanings are given in Table A.2. Take EOS3 and EOS4 flow modules as example. For EOS2 and ECO2N, component 'Air' in the table should be replaced with ' $\mathrm{CO}_{2}$ '. For EOS1, equation for air is not required. For EOS9, equations for air and heat are not required (only Richard's equation).

General governing equations: $\quad \frac{\partial \mathrm{M}_{\kappa}}{\partial \mathrm{t}}=-\nabla \mathrm{F}_{\mathrm{\kappa}}+\mathrm{q}_{\mathrm{\kappa}}$

Water: $\mathrm{M}_{\mathrm{w}}=\phi\left(\mathrm{S}_{1} \rho_{1} \mathrm{X}_{\mathrm{wl}}+\mathrm{S}_{\mathrm{g}} \rho_{\mathrm{g}} \mathrm{X}_{\mathrm{wg}}\right) \quad \mathrm{F}_{\mathrm{w}}=\mathrm{X}_{\mathrm{wl}} \rho_{\mathrm{l}} \mathbf{u}_{1}+\mathrm{X}_{\mathrm{wg}} \rho_{\mathrm{g}} \mathbf{u}_{\mathrm{g}} \quad \mathrm{q}_{\mathrm{w}}=\mathrm{q}_{\mathrm{wl}}+\mathrm{q}_{\mathrm{wg}}$

Air: $\quad \mathrm{M}_{\mathrm{c}}=\phi\left(\mathrm{S}_{1} \rho_{\mathrm{l}} \mathrm{X}_{\mathrm{cl}}+\mathrm{S}_{\mathrm{g}} \rho_{\mathrm{g}} \mathrm{X}_{\mathrm{cg}}\right) \quad \mathrm{F}_{\mathrm{c}}=\mathrm{X}_{\mathrm{cl}} \rho_{1} \mathbf{u}_{1}+\mathrm{X}_{\mathrm{cg}} \rho_{\mathrm{g}} \mathbf{u}_{\mathrm{g}}$

$$
\mathrm{q}_{\mathrm{c}}=\mathrm{q}_{\mathrm{cl}}+\mathrm{q}_{\mathrm{cg}}+\mathrm{q}_{\mathrm{cr}}
$$

Heat: $\quad \mathrm{M}_{\mathrm{h}}=\phi\left(\mathrm{S}_{1} \rho_{1} \mathrm{U}_{1}+\mathrm{S}_{\mathrm{g}} \rho_{\mathrm{g}} \mathrm{U}_{\mathrm{g}}\right)+(1-\phi) \rho_{\mathrm{s}} \mathrm{U}_{\mathrm{s}} \quad \mathrm{F}_{\mathrm{h}}=\sum_{\beta=1, \mathrm{~g}} \mathrm{~h}_{\beta} \rho_{\beta} \mathbf{u}_{\beta}-\lambda \nabla \mathrm{T} \quad \mathrm{q}_{\mathrm{h}}$

$$
\text { where } \mathbf{u}_{\beta}=-\mathrm{k} \frac{\mathrm{k}_{\mathrm{r} \beta}}{\mu_{\beta}}\left(\nabla \mathrm{P}_{\beta}-\rho_{\beta} \mathbf{g}\right) \quad \beta=1, \mathrm{~g} \quad \text { (Darcy's Law) }
$$

Chemical components in the liquid phase $\left(\mathrm{j}=1,2, \ldots, \mathrm{N}_{1}\right)$ :

$$
\begin{aligned}
& M_{j}=\phi S_{1} C_{j l} F_{j}=u_{1} C_{j 1}-\left(\tau \phi S_{1} D_{1}\right) \nabla C_{j 1} \quad q_{j}=q_{j 1}+q_{j s}+q_{j g} \\
& \tau_{\beta}=\phi^{1 / 3} S_{\beta}^{7 / 3} \quad \text { (Millington and Quirk, 1961) }
\end{aligned}
$$


Table A.2. Symbols used in Table A.1.

\begin{tabular}{llll}
\hline $\mathrm{C}$ & component concentration, $\mathrm{mol} \mathrm{L}^{-1}$ & $\rho$ & density, $\mathrm{kg} \mathrm{m}^{-3}$ \\
$\mathrm{D}$ & diffusion coefficient, $\mathrm{m}^{2} \mathrm{~s}^{-1}$ & $\mu$ & viscosity, $\mathrm{kg} \mathrm{m}^{-1} \mathrm{~s}^{-1}$ \\
$\mathrm{~F}$ & mass flux, $\mathrm{kg} \mathrm{m}^{-2} \mathrm{~s}^{-1}\left({ }^{*}\right)$ & $\lambda$ & heat conductivity, $\mathrm{W} \mathrm{m}^{-1} \mathrm{~K}^{-1}$ \\
$\mathrm{k}$ & permeability, $\mathrm{m}^{2}$ & \multicolumn{2}{l}{} \\
$\mathrm{k}_{\mathrm{r}}$ & relative permeability & Subscripts: \\
$\mathrm{g}$ & gravitational acceleration, $\mathrm{m} \mathrm{s}^{-2}$ & $\mathrm{c}$ & air \\
$\mathrm{M}$ & mass accumulation, $\mathrm{kg} \mathrm{m}^{-3}$ & $\mathrm{~g}$ & gas phase \\
$\mathrm{N}$ & number of chemical components & $\mathrm{h}$ & heat \\
$\mathrm{p}$ & pressure, Pa & $\mathrm{j}$ & aqueous chemical component \\
$\mathrm{q}$ & source/sink & 1 & liquid phase \\
$\mathrm{S}$ & saturation & $\mathrm{r}$ & reaction \\
$\mathrm{T}$ & temperature, ${ }^{\circ} \mathrm{C}$ & $\mathrm{s}$ & solid phase \\
$\mathrm{U}$ & internal energy, $\mathrm{J} \mathrm{kg}^{-1}$ & $\mathrm{~W}$ & water \\
$\mathbf{u}$ & Darcy velocity, $\mathrm{m} \mathrm{s}^{-1}$ & $\kappa$ & governing equation index \\
$\mathrm{X}$ & mass fraction & $\beta$ & phase index \\
$\phi$ & porosity & $\tau$ & medium tortuosity \\
\hline
\end{tabular}

$(*)$ For chemical transport and reaction calculations, molar units are used instead of $\mathrm{kg}$.

The primary governing equations given in Table A.1 must be complemented with constitutive relationships that express all parameters as functions of thermophysical and chemical variables. The expressions for non-isothermal multiphase flow are given by Pruess et al. (1999). The expressions for chemical reactions are given in Appendix B.

Gas species diffusion coefficients are computed as a function of temperature, pressure, molecular weight, and molecular diameter. Assuming ideal gas behavior, the tracer diffusion coefficient of a gaseous species can be expressed as follows (Lasaga, 1998):

$$
D=\frac{R T}{3 \sqrt{2} \pi P N_{A} d_{m}^{2}} \sqrt{\frac{8 R T}{\pi M}}
$$

where:

$\mathrm{D}=$ diffusion coefficient $\left(\mathrm{m}^{2} / \mathrm{s}\right)$

$\mathrm{R}=$ molar gas constant $\left(8.31451 \mathrm{~m}^{2} \mathrm{~kg} \mathrm{~s}^{-2} \mathrm{~mol}^{-1} \mathrm{~K}^{-1}\right)$

$\mathrm{T}=$ temperature in Kelvin units

$\pi=3.1415926536$

$\mathrm{P}=$ pressure $\left(\mathrm{kg} \mathrm{m}^{-1} \mathrm{~s}^{-2}\right)$

$\mathrm{N}_{\mathrm{A}}=$ Avogadro's number $\left(6.0221367 \times 10^{23}\right.$ molecules $\left./ \mathrm{mol}\right)$

$\mathrm{D}_{\mathrm{m}}=$ molecular diameter $(\mathrm{m})$

$\mathrm{M}=$ molecular weight $(\mathrm{kg} / \mathrm{mol})$ 


\section{Appendix B. Mathematical Formulation of Chemical Reactions}

To represent a geochemical system, it is convenient to select a subset of $\mathrm{N}_{\mathrm{C}}$ aqueous species as basis species (or component or primary species). All other species are called secondary species that include aqueous complexes, precipitated (mineral) and gaseous species (Reed, 1982; Yeh and Tripathi, 1991; Steefel and Lasaga, 1994). The number of secondary species must be equal to the number of independent reactions. Any of the secondary species can be represented as a linear combination of the set of basis species such as

$$
\mathrm{S}_{\mathrm{i}}=\sum_{\mathrm{j}=1}^{\mathrm{N}_{\mathrm{C}}} \mathrm{v}_{\mathrm{ij}} \mathrm{S}_{\mathrm{j}} \quad \mathrm{i}=1, \ldots, \mathrm{N}_{\mathrm{R}}
$$

where $\mathrm{S}$ represents chemical species, $\mathrm{j}$ is the basis species index, $\mathrm{i}$ is the secondary species index, $\mathrm{N}_{\mathrm{R}}$ is the number of reactions (or secondary species), and $v_{\mathrm{ij}}$ is the stoichiometric coefficient of $\mathrm{j}$ th basis species in the $\mathrm{i}$-th reaction.

Aqueous complexation. These reactions are assumed to be at local equilibrium. By making use of the mass action equation to the dissociation of the i-th aqueous complex (Equation B.1), concentrations of aqueous complexes can be expressed as functions of the concentrations of basis species:

$$
c_{i}=K_{i}^{-1} \gamma_{i}^{-1} \prod_{j=1}^{N_{c}} c_{j}^{v_{i j}} \gamma_{j}^{v_{i j}}
$$

where $c_{i}$ is molal concentration of the $i$-th aqueous complex, and $c_{j}$ is molal concentration of the $j$ th basis species, $\gamma_{i}$ and $\gamma_{j}$ are thermodynamic activity coefficients (details on calculation of activity coefficients are given in Appendix $\mathrm{H}$ ), and $\mathrm{K}_{\mathrm{i}}$ is the equilibrium constant. 
Equilibrium mineral dissolution/precipitation. The mineral saturation ratio can be expressed as

$$
\Omega_{\mathrm{m}}=\mathrm{K}_{\mathrm{m}}^{-1} \prod_{\mathrm{j}=1}^{\mathrm{N}_{\mathrm{C}}} \mathrm{c}_{\mathrm{j}}^{v_{\mathrm{mj}}} \gamma_{\mathrm{j}}^{v_{\mathrm{mj}}} \quad \mathrm{m}=1 \ldots \mathrm{N}_{\mathrm{P}}
$$

where $\mathrm{m}$ is the equilibrium mineral index, and $\mathrm{K}_{\mathrm{m}}$ is the corresponding equilibrium constant. At equilibrium, we have

$$
\mathrm{SI}_{\mathrm{m}}=\log _{10} \Omega_{\mathrm{m}}=0
$$

where $\mathrm{SI}_{\mathrm{m}}$ is called the mineral saturation index. The treatment for mineral solid solutions is given in Appendix I.

Kinetic mineral dissolution/precipitation. Kinetic rates could be functions of non-basis species as well. Usually the species appearing in rate laws happen to be basis species. In this model, we use a rate expression given by Lasaga et al. (1994):

$$
r_{n}=f\left(c_{1}, c_{2}, \ldots, c_{N_{C}}\right)= \pm k_{n} A_{n}\left|1-\Omega_{n}^{\theta}\right|^{\eta} \quad n=1 \ldots N_{q}
$$

where positive values of $r_{n}$ indicate dissolution, and negative values precipitation, $k_{n}$ is the rate constant (moles per unit mineral surface area and unit time) which is temperature dependent, $A_{n}$ is the specific reactive surface area per $\mathrm{kg} \mathrm{H}_{2} \mathrm{O}$ (details on $\mathrm{A}_{\mathrm{n}}$ calculations are given in Appendix G), $\Omega_{\mathrm{n}}$ is the kinetic mineral saturation ratio defined in (B.3). The parameters $\theta$ and $\eta$ must be determined from experiments; usually, but not always, they are taken equal to one. The temperature dependence of the reaction rate constant can be expressed reasonably well via an Arrhenius equation (Lasaga, 1984; Steefel and Lasaga, 1994). Because many rate constants are reported at $25^{\circ} \mathrm{C}$, it is convenient to approximate rate constant dependency as a function of temperature, thus 


$$
\mathrm{k}=\mathrm{k}_{25} \exp \left[\frac{-\mathrm{E}_{\mathrm{a}}}{\mathrm{R}}\left(\frac{1}{\mathrm{~T}}-\frac{1}{298.15}\right)\right]
$$

where $E_{a}$ is the activation energy, $k_{25}$ is the rate constant at $25^{\circ} \mathrm{C}, \mathrm{R}$ is gas constant, $\mathrm{T}$ is absolute temperature.

Carroll et al. (1998) noted that the rates of amorphous silica precipitation based on Rimstidt and Barnes (1980) are about three orders of magnitude lower than those observed in geothermal systems. Carroll et al. (1998) presented experimental data on amorphous silica precipitation for more complex geothermal fluids at higher degrees of supersaturation, and also for a near-saturation simple fluid chemistry. Under conditions far from equilibrium, the rate law for amorphous silica precipitation has been expressed as:

$$
\mathrm{r}=\mathrm{kA}(\Omega)^{\theta}
$$

This rate does not tend to zero as $\Omega$ goes to one, and therefore, in TOUGHREACT, a modification was made to this law so that it tends to zero as $\Omega$ approaches one

$$
r=k A\left[(\Omega)^{\theta}-\frac{1}{\Omega^{2 \theta}}\right]
$$

The $\mathrm{pH}$ dependence of mineral precipitation and dissolution rates is calculated using the following expressions:

$$
\begin{array}{cc}
k_{a d j}=k\left(10^{-p H c} / 10^{-p H 1}\right)^{\text {slopel }} & \text { if } \mathrm{pH}_{\mathrm{c}}<\mathrm{pH}_{1} \\
k_{\text {adj }}=k\left(10^{-p H c} / 10^{-p H 2}\right)^{- \text {slope } 2} & \text { if } \mathrm{pH}_{\mathrm{c}}>\mathrm{pH}_{2}
\end{array}
$$

where $k_{a d j}$ is the rate adjusted for $\mathrm{pH}, k$ is the original rate (Equation B.5), $p H_{c}$ is the current (calculated) $\mathrm{pH}, \mathrm{pH} 1$ is the $\mathrm{pH}$ below which the rate is adjusted by slopel and $\mathrm{pH} 2$ is the $\mathrm{pH}$ above which the rate is adjusted by slope2. Parameters slope1 and slope 2 are the absolute values 
(both positive numbers) of the $\log (k)$ versus $\mathrm{pH}$ slopes below $\mathrm{pH} 1$ and above $\mathrm{pH} 2$, respectively (Figure B.1). Between these two $\mathrm{pH}$ values, the rate is assumed to remain independent of $\mathrm{pH}$.

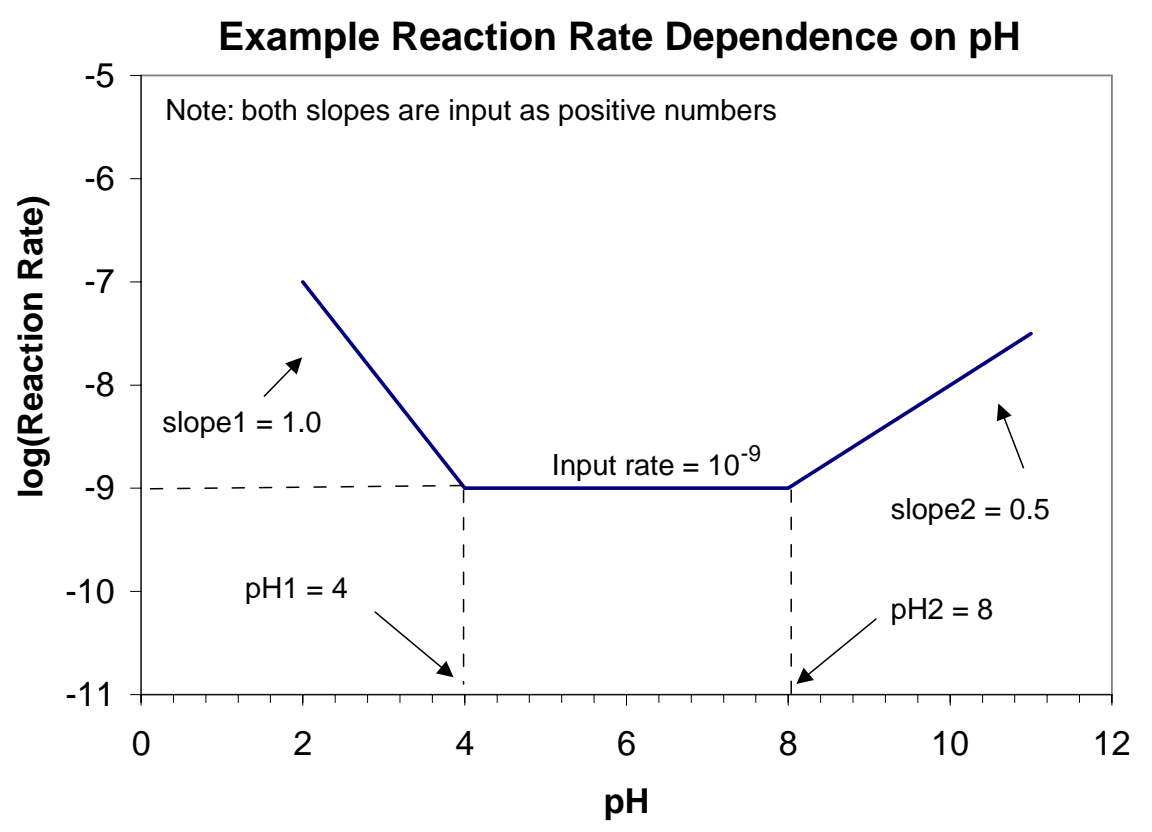

Figure B.1. Variation of reaction rate with $\mathrm{pH}$. Slopes shown are for the dissolution of silicate and aluminosilicate minerals (After Drever, 1997).

The kinetic rate constant k in Eqs. (B.5) and (B.6) only considers the most well-studied mechanism in pure $\mathrm{H}_{2} \mathrm{O}$ (at neutral $\mathrm{pH}$ ). Dissolution and precipitation of minerals are often catalyzed by $\mathrm{H}^{+}$(acid mechanism) and $\mathrm{OH}^{-}$(base mechanism). For many minerals, the kinetic rate constant k includes each of these three mechanisms (Lasaga et al., 1994; Palandri and Kharaka, 2004), or

$$
\begin{array}{r}
\mathrm{k}=\mathrm{k}_{25}^{\mathrm{nu}} \exp \left[\frac{-\mathrm{E}_{\mathrm{a}}^{\mathrm{nu}}}{\mathrm{R}}\left(\frac{1}{\mathrm{~T}}-\frac{1}{298.15}\right)\right]+\mathrm{k}_{25}^{\mathrm{H}} \exp \left[\frac{-\mathrm{E}_{\mathrm{a}}^{\mathrm{H}}}{\mathrm{R}}\left(\frac{1}{\mathrm{~T}}-\frac{1}{298.15}\right)\right] \mathrm{a}_{\mathrm{H}}^{\mathrm{n}_{\mathrm{H}}} \\
+\mathrm{k}_{25}^{\mathrm{OH}} \exp \left[\frac{-\mathrm{E}_{\mathrm{a}}^{\mathrm{OH}}}{\mathrm{R}}\left(\frac{1}{\mathrm{~T}}-\frac{1}{298.15}\right)\right] \mathrm{a}_{\mathrm{OH}}^{\mathrm{n}_{\mathrm{OH}}}
\end{array}
$$

where superscripts or subscripts nu, $\mathrm{H}$, and $\mathrm{OH}$ indicate neutral, acid and base mechanisms, respectively; $a$ is the activity of the species; and $n$ is power term (constant). Notice that 
parameters $\theta$ and $\eta$ (see Eq. B.5) are assumed the same for each mechanism. The rate constant $\mathrm{k}$ can be also dependent on other species such as $\mathrm{Al}^{3+}$ and $\mathrm{Fe}^{3+}$. Two or more species may be involved in one mechanism. A general form of species dependent rate constants (extension of Eq. B.11) is coded in TOUGHREACT, or,

$$
\mathrm{k}=\mathrm{k}_{25}^{\mathrm{nu}} \exp \left[\frac{-\mathrm{E}_{\mathrm{a}}^{\mathrm{nu}}}{\mathrm{R}}\left(\frac{1}{\mathrm{~T}}-\frac{1}{298.15}\right)\right]+\sum_{\mathrm{i}} \mathrm{k}_{25}^{\mathrm{i}} \exp \left[\frac{-\mathrm{E}_{\mathrm{a}}^{\mathrm{i}}}{\mathrm{R}}\left(\frac{1}{\mathrm{~T}}-\frac{1}{298.15}\right)\right] \prod_{\mathrm{j}} \mathrm{a}_{\mathrm{ij}}^{\mathrm{n}_{\mathrm{ij}}}
$$

where superscripts or subscripts $i$ is the additional mechanism index, and $j$ is species index involved in one mechanism that can be primary or secondary species. TOUGHREACT considers up to five additional mechanisms and up to five species involved in each mechanism. An application of multiple mechanisms (Eq. B.12) can be found in the $\mathrm{CO}_{2}$ disposal sample problem (Section 8.5).

The precipitation of a mineral can be suppressed up to a given, positive saturation index value, $\log (\Omega)_{\mathrm{w}}$. Within this "supersaturation window", the mineral is not allowed to precipitate. The mineral precipitates if its saturation index $\log (\Omega) \geq \log (\Omega)_{\mathrm{w}}$, and dissolves if $\log (\Omega)<0$. The size of the window can be set to decrease exponentially with temperature as follows:

$$
\log (\Omega)_{\mathrm{w}, \mathrm{T}}=\log (\Omega)_{\mathrm{w}, \mathrm{T}}^{0} \exp \left(-4.61\left(\mathrm{~T}-\mathrm{T}^{0}\right) /\left(\mathrm{T}_{1}-\mathrm{T}^{0}\right)\right)
$$

where $\log (\Omega)_{\mathrm{w}, \mathrm{T}}$ is the window at the current temperature $\mathrm{T}$ and $\log (\Omega)_{\mathrm{w}, \mathrm{T}}{ }^{0}$ is the initial (input) window at temperature $T^{0} . T_{1}$ is the temperature at which the window is one-hundredth the size of the initial window (thus the temperature at which the effect of the window essentially disappears, see Figure B.2). Values of $\log (\Omega)_{\mathrm{w}, \mathrm{T}}{ }^{0}, \mathrm{~T}_{0}$, and $\mathrm{T}_{1}$ are provided as input parameters. 


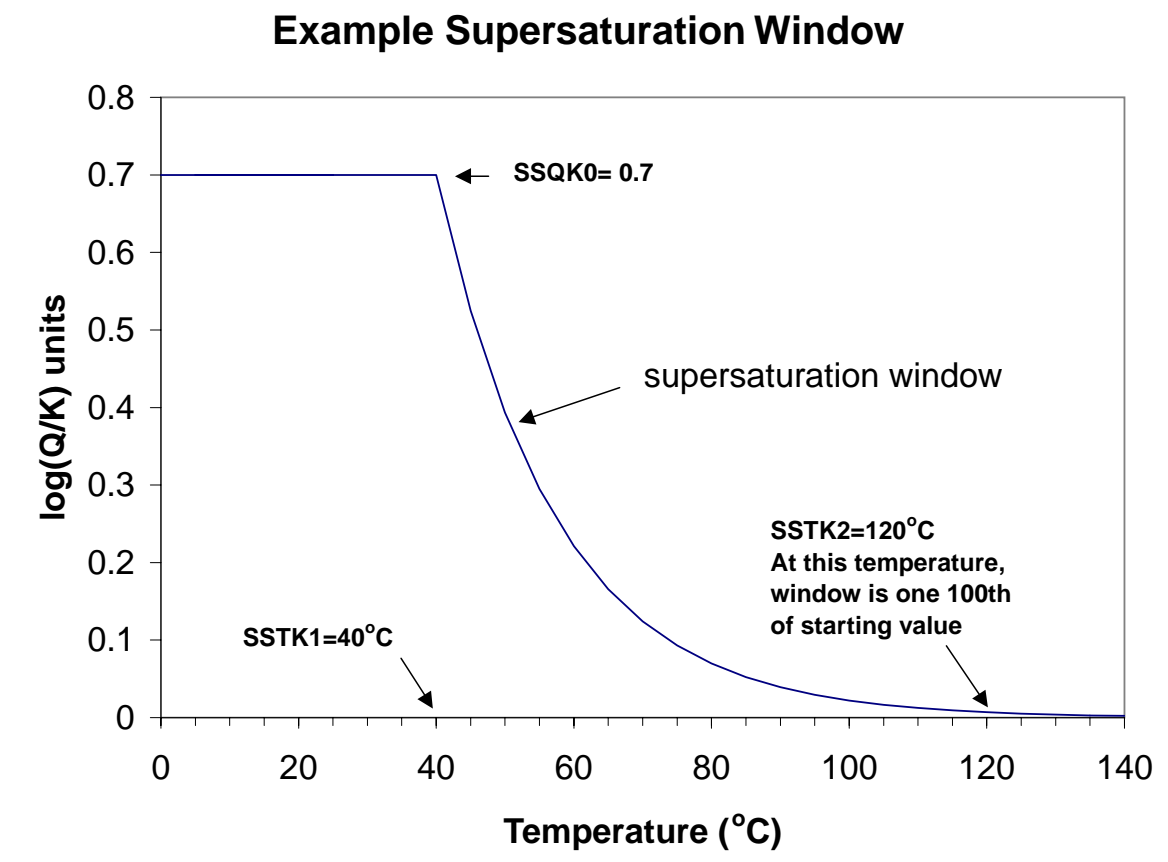

Figure B.2. Supersaturation window dependence on temperature.

Gas dissolution/exsolution. Reactions involving aqueous and gaseous phases are usually assumed to be at equilibrium. According to the Mass-Action Law, one has:

$$
p_{f} \Gamma_{f} K_{f}=\prod_{j=1}^{N_{C}} c_{j}^{v_{f j}} \gamma_{j}^{v_{f i}}
$$

where subscript $\mathrm{f}$ is gas index, $\mathrm{p}$ is the partial pressure (in bar), $\Gamma$ is the gas fugacity coefficient. For low pressures (in the range of atmospheric pressure), the gaseous phase is assumed to behave like an ideal mixture, and the fugacity coefficient $\Gamma$ is assumed equal to one. At higher temperatures and pressures, such as boiling conditions in hydrothermal systems and $\mathrm{CO}_{2}$ disposal in deep aquifers, the assumption of ideal gas and ideal mixing behavior is not valid, and the fugacity coefficients should be corrected according to temperatures and pressures (Spycher and Reed, 1988). For example, for $\mathrm{H}_{2} \mathrm{O}-\mathrm{CO}_{2}$ mixtures in boiling conditions, we assume that $\mathrm{H}_{2} \mathrm{O}$ and $\mathrm{CO}_{2}$ are real gases, but their mixing is ideal. Following Spycher and Reed (1988), the fugacity coefficients is calculated from 


$$
\ln \Gamma=\left(\frac{\mathrm{a}}{\mathrm{T}^{2}}+\frac{\mathrm{b}}{\mathrm{T}}+\mathrm{c}\right) \mathrm{P}+\left(\frac{\mathrm{d}}{\mathrm{T}^{2}}+\frac{\mathrm{e}}{\mathrm{T}}+\mathrm{f}\right) \frac{\mathrm{P}^{2}}{2}
$$

where $\mathrm{P}$ is the total gas pressure (vapor and $\mathrm{CO}_{2}$ ), $\mathrm{T}$ is absolute temperature, and a, b, c, d, e, and $\mathrm{f}$ are constants fitted from experimental data. For P-T ranges, $50-350{ }^{\circ} \mathrm{C}$, up to 500 bars, the fitted constants for $\mathrm{CO}_{2}$ have the following values: $\mathrm{a}=-1430.87, \mathrm{~b}=3.598, \mathrm{c}=-2.27376 \times 10^{-3}, \mathrm{~d}=$ $3.47644, \mathrm{e}=-1.04247 \times 10^{-2}$, and $\mathrm{f}=8.36271 \times 10^{-6}$. Examples of equilibrium calculations between aqueous and gas phases show that ideal mixing of real gases is a reasonable approximation near the water saturation pressure curve (Spycher and Reed, 1988). The fugacity correction (B.15) is currently only considered for EOS2 and ECO2N fluid flow modules.

For low ionic strength solution, the $\mathrm{CO}_{2}(\mathrm{aq})$ activity coefficient $\gamma$ can be assumed equal to one. For a high ionic strength sodium chloride solution, $\gamma$ should be corrected (salting out effect). Here we use an activity coefficient expression of Drummond (1981) for $\mathrm{CO}_{2}(\mathrm{aq})$ :

$$
\ln \gamma=\left(\mathrm{C}+\mathrm{FT}+\frac{\mathrm{G}}{\mathrm{T}}\right) \mathrm{I}-(\mathrm{E}+\mathrm{HT})\left(\frac{\mathrm{I}}{\mathrm{I}+1}\right)
$$

where $\mathrm{T}$ is the absolute temperature, $\mathrm{I}$ is ionic strength (or sodium chloride molality), $\mathrm{C}, \mathrm{F} \mathrm{G}, \mathrm{E}$, and $\mathrm{H}$ are constants $(\mathrm{C}=-1.0312, \mathrm{~F}=0.0012806, \mathrm{G}=255.9, \mathrm{E}=0.4445$, and $\mathrm{H}=-0.001606)$. This similar expression is used in other geochemical modeling codes such as in EQ3/6 (Wolery, 1992). The ionic strength $\mathrm{I}$ is defined by

$$
\mathrm{I}=\frac{1}{2} \sum_{\mathrm{i}} \mathrm{c}_{\mathrm{i}} \mathrm{z}_{\mathrm{i}}^{2}
$$

where the summation is over all aqueous species, and $\mathrm{c}_{\mathrm{i}}$ and $\mathrm{z}_{\mathrm{i}}$ are concentration $\left(\mathrm{mol} / \mathrm{kg} \mathrm{H}_{2} \mathrm{O}\right)$ and electrical charge of species $i$. 
Cation exchange. Cation exchange takes place when free cations in solution exchange with interlayer cations. This process can be described as an equilibrium reaction between an exchangeable cation and an exchange site. The equilibrium constant is usually known as the exchange coefficient because its value depends on the ionic strength of the solution. A general expression for cation exchange reactions according to the Gaines-Thomas convention is (Appelo and Postma, 1993):

$$
\frac{1}{v_{i}} S_{i}+\frac{1}{v_{j}}\left(X_{v_{j}}-S_{j}\right) \Leftrightarrow \frac{1}{v_{i}}\left(X_{v_{i}}-S_{i}\right)+\frac{1}{v_{j}} S_{j}
$$

where $v_{\mathrm{i}}$ and $v_{\mathrm{j}}$ are the stoichiometric coefficients (equal to their charges) of dissolved and interlayer cations, respectively; $S_{i}$ and $S_{j}$ denote dissolved cationic species and $\left(X_{v_{i}}-S_{i}\right)$ and $\left(\mathrm{X}_{v_{\mathrm{j}}}-\mathrm{S}_{\mathrm{j}}\right)$ represent exchange sites or exchange interlayer cations. The equilibrium equation for cation exchange is obtained from the Mass Action Law:

$$
\mathrm{K}_{\mathrm{ij}}^{*}=\frac{\overline{\mathrm{w}}_{\mathrm{i}}^{1 / v_{\mathrm{i}}} \cdot \mathrm{a}_{\mathrm{j}}^{1 / v_{\mathrm{j}}}}{\overline{\mathrm{w}}_{\mathrm{j}}^{1 / v_{\mathrm{j}}} \cdot \mathrm{a}_{\mathrm{i}}^{1 / v_{\mathrm{i}}}}
$$

where $K_{i j}^{*}$ is the exchange coefficient or selectivity, $a_{j}$ is the activity of the $\mathrm{j}$-th dissolved species and $\overline{\mathrm{W}}_{\mathrm{i}}$ is the activity of the i-th interlayer cation. Activities of dissolved cations are related to concentrations as given in Appendix H. Activities of interlayer cations are approximated by their equivalent fractions of the number of exchange sites. Thus, the activity of the interlayer cation $\overline{\mathrm{W}}_{\mathrm{i}}$ is assumed to be equal to its equivalent fraction $\beta_{\mathrm{i}}$, and is calculated as:

$$
\overline{\mathrm{W}}_{\mathrm{i}} \cong \beta_{\mathrm{i}}=\frac{\mathrm{w}_{\mathrm{i}}}{\sum_{\mathrm{i}=1}^{\mathrm{N}_{\mathrm{w}}} \mathrm{w}_{\mathrm{i}}}
$$


where $\mathrm{w}_{\mathrm{i}}$ is the concentration of the $\mathrm{i}$-th interlayer cation and $\mathrm{N}_{\mathrm{w}}$ is the total number of such interlayer cations. The sum of concentrations of exchange sites or interlayer cations is the socalled cation exchange capacity (CEC). Substituting (B.20) into (B.19) yields the general equation for cation exchange:

$$
\mathrm{K}_{\mathrm{ij}}^{*}=\frac{\beta_{\mathrm{i}}^{1 / v_{\mathrm{i}}} \cdot\left(\mathrm{c}_{\mathrm{j}} \gamma_{\mathrm{j}}\right)^{1 / v_{\mathrm{j}}}}{\beta_{\mathrm{j}}^{1 / v_{\mathrm{j}}} \cdot\left(\mathrm{c}_{\mathrm{i}} \gamma_{\mathrm{i}}\right)^{1 / v_{\mathrm{i}}}}
$$

where the activity of each dissolved species $\mathrm{a}_{\mathrm{i}}$ has been expressed as the product of its concentration $\mathrm{c}_{\mathrm{i}}$ time its activity coefficients $\gamma_{\mathrm{i}}$. From this equation, the equivalent fraction of the $\mathrm{j}$-th interlayer cation can be expressed as

$$
\beta_{j}=\left(K_{i j}^{*}\right)^{-v_{j}} c_{j} \gamma_{j}\left(\frac{\beta_{i}}{c_{i} \gamma_{i}}\right)^{v_{j} / v_{i}} \quad j=1,2, \cdots, N_{w}
$$

From the definition of equivalent fraction, one has:

$$
\sum_{j=1}^{N_{w}} \beta_{j}=1
$$

Substituting Equation B.22 into B.23 results in:

$$
\sum_{j=1}^{N_{w}}\left(K_{i j}^{*}\right)^{-v_{j}} c_{j} \gamma_{j}\left(\frac{\beta_{i}}{c_{i} \gamma_{i}}\right)^{v_{j} / v_{i}}=1
$$

which for given dissolved concentrations $c_{j}$ can be solved for the single unknown $\beta_{i}$. This equation is quadratic when cation exchange involves only homovalent and divalent cations. 
However, when cation exchange involves also trivalent cations a cubic equation is obtained. Once the equivalent fraction $\beta_{\mathrm{i}}$ is known the rest of exchange fractions can be calculated from Equation B.20. The concentration of the $\mathrm{i}$-th exchanged cation $\mathrm{w}_{\mathrm{j}}$ (in moles per liter of fluid) can be obtained from the i-th equivalent fraction according to Equation B.20 through:

$$
w_{j}=\beta_{j} C E C \rho_{s} \frac{(1-\phi)}{100 \phi z_{j}}
$$

where $\mathrm{CEC}$ is the cation exchange capacity (usually measured as the number of milli equivalents of cations per 100 gram of solid), $\phi$ is the porosity, $\rho_{\mathrm{s}}$ is the density of the solids ( $\mathrm{kg}$ of solids per $\mathrm{dm}^{3}$ of solids), and $\mathrm{z}_{\mathrm{j}}$ is the cation charge.

Three cation exchange conventions, Gaines-Thomas, Vanselow and Gapon (Appelo and Postma, 1993), are implemented in TOUGHREACT. 


\section{Appendix C. Solution Method for Solute Transport Equations}

Most chemical species are only subject to transport in the liquid phase. A few species can be transported in both liquid and gas phases such as $\mathrm{O}_{2}$ and $\mathrm{CO}_{2}$. We first derive the numerical formulation of reactive transport in the liquid phase. This will then be extended to transport in the gas phases for some gaseous species.

\section{C.1. Transport in the Liquid Phase}

In the sequential iteration approach (SIA), the mass transport equations and chemical reaction equations are considered as two relatively independent subsystems. They are solved separately in a sequential manner following an iterative procedure. If reactions taking place in the liquid phase are assumed to be at local equilibrium, mass transport equations can be written in terms of total dissolved component concentrations. By lumping all mass accumulation terms due to mass transfer between aqueous and solid phases including precipitated (kinetics and equilibrium), exchanged and sorbed species, and by using Equation (4.1) (in Chapter 4), we can write equations for multi-component chemical transport in the liquid phase as

$$
\begin{aligned}
& \frac{\Delta \mathrm{t}}{\mathrm{V}_{\mathrm{n}}} \sum_{\mathrm{m}} \mathrm{A}_{\mathrm{nm}}\left[\mathrm{u}_{\mathrm{nm}}^{\mathrm{k}+1} \mathrm{C}_{\mathrm{nm}}^{(\mathrm{j}), \mathrm{k}+1, \mathrm{~s}+1 / 2}+\mathrm{D}_{\mathrm{nm}} \frac{\mathrm{C}_{\mathrm{m}}^{(\mathrm{j}), \mathrm{k}+1, \mathrm{~s}+1 / 2}-\mathrm{C}_{\mathrm{n}}^{(\mathrm{j}), \mathrm{k}+1, \mathrm{~s}+1 / 2}}{\mathrm{~d}_{\mathrm{nm}}}\right]= \\
& \Delta \mathrm{M}_{\mathrm{n}}^{(\mathrm{j}), \mathrm{k}+1}-\mathrm{q}_{\mathrm{n}}^{(\mathrm{j}) \mathrm{k}+1} \Delta \mathrm{t}-\mathrm{R}_{\mathrm{n}}^{(\mathrm{j}), \mathrm{k}+1, \mathrm{~s}} \Delta \mathrm{t} \quad \mathrm{j}=1,2, \ldots, \mathrm{N}_{\mathrm{C}}
\end{aligned}
$$

where $\mathrm{n}$ labels the grid block, $\mathrm{m}$ label the adjacent grid blocks connected to $\mathrm{n}, \mathrm{j}$ labels the chemical component, $\mathrm{N}_{\mathrm{C}}$ is the total number of chemical components, 1 labels liquid phase (for simplicity, the liquid phase index 1 is neglected), $\mathrm{k}$ labels the number of the time step, $\mathrm{s}$ labels the number of the transport-chemistry iteration (details is given later), $\mathrm{u}_{\mathrm{nm}}$ is the liquid volumetric flux or the Darcy velocity $(\mathrm{m} / \mathrm{s}), \mathrm{D}_{\mathrm{nm}}$ is the effective diffusion coefficient (including effects of porosity, phase saturation, tortuosity and weighting factors between the two grid blocks), $\mathrm{d}_{\mathrm{nm}}$ is the nodal distance, $\mathrm{R}_{\mathrm{n}}^{(\mathrm{j}) \mathrm{k}+1}$ are the overall chemical reaction source/sink terms.

The concentrations in the advective and diffusive flux terms of Equation (C.1) can be evaluated by 


$$
\begin{aligned}
\mathrm{C}_{\mathrm{nm}}^{(\mathrm{j}), \mathrm{k}+1, \mathrm{~s}+1 / 2}= & \theta\left[\varepsilon_{\mathrm{nm}} \mathrm{C}_{\mathrm{n}}^{(\mathrm{j}), \mathrm{k}+1, \mathrm{~s}+1 / 2}+\left(1-\varepsilon_{\mathrm{nm}}\right) \mathrm{C}_{\mathrm{m}}^{(\mathrm{j}), \mathrm{k}+1, \mathrm{~s}+1 / 2}\right] \\
& (1-\theta)\left[\varepsilon_{\mathrm{nm}} \mathrm{C}_{\mathrm{n}}^{(\mathrm{j}), \mathrm{k}}+\left(1-\varepsilon_{\mathrm{nm}}\right) \mathrm{C}_{\mathrm{m}}^{(\mathrm{j}), \mathrm{k}}\right] \\
\mathrm{C}_{\mathrm{n}}^{(\mathrm{j}), \mathrm{k}+1, \mathrm{~s}+1 / 2}= & \theta \mathrm{C}_{\mathrm{n}}^{(\mathrm{j}), \mathrm{k}+1, \mathrm{~s}+1 / 2}+(1-\theta) \mathrm{C}_{\mathrm{n}}^{(\mathrm{j}), \mathrm{k}} \\
\mathrm{C}_{\mathrm{m}}^{(\mathrm{j}), \mathrm{k}+1, \mathrm{~s}+1 / 2}= & \theta \mathrm{C}_{\mathrm{m}}^{(\mathrm{j}), \mathrm{k}+1, \mathrm{~s}+1 / 2}+(1-\theta) \mathrm{C}_{\mathrm{m}}^{(\mathrm{j}), \mathrm{k}}
\end{aligned}
$$

where $\theta$ is the time weighting factor, with values in the range from 0 to $1 ; \theta=1$ indicates a fully implicit calculation; and

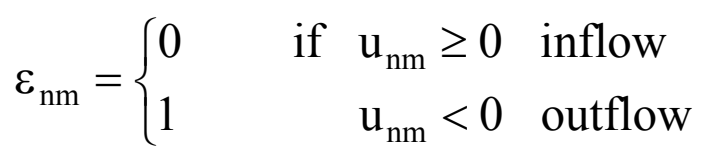

Fully upstream weighting is used for advective flux calculations. The mass accumulation terms can be evaluated as

$$
\Delta \mathrm{M}_{\mathrm{n}}^{(\mathrm{j}), \mathrm{k}+1}=\mathrm{S}_{1, \mathrm{n}}^{\mathrm{k}+1} \phi_{\mathrm{n}}^{\mathrm{k}+1} \mathrm{C}_{\mathrm{n}}^{(\mathrm{j}), \mathrm{k}+1, \mathrm{~s}+1 / 2}-\mathrm{S}_{1, \mathrm{n}}^{\mathrm{k}} \phi_{\mathrm{n}}^{\mathrm{k}} \mathrm{C}_{\mathrm{n}}^{(\mathrm{j}), \mathrm{k}}
$$

By substituting Equations (C.2) and (C.3) into (C.1), and then rearranging them in terms of unknowns, $\mathrm{C}^{(\mathrm{j}), \mathrm{k}+1, \mathrm{~s}+1 / 2}$ (total dissolved component concentrations), one has 


$$
\begin{aligned}
& {\left[\mathrm{S}_{1, \mathrm{n}}^{\mathrm{k}+1} \phi_{\mathrm{n}}^{\mathrm{k}+1}+\frac{\theta \Delta \mathrm{t}}{\mathrm{V}_{\mathrm{n}}} \sum_{\mathrm{m}} \mathrm{A}_{\mathrm{nm}}\left(-\mathrm{u}_{\mathrm{nm}}^{\mathrm{k}+1} \varepsilon_{\mathrm{nm}}+\frac{\mathrm{D}_{\mathrm{nm}}}{\mathrm{d}_{\mathrm{nm}}}\right)\right] \mathrm{C}_{\mathrm{n}}^{(\mathrm{j}), \mathrm{k}+1, \mathrm{~s}+1 / 2}+} \\
& \frac{\theta \Delta \mathrm{t}}{\mathrm{V}_{\mathrm{n}}} \sum_{\mathrm{m}} \mathrm{A}_{\mathrm{nm}}\left[\mathrm{u}_{\mathrm{nm}}^{\mathrm{k}+1}\left(\varepsilon_{\mathrm{nm}}-1\right)-\frac{\mathrm{D}_{\mathrm{nm}}}{\mathrm{d}_{\mathrm{nm}}}\right] \mathrm{C}_{\mathrm{m}}^{(\mathrm{j}), \mathrm{k}+1, \mathrm{~s}+1 / 2}= \\
& \frac{(1-\theta) \Delta \mathrm{t}}{\mathrm{V}_{\mathrm{n}}} \sum_{\mathrm{m}} \mathrm{A}_{\mathrm{nm}}\left(\mathrm{u}_{\mathrm{nm}}^{\mathrm{k}+1} \varepsilon_{\mathrm{nm}}-\frac{\mathrm{D}_{\mathrm{nm}}}{\mathrm{d}_{\mathrm{nm}}}\right) \mathrm{C}_{\mathrm{n}}^{(\mathrm{j}), \mathrm{k}}- \\
& \frac{(1-\theta) \Delta \mathrm{t}}{\mathrm{V}_{\mathrm{n}}} \sum_{\mathrm{m}} \mathrm{A}_{\mathrm{nm}}\left[\mathrm{u}_{\mathrm{nm}}^{\mathrm{k}+1}\left(\varepsilon_{\mathrm{nm}}-1\right)+\frac{\mathrm{D}_{\mathrm{nm}}}{\mathrm{d}_{\mathrm{nm}}}\right] \mathrm{C}_{\mathrm{m}}^{(\mathrm{j}), \mathrm{k}} \\
& \mathrm{S}_{1, \mathrm{n}}^{\mathrm{k}} \phi_{\mathrm{n}}^{\mathrm{k}} \mathrm{C}_{\mathrm{n}}^{(\mathrm{j}), \mathrm{k}}+\mathrm{q}_{\mathrm{n}}^{(\mathrm{j}) \mathrm{k}+1} \Delta \mathrm{t}+\mathrm{R}_{\mathrm{n}}^{(\mathrm{j}), \mathrm{k}+1, \mathrm{~s}} \Delta \mathrm{t} \\
& \mathrm{j}=1,2, \ldots, \mathrm{N}_{\mathrm{C}}
\end{aligned}
$$

For the sequential iteration approach, the iteration index $\mathrm{s}$ is essential. A new transport-chemistry iteration consists of two parts, transport part denoted by, $\mathrm{s}+1 / 2$, (it should be noted that $1 / 2$ does not mean $\Delta t / 2$ ), and chemistry part denoted by, $\mathrm{s}+1$. Equation (C.4) for each chemical component $\mathrm{j}$ is linear if $\mathrm{R}^{(\mathrm{j}), \mathrm{s}}$ is known, and has the same structure as the non-reacting (conservative) solute transport equation. The chemical reaction source/sink term $\mathrm{R}^{(\mathrm{j}), \mathrm{s}}$ represents mass transfer of component $\mathrm{j}$ between aqueous and solid phases. The values of these source/sink terms at the new transport iteration, $s+1 / 2$, are evaluated at the previous chemistry iteration, $s$. The resulting new values of $C^{(j), s+1 / 2}$, obtained by solving transport Equations (C.1), are substituted into chemical reaction subroutines and one can compute new values of $\mathrm{R}^{(\mathrm{j}) \mathrm{s}+1}$. Transport and chemical reaction equations are solved iteratively until the prescribed convergence criteria are satisfied. The essence of this sequential iteration approach is therefore the sequential solution of two independent sets of equations: the transport equations and the chemical equations. The transport equations are solved on a component-by-component basis, whereas the chemical equations are solved on a grid block by grid block basis. These two sets of equations are coupled by updating chemical source/sink terms.

For kinetic mineral dissolution-precipitation, the terms $\mathrm{R}^{(\mathrm{j})}$ can be calculated directly from kinetic expressions. For equilibrium, these terms can be obtained indirectly from component mass 
balance equations. The solution of chemical equilibrium system and calculation of the source/sink terms $\mathrm{R}^{(\mathrm{j})}$ are presented in Appendix D. From the chemistry point of view, equilibrium mineral dissolution-precipitation does not appear in an explicit rate expression. To avoid confusion, we write the last term in Equation (C.4) as

$$
\mathrm{R}_{\mathrm{n}}^{(\mathrm{j}), \mathrm{k}+1, \mathrm{~s}} \Delta \mathrm{t}=-\Delta \mathrm{P}_{\mathrm{n}}^{(\mathrm{j}), \mathrm{k}+1, \mathrm{~s}}
$$

where $\Delta \mathrm{P}_{\mathrm{n}}^{(\mathrm{j}), \mathrm{k}+1, \mathrm{~s}}$ means mass transfer of component $\mathrm{j}$ from the aqueous phase to the mineral phase at iteration $\mathrm{s}$, grid block $\mathrm{n}$ and time step $\mathrm{k}+1$ (or called mass accumulation in mineral phases; negative values indicate mass transfer from the mineral phase to the aqueous phase)

Returning to Equation (C.4), we can see that the coefficient matrix is the same for all chemical components as long as diffusion coefficients are the same for all aqueous species. The matrix depends on space and time discretization, and flow conditions. The equations for different components only differ in right-hand side terms.

The mathematical treatment of adding Kd linear adsorption and first-order decay effects in the model follows the work by Oldenburg and Pruess (1995, EOS7R), but no gas phase partitioning is considered. The mass accumulation term for any species (for simplification, the species index is not appeared in the following equations) with $\mathrm{Kd}$ adsorption on the solid matrix is

$$
\mathrm{M}=\phi \mathrm{S}_{1} \mathrm{C}+(1-\phi) \rho_{\mathrm{s}} \mathrm{CK}_{\mathrm{d}}
$$

where $\phi$ is porosity, $S_{1}$ is the liquid saturation, $C$ is the aqueous concentration $(\mathrm{mol} / \mathrm{l}), \rho_{\mathrm{s}}$ is the solid density $\left(\mathrm{kg} / \mathrm{dm}^{3}\right), K_{d}$ is the distribution coefficient $(1 / \mathrm{kg}=$ mass $/ \mathrm{kg}$ solid divided by mass $/ 1$ solution) and is species-dependent. The accumulation also term can be written in terms of a retardation factor 


$$
\mathrm{M}=\phi \mathrm{S}_{1} \mathrm{RC}
$$

and

$$
\mathrm{R}=1+\frac{(1-\phi) \rho_{\mathrm{s}}}{\phi \mathrm{S}_{1}} \mathrm{~K}_{\mathrm{d}}
$$

The input can be optionally by $\mathrm{Kd}$ and $\mathrm{R}$, depending on user convenience and data availability.

The first-order decay of a species is handled by the discretized equation (Oldenburg and Pruess, 1995)

$$
M_{n}^{k+1}(1+\lambda \Delta t)-M_{n}^{k}=\frac{\Delta t}{V_{n}}\left(\sum_{m} A_{n m} F_{n m}^{k+1}+V_{n} q_{n}^{k+1}\right)
$$

where $\lambda$ is decay constant ( $1 / \mathrm{s})$ which is species-dependent, subscript $\mathrm{n}$ labels grid block, superscript $\mathrm{k}$ labels time step, subscript $\mathrm{m}$ labels the grid block connected to grid block $\mathrm{n}, \Delta \mathrm{t}$ is time step size, $M_{n}$ is the average mass per unit volume, surface integrals are approximated as a discrete sum of

averages over surface segments $A_{n m}, F_{n m}$ is the average mass flux over the surface segment $A_{n m}$ between volume elements $V_{n}$ and $V_{m}$, and $q$ is the average value of source/sink term per unit volume and unit time.

\section{C.2. Transport in the Gas Phase}

Gaseous species concentrations can be related to partial pressures by

$$
\mathrm{C}^{\mathrm{g}}=\frac{10^{2}}{\mathrm{RT}} \mathrm{P}^{\mathrm{g}}
$$

where $\mathrm{C}^{\mathrm{g}}$ are gaseous species concentrations (in mol/l), $\mathrm{P}^{\mathrm{g}}$ is the gaseous species partial pressure (in bar), $\mathrm{R}$ is the gas constant $\left(8.314 \mathrm{~J} \cdot \mathrm{mol}^{-1} \cdot \mathrm{K}^{-1}\right)$ and $\mathrm{T}$ is the absolute temperature. By following 
the same principle as used for transport in liquid phase and by considering Equation (C.10), the numerical formulation of gaseous transport in the gas phases can be expressed as

$$
\begin{gathered}
{\left[\frac{10^{2}}{R T} S_{g, n}^{\mathrm{k}+1} \phi_{n}^{\mathrm{k}+1}+\frac{\Delta \mathrm{t}}{\mathrm{V}_{\mathrm{n}}} \sum_{\mathrm{m}} \mathrm{A}_{\mathrm{nm}} \frac{10^{2}}{\mathrm{RT}}\left(-\mathrm{u}_{\mathrm{nm}}^{\mathrm{g}, \mathrm{k}+1} \varepsilon_{\mathrm{nm}}^{\mathrm{g}}+\frac{\mathrm{D}_{\mathrm{nm}}^{\mathrm{g}}}{\mathrm{d}_{\mathrm{nm}}}\right)\right] \mathrm{P}_{\mathrm{n}}^{\mathrm{g},(\mathrm{j}), \mathrm{k}+1, \mathrm{~s}+1 / 2}+} \\
\frac{\Delta \mathrm{t}}{\mathrm{V}_{\mathrm{n}}} \sum_{\mathrm{m}} \mathrm{A}_{\mathrm{nm}} \frac{10^{2}}{\mathrm{RT}}\left[\mathrm{u}_{\mathrm{nm}}^{\mathrm{g}, \mathrm{k}+1}\left(\varepsilon_{\mathrm{nm}}^{\mathrm{g}}-1\right)-\frac{\mathrm{D}_{\mathrm{nm}}^{\mathrm{g}}}{\mathrm{d}_{\mathrm{nm}}}\right] \mathrm{P}_{\mathrm{m}}^{\mathrm{g},(\mathrm{j}), \mathrm{k}+1, \mathrm{~s}+1 / 2}= \\
\frac{10^{2}}{\mathrm{RT}} \mathrm{S}_{\mathrm{g}, \mathrm{n}}^{\mathrm{k}} \phi_{\mathrm{n}}^{\mathrm{k}} \mathrm{P}_{\mathrm{n}}^{\mathrm{g},(\mathrm{j}), \mathrm{k}}+\mathrm{q}_{\mathrm{n}}^{(\mathrm{j}) \mathrm{k}+1} \Delta \mathrm{t}+\mathrm{R}_{\mathrm{n}}^{(\mathrm{j}), \mathrm{k}+1, \mathrm{~s}} \Delta \mathrm{t} \quad \mathrm{j}=1,2, \ldots, \mathrm{N}_{\mathrm{g}}
\end{gathered}
$$

where $\mathrm{N}_{\mathrm{g}}$ is number of gaseous species. The structure of Equations (C.11) is the same as that of (C.4) for transport only in liquid phase. The same solution method can be applied for solving Equations (C.11). 


\section{Appendix D. Solution Method for Mixed Equilibrium-Kinetics Chemical System}

Aqueous complexation and gas dissolution/exsolution proceed according to local equilibrium, while mineral dissolution/precipitation are subject to equilibrium and/or kinetic conditions. Gas dissolution/exsolution is included in the model and treated in a similar way as equilibrium mineral dissolution/precipitation. The formulation is based on mass balances in terms of basis species as used by Parkhurst el al. (1980) and Reed (1982) for the equilibrium chemical system. The kinetic rate expressions for mineral dissolution/precipitation are included in the equations along with the mass balances of basis species (Xu et al., 1999b). At time zero (initial), the total concentrations of basis species $\mathrm{j}$ in the system are assumed to be known, and are given by

$$
\mathrm{T}_{\mathrm{j}}^{0}=\mathrm{c}_{\mathrm{j}}^{0}+\sum_{\mathrm{k}=1}^{\mathrm{N}_{\mathrm{x}}} \mathrm{v}_{\mathrm{kj}} \mathrm{c}_{\mathrm{k}}^{0}+\sum_{\mathrm{m}=1}^{\mathrm{N}_{\mathrm{p}}} \mathrm{v}_{\mathrm{mj}} \mathrm{c}_{\mathrm{m}}^{0}+\sum_{\mathrm{n}=1}^{\mathrm{N}_{\mathrm{q}}} \mathrm{v}_{\mathrm{nj}} \mathrm{c}_{\mathrm{n}}^{0} \quad \mathrm{j}=1, \ldots, \mathrm{N}_{\mathrm{C}}
$$

where superscript 0 represents time zero; $\mathrm{c}$ are concentrations (chemical reactions are always solved per $\mathrm{kg}$ of water, and concentration units used here are $\mathrm{mol} / \mathrm{kg}$ which is close to $\mathrm{mol} / \mathrm{l}$ when density is close to $1 \mathrm{~kg} / \mathrm{l}$ ); subscripts $\mathrm{j}, \mathrm{k}, \mathrm{m}$, and $\mathrm{n}$ are the indices of basis species, aqueous complexes, minerals at equilibrium and minerals under kinetic constraints, respectively; $N_{C}, N_{x}, N_{p}$, and $\mathrm{N}_{\mathrm{q}}$ are the number of the corresponding species and minerals; $v_{\mathrm{kj}}, v_{\mathrm{mj}}$, and $v_{\mathrm{nj}}$ are stoichiometric coefficients of the basis species in the aqueous complexes, equilibrium and kinetic minerals, respectively. After a time step $\Delta t_{r}$, the total concentration of basis species $\mathrm{j}$ is given by

$$
T_{j}=c_{j}+\sum_{k=1}^{N_{x}} v_{k j} c_{k}+\sum_{m=1}^{N p} v_{m j} c_{m}+\sum_{n=1}^{N_{q}} v_{n j}\left(c_{n}^{0}-r_{n} \Delta t_{r}\right) \quad j=1, \ldots, N_{C}
$$

where $\mathrm{r}$ is the kinetic dissolution rate (negative for precipitation, units used here are moles per $\mathrm{kg}$ water per time). For a closed system, according to mass conservation, we have 


$$
\mathrm{T}_{\mathrm{j}}^{0}=\mathrm{T}_{\mathrm{j}}
$$

The set of nonlinear chemical reactions is solved by the Newton-Raphson iterative method. The use of this method requires lumping all the terms in the right-hand side in a single term (or residual function which is zero in the limit of convergence), and we denote this term by $\mathrm{F}_{j}^{\mathrm{c}}$

$$
F_{j}^{c}=T_{j}-T_{j}^{0}=0
$$

By substitution of Equations (D.1) and (D.2) into (D.4), we obtain

$$
F_{j}^{c}=c_{j}+\sum_{k=1}^{N X} v_{k j} c_{k}+\sum_{m=1}^{N p} v_{m j} c_{m}-\sum_{n=1}^{N_{q}} v_{n j} r_{n} \Delta t_{r}-U_{j}^{0}=0 \quad j=1, \ldots, N_{C}
$$

where

$$
\mathrm{U}_{\mathrm{j}}^{0}=\mathrm{c}_{\mathrm{j}}^{0}+\sum_{\mathrm{k}=1}^{\mathrm{N}_{\mathrm{x}}} \mathrm{v}_{\mathrm{kj}} \mathrm{c}_{\mathrm{k}}^{0}+\sum_{\mathrm{m}=1}^{\mathrm{Np}} \mathrm{v}_{\mathrm{mj}} \mathrm{c}_{\mathrm{m}}^{0}
$$

According to mass action equations, concentrations of aqueous complexes $c_{k}$ can be expressed as functions of concentrations of the basis species $c_{j}$ (Equation B.2 in Appendix B). Kinetic rates $r_{n}$ are functions of $\mathrm{c}_{\mathrm{j}}$ (Equation (B.5)). No explicit expressions relate equilibrium mineral concentrations $c_{m}$ to $c_{j}$. Therefore, $N_{P}$ additional mass action equations (one per mineral) are needed, which are provided by Equation (B.4). At equilibrium we have the residual functions $F_{m}^{p}$

$$
\mathrm{F}_{\mathrm{m}}^{\mathrm{p}}=\mathrm{SI}_{\mathrm{m}}=0 \quad \mathrm{~m}=1, \ldots, \mathrm{N}_{\mathrm{P}}
$$

where $\mathrm{SI}_{\mathrm{m}}$ is the m-th equilibrium mineral saturation index which is a function of $\mathrm{c}_{\mathrm{j}}$ (see Equations B.3 and B.4 in Appendix B). $\mathrm{N}_{\mathrm{C}}$ equations in (D.5) and $\mathrm{N}_{\mathrm{p}}$ in (D.6) constitute a complete set of 
equations needed for $\mathrm{N}_{\mathrm{C}}+\mathrm{N}_{\mathrm{P}}$ primary variables, $\left(\mathrm{c}_{1}, \mathrm{c}_{2}, \ldots, \mathrm{c}_{\mathrm{N}_{\mathrm{C}}}, \mathrm{c}_{1}, \mathrm{c}_{2}, \ldots, \mathrm{c}_{\mathrm{N}_{\mathrm{p}}}\right)$. Denoting the set of primary variables collectively as $X_{i}\left(i=1,2, \ldots, N_{C}+N_{P}\right)$, using Newton-Raphson iteration we have

$$
\sum_{i=1}^{N_{C}+N_{P}} \frac{\partial F_{j}}{\partial X_{i}} \Delta X_{i}=-F_{j} \quad j=1, \ldots, N_{C}+N_{P}
$$

where $\mathrm{j}$ is a row index and $\mathrm{i}$ is a column index (here $\mathrm{j}$ as a row index can be thought of as also representing an "extended" basis set including the equilibrium minerals). In matrix form Eqs. (D.7) reduce to

$$
\mathbf{J} \Delta \mathbf{X}=\mathbf{-} \mathbf{F}
$$

where $\mathbf{J}$ is the so-called Jacobian matrix. The matrix elements are evaluated in Appendix E. The values of $\Delta \mathbf{X}$ are used to update the primary variables:

$$
\mathrm{X}_{\mathrm{i}}^{\mathrm{s}+1}=\mathrm{X}_{\mathrm{i}}^{\mathrm{s}}+\Delta \mathrm{X}_{\mathrm{i}}^{\mathrm{s}}
$$

where s labels iteration number. $\left|\Delta X_{\mathrm{i}}\right|$ are expected to decrease in successive iterations. The system of equations is considered satisfactorily solved when

$$
\max _{j}\left(\frac{\left|F_{j}^{c}\right|}{T_{j}^{0}}\right) \leq \tau \quad j=1, \ldots, N_{C}
$$

where $\tau$ is specified tolerance limit. In order to avoid negative values for concentrations of the basis species, the relative change is restricted to one (called under-relaxation), or $\frac{\left|\Delta_{X_{i}}\right|}{x_{i}}<1 \quad i=1 \ldots N_{C}+N_{P}+N_{S}\left(i=1 \ldots N_{C}\right)$. As a consequence, although the iteration method becomes more robust, the rate of convergence may slow down in some cases. When a negative value 
of $\mathrm{X}_{\mathrm{i}}\left(\mathrm{i}=\mathrm{N}_{\mathrm{C}}+1, \ldots, \mathrm{N}_{\mathrm{C}}+\mathrm{N}_{\mathrm{p}}\right)$ is obtained, the corresponding mineral is considered exhausted and must be removed from the chemical system, and its corresponding equation disappears (Reed, 1982). In this case, the speciation in solution may change drastically. This might have a strong effect on kinetic rate laws. So when a change occurs in the mineral assemblage, one might have to limit the time step to retain accuracy in rate law integration. In addition, for a given time step the code checks that dissolution of a mineral cannot be greater than the amount present in the medium, in order to avoid "over-dissolution".

The solution of the reaction system requires knowing initial total concentrations of basis species $\mathrm{j}$ in the equilibrium system (aqueous and mineral) or $\mathrm{U}_{\mathrm{j}}^{0}$ in Eqs. (D.5a), and the time step $\Delta \mathrm{t}_{\mathrm{r}}$. Adding kinetic mineral dissolution/precipitation processes does not require additional primary equations, because the reaction rate is a function of the concentrations of the basis species. Once the concentrations of the basis species are obtained, all other secondary variables can be computed in a straightforward manner. 


\section{Appendix E: Evaluation of the Jacobian Matrix for the Chemical Equations}

The Jacobian matrix of Equation (D.8) has $\mathrm{N}_{\mathrm{C}}+\mathrm{N}_{\mathrm{P}}$ rows and $\mathrm{N}_{\mathrm{C}}+\mathrm{N}_{\mathrm{P}}$ columns, as follows:

$$
\begin{array}{ccc}
N_{C} & \frac{\partial F_{j}^{c}}{\partial c_{i}} & \frac{\partial F_{j}^{c}}{\partial p_{i}} \\
N_{P} & \frac{\partial F_{j}^{p}}{\partial c_{i}} & \frac{\partial F_{j}^{p}}{\partial p_{i}}
\end{array}
$$

Based on Equations (D.3) and (D.5), and by neglecting the derivatives of activity coefficients with respect to the concentrations of the basis species, the entries of the Jacobian matrix are

$$
\begin{gathered}
J^{\mathrm{cc}}=\frac{\partial \mathrm{F}_{j}^{\mathrm{c}}}{\partial \mathrm{c}_{\mathrm{i}}}=\delta_{\mathrm{ji}}+\sum_{\mathrm{k}=1}^{\mathrm{N}_{\mathrm{x}}} v_{\mathrm{kj}} v_{\mathrm{ik}} \frac{\mathrm{c}_{\mathrm{k}}}{\mathrm{c}_{\mathrm{i}}}+\sum_{\mathrm{n}=1}^{\mathrm{N}_{\mathrm{q}}} v_{\mathrm{nj}} v_{\mathrm{ni}} \frac{\mathrm{k}_{\mathrm{n}} \mathrm{A}_{\mathrm{n}} \Omega_{\mathrm{n}}}{\mathrm{c}_{\mathrm{i}}} \\
\mathrm{J}^{\mathrm{cp}}=\frac{\partial \mathrm{F}_{\mathrm{j}}^{\mathrm{c}}}{\partial \mathrm{p}_{\mathrm{i}}}=v_{\mathrm{mj}} \\
\mathrm{J}^{\mathrm{pc}}=\frac{\partial \mathrm{F}_{\mathrm{j}}^{\mathrm{p}}}{\partial \mathrm{c}_{\mathrm{i}}}=\frac{v_{\mathrm{mj}}}{\mathrm{c}_{\mathrm{i}}} \\
\mathrm{J}^{\mathrm{pp}}=\frac{\partial \mathrm{F}_{\mathrm{j}}^{\mathrm{p}}}{\partial \mathrm{p}_{\mathrm{i}}}=0
\end{gathered}
$$

Let $\mathrm{J}^{\mathrm{cc}}, \mathrm{J}^{\mathrm{cp}}, \mathrm{J}^{\mathrm{pc}}$ and $\mathrm{J}^{\mathrm{pp}}$ be the submatrices expressed in Equations (E.1) through (E.4), then the Jacobian system of equations can be written as 


$$
\left[\begin{array}{ll}
\mathrm{J}^{\mathrm{cc}} & \mathrm{J}^{\mathrm{cp}} \\
\mathrm{J}^{\mathrm{pc}} & \mathrm{J}^{\mathrm{pp}}
\end{array}\right]\left[\begin{array}{l}
\Delta \mathrm{c} \\
\Delta \mathrm{p}
\end{array}\right]=\left[\begin{array}{l}
-\mathrm{F}^{\mathrm{c}} \\
-\mathrm{F}^{\mathrm{p}}
\end{array}\right]
$$

where $-\mathrm{F}^{\mathrm{c}}$ and $-\mathrm{F}^{\mathrm{p}}$ are the residual terms that can be calculated from Equations (D.5) and (D.6), respectively. 


\section{Appendix F: Effects of Mineral Precipitation/Dissolution on Hydrologic Properties}

\section{F.1. Porosity Changes}

Porosity changes in matrix and fractures are directly tied to the volume changes as a result of mineral precipitation and dissolution. The molar volumes of minerals created by hydrolysis reactions (i.e., anhydrous phases, such as feldspars, reacting with aqueous fluids to form hydrous minerals such as zeolites or clays) are often larger than those of the primary reactant minerals; therefore, constant molar dissolution-precipitation reactions may lead to porosity reductions. Porosity changes are taken into account in the code as follows:

The porosity of the medium (fracture or matrix) is given by

$$
\phi=1-\sum_{m=1}^{n m} f r_{m}-f r_{u}
$$

where $n m$ is the number of minerals, $f r_{m}$ is the volume fraction of mineral $m$ in the rock $\left(\mathrm{V}_{\text {mineral }} / \mathrm{V}_{\text {medium }}\right.$, including porosity), and $f r_{u}$ is the volume fraction of nonreactive rock. As the $f r_{m}$ of each mineral changes, the porosity is recalculated at each time step. The porosity is not allowed to go below zero.

Several options are available in TOUGHREACT to compute permeability changes as a result of mineral precipitation or dissolution. Some options depend solely on porosity changes, whereas others employ options related to, for example, fracture aperture changes or pore throat diameter changes.

\section{F.2. Fracture Permeability Changes}

Option 3: Fracture permeability changes can be approximated using the porosity change and an assumption of plane parallel fractures of uniform aperture (cubic law; e.g., Steefel and Lasaga, 1994). The modified permeability, $k$, is then given by 


$$
k=k_{i}\left(\frac{\phi}{\phi_{i}}\right)^{3}
$$

where $k_{i}$ and $\phi_{i}$ are the initial permeability and porosity, respectively. This law yields zero permeability only under the condition of zero fracture porosity.

Option 4: In most experimental and natural systems, permeability reductions to values near zero occur at porosities significantly greater than zero. This generally is the result of mineral precipitation in the narrower interconnecting apertures. The hydraulic aperture, as calculated from the fracture spacing and permeability (as determined through air-permeability measurements) assuming a cubic law relation, is a closer measure of the smaller apertures in the flow system. Using the hydraulic aperture, a much stronger relationship between permeability and porosity can be developed. This relationship can be approximated as follows:

The initial hydraulic aperture $b_{0, h}(\mathrm{~m})$ is calculated using the following cubic law relation:

$$
b_{0, h}=\left[12 k_{0} s\right]^{1 / 3}
$$

where $k_{0}$ is the initial fracture permeability $\left(\mathrm{m}^{2}\right)$ and $s$ is the fracture spacing $(\mathrm{m})$. The permeability $(k)$ resulting from a change in the hydraulic aperture, is given by

$$
k^{\prime}=\frac{\left(b_{0, h}+\Delta b\right)^{3}}{12 s}
$$

where $\Delta b$ is the aperture change resulting from mineral precipitation/dissolution.

The aperture change resulting from a calculated volume change can be approximated by assuming precipitation of a uniform layer over the entire geometric surface area of the fracture, assuming also that this area as well as the fracture spacing remains constant. The actual distribution of mineral alteration is much more heterogeneous and depends on many processes that are active at scales much smaller than the resolution of the model; however, the combined effect of the initial heterogeneities and localized precipitation processes can only be treated through model sensitivity studies and experiments. 
For a dual permeability model, changes in the fracture porosity are calculated based on the porosity of the fracture medium, so that $\Delta b$ can be approximated by

$$
\Delta b=\frac{\left(\phi_{f m}^{\prime}-\phi_{f m, 0}\right)}{\phi_{f m, 0}} b_{g}
$$

Equations (F.3), (F.4), and (F.5) were implemented in TOUGHREACT with input parameters of $b_{g}$ and $s$. An example of this type of porosity and permeability relationship is given in Sample Problem 4 (Section 8.4: Heater Test).

In this example problem, the initial aperture available for precipitation $\left(b_{g}\right.$, the geometric, rather than the hydraulic, aperture) was estimated from the ratio of the initial fracture porosity $\left(\phi_{f, 0}\right)$ to the fracture surface area $\left(A_{f}\right)$, as follows:

$$
b_{g}=\phi_{f, 0} / A_{f}
$$

However, the user can, of course, use any methodology to calculate the geometric aperture.

\section{F.3. Matrix Permeability Changes}

Option 1; Matrix permeability changes are calculated from changes in porosity using ratios of permeabilities calculated from the Carman-Kozeny relation (Bear, 1972), and ignoring changes in grain size, tortuosity and specific surface area as follows:

$$
k=k_{i} \frac{\left(1-\phi_{i}\right)^{2}}{(1-\phi)^{2}}\left(\frac{\phi}{\phi_{i}}\right)^{3}
$$

Option 5: The simple cubic law (Eq. F.2) and the Kozeny-Carman (Eq. F.7) porositypermeability equations may not reflect the complex relationship of porosity and permeability in geologic media that depends on an interplay of many factors, such as pore size distribution, pore shapes, and connectivity (Verma and Pruess, 1988). Laboratory experiments have shown that modest reductions in porosity from mineral precipitation can cause large reductions in 
permeability (Vaughan, 1987). Detailed analysis of a large set of field data also indicated a very strong dependence of permeability on small porosity changes (Pape et al., 1999). This is explained by the convergent-divergent nature of natural pore channels, where pore throats can become clogged by precipitation while disconnected void spaces remain in the pore bodies (Verma and Pruess, 1988). The permeability reduction effects depend not only on the overall reduction of porosity, but on the details of the pore space geometry and the distribution of precipitates within the pore space. These may be quite different for different media, which makes it difficult to achieve generally applicable predictions. To evaluate the effects of a more sensitive coupling of permeability to porosity, we also implemented an improved porosity-permeability relationship presented by Verma and Pruess (1988)

$$
\frac{\mathrm{k}}{\mathrm{k}_{\mathrm{i}}}=\left(\frac{\phi-\phi_{\mathrm{c}}}{\phi_{\mathrm{i}}-\phi_{\mathrm{c}}}\right)^{\mathrm{n}}
$$

where $\phi_{\mathrm{c}}$ is the value of "critical" porosity at which permeability goes to zero, and $\mathrm{n}$ is a power law exponent. Parameters $\phi_{c}$ and $\mathrm{n}$ are medium-dependent. An example of this porositypermeability relationship is given in Sample problem 8 (Section 8.8: Injection well scaling).

\section{F.4. Effects of Permeability and Porosity Changes on Capillary Pressures}

Permeability and porosity changes will likely result in modifications to the unsaturated flow properties of the rock. Changes to unsaturated flow properties are approximated by modification of the calculated capillary pressure $(P c)$ using the Leverett scaling relation (Slider, 1976) to obtain a scaled $P c^{\prime}$ as follows:

$$
P c^{\prime}=P c \sqrt{\frac{k_{i} \phi}{k \phi_{i}}}
$$

Scaled capillary pressures are subject to the maximum capillary pressure prescribed in the capillary pressure function in the ROCKS or RPCAP blocks (see TOUGH2 V.2 users manual). 


\section{Appendix G: Mineral Reactive Surface Areas}

This appendix describes ome methods for estimating reactive surface areas and how the input values are used to calculate the reactive surface area used in the rate law expression. Conceptually, the reactive surface area of minerals in a fracture is a little trickier to formulate from the standard measurements of reactive surface area in units of $\mathrm{cm}^{2} / \mathrm{g}$, or the units used in the rate law equation, $\mathrm{m}^{2} / \mathrm{kg} \mathrm{H}_{2} \mathrm{O}$. For the rock matrix, a discussion of a possible methodology for calculating reactive surface areas is also given, however, any approach may be used as long as the correct units are entered.

\section{G.1. Fractures}

In the dual permeability method, the porosity of the fracture medium can be taken as 1.0. However, for modeling of mineral dissolution and precipitation, there would then be no rock to dissolve. Because the dissolution rates of many minerals are quite small at temperatures below $100^{\circ} \mathrm{C}$, only a small volume of rock adjoining the open space of the fracture needs to be considered as the starting rock fraction. Reactive surface areas of minerals on fracture walls can be calculated from the fracture-matrix interface area/volume ratio, the fracture porosity, and the derived mineral volume fractions. These areas can be calculated based on the fracture densities, fracture porosities, and mean fracture diameter. The wall of the fracture is treated as a surface covered by mineral grains having the form of uniform hemispheres. The grain diameter and spatial density are not included in this calculation, so that the area is actually only marginally greater than the fracture geometric surface area. An alternative method to approximating the surface area in excess of the geometric area would be to include a roughness factor. The geometric surface area of the fracture wall can be approximated by:

$$
A_{r}=\frac{\pi A_{f-m}}{2 \phi_{f-m}}
$$


where $A_{r}$ is the reactive surface area $\left(\mathrm{m}^{2} / \mathrm{m}_{\text {fracture medium }}^{3}\right), A_{f-m}$ is the fracture-matrix interface area/volume ratio $\left(\mathrm{m}_{\text {fracture }}^{2} / \mathrm{m}_{\text {fracture+matrix }}^{3}\right.$ volume), and $\phi_{f-m}$ is the fracture porosity of the rock. $A_{f-m}$ is the surface area used as input (in flow.inp) to the model simulations as an approximation of the reactive surface area. This model for the fracture surface area considers that the areal coverage is approximately equivalent to the mineral volume fraction. A further modification, which was implemented in TOUGHREACT, relates the 3-D cross-sectional area to the 2-D surface area in the fracture, which yields a factor of $3 / 2$, i.e. an increase of $50 \%$ in the reactive surface area. The reactive surface area of each mineral (in units of $\mathrm{m}_{\text {min eral }}^{2} / \mathrm{kg}_{\text {water }}$ ) that is used in geochemical calculations is then given by:

$$
A_{m}\left(m^{2} / k g_{\text {water }}\right)=\frac{A_{r} f_{m}}{\rho_{w} \phi_{f}}
$$

where $f_{m}$ is the volume fraction of the mineral in the mineral assemblage, $\rho_{w}$ is the density of water (in $\mathrm{kg} / \mathrm{m}^{3}$ ) and $\phi_{f}$ is the porosity of the fracture medium, as opposed to the fracture porosity of the rock. This is the surface area/water mass ratio for a mineral in a liquid-saturated system. To provide the correct rock/water ratio in an unsaturated system, the form of this surface area can be written as:

$$
A_{m}\left(m^{2} / k g_{\text {water }}\right)=\frac{A_{r} f_{m}}{\rho_{w} \phi_{f} S_{w}}
$$

where $S_{w}$ is the water saturation. However, as $S_{w}$ goes to zero, the reactive surface area would tend to infinity. Clearly, at a very low liquid saturation, the surface area of the rock contacted by water is likely much smaller than the total area. Two methods have been implemented to address this phenomenon. The first method considers that the surface area contacted by water diminishes proportionately to the saturation. This yields the saturated surface area given by Equation G.1. The second method employs the active-fracture-model concept (Liu et al. 1998) modified to consider water-rock reactions taking place below the residual saturation. The form of the active fracture parameter for reaction is then given by the following set of equations: 


$$
\begin{gathered}
S_{a r}=\left(S_{w}-S_{m}\right) /\left(1-S_{m}\right) \\
a_{f m r}=S_{a r}{ }^{(1+\gamma)}
\end{gathered}
$$

where $S_{m}$ is the minimum liquid saturation for which water-rock reactions are considered and $S_{a r}$ is the effective saturation for reaction. The active fracture parameter, $\gamma$, is obtained from the calibrated hydrological properties. The factor that reduces the surface area contacted by the water phase is given by $a_{f m r} . S_{m}$ is generally set to a small saturation (e.g., $1 \times 10^{-4}$ ), to ensure that reactions take place until virtually no water is left (e.g., during dryout via ventilation or heating). Finally, the reactive surface area, using this modified form of the active fracture model, is given by:

$$
A_{m}\left(\mathrm{~m}^{2} / \mathrm{kg}_{\text {water }}\right)=\frac{A_{r} f_{m} a_{f m r}}{\rho_{w} \phi_{f} S_{w}}
$$

Note that this area is not the input surface area.

\section{G.2. Matrix (porous medium)}

Mineral surface areas in the rock matrix (or porous medium) are input parameters in the chemical.inp file. One method to calculate the reactive surface areas of minerals in a rock or granular material is to use a geometric area of a cubic array of truncated spheres to make up the framework of the rock (Sonnenthal and Ortoleva, 1994). Clay minerals can be considered as coatings of plate-like grains. The mineral surface areas of framework grains (truncated spheres) in contact with the open pore space can be calculated using an initial grain diameter, followed by successive truncation of the grains in the vertical direction until the porosity of this system is close to the measured porosity of the rock. The abundance of secondary phases (i.e., those that

formed as alteration products or low-temperature coatings on the primary assemblage), such as clay minerals, can be used to reduce the free surface area of the framework grains. The surface areas of the secondary phases can be calculated based on their size and morphology.. 


\section{Appendix H: Calculation of Activity Coefficients of Aqueous Species}

\section{H.1 Activity Coefficients of Charged Aqueous Species}

Activity coefficients of charged aqueous species are computed using an extended DebyeHuckel equation and parameters derived by Helgeson et al. (1981) (HKF). The assumption is made that the dominant cation and anion in solution are sodium and chloride, respectively, so that HKF Equation 298 can be used directly, as follows:

$$
\begin{aligned}
\log \left(\gamma_{j}\right)=-\frac{\mathrm{A}_{\gamma} z_{j}^{2} \mathrm{I}^{0.5}}{\Lambda}+\log \left(1+0.0180153 \mathrm{~m}^{*}\right)- \\
{\left[\omega_{j} \mathrm{~b}_{\mathrm{NaCl}}+\mathrm{b}_{\mathrm{Na}^{+}, \mathrm{Cl}}-0.19\left(\left|z_{j}\right|-1\right)\right] \mathrm{I} }
\end{aligned}
$$

and

$$
\begin{aligned}
& \Lambda=1+\mathrm{a}_{\gamma} \overline{\mathrm{I}}^{1 / 2} \\
& \omega_{j}=\eta \frac{z_{j}^{2}}{\mathrm{r}_{\mathrm{e}, j}}
\end{aligned}
$$

where the subscript $j$ refers to each ion, $\gamma$ is the activity coefficient of the ion, Debye-Huckel parameters $\mathrm{b}_{\mathrm{Na}}{ }^{+}{ }_{\mathrm{Cl}}^{-}, \mathrm{b}_{\mathrm{NaCl}}, \mathrm{A} \gamma$ and $\mathrm{B} \gamma$ are given in HKF Tables 1, 29, and 30, Debye-Huckel parameter å is calculated as discussed below, $z$ is the ion electric charge, I is taken as the true ionic strength of the solution, $\omega$ is the Born coefficient, $\eta$ is a constant equal to 1.66027 ( $\AA$ $\mathrm{cal} / \mathrm{mol}$ ), and $r_{e, j}$ is the ion effective ionic radius given in HKF Table 3 or estimated as shown on Table H.1 when not available.

Debye-Huckel parameters $\mathrm{b}_{\mathrm{Na}}{ }^{+}, \mathrm{Cl}^{-}, \mathrm{b}_{\mathrm{NaCl}}, \mathrm{A} \gamma$ and $\mathrm{B} \gamma$ were regressed as a function of temperature and the resulting functions and regression coefficients are currently built into TOUGHREACT. Values of å are calculated by TOUGHREACT using effective ionic radii $r_{e, j}$. Making the assumption that $\mathrm{NaCl}$ is the dominant electrolyte, and using the ion charge to determine stoichiometry coefficients, HKF Equation 125 simplifies to (as implemented in models by Reed, 1982): 


$$
\begin{aligned}
& \AA_{j}=2\left(r_{e, j}+1.91\left|z_{j}\right|\right) /\left(\left|z_{j}\right|+1\right) \text { for anions } \\
& \AA_{j}=2\left(r_{e, j}+1.81\left|z_{j}\right|\right) /\left(\left|z_{j}\right|+1\right) \text { for cations }
\end{aligned}
$$

where the subscript $\mathrm{j}$ refers to each ion and other parameters are as defined above. The values of 1.91 and 1.81 in the above equations correspond to $\mathrm{r}_{\mathrm{e}, \mathrm{Na}}{ }^{+}$and $\mathrm{r}_{\mathrm{e}, \mathrm{Cl}}{ }^{-}$, respectively. Values of $\mathrm{r}_{\mathrm{e}, \mathrm{j}}$ are input from the TOUGHREACT database and can be changed as deemed necessary in this database.

Table H.1. Estimated values of effective ionic radii $\left(\mathrm{r}_{\mathrm{e}, \mathrm{j}}\right)$ currently in the TOUGHREACT thermodynamic database for species that are not reported in HKF Table 3. When available, values from HKF Table 3 are used directly instead of those shown here.

\begin{tabular}{|l|l|l|}
\hline Ion Charge & $\mathbf{r}_{\mathrm{e}, \mathrm{j}}$ & \multicolumn{1}{c|}{ Source } \\
\hline-1 & 1.81 & Cl- value \\
\hline-2 & 3.00 & Rounded average of CO3-- and SO4-- values \\
\hline-3 & 4.2 & Estimated from straight line fit with charge \\
\hline+1 & 2.31 & NH4+ value \\
\hline+2 & 2.8 & Rounded average for +2 species in HKF Table 3 \\
\hline+3 & 3.6 & Rounded average for +3 species in HKF Table 3 \\
\hline+4 & 4.5 & $\begin{array}{l}\text { Estimated using HKF Equation 142 and average } \\
\text { crystallographic radii of }+4 \text { species in CRC Handbook }\end{array}$ \\
\hline$<-3$ & & Linear Extrapolation (charge $\times 4.2 / 3.0)$ \\
\hline$>+3$ & & Linear Extrapolation (charge $\times 4.5 / 4.0)$ \\
\hline & & \\
\hline
\end{tabular}

The limits of applicability of this method depend on how well the assumption of $\mathrm{NaCl}$ dominance in solution is satisfied. Also, consistency between the activity coefficient model and the types of ion pairs included in the thermodynamic database is critical. A good example is that of the $\mathrm{NaCl}^{0}$ ion pair. HKF fitted their Debye-Huckel data assuming that no significant formation of $\mathrm{NaCl}^{0}$ took place. Excluding this ion pair from the thermodynamic database, the model reproduces fairly well the mean activity coefficients determined by Robinson and Stokes (1965) at $25^{\circ} \mathrm{C}$ (Figure H.1) up to at least $6 \mathrm{M} \mathrm{NaCl}$ (ionic strength 6). However, this is not true when 
$\mathrm{NaCl}^{0}$ and the dissociation constants from Shock et al. (1989), for example, are included in the database (at least at $25^{\circ} \mathrm{C}$ ). The reverse is true for species like $\mathrm{MgSO}_{4}$ and $\mathrm{Na}_{2} \mathrm{SO}_{4}$, for which accurate activities cannot be computed without including the $\mathrm{MgSO}_{4}$ and $\mathrm{NaSO}_{4}{ }^{-}$species in the thermodynamic database. In this case, using dissociation constants from Shock et al. (1989) for these species, and the HKF activity coefficient model discussed above, mean activities determined by Robinson and Stokes $(1965)$ at $25^{\circ} \mathrm{C}$ can be reproduced fairly well up to $2 \mathrm{M}$ $\mathrm{MgSO}_{4}$ (ionic strength $=8$ ) and $1 \mathrm{M} \mathrm{Na}_{2} \mathrm{SO}_{4}$ (ionic strength = 3) (Figures H.2). Although no general rule can be made as to the limit of applicability of the activity coefficient model, we would not recommend using this model at ionic strengths greater than 3 or 4 , especially at higher temperatures. 

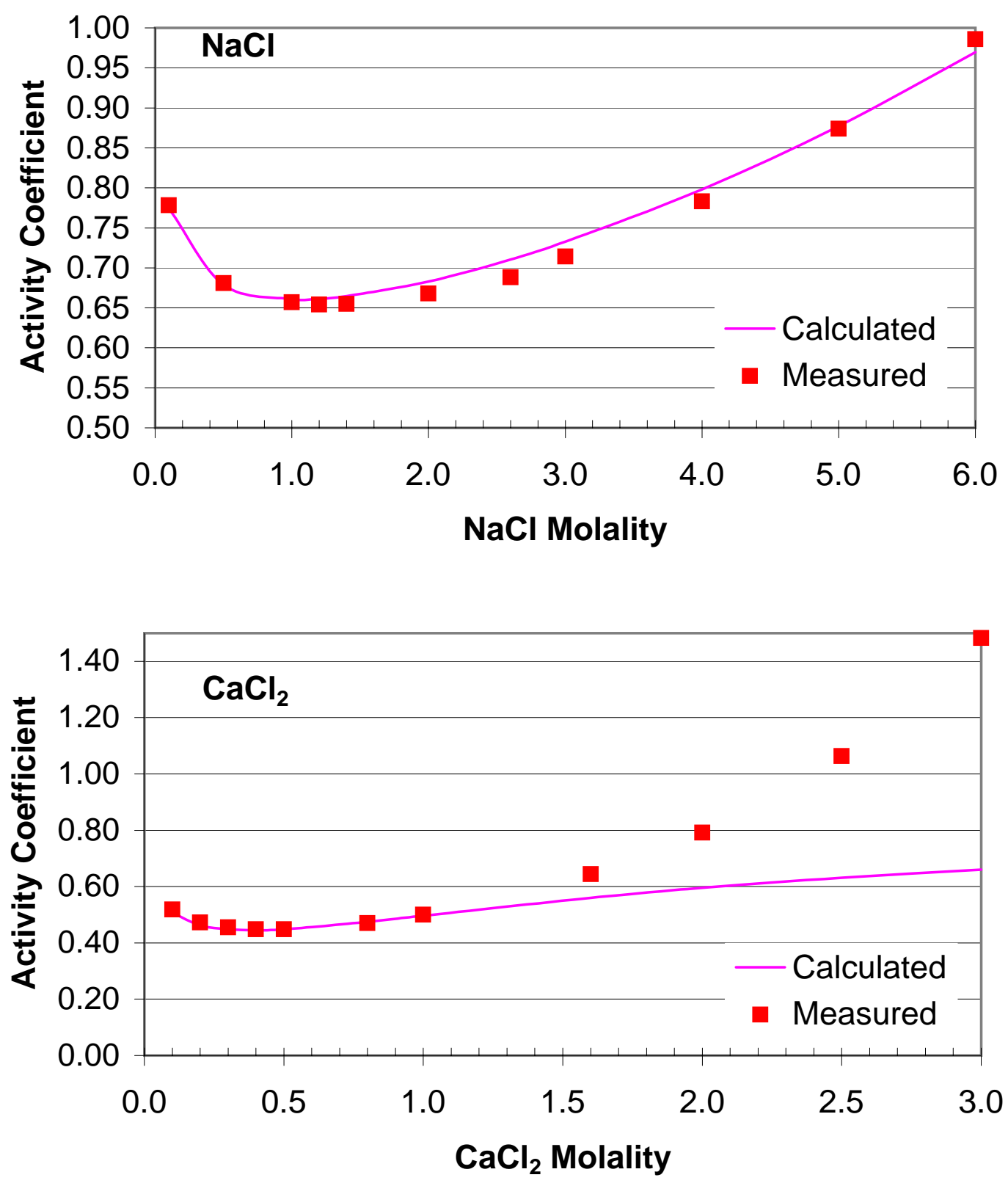

Figure H.1. Mean-ion activity coefficients of $\mathrm{NaCl}$ and $\mathrm{CaCl}_{2}$ derived from individual activity coefficients calculated with Equation H.1. Symbols represent data from measurements by Robinson and Stokes (1965). 

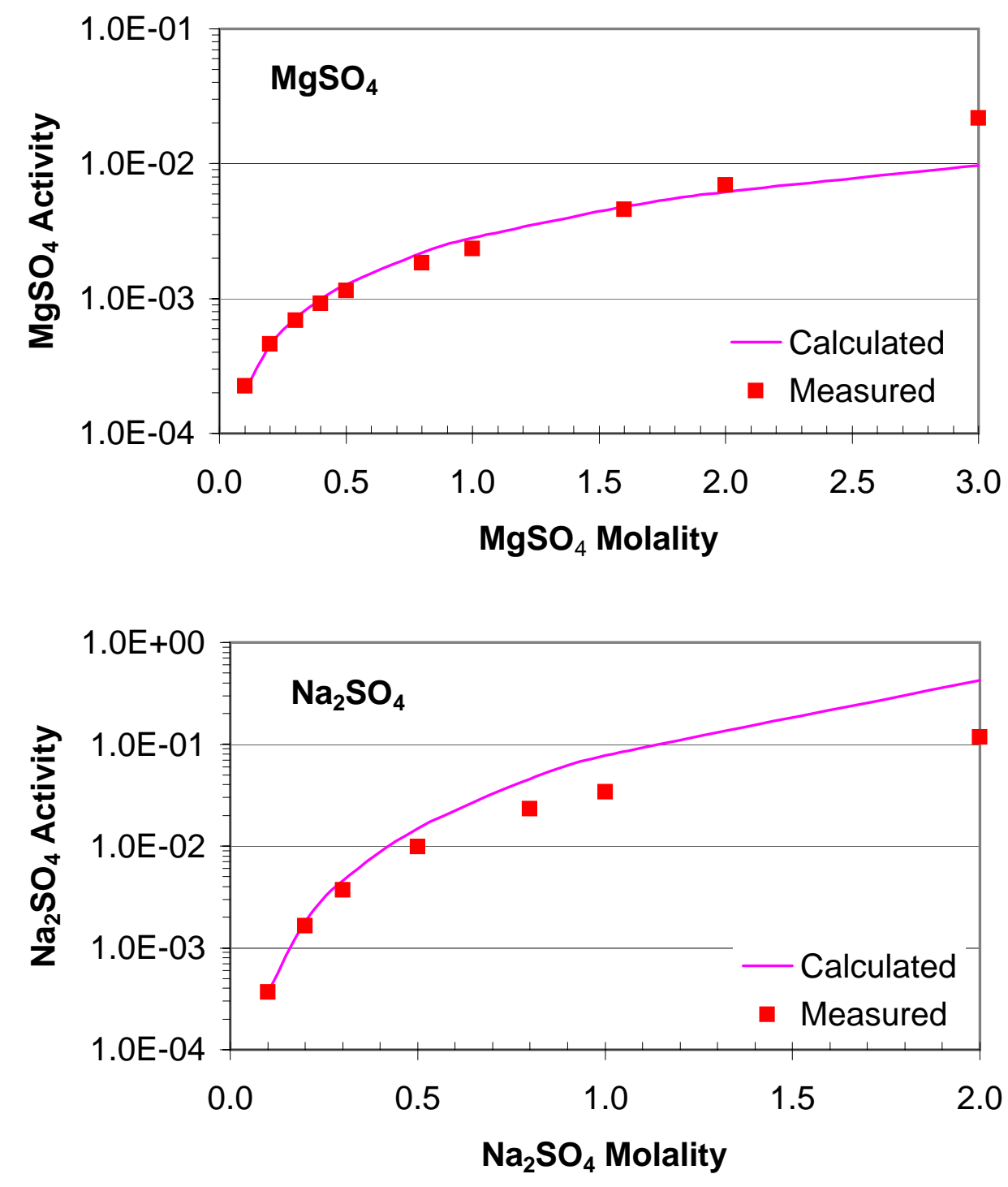

Figure H.2. Activities of $\mathrm{MgSO}_{4}$ and $\mathrm{Na}_{2} \mathrm{SO}_{4}$ derived from individual activity coefficients calculated with Equation H.1. Symbols represent data from measurements by Robinson and Stokes (1965). Actual activities, rather than activity coefficients, are compared here because significant ion association takes place. 


\section{H.2 Activity of Water}

The activity of water is also calculated from equations and parameters given by Helgeson et al. (1981) (HKF). First, a simplification of HKF Equation 190 is used to compute the osmotic coefficient of the solution, $\Phi$, as follows:

$$
\begin{aligned}
\Phi= & -\frac{2.303}{\mathrm{~m} *} \sum_{\mathrm{j}}\left[\mathrm { m } _ { \mathrm { t } , j } \left[\frac{\mathrm{A}_{\gamma} z_{j}^{2} \overline{\mathrm{I}}^{0.5} \sigma}{3}+\frac{\log \left(1+0.0180153 \mathrm{~m}^{*}\right)}{0.0180153 \mathrm{~m}^{*}}-\right.\right. \\
& \left.\left.-0.5\left(\omega_{j} \mathrm{~b}_{\mathrm{NaCl}} \overline{\mathrm{I}}\right)+\left(\mathrm{b}_{\mathrm{Na}^{+}, \mathrm{Cl}^{-}}-0.19\left(\left|z_{j}\right|-1\right)\right) \frac{m c h r}{2}\right]\right]
\end{aligned}
$$

with

$$
\sigma=\frac{3}{\stackrel{\mathrm{a}}{\mathrm{B}_{\gamma}^{3} \overline{\mathrm{I}}^{3 / 2}}}\left[\Lambda-\frac{1}{\Lambda}-2 \ln (\Lambda)\right]
$$

and with

$$
\Lambda=1+\stackrel{\mathrm{a}}{\mathrm{B}_{\gamma}} \overline{\mathrm{I}}^{1 / 2} \quad \text { and } \quad \omega_{j}=\eta \frac{z_{j}^{2}}{\mathrm{r}_{\mathrm{e}, j}}
$$

where the subscript $j$ refers to each charged species in solution, $\mathrm{m}^{*}$ is taken as the sum of the molalities of all species in solution, $\mathrm{m}_{\mathrm{t}}$ is the total molality of each charged species, $m c h r$ is the sum of the molalities of all charged species, and $\overline{\mathrm{I}}$ is taken as the stoichiometric ionic strength. Other parameters are as defined for Equation H.1. The simplifications made in Equation H.6 assume dominance of $\mathrm{NaCl}$ in solution, and are essentially the same as the simplifications made to derive Equation H.1. Two differences are the use of the stoichiometric ionic strength instead of the true ionic strength, and the use of $m c h r / 2$ instead of true ionic strength. These modifications were made because they seemed to reproduce water activity data reported by Stokes and Robinson (1965) better than without these modifications. Once the osmotic coefficient is calculated, the water activity is then given by HKF Equation 126, as: 


$$
\ln \left(\mathrm{a}_{\mathrm{w}}\right)=-\Phi \mathrm{m} * \frac{1}{55.51}
$$

Examples of calculated and measured water activities at $25^{\circ} \mathrm{C}$ are shown on Figure H.3.
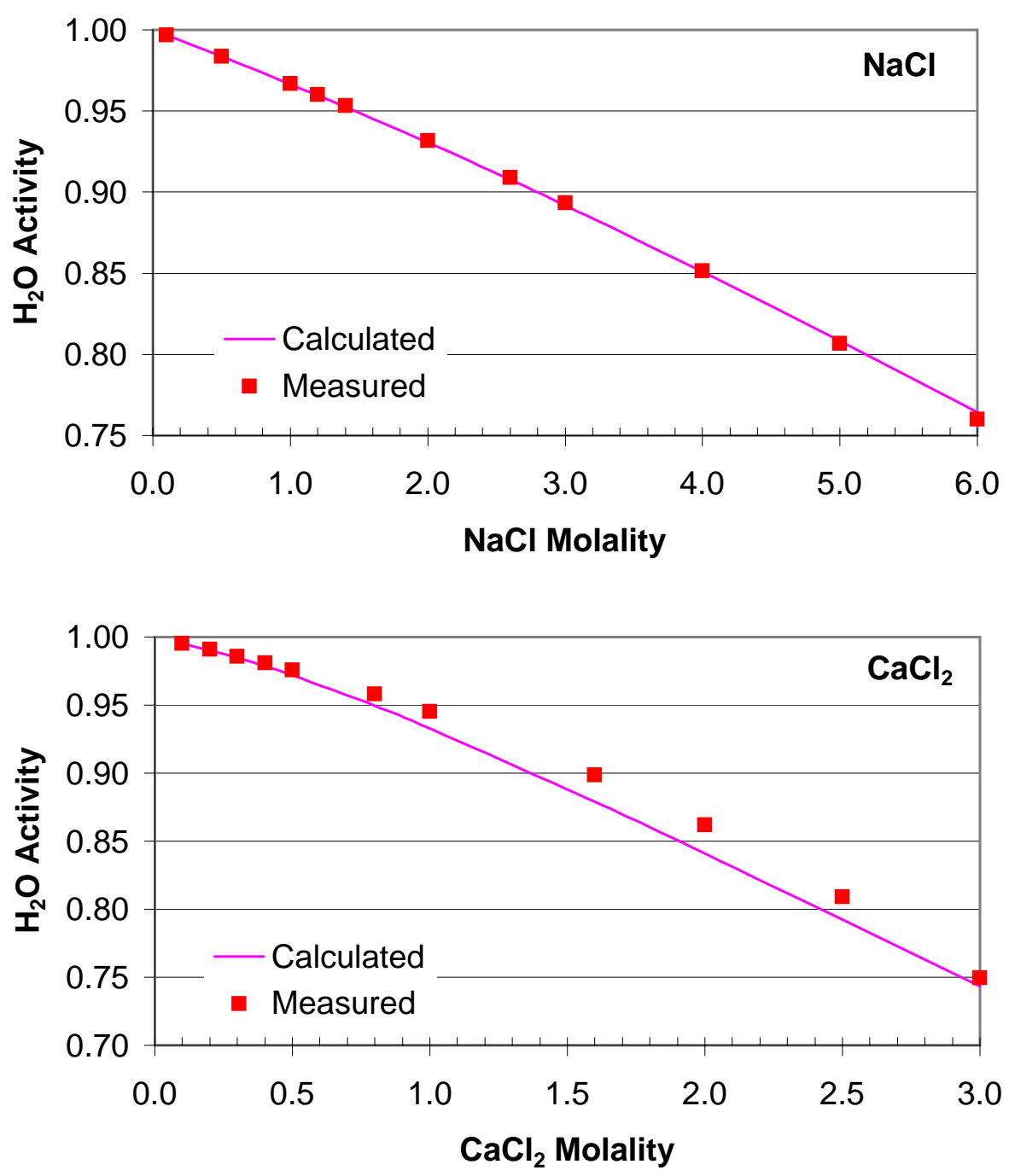

Figure H.3. Activities of water in $\mathrm{NaCl}$ and $\mathrm{CaCl}_{2}$ solutions calculated with Equations H.6 and H.7. Symbols represent data from measurements by Robinson and Stokes (1965). 


\section{H.3 Activity Coefficients of Neutral Aqueous Species}

For dissolved gases with the following exact names in the thermodynamic database, activity coefficients are computed using an equation derived from correlations developed by Drummond (1985) for $\mathrm{CO}_{2}$ gas dissolution in $\mathrm{NaCl}$ solutions up to 6 molal (see also Section B.4 in Appendix B):

$$
\begin{aligned}
& \text { 'co2(aq)' or 'CO2(aq)' } \\
& \text { 'ch4(aq)' or 'CH4(aq)' } \\
& \text { 'h2(aq)' or 'H2(aq)' } \\
& \text { 'h2s(aq)' or 'H2S(aq)' } \\
& \text { 'o2(aq)' or 'O2(aq)' } \\
& \text { 'so2(aq)' or 'SO2(aq)' } \\
& \qquad \ln (\gamma)=(\mathrm{C}+\mathrm{F} T+\mathrm{G} / T) I-(\mathrm{E}+\mathrm{H} T) I /(I+1)
\end{aligned}
$$

where $I$ and $T$ are is the true ionic strength and absolute temperature, respectively, and C, E, F, G, and $\mathrm{H}$ are fit coefficients as follows:

\begin{tabular}{|lr|}
\hline C & -1.0312 \\
E & 0.4445 \\
$F$ & 0.0012806 \\
G & 255.9 \\
$H$ & -0.001606 \\
\hline
\end{tabular}

For other uncharged molecular species activity coefficients are set to one by default or can be optionally computed as (e.g. Langmuir 1997):

$$
\log \left(\gamma_{\mathrm{i}}\right)=K_{\mathrm{i}} I
$$

where $K_{\mathrm{i}}$ are salting-out coefficients and $I$ is the true ionic strength of the solution. Currently, values of $K_{i}$ are assumed to be independent of temperature. These salting-out coefficients are input from the TOUGHREACT thermodynamic database (A0 in the primary and secondary species blocks, see Section 6.4), and default to zero (unit activity coefficients). 


\section{Appendix I: Treatment for Mineral Solid Solutions}

Currently, the only solid solution model implemented in TOUGHREACT is an ideal solid solution model. This model is only available for minerals that react under kinetic constraints.

The condition of equilibrium for a solid solution is

$$
\left(Q_{s s} / K_{s s} a_{s s}\right)=1
$$

where the subscript ss refers to the solid solution, and $Q$ and $\mathrm{K}$ are the ion activity product and equilibrium constant for that solid solution, respectively, and $a$ is the activity of the solid solution. By convention, $a_{s s}=1$.

A similar expression can be written for the condition of equilibrium for each end-member of the solid solution:

$$
\left(Q_{i} / K_{i} a_{i}\right)=1
$$

In this case, the subscript $i$ refers to each end member, and $a_{i} \neq 1$.

In the case of an ideal solid solution, the activity of each endmember, $a_{i}$, is assumed to equal its mole fraction $x_{i}$ in the solid solution. Making this assumption and combining Equations (I.1) and (I.2) (with $a_{s s}=1$ ) yields:

$$
\left(Q_{i} / K_{i} x_{i}\right)=\left(Q_{s s} / K_{s s}\right)
$$

For a solid solution composed of $n$ end-members, Equation (I.3) is consistent with the relation (e.g. Reed, 1982): 


$$
\left(Q_{s s} / K_{s s}\right)=\sum_{i=1}^{n}\left(Q_{i} / K_{i}\right)
$$

Alternatively, combining Equations (I.3) and (I.4) yields

$$
x_{i}=\frac{\left(Q_{i} / K_{i}\right)}{\sum_{i=1}^{n}\left(Q_{i} / K_{i}\right)}
$$

For a solid solution reacting under kinetic constraints we can then write a rate law similar to Equation (B.5) in Appendix B.

$$
R_{s s}=k_{s S} A_{s s}\left[1-\left(Q_{s s} / K_{s s}\right)\right]
$$

where $R, A$, and $k$ stand for the reaction rate, surface area, and rate constant of the whole solid solution ss. If we then write:

$$
\begin{aligned}
& k_{s s}=\sum_{i=1}^{n}\left(x_{i} k_{i}\right) \\
& A_{s s}=\sum_{i=1}^{n}\left(A_{i}\right)
\end{aligned}
$$

and combine Equations (I.7), (I.8) and (I.3) into (I.6), the following relationship can be derived:

$$
R_{s s}=\sum_{i=1}^{n}\left[R_{i}+k_{i} A_{s s}\left(x_{i}-1\right)\right]
$$

where

$$
R_{i}=k_{i} A_{s s}\left[1-\left(Q_{i} / K_{i}\right)\right]
$$


Equation (I.9) is implemented in TOUGHREACT by adding a term equal to $k_{i} A_{S s}\left(x_{i}-1\right)$ to the computed rates $R_{i}$ of each individual mineral assumed to form a solid solution, and using Equation (I.5) to compute $x_{i}$. It should be noted, however, that this method is currently valid only for rate expressions without exponents on the affinity term (i.e. with exponents $m$ and $n$ set to 1 in Equation B.5). 


\section{Appendix J: Additions to the flow input file for Yucca Mountain Project}

As mentioned in Section 6.1 "Flow Input", TOUGHREACT also incorporates options of other TOUGH2 versions that are specific to the Yucca Mountain project. Yucca Mountain in southern Nevada (USA) is being investigated as a possible site for an underground nuclear waste repository. The addition to the flow input file for this project include the active fracture model, enabled with input TOUGH2 parameter $\mathrm{CP}(6) \neq 0$ in keyword block 'ROCKS', and linearization of the Van Genuchten capillary pressure-saturation function at small liquid saturations, enabled with TOUGH2 input parameter ICP = 10. In addition, keyword blocks 'PARAM' and 'INCON' in the original TOUGH2 were extended. Inputs for these additional options are discussed below.

PARAM When parameter MOPR(5)=2 (see Section 6.1), the format of record PARAM.1 changes slightly to allow input of a diffusion coefficient for water vapor, DIFF0, as follows:

Format (2I2, 3I4, 24I1, 3E10.4)

NOITE, KDATA, MCYC, MSEC, MCYPR, (MOP(I), I = 1, 24), DIFF0, TEXP, BE

Values of TEXP and BE are used as in TOUGH2 (Pruess et al., 1999, p. 166). Note that when $\operatorname{MOPR}(5) \neq 2$, vapor diffusion is only computed if diffusion coefficients for different phases are input using the optional input block key word 'DIFFU' (Pruess et al., 1999, p. 170).

Variable ELST in record PARAM.2 was also modified so that if the keyword "wdata" is used the program will look for a line after PARAM.2 giving the number of grid blocks to write out specific flow data. Following the integer variable, the 5 character identifiers for the grid blocks must be listed sequentially in column format. The name of the output file is fixed as GASOBS.DAT. The records PARAM.3 and PARAM.4 should follow immediately after the last grid block name. An example is shown below.

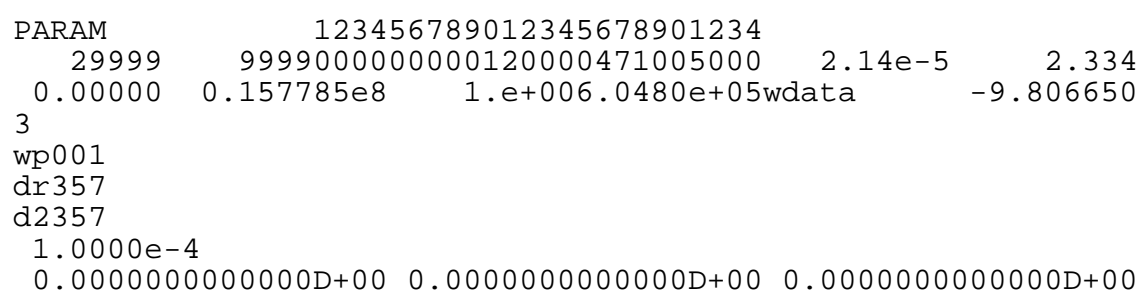


Also note a minor format difference for Record PARAM.4 for default initial conditions (inconsequential change from E20.14 to E20.13):

Format (4E20.13)

DEP(I), I = 1, NKIN+1

INCON As explained in the TOUGH2 manual for restarts (Pruess et al., 1999, p. 61-62, 169), when record INCON.3 starts with the string ' +++ ', the code will look for time stepping information in one additional record. This record is generated by the code and is output in file SAVE. This additional record has the following format (unchanged from TOUGH2, but format not listed in the TOUGH2 manual):

Format (3I5, 2E15.8)

KCYCX, INTERCX, NMX, TSTX, TIMINX

where KCYCX is the total (cumulative) number of time steps at the current time, INTERCX is the total (cumulative) number of iterations at the current time, NMX is the total number of rock types in the present simulation, TSTX is the prior starting simulated time, and TIMINX is the current simulated time (i.e. when the SAVE file was generated).

ROCKS The following additional options, compared to TOUGH2 V2 (Pruess et al., 1999), are available with parameters in the ROCKS second and third input records

$\mathrm{ICP}=10$ Capillary pressure linearization at small liquid saturations, as implemented in $\mathrm{Wu}$ and Mishra (1998). With this option, the input parameters CP(I) are the same as for the Van Genuchten function option ( ICP $=7)$, except that $\mathrm{CP}(4)$ is set to parameter epsilon instead of $P_{\max }$. In this case, the capillary pressure is linearly extrapolated from $S_{l}=S_{r}+$ epsilon (with $S_{l}$ and $S_{r}$ being the current and residual liquid saturations, respectively) down towards $S_{l}=0$. The slope of the linear extrapolation corresponds to the slope of the capillary-pressure/liquid-saturation function at $S_{l}=S_{r}+$ epsilon.

$\mathrm{CP}(6)>0$ This option, with either ICP $=7$ or ICP $=10$, and together with flag ISOT $=-10$ in the CONNE first input record, enables the active fracture model (Liu et al., 1998) as implemented by Wu et al. (1999). In this option, CP(6) is used to input the active fracture parameter $\gamma$.

$\mathrm{RP}(5)>0$ This option, with IRP $=7$ and $\mathrm{RP}(4)=0$, enables the modified Brooks-Corey for gas relative permeability, as implemented by Wu et al. (1999). Note that RP(4) must be smaller than or equal to zero if this option $(\operatorname{RP}(5)>0)$ is used.

GENER An option was added for time-dependent thermal conductivity. For this option, one more parameter, KTAB, was added at the end of record GENER.1: 
Format (A3, I2, A3, I2, 4I5, 5X, A4, A1, 3E10.4, I2)

EL, NE, SL, NS, NSEQ, NADD, NADS, LTAB, TYPE, ITAB, GX, EX, HX, KTAB

$\mathrm{KTAB}$ is the number of points (number of time values and same number of factors) to read in following records for time-dependent thermal conductivities (variables before KTAB are unchanged from Pruess et al., 1999, p174).

If $\mathrm{KTAB}>0$, sets of time values and factors are read as follows:

Record GENER.1.4 (unchanged from GENER.1.1):

Format (4E14.7)

TIMKTH (1:KTAB)

TIMEKTH (1:KTAB) are the time values ("generation times") at which thermal conductivity values change

Record GENER.1.5:

Format (4E14.7)

FACKTH (1:KTAB)

FACKTH (1:KTAB) are the values of the time-dependent factors corresponding to the list of time values given in GENER.1.4. At each time values specified in record GENER.1.4, the thermal conductivity (determined from wet and dry conductivity values input in records ROCKS.1 and ROCKS.2) is multiplied by these factors. 


\section{Appendix K: Utility Programs for the Thermodynamic Database}

\section{K.1. Converting from EQ3/6 to TOUGHREACT Format}

\section{Description}

Program DBCONV2 reads the thermodynamic database of EQ3/6 v7.2b (data0.dat), and formats the data for input into TOUGHREACT. The source code (dbconv2.f) is given in the distribution CD (subdirectory: /utility-programs/convert-eq36). For the most part, the conversion requires only reformatting of the same data values. However, the program also regresses input equilibrium constant values as a function of temperature in the form: $\log (\mathrm{K})_{\mathrm{T}}=\mathrm{a} * \ln (\mathrm{Tk})+\mathrm{b}+$ $\mathrm{c}^{*} \mathrm{Tk}+\mathrm{d} / \mathrm{Tk}+\mathrm{e} / \mathrm{Tk}^{2}$ where $\mathrm{Tk}$ is temperature in degrees $\mathrm{K}$. The program also assigns values of effective ionic radii to aqueous species by reading these values in a special input file (rej.dat). Currently, this file contains effective ionic radii from Helgeson, Kirkham and Flowers (1981; AJS, 1249-1516, Table 3). Radii of species for which data listed in rej.dat are computed as a function of ionic charge as shown in Table H.1 in Appendix H.

\section{Input and output files:}

The program needs to read in two input files and generates four output files. Samples of two input files are given in the distribution CD (subdirectory: /utility-programs/convert-eq36). The names of input and output files are entered interactively when running the program. File contents and default names are as follows:

data0.dat $\begin{aligned} & \text { Main input file - original EQ3/6 thermodynamic database. } \\ & \text { rej.dat }\end{aligned}$
Input data file containing effective ionic radii from
Helgeson, Kirkham and Flowers (1981, AJS, 1249-1516,
Table 3). The species listed in this file must have the same
spelling as the species in the input thermodynamic database.
If no match is found, rej values are computed based on ionic
charge (See Table H.1 in Appendix H).
Main output file - converted database (for the file format,
dbconv2.out
see Section 6.4 of this manual).




$$
\begin{array}{ll}
\text { dump_aux.out } & \text { Separate subset of main output file containing converted } \\
& \text { data for auxiliary species only. To complete the conversion } \\
& \text { of the database, this file is to be manually inserted in } \\
& \text { dbconv2.out at the location indicated in that file. } \\
\text { checkfit.out } & \text { Print-plot file to visually check the quality of the } \log (\mathrm{K}) \\
& \text { regression. A user should always look at this file before } \\
& \text { using the output data. } \\
\text { checkdat.out } & \text { Printout of species for which one or more regressed log(K) } \\
& \text { value exceeds } 0.1 \log (\mathrm{K}) \text { units (generally, but not } \\
& \text { necessarily, indicating some problems with the regression). }
\end{array}
$$

\section{Range of input parameters:}

The input file must have the format of EQ3/6 thermodynamic databases, with the following successive blocks of data. All these blocks are required in the input file and these data blocks must occur in the same order as shown below, otherwise input errors occur:

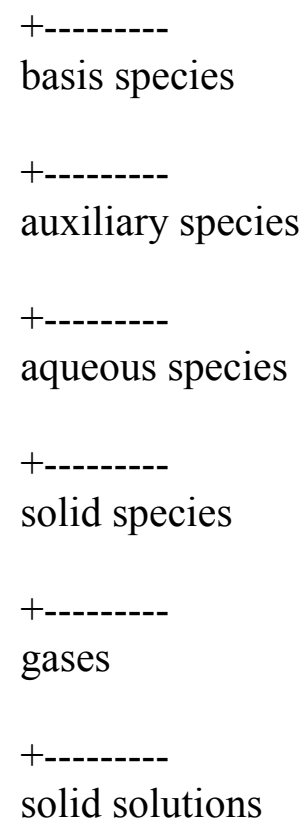

The program will work only with input $\log (\mathrm{K})$ grids composed of eight values, at the following temperatures: $0,25,60,100,150,200,250$, and $300^{\circ} \mathrm{C}$. $\mathrm{A} \log (\mathrm{K})$ value of 500 is interpreted as 
"no available data" and regression of $\log (\mathrm{K})$ values is not performed if at least one of $\log (\mathrm{K})$ value is set to 500 .

\section{K.2. Switching Basis (Primary) Species}

\section{Description}

The program KSWITCH reads TOUGHREACT thermodynamic database entries and creates another identical set of entries with one of the component species "switched" with a derived species. For example, use KSWITCH to replace $\mathrm{Al}+++$ (as a basis species) with new component species such as AlO2-. The source code is given in the distribution CD (subdirectory: / utility-programs/switch-basis).

\section{Input data files and formats}

One input file is needed (with default name thermok.dat, but any name can be chosen and input interactively). This file contains component species data, reaction stoichiometries and $\log (\mathrm{K})$ data entries that must have the same format as the entries for aqueous species, gases, and minerals in the TOUGHREACT thermodynamic database, including the same structure as the thermodynamic database (with a top record specifying temperature values for the $\log (\mathrm{K})$ data, then component (basis) species, derived species, minerals, and gases separated by records starting with 'null'). The entire thermodynamic database, or a subset of it, can be used as an input file. Also, any number of headers can appear at the top of the file before the temperature header. The remaining input is done interactively with self-explanatory prompts that ask for the names of input and output files, the species to switch (use the exact same spelling as in the input file), and the molecular weight of the switched species. The latter is used only for inclusion in the new component species entry and is not used in calculations. Note that the new component species must always be a derived species that is present in the input file. Also, only one switch is allowed for each run. For multiple switches, run the program more than once, reading the output of each run as input for the following run.

An example of the input file (eq36O2g) is given in the distribution CD (subdirectory: / utility-programs/switch-basis). This file is converted from EQ3/6 database (data0) eq36O2g.dat. In eq36O2g.dat, $\mathrm{O} 2(\mathrm{~g})$ is used for component (basis) species of redox reactions. TOUGHREACT 
must use $\mathrm{O} 2(\mathrm{aq})$ as the basis species. Basis species $\mathrm{O} 2(\mathrm{~g})$ must be replaced by $\mathrm{O} 2(\mathrm{aq})$, in order to use TOUGHREACT. Steps for running the basis switch program are given below.

Run the program using the provided input file eq36O2g.dat. When asked for the name of the component species to replace, type $O 2(g)$, and for the name of the new component species type O2(aq). One output file will be created (the default is switch.out, in this example eq3602aq.dat is used) containing the same data as the input file, in the same format, but with switched species and adjusted stoichiometry and $\log (\mathrm{K})$ values and regression coefficients that reflect the switch. The new stoichiometry is then checked visually to be in mass and charge balance. The new $\log (\mathrm{K})$ and regression coefficient values are checked manually for a few derived species, minerals and temperatures. Stoichiometries and $\log (\mathrm{K})$ data for aqueous species, minerals, and/or gases that do not contain one of the switched species will be unchanged, and this can be checked visually.

\section{K.3. Regression of $\log (K)$ Data}

\section{Description}

Program KREG1 is used to regress $\log (\mathrm{K})$ data in the thermodynamic database of TOUGHREACT as a function of temperature, and to generate records for aqueous species, minerals, and/or gases including the $\log (\mathrm{K})$ regression coefficients formatted for input into this thermodynamic database. The source code is given in the distribution CD (subdirectory: / utilityprograms/regress-logK).

\section{Input data files and formats}

The names of input and output files are entered interactively when running the program. One input file (default name: kreg.dat) is required, containing: the first record identical to the first record of the thermodynamic database indicates the temperatures for which $\log (\mathrm{K})$ data are given, followed by records identical to those in the thermodynamic database for derived aqueous species, minerals, and/or gases. (3 records per entry: the first for stoichiometry, second for individual $\log (\mathrm{K})$ values, and the third for regression coefficients. The regression coefficients can be left blank, but the name of the species, mineral, or gas preceding the regression coefficients must be present). The entire thermodynamic database, with component species removed, can also be used as an input file. 


\section{K.4. Checking Mass and Charge Balances}

\section{Description}

Program THERMOCHK1 reads the thermodynamic database of TOUGHREACT and checks the mass and charge balances of all reactions entered in that database. It does so by adding the molecular weights multiplied by stoichiometric coefficients (mass balance) and adding ionic charges multiplied by stoichiometric coefficients (charge balance) of each specified reaction. The program then flags non-zero charge balances and mass balances greater than $5 \times 10^{-5}$ times the molecular weight of the species/mineral/gas to which the reaction pertains. The source code is given in the distribution CD (subdirectory: /utility-programs/check-balance).

\section{Input data files and formats}

The program needs to read in two input files and generates two output files. The names of input and output files are entered interactively when running the program. File contents and default names are as follows:

thermok.dat (default) Main input file (TOUGHREACT database to check) molwt_aq.dat Input file with molecular weights of aqueous species, used only if this information is not already provided in the thermok.dat input file (i.e., as in earlier versions of the database).

thermochk.out Ouput file listing charge and mass balances for all reactions. error.out Output file listing only those species, minerals, and gases for which reactions have non-zero charge balances and mass balances exceeding $5 \times 10^{-5}$ times the molecular weight of the species, mineral, or gas in question. 


\section{Subject Index}

\section{A}

Accumulation terms 158, 159

Accuracy 12, 167

Acidizing 119

Activation energy 26, 27, 92, 115

Activity coefficient 149, 154, 177, 178, 179

Adsorption 5, 6, 14, 22, 23, 24, 36, 37, 48, $49,50,51,52$

Advection 5, 6, 7, 146

Air 2, 10, 67, 132, 146

Ankerite 98

Aqueous 1, 4, 5, 6, 13, 14, 15, 20, 21, 24, $25,29,31,38,40,48$ complexation $5,25,148$

Aquifer 1, 2, 54, 88

Arrays 3

Automatic time stepping 11

\section{B}

Balance equations 10,161

Basis species (see Primary species)

Benchmark 4, 48

Boiling 12, 19, 47, 74, 83

Boundary conditions $4,13,67,80$

Brine 2, 89, 90, 119

Buoyancy 90

\section{C}

Calcite 61, 62, 71, 92, 115, 116

Capillary 2, 6, 16, 17, 19, 91, 173

Caprock alteration 111

Carman-Kozeny 35, 172

Cation exchange $1,6,7,38,39,54,154$, 155

Chemical property zone 22

Chemical reaction $1,5,6,8,11,12,1416$, $148,158,160$

Chemical transport 10, 11, 15

Chemical input (chemical.inp) 39, 49, 5155

output (chemical.out) 14

Chemical zone 14, 48, 51, 55

CO2 2, 4, 18, 19, 21, 61, 63, 73, 83, 95,153, $154,158,163$

disposal 1, 2, 5, 27, 88, 152

Code installation 2, 3, 48

Compilation 3

Components $6,7,11,13,21,22,32,41,42$, $43,51,146,147,148,158$

Computer requirement 3

Concentration 21, 32, 49, 148, 154, 156, $157,161,164,168$

Condensation $74,84,86$

Confining beds 54

Conjugate gradient solvers 18

Constitutive relations 147

Continuation run (see Restart)

Continuum 74, 79, 102

Convergence $4,13,14,15,21,46,47,49$, 160,166

Criteria 21

Coordinates 15, 132

Copper deposits 100

Corrosion 39

Courant number $12,18,19$

\section{D}

Darcy's law 146

Database (thermodynamic) 13, 40, 191

Dawsonite 98

Decay 5, 29, 468161

Defaults 22, 48

Density 5, 8, 38, 48, 161

Derivatives 19, 168

Diffusion

coefficient $13,20,43,49,55,146$, 147,158

molecular $5,7,12,74$

Diffusive flux $78,101,159$

Dilution 8, 130

Discretization 10, 11, 12

Dispersion 7, 8, 49 
Dissolution (mineral) 6, 7, 17, 19, 21, 26, $27,28,148,149,150,151,152$, $160,164,167,170$

Distribution coefficient (Kd) 48, 161

Domain 5, 10, 80

Double precision 3

Drift scale test 73

Dual permeability $61,62,74,102,172,174$

\section{$\mathbf{E}$}

Elements $10,75,162$

EOS1 2, 119, 146

EOS2 2, 19, 95, 111, 146

EOS3 2, 61, 95, 146

EOS4 2, 73, 95, 146

EOS9 2, 48, 54, 100, 146

ECO2N 2, 19, 88, 146

Equations

mass and energy balance 146 chemical reaction 148

Equilibrium 1, 6, 11, 14, 26, 33, 148, 149, $153,154,158,185$

EQ3/6 database $40,133,190$

Error message 14, 45

Executable 3, 4

Execution 3, 45

Explicit 18, 20, 161

Exsolution 1, 6, 153, 164

\section{F}

Files

input 13,16

output 14,15

Finite differences 10

Flow

chart (program) 9

input (flow.inp) 13, 16, 50, 188

output (flow.out) 14, 69, 96, 107

Flux 10, 14, 26, 61, 147, 158, 159

Formats (input) 4, 13, 15, 16, 18, 24, 40

FORTRAN 3, 18, 48

Fracture 170, 174

Fractured rock 5, 10, 73, 101

\section{G}

Gas 4, 5, 6, 12, 15, 16, 18, 19, 20, 22, 23, $28,33,43,147,153$ phase $5,6,12,15,147,154,158$, 162,163

Generation 73, 76, 104

Geochemical

speciation $14,19,40$

transport $2,5,15,16,18,19$

input 24,79

Geometry 11, 115

Geothermal fields (reservoirs) 48, 111, 114

Governing equations 6,146

Gradient 61, 62,

Gravity 6,64

Grid (see also MESH)

block 10, 11, 14, 158, 160, 161, 162

irregular 10, 132

nested 101

\section{H}

Half-life 48

Hardware 3,4

Heat test 73

conduction 79

conductivity 147

flow $1,6,7,10,11,101,146$

exchange 121

generation 87,107

pipe 87

sink/source 174

specific 70,112

Heterogeneity 1, 5132

Hydrothermal 111, 113

\section{I}

Ideal gas $105,147,153$

Implicit 3, 10, 20, 159

Inactive block 16

INCON 17

Infinitive volume 16

Inactive block 16

Initial conditions 15,94 
Initial water $14,22,32$

Initialization 46

Injection $18,31,88,119$

Injectivity $119,120,124$

Input file

Chemical (chemical.inp) 39, 49, 51

55

Flow (flow.inp) 13, 16, 50, 188

inchem 15

solute (solute.inp) 13, 15, 18, 51

thermodynamic database $5,13,40$

Installation (of code) 2, 3, 48

Integral finite differences (IFD) $10,11,132$

Integration 167

Interface 23, 66, 174

Interpolation 79

Ionic strength $5,19,154,155,177,178$

Iteration $11,13,15,18,20,21,45,160,166$

\section{$\mathbf{J}$}

Jacobian matrix $\quad 166,168$

\section{$\mathbf{K}$}

Kd (distribution coefficient) 5, 14, 22, 23, $24,29,37,48$

Keywords 16, 48, 55

Kinetics 5, 13, 14, 19, 26, 33, 94, 105, 115, $149,151,160,164$

\section{$\mathbf{L}$}

Linear equations $11,18,47$

Linking 3

Liquid 5, 6, 12, 14, 15, 19, 141, 146, 158

Phase $6,12,103,146,148,158,163$

Long Valley Caldera 111

\section{M}

Main scope (of the model) 5

Main processes 5

Mass

balances $14,17,164$

flux 14,147 fraction 91,147

transport (transfer) 5, 158, 160, 161

Matrix blocks $101,102,112$

Memory requirements 3

MESH (see also Grid) 22, 74, 75, 76 radial 75,90

MINC (multiple interacting continua) 101, 102,103

Mineral

dissolution or precipitation $6,7,17$, $19,21,26,27,28,148,149,150$, $151,152,160,164,167,170$ saturation $15,17,148,149,165$

Mixture 2, 153

Molecular diffusion (see Diffusion)

MOPR options 15, 16, 17

Multiphase 2, 4, 5, 6, 147

\section{$\mathbf{N}$}

$\mathrm{NaCl}$ 2, 3, 19, 90, 177

Newton-Raphson iteration $11,165,166$

Nodal distance 158

Nonisothermal 4, 6, 12, 147

Nuclear waste $5,61,73$

Numerical dispersion 49

Numerical solution 9,10

\section{$\mathbf{O}$}

Option variables 18,19

Output 75

aqueous species 20,21, 15

chemical (chemical.out) 14

chdump.out 14

flow (flow.out) 14

gas 15

iteration 15

mbanlance.out 14

mineral abundance (or solid) 15

min_SI.out 14

runlog.out 14

savechem 14, 15

solute (solute.out) 14

Oxygen (O2) 6, 7, 12, 101, 105 
 \\ PARAM (keyword) 17 \\ PARAMETER statement 3, 4 \\ Permeability $6,7,17,19$ \\ change $7,170,171,172,173,174$ \\ dual $61,62,73$ \\ fracture $67,68,122,170,171$ \\ matrix 172 \\ reduction 171,173 \\ relative $6,16,91,103$ \\ Permeability-porosity relationship 7, 23, \\ $34,35,170,171,172,173,174$ \\ Phase 144, 162 \\ aqueous 161 \\ gas $5,6,12,15,147,154,158,162$, \\ 163 \\ liquid $6,12,103,146,148,158,163$ \\ partitioning 161
}

Plot 15,20

Porosity 7, 17, 20, 147, 157, 170, 171

Porosity-permeability relationship 7,23 , $34,35,170,171,172,173,174$

Porous medium 12, 48, 101, 176

Precipitation (mineral) 6, 7, 17, 19, 21, 26, $27,28,148,149,150,151,152$, $160,164,167,170$

Precision 3

Pressure 5, 6, 12, 14 capillary 2, 6, 16, 17, 19, 91, 173 partial 12, 15, 19, 23, 34, 153, 162 vapor 2,73

Primary species $6,19,24,25,29,31,32$, $38,40,148$

Primary variables 166

Printout 13, 14, 15, 19, 48

Protore 100, 105

Proximity function 102

Pyrite 100

\section{$\mathbf{Q}$}

Quasi-steady 7

QSS (quasi-stationary states) $11,16,21$

$\mathbf{R}$
Radial flow 90, 121

Rate

law $7,26,27,90,94,149,150,167$, 186

constant 13, 26, 27, 80, 92, 94

REACT (keyword) 16

Reaction

aqueous (complexation) 5, 25, 148

Cation exchange $1,6,7,38,39,54$, 154,155

mineral (dissolution or precipitation) $6,7,17,19,21,26,27,28,148,149$, $150,151,152,160,164,167,170$

rate $149,151,167,186$

redox $6,7,25,89,106,191$

source/sink 6, 18, 19, 20, 158, 160

Reactive surface area $33,66,94,174,175$

Records (data) 18, 24

Relative (see Permeability)

Reservoir 48, 88, 92, 112, 120

Residual

function 165,169

saturation 78,175

Restart (run) 14, 15, 95

Retardation factor 48,49

Richards' equation 2, 12

\section{$\mathbf{S}$}

Salinity 89

Salting out 154

Sample problems 48

Saturation

$$
\begin{aligned}
& \text { mineral } 15,17,148,149,165 \\
& \text { residual } 78,175 \text { Scaling } \\
& \text { Leverett } 17,80,173 \\
& \text { well } 119
\end{aligned}
$$

Secondary species (see species)

Selectivity 56

Semi-analytical 121

Sequential iteration $11,18,20,158,160$

Silica scale 120

SIA (sequential iterative approach) 11,12 158

Simplifying approximation 7 
Sink (reaction) 6, 18, 19, 20, 158, 160

Solubility 62,88

Solver (linear) 18

Solution method 9, 158, 164

Solid solution 26, 66, 185

Source (see Sink)

SNIA (sequential non-iterative approach)

$$
11,12
$$

Speciation data 14

Species

Primary (basis) 6, 19, 24, 25, 29, 31, 32, 38, 40, 148

Secondary (derived) 6, 27, 41, 148, 152

Stability condition 12

Supergene copper 100

Supersaturation window 28, 152

Surface area (see Reactive surface area)

\section{T}

Temperature $5,7,13,14,15,27,28,31,40$, $41,147,149,152,154$

Templates 2, 48

Thermodynamic state variables 11

database 13,40

Thermophysical properties 8,112

Tiwi geothermal field 119

Time

automatic 11

discretization 11,161

stepping 11

Tortuosity $20,147,158,172$

Total dissolved concentration 6,146

TOUGH2 V2 1, 2, 13, 15, 18, 45

Tracer $8,49,147$

\section{$\mathbf{U}$}

Units 21

Upstream weighting 20,49, 159

Utility programs 191
Vadose zone 2

van Genuchten 78, 91

Vapor pressure lowering 2, 73

Variables primary (see Primary variables) secondary 167

Verma-Pruess $36,121,172,173$

Viscosity 5, 8, 111, 147

Void space 173

Volume elements (see also Grid blocks) 13, $19,25,29,148,172$

W

Weathering 100

Weighting

Parameter 20

time 20, 159

upstream (see Upstream weighting)

Well

field 91

radius 128

Writing control variable 21, 51

X-(cation exchange sites) 55

$\mathbf{Y}$

Yucca Mountain 4, 17, 61, 73, 188

$\mathbf{Z}$

Zones (initial)

cation exchange $13,16,50$

gas $13,16,50$

linear $\mathrm{Kd}$ 13, 16, 50

mineral $13,16,50$

porosity-permeability 34,35

water $39,49,5155$ 